\title{
Flexible Decision Analysis Procedures for Optimizing the Sustainability of Ageing Infrastructure under Climate Change
}

\author{
By \\ Yan Zhang \\ Department of Civil Engineering and Applied Mechanics
}

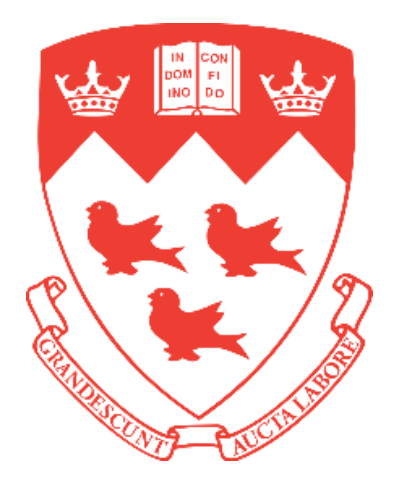

McGill University

Montréal, Québec, Canada

April 2020

\begin{abstract}
A thesis submitted to McGill University in partial fulfillment of the requirements for the degree of Doctor of Philosophy
\end{abstract}

(C) Yan Zhang, 2020 


\begin{abstract}
Over the past decade, tremendous attention has been dedicated to the issue of sustainability and serviceability of the infrastructure in the context of climate change. A large proportion of the existing infrastructure is already in an advanced state of deterioration, which is expected to increase at a higher rate with climate change. This fact highlights the need for better planning and decision analysis tools for managing maintenance, repair and replacement activities in both space and time. An important component for improving decision-making (DM) is improved models for predicting the residual life of structures while also accounting for both physical and financial uncertainties.
\end{abstract}

The uncertainties associated with climate change and material properties can be particularly large and affect the accuracy of predictions, which have an impact on the optimal timing and type of intervention. Option theory is well-suited for analyzing financial decisions in the context of uncertainty, especially in the context of climate change. The value of an option measures the value of delaying decisions to a specific time in the future. For example, given the uncertainty on climate change scenarios, it may be optimal in some instances to delay important investments in infrastructure at a point in time when the uncertainty on the proper climate change scenario has decreased significantly.

The primary process of deterioration of concrete structures in Canada is corrosion of the reinforcing steel due to the usage of de-icing salts. Numerical models of the diffusion process and chemical reactions of chloride ions in concrete are used to evaluate the time to the initiation of corrosion followed by models for the progression of corrosion and damage to the concrete cover. 
The main input parameters for these models are the diffusion properties of the concrete and a time history of the meteorology at the site. The material properties can be obtained from samples or non-destructive tests performed on structures but more typically through compiled data bases of concrete properties. Meteorological data is obtained from historical databases to evaluate the condition of existing structures and from climate scenario simulations for predicting their residual life. Given the large uncertainties involved, the analyses are better performed probabilistically.

DM for managing maintenance/repair/replacement tasks is challenging given the large number of structures, the limits on physical and financial resources, contradictory management objectives, and uncertainties. Optimization methods are frequently used to assist managers in selecting maintenance and replacement strategies. Two examples are presented for typical bridges in Montreal by using single-objective optimization (SOO) and multi-objective optimization (MOO). The application of SOO in this work is to find the optimal time for the first major replacement of a concrete deck by maximizing the Net Present Value (NPV) of bridge benefits and costs. Conversely, MOO is used when considering two or more objectives, in this instance, the Net Present Value (NPV) of bridge benefits and costs and the infrastructure performance. Depending on the Pareto optimal solutions obtained from the two efficient Meta heuristic algorithms, a decision-maker can simply acquire the information of the maintenances and rehabilitations (M\&R) strategies and thereby better understand their relationships and final trade-offs. 


\section{RÉSUMÉ}

Au cours de la dernière décennie, une attention considérable a été accordée à la question de la durabilité et de la viabilité de l'infrastructure dans le contexte des changements climatiques. Beaucoup des infrastructures existantes sont déjà dans un état de détérioration avancé. Les changements climatiques ne feront qu'accentuer la tendance. Ainsi, il est primordial de développer de meilleurs outils de planification et d'analyse des décisions pour gérer les activités d'entretien, de réparation et de remplacement dans l'espace et dans le temps. Un élément important pour améliorer la prise de décision (DM) est le perfectionnement des modèles de prévision de la durée de vie résiduelle des structures tout en tenant compte des incertitudes physiques et financières.

Les incertitudes associées aux changements climatiques et aux propriétés des matériaux peuvent être particulièrement importantes et affecter la précision des prévisions, ce qui a un impact sur le choix du type d'intervention et le moment optimal pour intervenir. La théorie des options est bien adaptée pour analyser les décisions financières dans le contexte d'incertitude, en particulier dans le contexte des changements climatiques. La valeur d'une option mesure la valeur du report des décisions à un moment précis dans le futur. Par exemple, étant donné l'incertitude sur les scénarios de changements climatiques, il peut être optimal, dans certains cas, de retarder d'importants investissements dans les infrastructures à un moment où l'incertitude sur le bon scénario a considérablement diminué.

Le principal processus de détérioration des structures en béton au Canada est la corrosion de l'acier d'armature en raison de l'utilisation de sels de déglaçage. Des modèles numériques du processus de diffusion et des réactions chimiques des ions chlorures dans le béton sont utilisés pour évaluer 
le temps de déclenchement de la corrosion, suivis de modèles de progression de la corrosion et des dommages à la couverture de béton.

Les principaux paramètres d'entrée de ces modèles sont les propriétés de diffusion du béton et un historique temporel de la météorologie sur le site. Les propriétés des matériaux peuvent être obtenues à partir d'échantillons ou d'essais non destructifs effectués sur des structures, mais aussi à l'aide de bases de données compilant les propriétés du béton. Les données météorologiques sont obtenues à partir de bases de données historiques pour évaluer l'état des structures existantes et à partir de simulations de scénarios climatiques pour prédire leur durée de vie résiduelle. Compte tenu des grandes incertitudes, il est préférable d'effectuer les analyses de façon probabiliste.

Le DM pour la gestion des tâches d'entretien / réparation / remplacement est difficile étant donné le grand nombre de structures, les limites des ressources physiques et financières, les objectifs de gestion contradictoires et les incertitudes. Les méthodes d'optimisation sont fréquemment utilisées pour aider les gestionnaires à sélectionner les stratégies d'entretien et de remplacement. Deux exemples sont présentés pour les ponts typiques de Montréal en utilisant l'optimisation à objectif unique (SOO) et l'optimisation à objectifs multiples (MOO). L'application de SOO dans ce travail est de déterminer le moment optimal pour le premier remplacement majeur d'un tablier en béton en maximisant la valeur actuelle nette (VAN) des avantages et des coûts du pont. Inversement, MOO est utilisé lorsque l'on considère deux objectifs ou plus, dans ce cas, la valeur actuelle nette (VAN) des avantages et des coûts du pont ainsi que les performances de l'infrastructure. En fonction des solutions optimales de Pareto obtenues à partir des deux algorithmes méta heuristiques efficaces, un décideur peut acquérir les informations des stratégies d'entretien et de réhabilitation $(M \& R)$ et ainsi mieux comprendre leurs relations et les compromis des options qui s'offrent à lui. 


\section{ACKNOWLEDGMENTS}

Foremost I would like to express my sincere gratitude to my supervisor, Prof. Luc E. Chouinard. He has given me tremendous amount of knowledge, perspective, and guidance throughout the many years of this thesis. His inspiration, encouragement, and continuous help made this work possible. One simply could not wish for a better or friendlier supervisor.

I would like to express my special thanks to my co-supervisors Prof. David Conciatori and Prof. Gabriel J. Power from Laval University. Their superb mentorships and supports lead me to a stimulating research program. I sincerely appreciate all their contributions of time and ideas, which allowed me to conduct my research in a self-dependent way.

Many thanks are due to the Technical Staff of the Department of Civil Engineering and Applied Mechanics at McGill University. I would like to acknowledge the financial support of the McGill Engineering Doctoral Award, the Fonds de Recherche du Québec - Nature et Technologies (FRQNT), the Natural Sciences and Engineering Research Council (NSERC).

I am especially thankful to Danwei Zheng for her time, support and unending kindness. I would like to express my deepest appreciation to my family. I am beyond lucky for having my loving and supportive parents for their prolonged understanding and encouragement; since without them, I could not make it this far. 


\section{PUBLICATIONS, MANUSCRIPTS}

[1] Zhang, Y, Chouinard, L. E, \& Conciatori, D (2018). Markov Chain Based Stochastic Modeling of Chloride Ion Transport in Concrete Bridges. Frontiers in Built Environment, 4, 12. Front. Built Environ. | doi: 10.3389/fbuil.2018.00012

[2] Yan Zhang, Luc E. Chouinard, Gabriel J. Power, Charli D. Tandja M. \& Josée Bastien (2018) Flexible decision analysis procedures for optimizing the sustainability of ageing infrastructure under climate change, Sustainable and Resilient Infrastructure, DOI: $10.1080 / 23789689.2018 .1448665$

[3] Zhang, Y, Chouinard, L. E, Power, G. J, \& Conciatori, D (2020). Multi-objective optimization for maintenance strategies of infrastructure projects under the influence of climate change. (Manuscript to be submitted).

[4] Zhang, Y, Chouinard, L. E, Power, G. J, Conciatori, D, \& Nicolas Zufferey (2020). Bayesian Estimation of Model Parameters for Chloride Ion Ingress in Concrete Using Core Sample Data. (Manuscript to be submitted). 


\section{TABLE OF CONTENTS}

Chapter 1. Introduction -------------------------------------------------------------------------------- 1

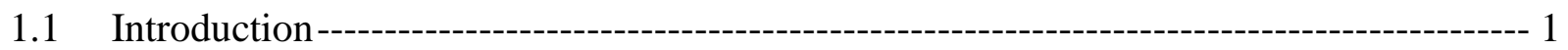

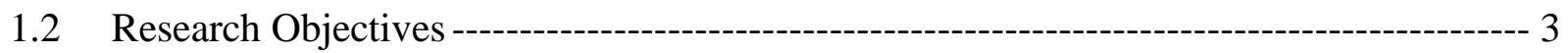

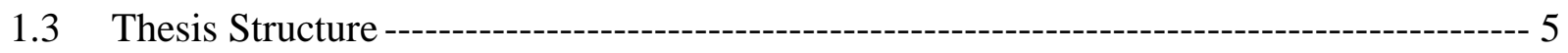

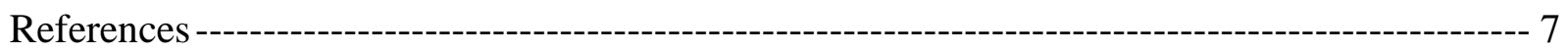

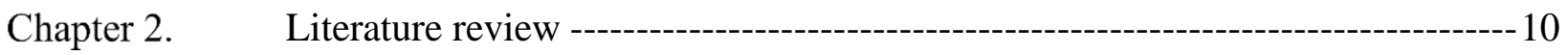

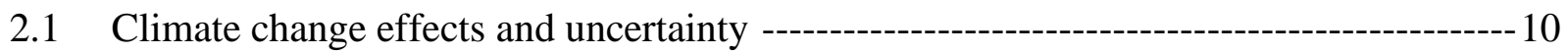

2.2 Chloride-induced deterioration modeling of concrete structures ---------------------------13

2.3 TransChlor ${ }^{\circledR}$ model -------------------------------------------------------------------------------- 15

2.4 Markov Chain Model and Bayesian approach-based analysis method --------------------- 18

2.5 Optimization procedures-----------------------------------------------------------------------------22

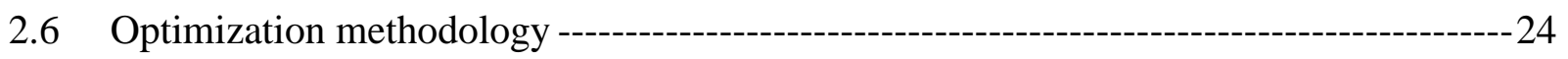

References ----------------------------------------------------------------------------------------------------------25

Chapter 3. Markov Chain Based Stochastic Modeling of Chloride Ion Transport in Concrete Bridges 29

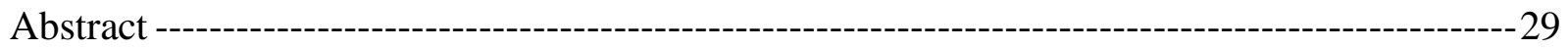

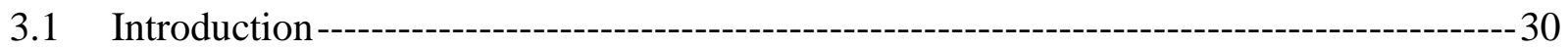

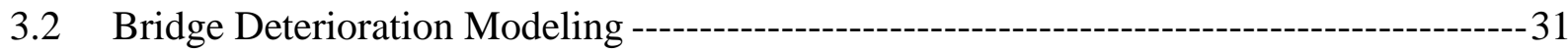

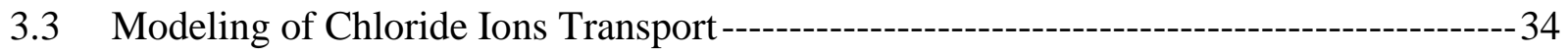

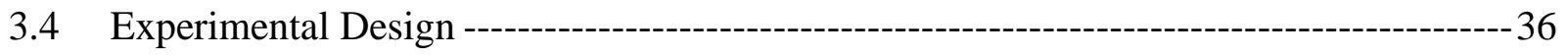

3.5 Surrogate Markov chain Model----------------------------------------------------------------------43 
3.5.1 Modeling chloride ions content prediction with Markov Chains

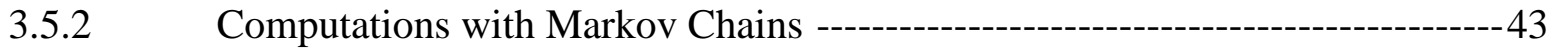

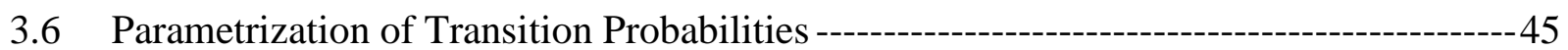

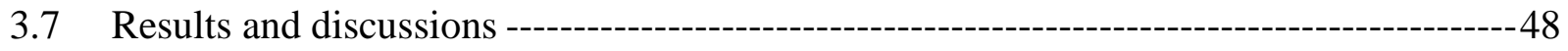

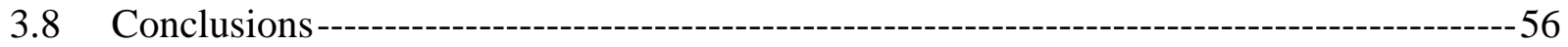

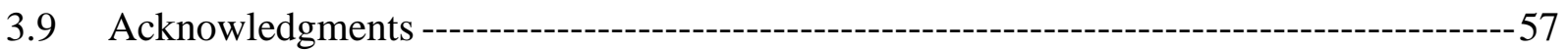

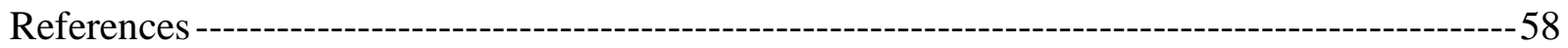

Chapter 4. Flexible Decision Analysis Procedures for Optimizing the Sustainability of

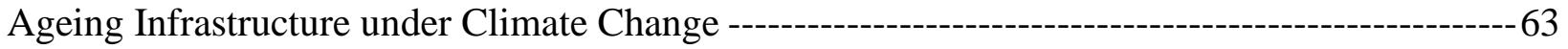

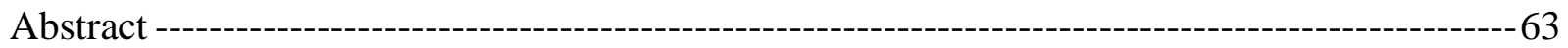

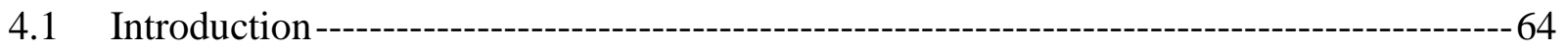

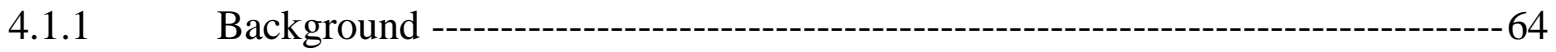

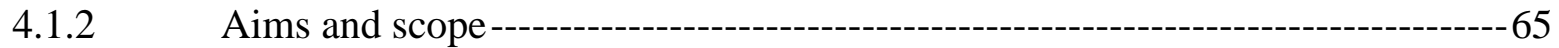

4.2 Modelling of climate change effects and uncertainty ----------------------------------------66

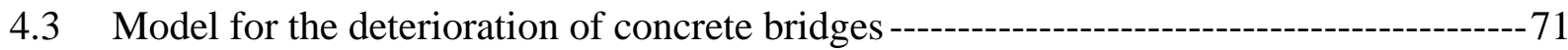

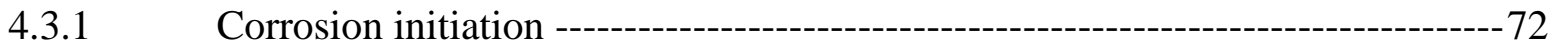

4.3.2 Corrosion propagation-----------------------------------------------------------------75

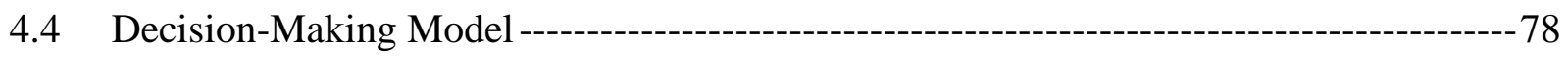

4.4.1 Estimation of the additional revenue ---------------------------------------------------80

4.4.2 Estimation of costs for the first major repair----------------------------------------81

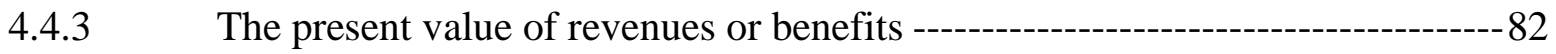

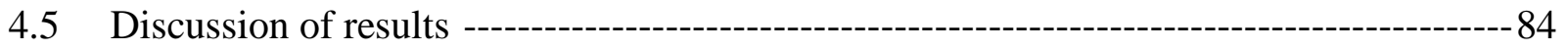

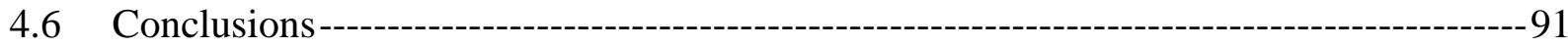

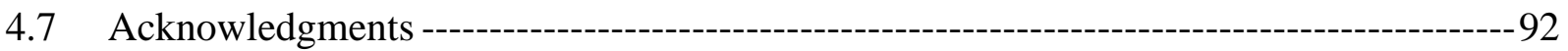


Chapter 5. Multi-objective optimization for maintenance strategies of infrastructure projects under the influence of climate change

Abstract 97

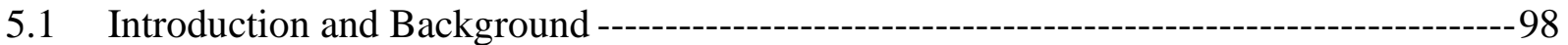

5.1.1 Optimization procedures with conflicting objectives ------------------------------99

5.1.2 Optimization procedures classified by solution approach 102

5.1.3 Common decision-making maintenance, repair and replacement strategies - 105

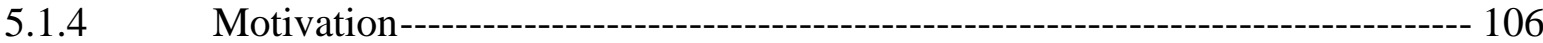

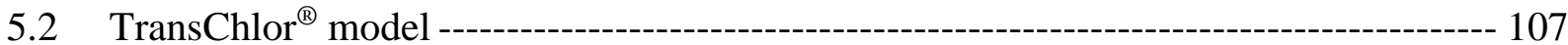

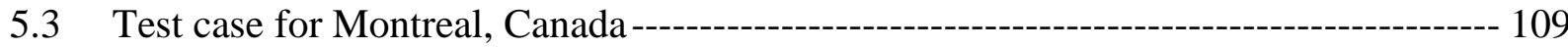

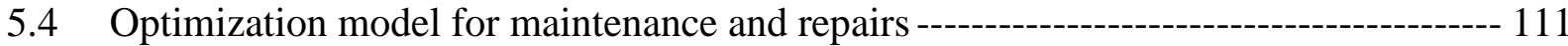

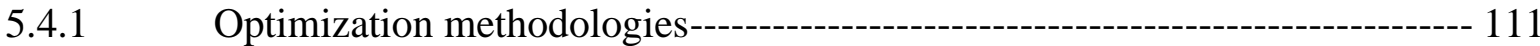

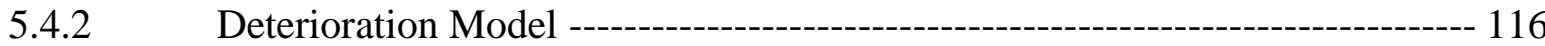

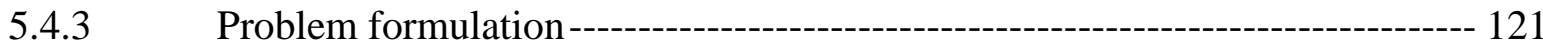

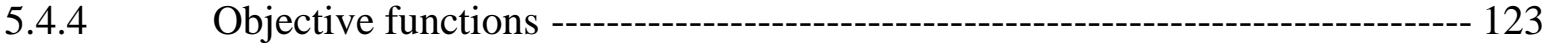

5.5 Application of the model and discussion of the results ------------------------------- 125

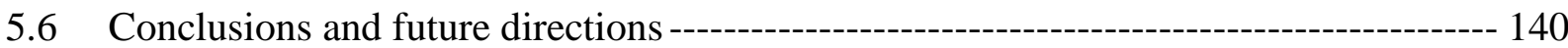

Chapter 6. Bayesian Estimation of Model Parameters for Chloride Ion Ingress in Concrete

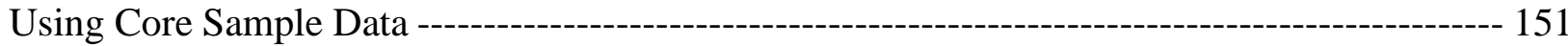

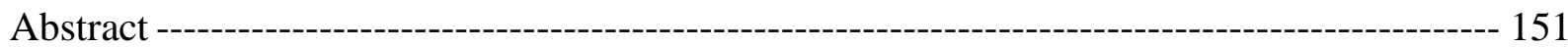

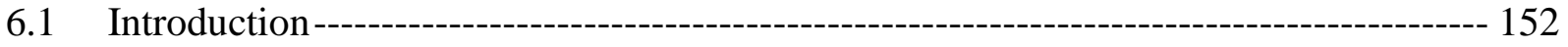

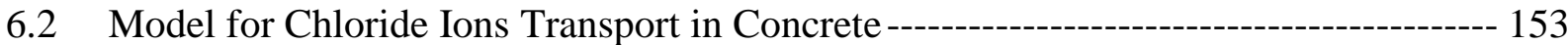

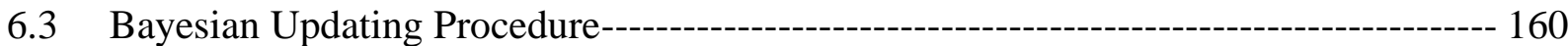

6.4 Application to Bridges in Montreal ---------------------------------------------------------- 168 


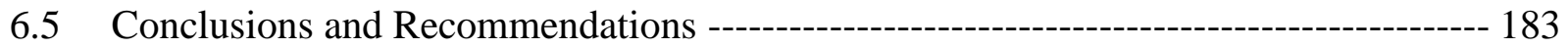

Chapter 7. Original Research Contributions and Recommendations for Future Research 192

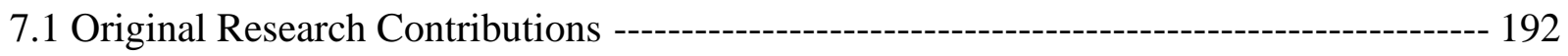

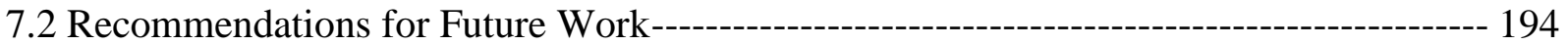




\section{LIST OF FIGURES}

Figure 2-1 (a) Interactions in climate models and (b) discrete grids to compart the climate system

(Charron, 2016) 10

Figure 2-2 Framework of the TransChlor ${ }^{\circledR}$ software (Conciatori et al. 2018)......................... 17

Figure 2-3 The regression model that best fits bridge deck data (Morcous \& Akhnoukh, 2006). 19

Figure 3-1 Example Markov Chain graph with three states.............................................. 33

Figure 3-2 Sample of climate data for Montreal (A) temperature; (B) relative humidity; (C)

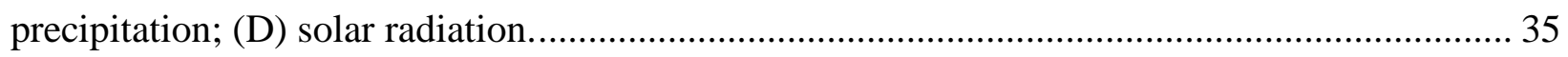

Figure 3-3 Dataset simulated from TransChlor ${ }^{\circledR}$ for $50 \mathrm{~mm}$ depth. ...................................... 40

Figure 3-4 Dataset simulated from TransChlor ${ }^{\circledR}$ for $26 \mathrm{~mm}$ depth. ....................................... 40

Figure 3-5 Annual average of chloride ions content based on TransChlor ${ }^{\circledR}$ Dataset for $50 \mathrm{~mm}$

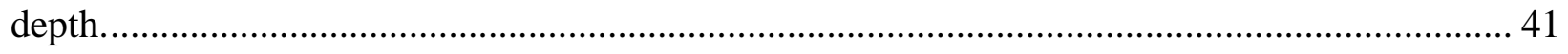

Figure 3-6 Annual average of chloride ions content based on TransChlor ${ }^{\circledR}$ Dataset for $26 \mathrm{~mm}$

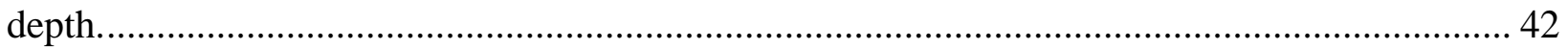

Figure 3-7 Transition probabilities and expected categories of chloride ions content for Case 1120

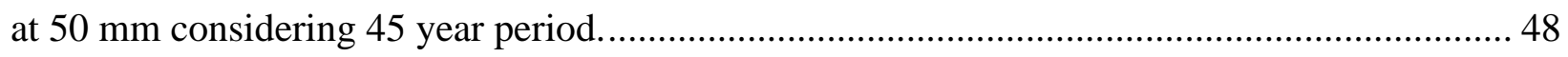

Figure 3-8 Transition probabilities and expected categories of chloride ions content for Case 1220 at $50 \mathrm{~mm}$ considering 45 year period.

Figure 3-9 Transition probabilities and expected categories of chloride ions content for Case 2120 at $50 \mathrm{~mm}$ considering 45 year period 50

Figure 3-10 Transition probabilities and expected categories of chloride ions content for Case 2220 at $50 \mathrm{~mm}$ considering 45 year period. 51

Figure 3-11 Transition probabilities and expected categories of chloride ions content for Case 1120 at $26 \mathrm{~mm}$ considering 45 year period. 52 Figure 3-12 Transition probabilities and expected categories of chloride ions content for Case 1220 at $26 \mathrm{~mm}$ considering 45 year period. 53 
Figure 3-13 Transition probabilities and expected categories of chloride ions content for Case 2120 at $26 \mathrm{~mm}$ considering 45 year period.

Figure 3-14 Transition probabilities and expected categories of chloride ions content for Case 2220 at $26 \mathrm{~mm}$ considering 45 year period. 55

Figure 4-1 GCMs and RCMs (Source: (Charron 2016)). 67

Figure 4-2 Yearly average temperature. Historical Records and projections between RCP8.5 and RCP4.5 69

Figure 4-3 Total yearly number of rainy days (daily precipitation $>0.1 \mathrm{~mm}$ ). Historical Records and projections from RCP8.5 and RCP4.5 70

Figure 4-4 Chloride Ion Distribution as a function of time and depth (Wolofsky 2011a).......... 73

Figure 4-5 Chloride content at a given depth and time and Chloride Threshold level (Wolofsky 2011a). 73

Figure 4-6 Cumulative Probability of time to initiation of corrosion at a given depth (Wolofsky 2011a). 74

Figure 4-7 Schematic representation of the model. 83

Figure 4-8 Condition state probabilities as a function of time(year) for a concrete cover of $25 \mathrm{~mm}$ (1) historical climate, (2) Climate Scenario RCP4.5, (3) Climate Scenario RCP8.5. 85

Figure 4-9 Condition state probabilities as a function of time(year) for a concrete cover of $50 \mathrm{~mm}$ (1) historical climate, (2) Climate Scenario RCP4.5, (3) Climate Scenario RCP8.5. 86

Figure 4-10 Stacked histogram of the optimal date of the bridge deck first repair at $25 \mathrm{~mm}$ (1) historical climate, (2) Climate Scenario RCP4.5, (3) Climate Scenario RCP8.5 ...................... 88

Figure 4-11 Stacked histogram of the optimal date of the bridge deck first repair at $50 \mathrm{~mm}$ (1) historical climate, (2) Climate Scenario RCP4.5, (3) Climate Scenario RCP8.5 ...................... 88

Figure 5-1 The concept of Pareto front.................................................................. 101

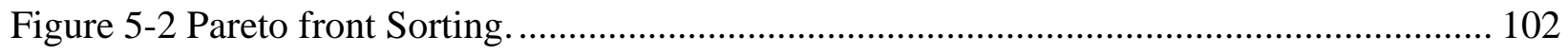

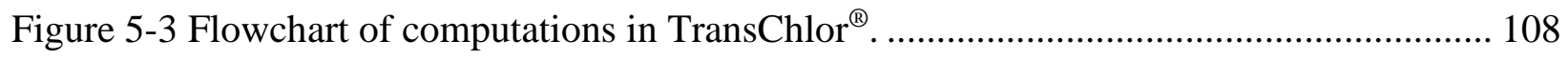

Figure 5-4 Locations of field tests performed on the bridge .......................................... 110 
Figure 5-5 Nomogram for determining the quality classes of concrete as a function of air permeability and resistivity (test results are shown as red dots) (Proceq 2005). 111

Figure 5-6 MOPSO algorithm. 114

Figure 5-7 Reproduction operation: (a) crossover and (b) mutation operations...... 115

Figure 5-8 NSGA-II algorithm. 116

Figure 5-9 Definition of durability condition states. 118

Figure 5-10 An overview of the proposed framework. 125

Figure 5-11 Total yearly number of winter precipitation days (daily precipitation $>.1 \mathrm{~mm}$ ). Historical Records and projections from RCP8.5 and RCP4.5. 126

Figure 5-12 Condition state probabilities as a function of time (year) for three climate scenarios (Historical, RCP4.5 and RCP8.5) and concrete cover thickness (25mm, 50mm and 70mm)... 128 Figure 5-13 Optimal solutions for three climate scenario and a concrete cover thickness of 25mm. 132

Figure 5-14 (a) Optimal solutions for three climate scenarios and a concrete cover thickness of 50mm; (b) Comparison of Maintenance Plan for the considered optimization techniques........ 133

Figure 5-15 Optimal solutions for three concrete cover thickness for the RCP8.5 climate change scenario. 134

Figure 5-16 Optimal solutions for three climate scenario and a concrete cover thickness of 70mm. 134

Figure 5-17 Optimal solutions for three concrete cover thickness for the RCP4.5 climate change scenario. 135

Figure 5-18 Optimal solutions for three concrete cover thickness for the Historical climate change scenario. 135

Figure 5-19 Optimized deterioration pattern for the six representative M\&R actions of the bridge deck showing different action spread and level throughout the bridge lifetime. (a) two major maintenances and one replacement $\left(\mathrm{X}_{1}\right)$; (b) three replacements $\left(\mathrm{X}_{2}\right)$; (c) six major repairs $\left(\mathrm{X}_{3}\right)$; (d) three minor maintenances, one major maintenance and one replacement $\left(\mathrm{Y}_{1}\right)$; (e) five minor 
maintenances and two major maintenances $\left(\mathrm{Y}_{2}\right)$; (f) four minor maintenances and four major maintenances

Figure 5-20 Number of M\&R actions as a function of NPVC for two optimization methods (a) MOPSO, RCP4.5, 50mm; (b) NSGA-II, RCP4.5, 50mm. 138

Figure 5-21 Number of M\&R actions as a function of Probability of Spalling for two optimization methods. (a) MOPSO, RCP4.5, 50mm; (b) NSGA-II, RCP4.5, 50mm. 138

Figure 6-1 Exposure Types and Periods for TransChlor ${ }^{\circledR}$ 155

Figure 6-2 Types of exposures for bridge components. 155

Figure 6-3 Flowchart of computations in TransChlor ${ }^{\circledR}$ 157

Figure 6-4 Chloride ion distribution at the depth of A) $25 \mathrm{~mm}$ and B) $50 \mathrm{~mm}$ in 45 years with the salt/water dissolution ratio of $8 \%$. Chloride ion profiles after 45 years for salt/water dissolution ratio of C) $6 \%$ and D) $8 \%$. 171

Figure 6-5 Typical Data on Exposure Conditions for Montreal. (A) Air temperature, (B) Relative humidity, (C) Precipitation, and (D) Solar radiation. 172

Figure 6-6 Prior, likelihood and posterior distributions of $D_{H R}$ at A) $25 \mathrm{~mm}$ and B) $50 \mathrm{~mm}$ depth; C) $25 \mathrm{~mm}$ (with model and sampling uncertainties) and D) $50 \mathrm{~mm}$ depth (with model and sampling uncertainties) (the black lines correspond to the conditional distribution of $\mathrm{Cl}$ as a function of DHR, the red lines corresponds to the core sample data). 175

Figure 6-7 Prior, likelihood and posterior distributions of $D_{H R}$ for the combined likelihoods assuming independence: A) No model and no sampling uncertainty; B) With model and sampling uncertainties. 176

Figure 6-8 Prior, likelihood and posterior distributions of $D_{C A P}$ at A) $25 \mathrm{~mm}$ and B) $50 \mathrm{~mm}$ depth; C) $25 \mathrm{~mm}$ (with model and sampling uncertainties) and D) $50 \mathrm{~mm}$ depth (with model and sampling uncertainties) (the black lines correspond to the conditional distribution of $\mathrm{Cl}$ as a function of $D_{C A P}$, the red lines corresponds to the core sample data). 177 Figure 6-9 Prior, likelihood and posterior distributions of $D_{C A P}$ for the combined likelihoods assuming independence: A) No model and no sampling uncertainty; B) With model and sampling uncertainties. 178 
Figure 6-10 Prior, likelihood and posterior distributions of $D_{C L}$ at A) $25 \mathrm{~mm}$ and B) $50 \mathrm{~mm}$ depth; C) $25 \mathrm{~mm}$ (with model and sampling uncertainties) and D) $50 \mathrm{~mm}$ depth (with model and sampling uncertainties) (the black lines correspond to the conditional distribution of $\mathrm{Cl}$ as a function of $D_{C L}$, the red lines corresponds to the core sample data). 179

Figure 6-11 Prior, likelihood and posterior distributions of $D_{C L}$ for the combined likelihoods assuming independence: A) No model and no sampling uncertainty; B) With model and sampling uncertainties. 180

Figure 6-12 Prior, likelihood and posterior distributions of $D_{H R}$ for the joint distribution of chloride ions at $25 \mathrm{~mm}$ and $50 \mathrm{~mm}$ jointly: A) No model and no sampling uncertainty; B) With model and sampling uncertainties. 181

Figure 6-13 Prior, likelihood and posterior distributions of $D_{C A P}$ for the joint distribution of chloride ions at $25 \mathrm{~mm}$ and $50 \mathrm{~mm}$ jointly: A) No model and no sampling uncertainty; B) With model and sampling uncertainties 182

Figure 6-14 Prior, likelihood and posterior distributions of $D_{C L}$ for the joint distribution of chloride ions at $25 \mathrm{~mm}$ and $50 \mathrm{~mm}$ jointly: A) No model and no sampling uncertainty; B) With model and sampling uncertainties. 182 


\section{LIST OF TABLES}

Table 2-1: Key characteristics of RCPs and SRES scenarios (Source: Charron (2016))........... 12

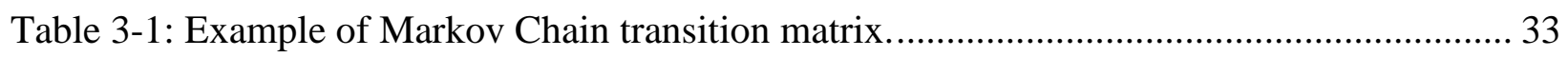

Table 3-2: Distinct Values and Associated Probabilities for Normal and Log-normal Distribution.

Table 3-3: Average Values, Distinct Values, and Associated Probabilities (lognormal)............ 39

Table 3-4: Transition counts matrix of the chloride ions content for $26 \mathrm{~mm}$ depth.................. 45

Table 3-5: Counts for the initial state 1, 26mm depth. ................................................... 46

Table 3-6: Predicted probabilities from STATISTICA ${ }^{\circledR}$ and Surrogate Markov Chain Model for

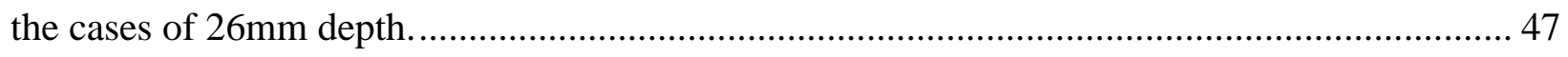

Table 4-1: Key characteristics of RCPs and SRES scenarios (Source: Charron (2016))............ 68

Table 4-2: The random variables loading in the propagation model....................................... 76

Table 4-3: Average NPV of 10,000 simulations for each scenario with no repair for each decision

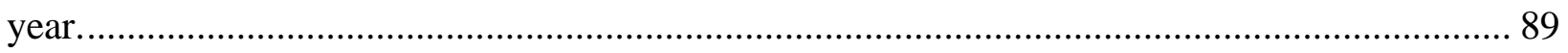

Table 5-1: Quality Classes of Cover Concrete for non-saturated concrete (Proceq 2005)........ 110

Table 5-2: Random variables of the propagation model.................................................. 119

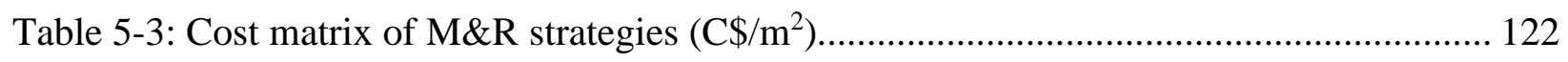

Table 5-4: Yearly Transition Probability Matrices (at the time of actions)............................ 122

Table 5-5: Yearly Transition Probability Matrices for three climate scenarios (Historical, RCP4.5

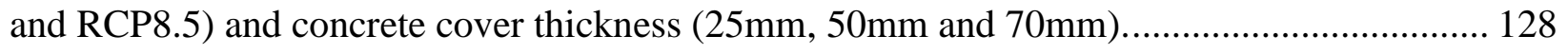

Table 6-1: Average values, distinct values, and weights for Rosenblueth point estimation. ..... 172 Table 6-2: Chloride content after 45 years at $25 \mathrm{~mm}$ and $50 \mathrm{~mm}$ depth for direct exposure (run: ijk,

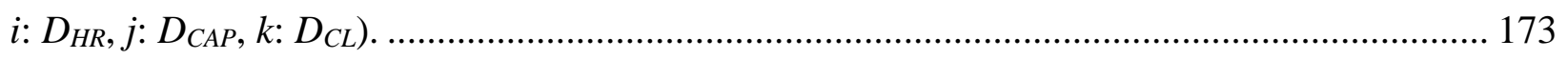

Table 6-3: Rosenblueth point estimates for the conditional mean and standard deviation of chloride

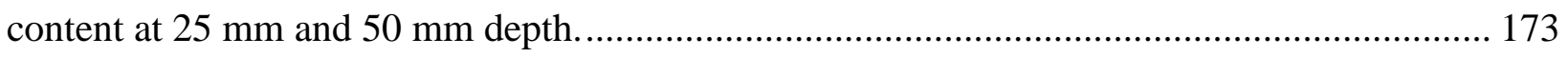


Table 6-4: Correlation coefficients (lognormal and normal) for the conditional distributions of

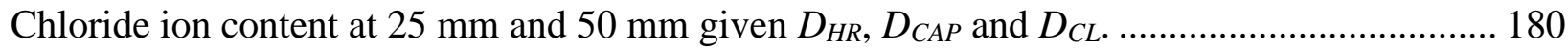




\section{Chapter 1. Introduction}

\subsection{Introduction}

Over the last decade, there has been a significant interest in ensuring the sustainability and serviceability of infrastructure systems in the context of climate change. Indeed, a large proportion of existing structures in North America already are in an advanced state of deterioration, thus affecting the sustainability and usefulness of these structures, and highlighting the need for better predicting and decision analysis tools. The management of ageing infrastructures presents many challenges to their owners and operators. Large investments are required to maintain existing infrastructures, to rectify deficiencies, and to eventually replace or upgrade them (Herrmann 2013; OECD 2013; Ottesen 2011).

Among these, reinforced concrete (RC) structures represent a significant part of the built environment, which are the focus of the present research. The durability of RC bridge decks is influenced both by environmental and operational conditions. Among these, exposition to chloride ions is one of most important factors that contributes to the premature deterioration of these structures (Bastidas-Arteaga et al. 2011; Breysse et al. 2014; Saetta et al. 1993). Once a RC structure has been exposed to chloride ions, the sequence of events is: 1) initiation of corrosion, 2) expansion of steel due to corrosion products, 3) cracking of the concrete cover and 4) spalling of the concrete cover.

Climate change and extreme weather events threaten existing infrastructure across the country, impacting its effectiveness, lifespan, cost, maintenance, rehabilitation and renewal. It can also 
adversely affect the durability of structures by increasing the number of freeze-thaw cycles, the level of relative humidity, average temperatures, and frequency of winter precipitation (NACE 2012). Talukdar et al. (2012) estimate that climate change has increased carbonation depth by $45 \%$ for concrete structures in Vancouver and Toronto over the past century. Similarly, De Larrard et al. (2014) estimate that climate change has significantly increased the risk of corrosion initiation resulting from carbonation in several French cities. Bastidas-Arteaga and Stewart (2013) propose a probabilistic cost-benefit procedure to analyse two climate change adaptation strategies for new RC structures exposed to chloride ions. The results indicate that the cost-effectiveness of specific adaptation strategies is dependent on the climate change scenario, exposure conditions and type of structural system.

Several models have been developed over the last decades to address several of the issues associated with deterioration of concrete structures. Physical models were developed that describe the progress of chloride ions in concrete which can be used to predict the time of initiation for corrosion. A variety of these models have been proposed that include to various degrees of detail exposure to climatic conditions and chemical reactions (Conciatori et al. 2010; Conciatori et al. 2009b; Zhang, Chouinard, and Conciatori 2018).

The gradual deterioration of the transportation infrastructure can result in unsafe conditions for the public, more frequent maintenance interventions traffic disruptions and higher user costs. Without effective planning, monitoring and evaluation, it would be difficult to estimate if maintenance implementation is moving in the right direction (Menon et al. 2009). Consequently, prospective maintenance scheduling and budgeting will be affected as well, influencing the public and the economy for relatively long period of time, longer than the lifecycle of an individual infrastructure component. Therefore, an optimized infrastructure management strategy is crucial for decision- 
makers, with the required methodologies, for an efficient sustainable management of structures (Marlow et al. 2010; Santos et al. 2017).

In parallel, numerous decision analysis tools have been developed to assist managers that rely on models to estimate the residual life of existing structures and determine the optimal timing of repairs in the lifecycle of a structure. Moreover, financial considerations such as cost functions are important factors affecting decisions. Both physical and financial processes have uncertainties that must be properly integrated in the decision analysis to yield accurate results (Power et al. 2015).

This problem is generally formulated as an optimization problem with constraints to assist the infrastructure manager in the decision-making process. Sarma and Adeli (1998) reviewed cost optimization of concrete structures and pointed out that life-cycle cost optimization should replace the initial cost optimization. Zhang and Wang (2017) developed a decision model for determining a prioritized maintenance schedule for a deteriorated bridge network. Maintenance actions must be effectively planned throughout the life cycle of infrastructures to optimize budget allocation under the constraints of service life (Frangopol and Soliman 2016). A maintenance action can reduce the degree of damage and provide the required level of service of a deteriorating structure.

\subsection{Research Objectives}

Improving the serviceability and sustainability of infrastructures in the most economical way are among the important objectives for decision-makers given the current state of uncertainty with climate change and the general state of the infrastructure. Various approaches to these issues have been presented, yet a comprehensive framework is lacking. This research work aims to develop a novel updatable framework that models the physical deterioration process through a probabilistic 
approach, and that incorporates uncertainties in both physical and financial processes to benefit investors as well as engineers and decision-makers. The specific objectives of the proposed research can be summarized as follow:

Objective 1: Develop deterioration and time-variant reliability models for bridge components for specified performance functions (e.g. initiation of corrosion, degree of corrosion, cracking of concrete, spalling of concrete).

Objective 2: Derive surrogate Markov Chain models for transition states of bridge systems for homogenous regions and types of bridges, which utilize historical and future climate data.

Objective 3: Derive procedures for updating physical and surrogate models based respectively on core sample data and inspection data to improve the prediction of future condition states.

Objective 4: Develop a multi-disciplinary decision analysis procedure that accounts for physical and financial uncertainties to optimize for sustainability of bridge components as a function of maintenance, sequence of minor and major repairs as well as replacement strategies for different climate change scenarios.

Overall Objective: To develop a novel updatable model (computer-aided program) integrating the physical deterioration process and decision-making strategy through a probabilistic approach to optimize the sustainability of infrastructures and to account for changes in the level of uncertainty on deterioration and financial variables as a function of time. 


\subsection{Thesis Structure}

This thesis follows a manuscript-based structure. Each of the main chapters consists of an article published or submitted in a peer-reviewed journal. Therefore, repetitions could not completely be avoided, especially in the introduction sections. All papers are the candidate's original work including the development of software to perform the analyses.

Chapter 1 provides the background on the issues that are being addressed, the motivation for the research, the research objectives, the main lines of the proposed methodology and the structure of the thesis.

Chapter 2 presents a detailed literature review on past studies related to the deterioration of reinforced concrete structures, the prediction of residual life in the context of climate change, maintenance and repair of infrastructure and optimisation procedures for planning these activities.

Chapter 3 (Article No. 1) describes numerical models of the diffusion process and chemical reactions of chloride ions in concrete to estimate the time to initiation of corrosion and for the progression of corrosion. Markov Chain-based stochastic models are used to develop surrogate models for the imitation and the propagation of corrosion for reinforcing steel at different depths and for existing structures. The analyses are performed for a range of typical concrete properties, exposure and climatic conditions. The procedure provides an alternative to Markov models derived from condition ratings when historical inspection data is limited.

Chapter 4 (Article No. 2) presents a framework that incorporates risks in economic benefits and costs by modelling the interactions and uncertainties associated with physical and financial variables in the context of infrastructure management. A probabilistic deterioration model is used 
to predict the residual life of concrete decks as a function of exposure to de-icing salts using historical data and predictions from climate change scenarios. Historical data is used to validate model assumptions by comparing predicted condition states to observations from periodic inspections, while the climate scenarios are used to evaluate the impact of climate change on deterioration rates assuming that current deck design and de-icing salt management strategies are not modified.

Chapter 5 (Article No. 3) focuses on the novel optimization procedures for multiple preventive maintenances and major repairs during the lifetime of the bridge. A risk-informed decision-making process is proposed to identify the most effective strategies to satisfy performance requirements at minimal cost. Two Meta-heuristic algorithms in conjunction with the deterioration model are applied to optimize the decision-making strategies for reinforced concrete bridge decks in Montreal. Solutions are presented in the form of a Pareto front, which corresponds to a set of optimal solutions satisfying both objectives at varying degrees. The presentation of optimal solutions as a Pareto Front defines a spectrum of solutions that provides flexibility as a function of the priorities of the decision-maker.

Chapter 6 (Article No. 4) investigates an efficient and novel system identification procedure based on a conditional surrogate model and a Bayesian updating procedure for the diffusion parameters in concrete when data on chloride content is available from core samples. The conditional surrogate model provides a novel and very efficient procedure for modelling uncertainty in complex and computing intensive numerical models. The proposed procedure can be applied for any number of core samples sampled at different times and accounts for correlations between chloride content predictions at different times and depths. 
Chapter 7 summarizes the main conclusions in this thesis, the original contributions of the research, and recommendations for future research.

\section{References}

Bastidas-Arteaga, E., Chateauneuf, A., Sánchez-Silva, M., Bressolette, P., \& Schoefs, F. (2011). A comprehensive probabilistic model of chloride ingress in unsaturated concrete. Engineering Structures, 33(3), 720-730.

Bastidas-Arteaga, E., \& Stewart, M. G. (2013). Probabilistic cost-benefit analysis of climate change adaptation strategies for new RC structures exposed to chloride ingress. Paper presented at the 11th International Conference on Structural Safety \& Reliability.

Breysse, D., Chaplain, M., Marache, A., \& Rodney, E. (2014). Simulation of synthetic climate at local scale as a mean to assess the impact of climate change on infrastructures. Civil Engineering and Environmental Systems, 31(2), 165-178.

Conciatori, D., Brühwiler, E., \& Morgenthaler, S. (2009). Calculation of reinforced concrete corrosion initiation probabilities using the Rosenblueth method. International Journal of Reliability and Safety, 3(4), 345-362. 
Conciatori, D., Laferrière, F., \& Brühwiler, E. (2010). Comprehensive modeling of chloride ion and water ingress into concrete considering thermal and carbonation state for real climate. Cement and Concrete Research, 40(1), 109-118.

De Larrard, T., Bastidas-Arteaga, E., Duprat, F., \& Schoefs, F. (2014). Effects of climate variations and global warming on the durability of RC structures subjected to carbonation. Civil Engineering and Environmental Systems, 31(2), 153-164.

Frangopol, D. M., \& Soliman, M. (2016). Life-cycle of structural systems: recent achievements and future directions. Structure and infrastructure engineering, 12(1), 1-20.

Herrmann, A. W. (2013). Asce 2013 report card for america's infrastructure. Paper presented at the IABSE symposium report.

Marlow, D., Beale, D., \& Burn, S. (2010). A pathway to a more sustainable water sector: sustainability-based asset management. Water Science and Technology, 61(5), 1245-1255.

Menon, S., Karl, J., \& Wignaraja, K. (2009). Handbook on planning, monitoring and evaluating for development results. UNDP Evaluation Office, New York, NY.

NACE. (2012). A NACE International White Paper. CORROSION CONTROL PLAN FOR BRIDGES. The Corrosion Society.

OECD. (2013). Spending on transport infrastructure 1995-2011: trends, policies, data. Paper presented at the International Transport Forum, Paris.

Ottesen, F. (2011). Infrastructure Needs and Pension Investments. OECD Journal: Financial Market Trends, 2011(1), 97-109. 
Power, G. J., Tandja M, C. D., Bastien, J., \& Grégoire, P. (2015). Measuring infrastructure investment option value. The Journal of Risk Finance, 16(1), 49-72.

Saetta, A. V., Scotta, R. V., \& Vitaliani, R. V. (1993). Analysis of chloride diffusion into partially saturated concrete. Materials Journal, 90(5), 441-451.

Santos, J., Ferreira, A., \& Flintsch, G. (2017). A multi-objective optimization-based pavement management decision-support system for enhancing pavement sustainability. Journal of cleaner production, 164, 1380-1393.

Sarma, K. C., \& Adeli, H. (1998). Cost optimization of concrete structures. Journal of structural engineering, 124(5), 570-578.

Talukdar, S., Banthia, N., Grace, J., \& Cohen, S. (2012). Carbonation in concrete infrastructure in the context of global climate change: Part 2-Canadian urban simulations. Cement and Concrete Composites, 34(8), 931-935.

Zhang, W., \& Wang, N. (2017). Bridge network maintenance prioritization under budget constraint. Structural safety, 67, 96-104.

Zhang, Y., Chouinard, L. E., \& Conciatori, D. (2018). Markov Chain-Based Stochastic Modeling of Chloride Ion Transport in Concrete Bridges. Frontiers in Built Environment, 4, 12. 


\section{Chapter 2. Literature review}

\subsection{Climate change effects and uncertainty}

When acknowledging the increasing length of infrastructure asset life and the importance of services and expenses needed to upgrade and maintain these facilities, it is essential to characterize the vulnerability of the infrastructure and the changing climate (Chester et al. 2020).

A climate model is comprised of numerous interconnected equations that possess multiple processes, inside the climate system. These types of equation rely on the physical law from the fluid mechanics, containing momentum equations, energy conservation, and mass conservation, etc. A climate model describes the interactions between the biosphere, cryosphere, hydrosphere, and atmosphere deal with the natural earth environment. Figure 2-1 presents the explanation of a climate model (Charron 2016).

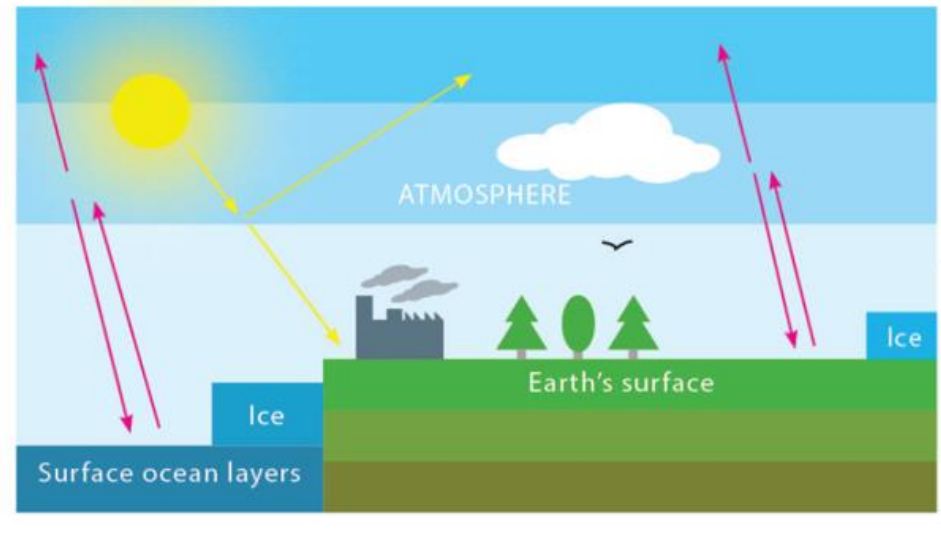

(a)

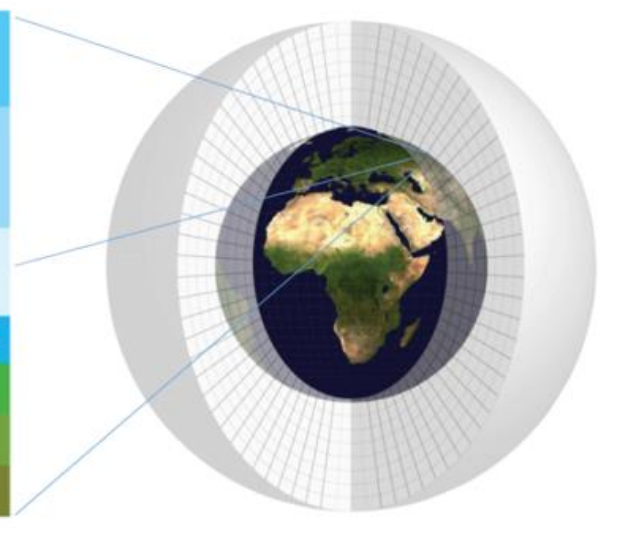

(b)

Figure 2-1 (a) Interactions in climate models and (b) discrete grids to compartmentalize the climate system (Charron, 2016). 
The climate change models can be categorized as a function of the spatial resolution of the prediction domain. Global Climate Models (GCM) has ability to cover the whole planet and can give grid resolution of approximately $200 \mathrm{~km}$, on the other hand, Regional Climate Models (RCMs) contain spatial resolution that is below $45 \mathrm{~km}$. The results for specific location need the use of statistically downscaled data and higher resolution models.

Greenhouse gases (GHGs) mainly influence the climate changes. Emission scenarios explains the plausible expected release of greenhouse gases, aerosols, and other anthropogenic gases into environment, based on clear and comprehensible internal assumptions regarding the socioeconomic and demographic development and technological change and their connections (IPCC 2007). By using the Representative Concentration Pathways (RCPs), the concentrations of greenhouse gases are explained. RCPs are the greenhouse gas concentration trajectories, that are adopted by the IPCC in 2014 for its fifth Assessment Report (AR-5) that changed the Special Report on Emissions Scenarios (SRES) projections, that was published in 2000 (Table 2-1). The four scenarios, which are normally considered have the designations RCP 8.5, RCP 6, RCP 4.5, and RCP 2.6, where the numerical values relate to radiative forcing values $(+8.5,+6.0,+4.5$, and $+2.6 \mathrm{~W} / \mathrm{m}^{2}$ ) in 2010 (can refer to Table 2-1). For instance, RCP 2.6 responds to the scenario with the minimum temperature change globally and suppose that the greenhouse gases will reach to highest point in between 2010 and 2020, and the emission of GHGs will reduce significantly. On the other hand, RCP 8.5 estimates a quick increase in carbon dioxide emissions and responds to the scenario with the highest projected changes in global temperatures by the end of this century. 
Table 2-1: Key characteristics of RCPs and SRES scenarios (Source: Charron (2016)).

\begin{tabular}{|c|c|c|c|c|c|}
\hline Scenario & Radioactive forcing & $\begin{array}{c}\mathrm{CO}_{2} \text { equivalent } \\
(\mathbf{p p m})\end{array}$ & $\begin{array}{c}\text { Temp. } \\
\text { anomaly }\left({ }^{\circ} \mathrm{C}\right)\end{array}$ & Pathway & $\begin{array}{c}\text { SRES temp anomaly } \\
\text { equivalent }\end{array}$ \\
\hline RCP8.5 & $8.5 \mathrm{~W} / \mathrm{m}^{2}$ in 2100 & $>1370$ & 4.9 & Rising & SRES A1FI* \\
\hline RCP6.0 & $6 \mathrm{~W} / \mathrm{m}^{2}$ post 2100 & $\sim 850$ & 3.0 & $\begin{array}{c}\text { Stabilizing } \\
\text { without overshoot }\end{array}$ & SRES B2 \\
\hline $\mathrm{RCP} 4.5$ & $4.5 \mathrm{~W} / \mathrm{m}^{2}$ post 2100 & $\sim 650$ & 2.4 & $\begin{array}{c}\text { Stabilizing } \\
\text { without overshoot }\end{array}$ & SRES B1 \\
\hline $\begin{array}{c}\mathrm{RCP} 2.6 \\
\text { (RCP3PD) }\end{array}$ & $\begin{array}{l}3 \mathrm{~W} / \mathrm{m}^{2} \text { mid-century, } \\
\text { decline to } 2.6 \mathrm{~W} / \mathrm{m}^{2} \\
\text { by } 2100\end{array}$ & $\sim 490$ & 1.5 & Peak and decline & None \\
\hline
\end{tabular}

On the basis of research, it has been expected that climate change will create huge effects on the environment. Chemical and physical deterioration will be mainly effected by the climate conditions, like humidity and temperature (Neville 2008). With the increase concentration of carbon dioxide, precipitation, and global temperatures, the structures are now more vulnerable to harsh environment, and thus their deterioration is increased to some level. Other than that, the expected increase in the severity and incidence of harsh weather may have significant effect on the loading actions, which should be considered in the structural design criteria (Wang and Wang 2009).

Carlos Lam et al. (2020) explored extreme hydrometeorological hazard events and presented a simulation reduction technique in order to calculate the risk for transportation networks. This was calculated by conducting statistical analysis on the predicted risks when simulating the impact of non-extreme events. Network managers may be interested in this type of research when they need to make decisions with consideration to possible future climate scenarios. 


\subsection{Chloride-induced deterioration modeling of concrete structures}

Despite the implementation of suggested approaches to show the corrosion of infrastructure and evaluate any potential dangers, to accurately calculate the longevity of a structure is near impossible. Various uncertainties can affect the lifespan, notwithstanding the state it was originally in, but the duration of the process of corrosion and the subsequent spread of deterioration are also major factors. (Frangopol 2011).

For reinforced concrete $(\mathrm{RC})$ infrastructure situated in the Northern area, corrosion plays a key part in the degradation of a structure. This is due to the susceptibility of chloride ions and the speed of the deterioration itself depends on the structure, such as materials characteristic (diffusion coefficient), geometrical properties (depth of concrete cover, cross-sectional dimensions), climate conditions (humidity, temperature, and winter precipitation) as well as exposure conditions (splash, mist or direct) (Angst 2018; Cao et al. 2019; Zhang, Chouinard, Power, Tandja M, et al. 2018). Fick's second law of diffusion allows the profiling of chloride to be formulated at a suitable estimation in many cases. This takes into account that the process of diffusion is non-stationary (Nilsson et al. 1996) and that the transition of chloride into concrete is for the most part dictated by diffusion (Hunkeler 2005).

Chloride-induced corrosion and concrete cracking can negatively impact the safety and servicing of RC structures. The lifespan of RC structures becomes difficult to predict once both of these phenomena occur in the same instance (Imounga et al. 2020).

Steel reinforcing bars are typically passive or non-corroding, due to the concrete pore solution that has high levels of alkalinity. The passivity of this substance may change for two different reasons. (1) carbonation of the cover concrete which would in turn lose the alkalinity; (2) chloride ions 
being highly present on the surface of the steel. The former causes the instability of the passive film on the uncovered reinforcing bars and results the corrosion on the surface of steel; while the latter causes in the onset of localized corrosion, also known as pitting corrosion (Jamali et al. 2013).

The time it takes for chloride ion content (e.g. \% of $\mathrm{Cl}$ - per weight of cement) to come to a critical level $\left(C_{c r i t}\right)$ is when corrosion will begin. In concrete, the $C_{c r i t}$ is vital for the evaluation of the condition of any current infrastructure as well as for when the lifespan of a facility in a new structure that will be exposed to chloride is being determined. It's become clear that $C_{c r i t}$ disseminates and therefore it is difficult to evaluate it through such aspects as the condition of the outward steel, the w/b ratio or the type of binder used (Angst 2011).

The rate of corrosion is near impossible to approximate as it depends almost entirely on oxygen and moisture levels. Molecular equations are utilised by various prediction models to estimate the rate of oxygen diffusion against the corrosion of steel (Vu and Stewart 2000). Nonetheless, nothing can be more accurate than field measurements and tests themselves (Stewart and Rosowsky 1998).

Bazant (1979) and Lounis and Daigle (2008) put forward various streamlined methods to evaluate the effects of corrosion and the compromising of the reinforced concrete. Once a crack appears, any resulting pressure from rust is assumed to remain constant until the cover itself breaks off. The following equation was suggested by Lounis and Daigle (2008) to evaluate time between the commencement of the corrosion and the commencement of the spalling (i.e. the propagation time).

$$
t_{p}(s p)=\frac{\pi}{2 S j_{r}\left[\frac{1}{\rho_{r}}-\frac{\alpha}{\rho_{s}}\right]}\left[1+v+\frac{d^{2}}{2 c(c+d)}\right] \frac{\left(2 c d+d^{2}\right) f_{t}^{\prime}}{E_{c}}
$$


where $S=$ rebar spacing; $\rho_{r}=$ density of corrosion products (assumed at $3,600 \mathrm{~kg} / \mathrm{m}^{3}$ for $\left.\mathrm{Fe}(\mathrm{OH})\right)_{3}$; $\rho_{s}=$ density of steel $\left(7,860 \mathrm{~kg} / \mathrm{m}^{3}\right) ; \alpha=$ molecular weight ratio of metal iron to the corrosion product (assumed at 0.52); and $j_{r}=$ corrosion production rate per unit area $\left(\mu \mathrm{A} / \mathrm{cm}^{2}\right)$ (Bazant 1979). This model is used to relate changes in the diameter of steel rebars to corrosion-induced damage limit states (Lounis and McAllister 2016).

Imounga et al. (2020) discussed that Bayesian networks that can be used to update the lifetime assessment based on experimental information. In addition, uncertainties of the input parameters of a chlorination model that includes a chloride diffusion acceleration factor can be characterized.

Jamali et al. (2013) examined different empirical, analytical, and mathematical models to predict the time a reinforced steel would take to crack because of the corrosion in reinforced structures. The empirical models are primarily focused on mathematical expressions and are dependent on the rate of corrosion, cover thickness and diameter of reinforcing bars. In contrast, the numerical and analytical models comprise more refined and mechanistic considerations such as the stiffness and strength parameters of the concrete and the specific type of corrosion product. It was found that most models could only predict the time-to-cracking for the fitted experiments.

\subsection{TransChlor $^{\circledR}$ model}

To simulate the transport phenomena of different materials in concrete, a numerical method named TransChlor $^{\circledR}$ is recommended to take the environmental (i.e. climatic and chemical) conditions into consideration. The model employs a 1-dimensional linear transport equation of chlorides into the concrete, which involves a finite element method to deal with the ion propagation within the concrete cover as well as applies a finite difference method to handle the progression as a function 
of time. On the basis of kinematics equations and Fick's diffusion law, this model is composed of connected nonlinear partial differential equations. Moreover, the proposed model deviates the structural modeling through the segmentation of structure into distinctive units regarding corrosion vulnerability and functional role (i.e., exposure level to corrosive agents, cover concrete permeability, local defects, etc.) (Conciatori et al. 2004).

The model is originally proposed to tackle the transport of chloride ion and water in concrete. More importantly, it differentiates the structural components exposed to water vapour and liquid water. According to the data released by the meteorological station, the stimulation experiment successfully addresses the influence of microclimatic conditions, comprising weather, exposure to de-icing salts, concrete depth, on chloride penetration in concrete. The framework of the TranChlor $^{\circledR}$ is shown in Figure 2-2. A more detailed description of the model is presented in (Conciatori et al. 2018). 


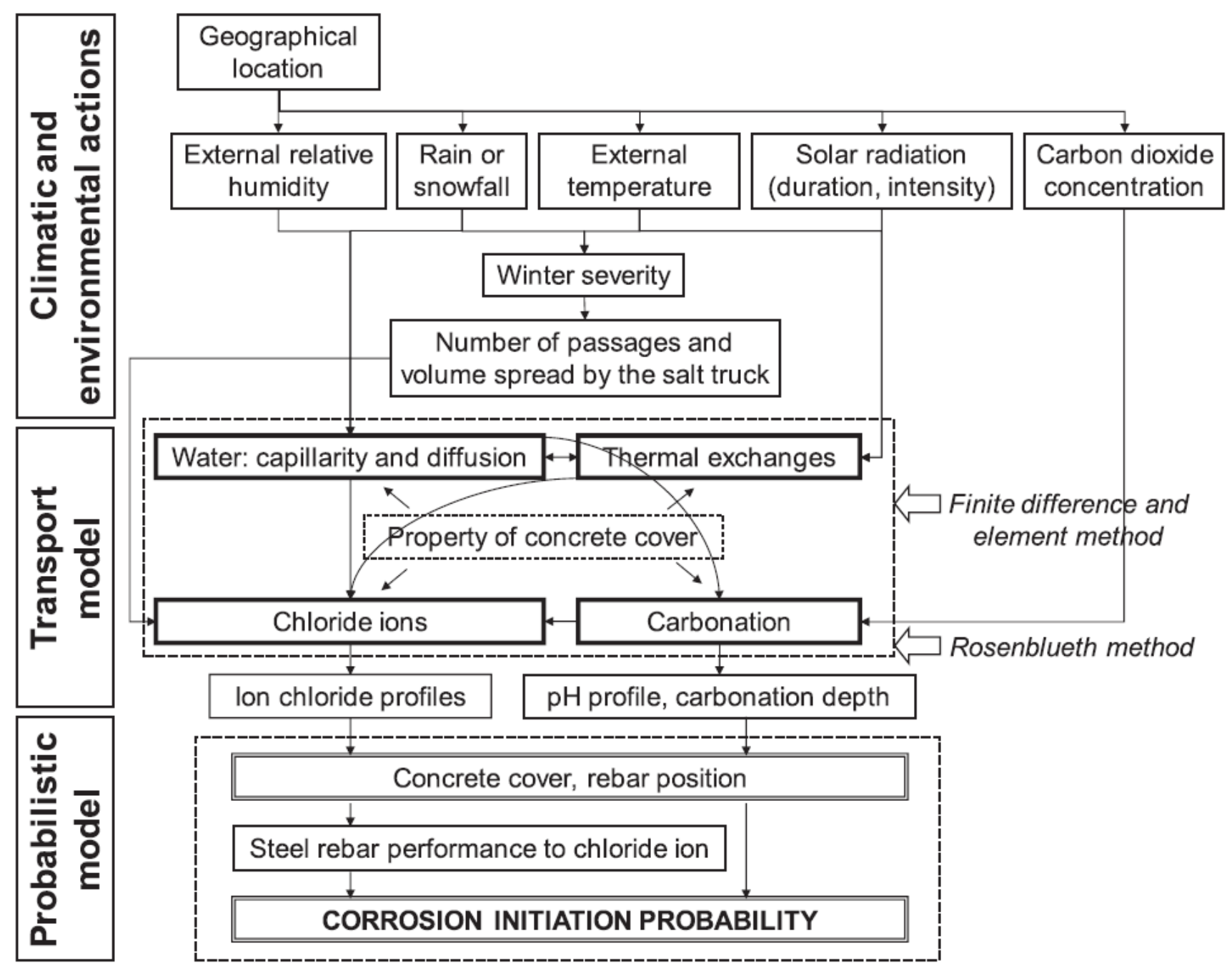

Figure 2-2 Framework of the TransChlor ${ }^{\circledR}$ software (Conciatori et al. 2018).

In order to examine the uncertainties of material performance, TransChlor ${ }^{\circledR}$ conducts an analysis on the specific four parameters of concrete, including the water vapor transport diffusion parameter $\left(D_{H R}\right)$, the liquid water capillary suction parameter $\left(D_{C A P}\right)$, the chloride ion transport diffusion parameter $\left(D_{C L}\right)$, and the carbonation parameter $\left(D_{C O 2}\right)$. The four parameters are assumed as random variables, which are mutually independent from one another, as their characteristics are 
completely described, by mean and variance. Given this, the two-point Rosenblueth method is taken to compute the moments of random variables, propagate uncertainties in the transport model and estimate how chloride ion concentrations vary as a function of the time and depth of concrete. Though numerical integration methods and Monte-Carlo modeling can be also adopted in place of aforementioned method, they remain defective in the transport model because of more intensive computation (Conciatori et al. 2014).

\subsection{Markov Chain Model and Bayesian approach-based analysis method}

The development of deterioration curves for bridge is most often performed with the application of discrete Markov chains. The Markov chain is defined for a sequence of condition states starting with a new structure and ending with a failed or obsolete structure. The Markov chain is completely characterized by the transition probabilities and the initial probabilities for each state. The probability of being a future state in the process is determined by the current state, which means that the future condition is only dependent on the present state. This property is represented by a parameter stochastic process $\left(X_{t}\right)$ and a discrete state space as below (Parzen 1962):

$$
P\left(X_{i+1}=i_{i+1} \mid X_{i}=i_{i}, X_{i-1}=i_{i-1, \ldots \ldots .,} X_{1}=i_{1}, X_{0}=i_{0}\right)=P\left(X_{i+1}=i_{i+1} \mid X_{i}=i_{i}\right)
$$

where $P$ is the transition probabilities and $i$ is the step.

Given the initial condition probabilities vector $q(0)$ is identified, which indicates the initial probability of each chloride ions content state, the future probability state vector $q(t)$ at the transition periods $t$ can be calculated as the matrix product (Collins 1975): 


$$
\begin{gathered}
q(t)=q(0) \times P^{\mathrm{t}} \\
P^{t}=\left[\begin{array}{cccc}
p_{1,1} & p_{1,2} & \ldots & p_{1, n} \\
p_{2,1} & p_{2,2} & \ldots & p_{2, n} \\
. . & . & . . & . . \\
. . & . . & \ldots & . . \\
. . & . . & \ldots & . . \\
p_{n, 1} & p_{n, 2} & \ldots & p_{n, n}
\end{array}\right] \\
Q(t)=\left[\begin{array}{cccc}
q_{1}(0) & q_{2}(0) & \ldots & q_{\mathrm{n}}(0) \\
q_{1}(1) & q_{2}(1) & \ldots & q_{\mathrm{n}}(1) \\
. . & . & \ldots & . . \\
. . & . . & . . & . . \\
. . & . . & \ldots & . . \\
q_{1}(n) & q_{2}(n) & \ldots & q_{\mathrm{n}}(n)
\end{array}\right]
\end{gathered}
$$

Morcous and Akhnoukh (2006) have developed the stationary Markov-chain model as the application example to illustrate the stochastic deterioration model based on state utilizing the expected-value approach. According to this application, bridge deck data are marked in a 2D diagram, with the horizontal and vertical axes representing the age in years and the MCR (i.e. material condition rating obtained from the Ministére des Transports du Québec database), respectively. Figure 2-3 shows the regression model $Y(t)$ which best matches the data points.

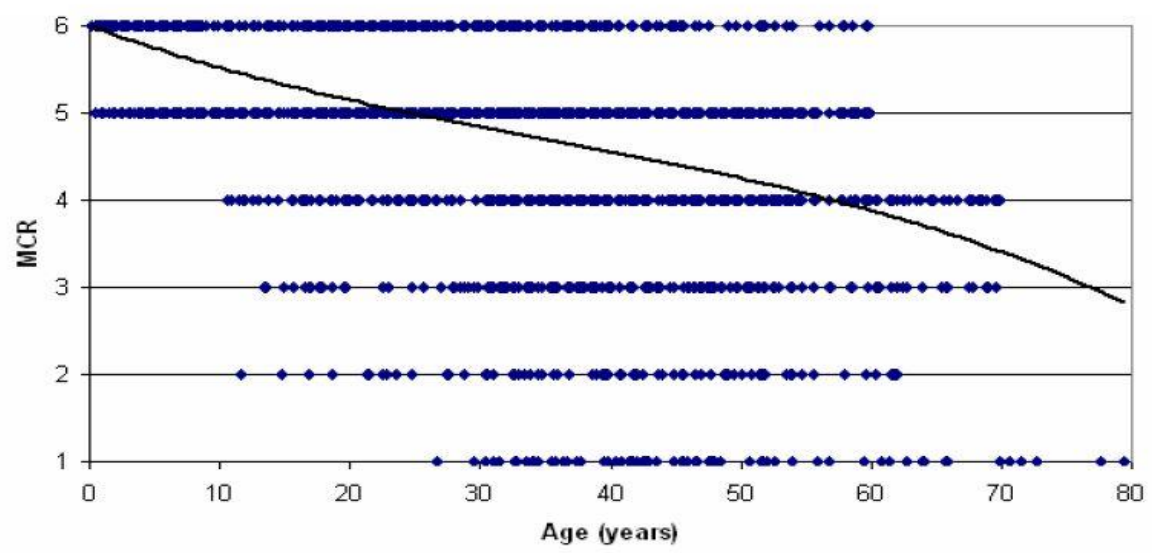

Figure 2-3 The regression model that best fits bridge deck data (Morcous \& Akhnoukh, 2006). 
Madanat et al. (1995) proposed an estimation of Transition probabilities by minimizing the sum of absolute differences between the regression model $Y(t)$ and the expected value $E(t)$ derived from Markov-chain model. The constraints and objective functions of this non-linear optimization are as below:

$$
\begin{aligned}
\text { Minimize } & \sum_{t=1}^{N}|Y(t)-E(t)| \\
\text { Subject to }: & 0 \leq p_{i j} \leq 1 \quad \text { for } \quad i, j=1,2, \ldots \ldots, n \\
& \sum_{i=1}^{n} p_{i j}=1
\end{aligned}
$$

where $Y(t)=$ average condition rating for facilities in the group at age $t$ predicted by the deterioration model; $E(t)=$ theoretical expected value of condition rating at age $t$ as a function of the Markov transition probabilities. The first constraint ensures that the probabilities are bounded by 0 and 1, and the second constraint ensures that the elements of each row of the transition matrix sum to one. By definition, $E(t)$ is given by:

$$
E(t)=q(t) \times R
$$

where $q(t),=$ a row vector representing the probability mass function of the state of the facility at age $t$ given in Eq. 2-5; and $R=$ a column vector of condition states.

Mizutani et al. (2017) estimated the transition probabilities used in Markov models from mechanistic-empirical models. The methodology is adopted when there are minimal time-series inspection information available but rather mechanistic-empirical models available. The planned methodology uses analytical solutions when it is possible and Bayesian statistics will be used when analytical solutions are not suitable. 
The improvement in the rate of sampling with computers has contributed to the popularity of the Bayesian approach-based analysis method (Mishalani and Madanat 2002). Markov Chain Monte Carlo (MCMC) simulation is used extensively in the Bayesian framework for computing the posterior distribution of parameters in complex statistical models as well in deterioration models (Kobayashi et al. 2012; Hong and Prozzi 2006).

Assuming that $Y=\left(y_{1}, y_{2}, y_{3}, \ldots, y_{\mathrm{n}}\right)$ refers to a sample of condition ratings on specific bridge element from many bridges and $\theta$ is an unknown parameter vector of the model ( $p_{i j}$ of the TPM in this case). The joint probability distribution $P(Y / \theta)$ refers to the likelihood function or sampling distribution which can perform inference (Mishalani and Madanat 2002). $P(\theta)$ is the prior distribution of the unknown model parameter, and $P(\theta / Y)$ is the target distribution or posterior distribution given the set of observations. Based on Bayes' rule of the known value $Y$, the posterior distribution of parameters of models is formulated by:

$$
P(\theta / Y)=\frac{P(\theta, Y)}{P(Y)}=\frac{P(\theta) P(Y / \theta)}{P(Y)}
$$

Clearly, $P(Y)$ cannot be regarded as a function of the parameter $\theta$. But it can be considered as normalizing constant for fixed $Y$. The posterior distribution density can be in proportion to the product of prior distribution density if the normalizing constant is omitted. The likelihood function is then shown as:

$$
P(\theta / Y) \propto P(\theta) P(Y / \theta)
$$

The first step for the application is to propose a model for $P(\theta, Y)$ followed by computing the target density $P(\theta / Y)$ (Mishalani and Madanat 2002). The Non-informative density can be assumed to 
realize uniform distribution on the basis of the Bayes-Laplace "principle of insufficient reason" (Sorensen and Gianola 2002). Thus, the posterior distribution density is proportional to the likelihood function. The joint probability theory can be applied to simplify the likelihood function of unknown transition probability density of the Markov model for the specific bridge data set $Y=$ $\left(y_{1}, y_{2}, y_{3}, \ldots, y_{\mathrm{n}}\right)$, and this can derive a logarithmic form for computation (Tran 2007; Micevski et al. 2002; Ranjith et al. 2013) as:

$$
\log [L(Y / \theta)]=\sum_{t=1}^{T} \sum_{i=1}^{5} N_{i}^{t} \log \left(C_{i t}\right)
$$

where, $L(Y / \theta)$ refers to the likelihood of finding the condition rating data set $Y=\left(y_{1}, y_{2}, y_{3}, \ldots\right.$, $y_{\mathrm{n}}$ ) of a bridge element from a bridge group having $\mathrm{n}$ records; $t$ represents the age in years of the bridge element; $T$ is the biggest age observed in the dataset; $N_{i}^{t}$ refers to the number of elements in the condition state $i$ at the year of $t ; C_{i t}$ represents the possibility in condition state $i$ at the year of $t$ and can be expressed as a function of TPM by Eq.2-4.

\subsection{Optimization procedures}

A vital element in the control of assets relating to infrastructure, decision-making (DM) establishes techniques utilized for intervention by management in the project. However, DM is not an easy task, as a variety of challenges such as contradictory goals, uncertainties, and limited resources should be clarified by decision-makers. Quantifying the net-benefit of the intervention taking into consideration the effects on service and intervention costs is needed, as the use of proxies make it very difficult to make consistent and comparable decisions, especially speaking with managers. 
Moreover, certain room should be provided to decision-makers for their personal judgement based on the ever-changing situations.

Fortunately, with development of computer technology, reliable optimization techniques become more popular and can be efficiently applied for DM problems (Ng et al. 2011).

The two most common forms of optimization are single-objective optimization (SOO) and multiobjective optimization (MOO) (Hillier 2012). The former seeks to maximise or minimise a singular objective with different constrains, whereas the goal of the latter is to find the best tradeoff amongst multiple objectives while ensuring an effective solution in optimization. In addition to pursuing an ideal assessment of the objective, SOO aims to also satisfy any constrains attached. This is exemplified in a situation where SOO is utilized to allow management intervention at a good level of service but at a budgeted cost (Zhang et al. 2017). Similarly, the optimization of the functionality of infrastructure can be achieved on a limited annual budget (Rashedi and Hegazy 2015). By comparison, MOO produces Pareto solutions and the optimal values cannot be improved if another objective is not sacrificed (Horn et al. 1994). Moreover, in most circumstances, MOO deals with numerous Pareto solutions, typically referred to as Pareto Front and satisfies all constrains. The number of Pareto solutions is left to the discretion of the policy makers (Chen and Bai 2019).

Contradicting functions of multiple objectives raise the difficulty of resolving a MOO issue. For example, the weighty expenditure linked to the upkeep and repair of infrastructure improves its ability to continue and stay in good service. Therefore, these two objectives - to manage costs and to provide a better service - contradict each other. An effective solution to this would be what is most commonly known as scalar optimization which effectively prioritises objectives to facilitate the formation of a single composite objective function (Bhatti 2012). Using data on transportation 
acquired from Wyoming Department of Transportation, Shim and Lee (2017) recently put forward a mathematical framework for a multi-objective problem related to bridge deck interventions. However, the assigned weights for the two objective functions are random and thus render the model limited.

The relationships between objectives, their values and the possibility for trade-off alternatives are all better informed with the Pareto Solution Set which can help find solutions to current issues as well as create balanced objectives and assist with making informed judgments (Chen et al. 2015; Rifai et al. 2016; Santos et al. 2019; Chen and Bai 2019).

\subsection{Optimization methodology}

Two types of modeling methods, namely heuristic and deterministic, can generally solve optimization problem. Silver et al. (1980) interpreted heuristic method as an intuitive method aiming at acquiring plausible solution via the intelligent explanation. In most cases, heuristics are based on accepted basic knowledge, which is embodied in relative general knowledge and unrelated repetitive solutions (Yaseen and Al-Slamy 2008). On the other side, in virtue of inference and mathematical theorem, deterministic methods are deemed as mechanic ones to render solutions to optimization problems Moteleb (2010).

Genetic algorithm (GA) is a random search measure in terms of natural selection mechanism, equipped with a simple process but powerful function (Goldberg and Holland 1988). Initiating from initial population of random solution called "chromosomes", each chromosome contains unit sequences known as "genes" that are able to encrypt specific components in the solution. It is simple and maneuverable to take advantage of GA methods, involving the complex DM problems 
proposed in recent literature (Belevičius et al. 2013; Morcous and Lounis 2005; Elhadidy et al. 2015; Hadiwardoyo et al. 2017). Meanwhile, it has also been used in the field of infrastructure management. Farran and Zayed (2012) made full use of GA and the Markov Chains to ascertain the optimized repair scheme of the bridge.

Eberhart and Kennedy (1995) exploited a strong algorithm, Particle Swarm Optimization (PSO), to resolve the sophisticated continuous problems. For the sake of mimicking the animals' social behavior such as fish of school and birds in flocks, PSO randomly starts with individuals or particle flies, in order to find the best solution in search space. Each particle is recognized by its location and velocity. Founded in 1999, Multi-Objective PSO (MOPSO) has amounts of software and extensive literature and applications; Within the scope of engineering management, the problem of MOO has become a developing field. AL-Smadi (2019) solved the PSO based method to optimize the building maintenance strategy in light of the cost, while (Babapour et al. 2018) has used MOPSO technology to evaluate the cost-effectiveness tradeoffs in the pavement maintenance strategy.

\section{References}

Angst, U. (2011). Chloride induced reinforcement corrosion in concrete. Doctoral theses, Norwegian University of Science and Technology, Trondheim.

Angst, U. M. (2018). Challenges and opportunities in corrosion of steel in concrete. Materials and Structures, 51(1), 4. 
Bazant, Z. P. (1979). Physical model for steel corrosion in concrete sea structures--theory. Journal of the Structural Division, 105(ASCE 14651 Proceeding).

Cao, Y., Gehlen, C., Angst, U., Wang, L., Wang, Z., \& Yao, Y. (2019). Critical chloride content in reinforced concrete-An updated review considering Chinese experience. Cement and Concrete Research, 117, 58-68.

Carlos Lam, Juan, Jürgen Hackl, Magnus Heitzler, Bryan T Adey, and Lorenz Hurni. 2020. 'Impact Assessment of Extreme Hydrometeorological Hazard Events on Road Networks', Journal of Infrastructure Systems, 26: 04020005.

Charron, I. (2016). A Guidebook on Climate Scenarios: Using Climate Information to Guide Adaptation Research and Decisions, 2016 Edition. Retrieved from

Chester, Mikhail V, B Shane Underwood, and Constantine Samaras. 2020. 'Keeping infrastructure reliable under climate uncertainty', Nature Climate Change: 1-3.

Conciatori, D., Brühwiler, E., \& Linden, C. (2018). Numerical simulation of the probability of corrosion initiation of $\mathrm{RC}$ elements made of reinforcing steel with improved corrosion performance. Structure and Infrastructure Engineering, 14(11), 1446-1454.

Conciatori, D., Denarié, E., Sadouki, H., \& Brühwiler, E. (2004). Chloride penetration model considering microclimate. In Life-Cycle Performance of Deteriorating Structures: Assessment, Design and Management (pp. 68-74).

Conciatori, D., Grégoire, É., Samson, É., Marchand, J., \& Chouinard, L. (2014). Statistical analysis of concrete transport properties. Materials and structures, 47(1-2), 89-103. 
Frangopol, D. M. (2011). Life-cycle performance, management, and optimisation of structural systems under uncertainty: accomplishments and challenges 1. Structure and infrastructure engineering, 7(6), 389-413.

Hunkeler, F. (2005). Corrosion in reinforced concrete: processes and mechanisms. Corrosion in reinforced concrete structures, 1-45.

Imounga, Henriette Marlaine, Emilio Bastidas-Arteaga, Rostand Moutou Pitti, Serge Ekomy Ango, and Xiao-Hui Wang. 2020. 'Bayesian Assessment of the Effects of Cyclic Loads on the Chloride Ingress Process into Reinforced Concrete', Applied Sciences, 10: 2040.

IPCC. (2007). Climate Change 2007: Synthesis Report. Contribution of Working Groups I, II and III to the Fourth Assessment Report of the Intergovernmental Panel on Climate Change [Core Writing Team, Pachauri, R.K and Reisinger, A. (eds.)] (1462-9011). Retrieved from Geneva, Switzerland:

Jamali, Amin, Ueli Angst, Bryan Adey, and Bernhard Elsener. 2013. 'Modeling of corrosioninduced concrete cover cracking: A critical analysis', Construction and Building Materials, 42: $225-37$.

Lounis, Z., \& Daigle, L. (2008). Reliability-based decision support tool for life cycle design and management of highway bridge decks. Paper presented at the Annual Conference of the Transportation Association of Canada.

Lounis, Z., \& McAllister, T. P. (2016). Risk-based decision making for sustainable and resilient infrastructure systems. Journal of Structural Engineering, 142(9), F4016005. 
Mizutani, Daijiro, Nam Lethanh, Bryan T Adey, and Kiyoyuki Kaito. 2017. 'Improving the Estimation of Markov Transition Probabilities Using Mechanistic-Empirical Models', Frontiers in Built Environment, 3: 58.

Neville, A. (2008). Properties of concrete CTP-VVP. Malaysia.

Nilsson, L., Poulsen, E., Sandberg, P., Sørensen, H., \& Klinghoffer, O. (1996). HETEK, Chloride penetration into concrete, State-of-the-Art, Transport processes, corrosion initiation, test methods and prediction models. Denmark, ISSN/ISBN, 0909-4288.

Stewart, M. G., \& Rosowsky, D. V. (1998). Time-dependent reliability of deteriorating reinforced concrete bridge decks. Structural safety, 20(1), 91-109.

Vu, K. A. T., \& Stewart, M. G. (2000). Structural reliability of concrete bridges including improved chloride-induced corrosion models. Structural safety, 22(4), 313-333.

Wang, C., \& Wang, X. (2009). Hazard of extreme wind gusts in Australia and its sensitivity to climate change. Paper presented at the 18th world IMACS/MODSIM Congress.

Zhang, Y., Chouinard, L. E., Power, G. J., Tandja M, C. D., \& Bastien, J. (2018). Flexible decision analysis procedures for optimizing the sustainability of ageing infrastructure under climate change. Sustainable and Resilient Infrastructure, 1-12. 


\title{
Chapter 3. Markov Chain Based Stochastic Modeling of Chloride Ion Transport in Concrete Bridges
}

\begin{abstract}
Over the last decade, there has been an increasing interest in models for the evaluation and prediction of the condition of bridges in Canada due to their large number in an advanced state of deterioration. The models are used to develop optimal maintenance and replacement strategies to extend service life and optimally allocate financial and technical resources. The main process of deterioration of concrete bridges in Canada is corrosion of the reinforcing steel due to the widespread use of de-icing salts. In this article, numerical models of the diffusion process and chemical reactions of chloride ions in concrete are used to estimate the time to initiation of corrosion and for the progression of corrosion. The analyses are performed for a range of typical concrete properties, exposure and climatic conditions. The results from these simulations are used to develop parametric surrogate Markov chain models of increasing states of deterioration. The surrogate models are more efficient than physical models for the portfolio analysis of a large number of structures. The procedure provides an alternative to Markov models derived from condition ratings when historical inspection data is limited.
\end{abstract}

Keywords: Concrete bridges, deterioration, Markov Chain, transition probabilities, chloride ions content. 


\subsection{Introduction}

Reinforced concrete bridges are critical elements of the transportation network in Canada. Many of these bridges are reaching the end of their service life and showing advanced stages of deterioration. Due to the large number of structures requiring repairs or replacement, a rational procedure is needed to prioritize interventions and optimally allocate financial and technical resources. The main process of deterioration for concrete bridges in Canada is due to the use of de-icing salts to maintain bare pavement conditions during winter (NACE 2012). Several physical models are available to predict the ingress of chloride ions in concrete. The simplest models are based on the diffusion equation (Crank and Gupta 1975) while more advanced models can account for other ion transport mechanisms, types of exposure, climatic conditions (Conciatori et al. 2010; Conciatori et al. 2009b) and chemical reactions (Samson and Marchand 2007). Most models are developed for undamaged concrete elements; however, corrosion induced cracking of the concrete can greatly accelerate the deterioration process once corrosion has progressed (Jefremczuk 2005).

The model used in this application is TransChlor $^{\circledR}$ (Conciatori et al. 2010), which uses hourly climate data (precipitation, temperature, relative humidity, solar radiation) to replicate the application of de-icing salts within a given climatic region. The model also differentiates between the types of exposure (direct, splash or mist) for different bridge elements. However, the onedimensional finite element program is computer intensive, which limits its application in practice to a limited number of cases.

When data from inspections and condition assessments are available, statistical models for the evolution of condition states can be used as an alternative to physical models. Markov chain models have been used extensively for predicting conditions states (Jiang and Sinha 1989; Cesare 
et al. 1992; Thomas and Sobanjo 2016). The transition probabilities for these models are usually estimated using statistics from inspection data but have also been derived from simulations with physical models that are correlated to condition states (O’Connor et al. 2011).

The transition probabilities can be parametrized as a function of physical characteristics of the concrete or of the climatic region. The latter approach is proposed in this work to derive parametrized transition probabilities for specified geographical regions as a function of concrete properties. For this purpose, a multinomial logit model is used for the transition probabilities as a function of diffusion properties of concrete for specific climatic and exposure conditions. The model is applied and demonstrated for bridges located in the Montreal area.

\subsection{Bridge Deterioration Modeling}

Decisions on the maintenance, rehabilitation or replacement of bridges are based on evaluations of current condition and predicted residual life. Current condition is evaluated qualitatively from inspection reports and rating procedures and quantitatively using standards that account, among others, for the level of investigations performed for a specific structure (CSA 2014). Similarly, future conditions can be qualitatively extrapolated from current conditions when historical data from inspections and condition ratings is sufficient to develop empirical prediction models or quantitatively by using numerical models of deterioration. In the latter case, predictions may be tainted by large uncertainties on the model, the history of exposure, and material properties, which

must be accounted for in the development of maintenance and rehabilitation strategies (Estes and Frangopol 2005). 
Discrete Markov chain models are usually derived for a small number (3 to 4) of condition states. Four types of models are most often used for this purpose: 1) Physical models to determine the time to the initiation of corrosion, 2) Regression Models, 3) Duration Models, and 4) Artificial Intelligence Prediction Models.

Regression models are the most commonly used by agencies for modeling asset performance. Adaptive methods and latent variables can be employed to gradually forecast condition as a function of previous performance and features as well (Washington et al. 2010b). If inspection data on bridge condition is not available, a duration model can be used to determine the residual life defined as the period of time remaining before the threshold of lowest admissible performance is reached (Caner et al. 2008). Duration (also survival or reliability) analysis is a probabilistic method to predict the time to failure of a structure and is commonly used for mechanical and electrical components (Yang 2007). Duration models may be parametric, semi-parametric, or nonparametric (Washington et al. 2010a). Artificial Intelligence (AI) refers to computer techniques for automating decisions based on a set of inputs. AI techniques include genetic algorithm (GA), expert systems, case based reasoning (CBR) and artificial neural networks (ANN). Sobanjo (1997) uses ANN for modeling bridge deterioration. A multilayer ANN is used to relate the condition of the bridge superstructure to the number of years of service of the bridge and other relevant inputs. Tokdemir et al. (2000) use ANN to forecast the bridge condition as a function of bridge geometry, level of traffic, years in service and structural attributes as explanatory variables.

The development of deterioration functions for bridge is most often accomplished with discrete Markov chains. The Markov chain is defined for a sequence of condition states starting with a new structure and ending with a failed or obsolete structure (Micevski et al. 2002). The condition states can be defined on either a qualitative or quantitative scale. The Markov chain is a memoryless 
process since the probability of transition probabilities from one state to the next are only a function of the current state (Morcous 2006). The Markov chain is completely characterized by the transition probabilities and the initial probabilities for each state. The transition probabilities are typically defined for a standard step or time interval of 1 year corresponding to the interval between inspections. The transition probabilities can be parametrized as a function of material properties, degree of exposure, and even number of years of service. The probabilities can be displayed on a directed graph (Figure 3-1 or in a matrix (Table 3-1)) (Jiang and Sinha 1989).

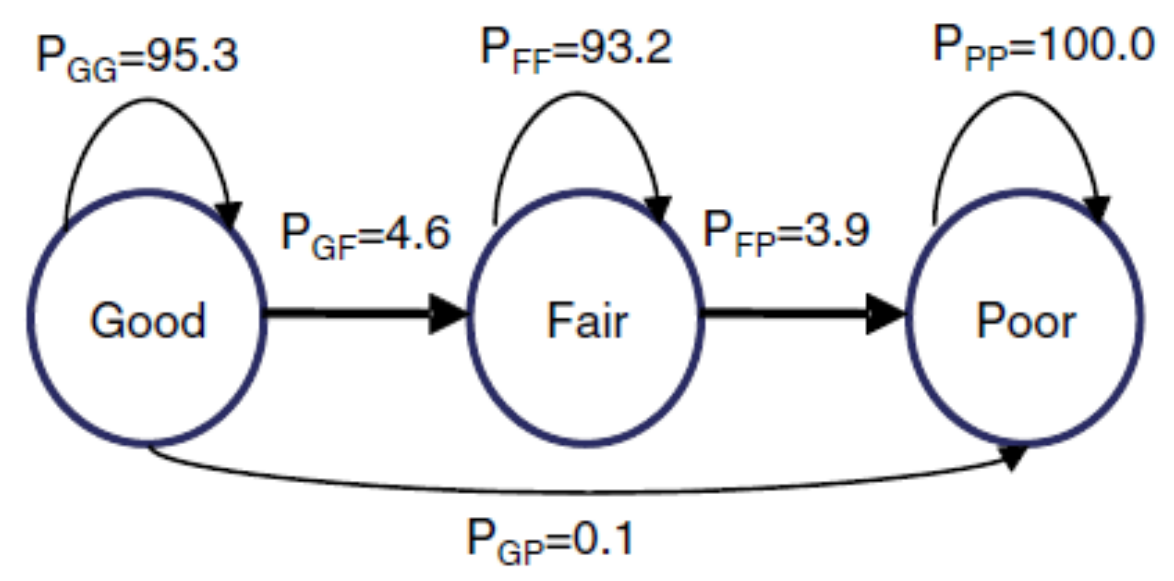

Figure 3-1 Example Markov Chain graph with three states.

Table 3-1: Example of Markov Chain transition matrix. 
Markov Transition Matrix

\begin{tabular}{cccc}
\hline State at time $t$ & \multicolumn{3}{c}{ State at time $t+1$} \\
\cline { 2 - 4 } & Good $(\mathrm{G})$ & Fair $(\mathrm{F})$ & Poor $(\mathrm{P})$ \\
\hline Good $(\mathrm{G})$ & 95.3 & 4.6 & 0.1 \\
Fair $(\mathrm{F})$ & 0 & 93.2 & 3.9 \\
Poor $(\mathrm{P})$ & 0 & 0 & 100.0 \\
\hline
\end{tabular}

\subsection{Modeling of Chloride Ions Transport}

In probabilistic service life prediction for reinforced concrete structures, modeling, the time to initiation of corrosion is the most critical parameter (Shafei and Alipour 2015). The time to initiation of corrosion corresponds to the time required for the chloride ion content (e.g. \% of $\mathrm{Cl}$ per unit weight of cement) to reach a critical level $\left(C_{c r i t}\right)$. Reported values for the critical level vary greatly due to differences in the definition of initiation, the type of reinforcement, and the stochastic nature of corrosion. In some cases, the critical value corresponds to the depassivation of the protective layer at the surface of the reinforcing steel while from a practical engineering point of view it is identified as the level when the degree of deterioration of the concrete becomes unacceptable which is highly subjective (Deb 2012).

The surrogate Markov model is derived by defining a set of discrete states for the chloride ion concentration at the depth of the reinforcement from the concrete surface. Historical climatic data is used to model the time series for the chloride content and uncertainties associated with transport properties are addressed by performing a set of analyses for optimally selected values from the probability distribution functions of the transport and diffusion parameters using the Rosenblueth point estimation procedure (Conciatori et al. 2009b; Rosenblueth 1975; Wolofsky 2011a). The 
simulation is used to generate a large sample of state transitions for estimating the transition probabilities. In this application, only direct exposure is considered since the analysis is performed only for the concrete deck. Hourly climate data was obtained for a period starting at the beginning of the service life (1965) of a typical older bridge in Montreal until present (Figure 3-2).
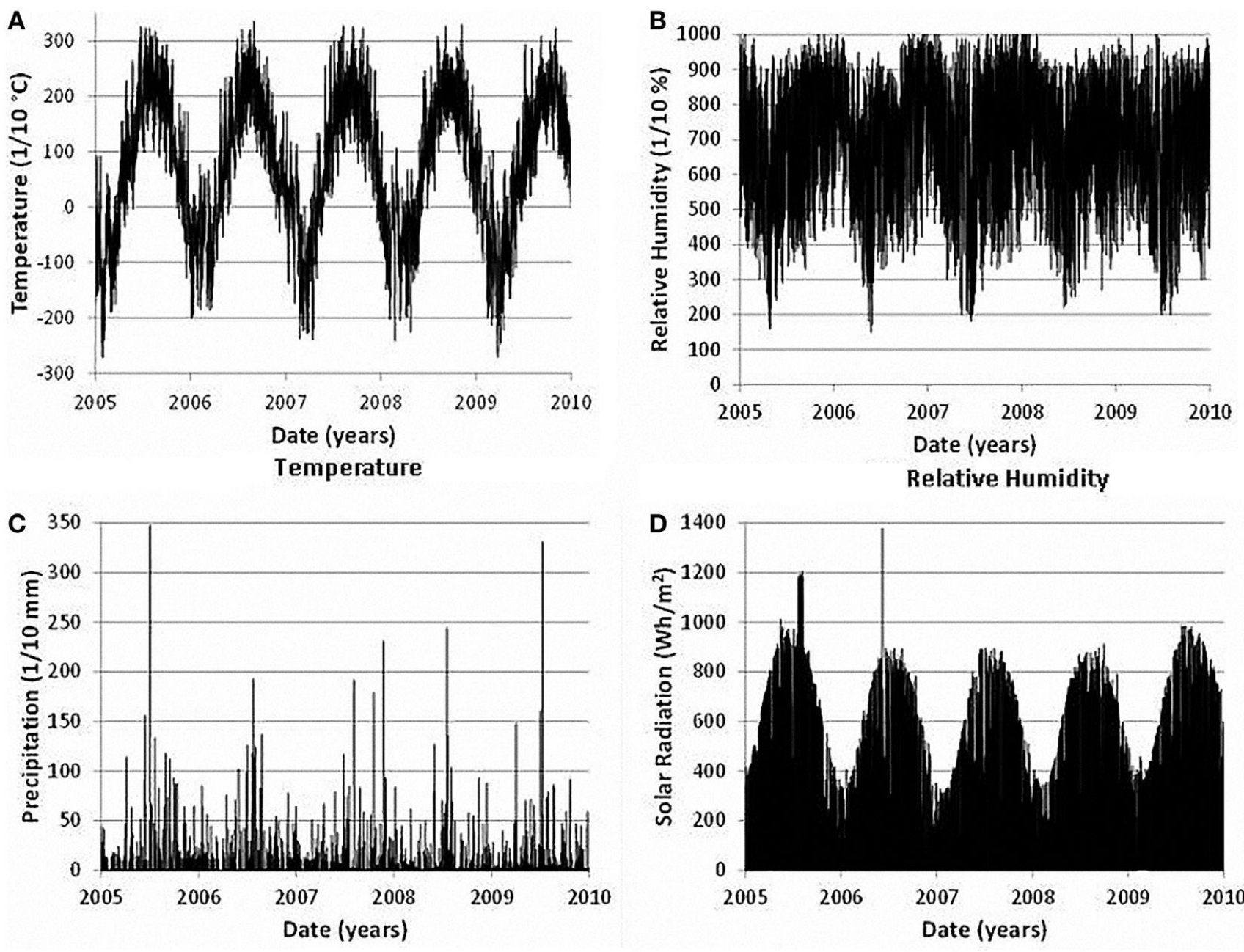

Precipitation

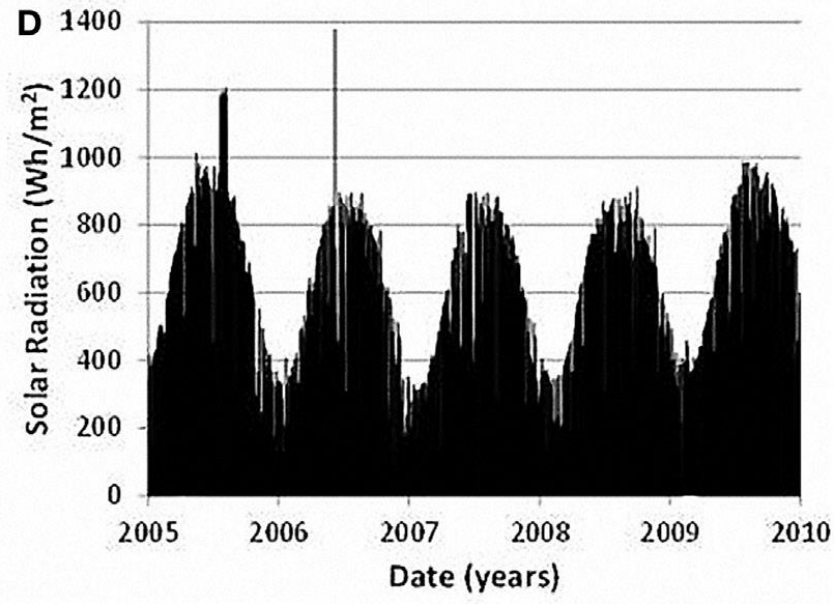

Solar Radiation

Figure 3-2 Sample of climate data for Montreal (A) temperature; (B) relative humidity; (C) precipitation; (D) solar radiation. 
The TransChlor ${ }^{\circledR}$ model includes the effects of two primary chemical reactions: carbonation and adsorption of chloride ions by the cement paste. The model is implemented through a 1dimensional linear finite element model for the transport of chlorides in space and a finite difference model in time. The transport modules include thermal and vapor transfers, liquid water transport with and without chloride ions, capillary suction, chloride ion diffusion in water, and carbon dioxide diffusion in concrete (Conciatori et al. 2010; Wolofsky et al. 2015). Calculations are performed at intervals of 1 hour which provide the adequate level of resolution for the simulation of temperature profiles, precipitation history and wetting/drying cycles (Conciatori et al. 2008; Conciatori et al. 2010). Computing time for 45 years exposure period is in the order of 2 to 24 hours depending on the performance of the computer.

\subsection{Experimental Design}

TransChlor $^{\circledR}$ allows a probabilistic analysis for up to four concrete properties to account for uncertainties on material properties. The four concrete properties are: 1) the water vapor transport diffusion parameter $\left.\left(D_{H R}\right), 2\right)$ the liquid water capillary suction parameter $\left.\left(D_{C A P}\right), 3\right)$ the chloride ion transport diffusion parameter $\left(D_{C L}\right)$, and 4$)$ the carbonation parameter $\left(D_{C O 2}\right)$. The four concrete properties are assumed to be mutually independent random variables that are fully characterized by their mean and variance. The two-point Rosenblueth method for calculating moments of a random variable is used to propagate uncertainty in the transport model and to estimate the mean and variance of chloride ion concentrations as a function of time and depth inside a concrete element. Numerical integration methods or Monte-Carlo modeling can be used in theory as an alternative, however, these are computationally too intensive for the transport 
model (Conciatori et al. 2014). Details of the Rosenblueth point estimators method and comparisons with results from Monte Carlo simulations are presented in (Conciatori et al. 2014). The Rosenblueth method is used to estimate the mean value of the chloride content and its standard deviation as a function of time and depth into the concrete elements. In this work, only the three main contributors $\left(D_{H R}, D_{C A P}, D_{C L}\right)$ to uncertainty are included in the analysis which requires a total of $2^{3}=8$ simulations.

In the simulations, the lower value is represented by $X_{1}$ and the upper value by $X_{2}$. The formulas used to determine the distinct values $\left(X_{1}, X_{2}\right)$ and the associated probabilities $\left(F_{1}, F_{2}\right)$ are defined as follows (Rosenblueth 1975; Conciatori et al. 2009b)

$$
\begin{gathered}
F_{2}=\frac{1}{2}\left[1-\frac{\beta}{|\beta|} \sqrt{1-\frac{1}{1+(\beta / 2)^{2}}}\right] \\
F_{1}=1-F_{2} \\
X_{2}=\mu_{x}+\sigma_{x} \cdot \sqrt{\frac{F_{1}}{F_{2}}} \\
X_{1}=\mu_{x}-\sigma_{x} \cdot \sqrt{\frac{F_{2}}{F_{1}}}
\end{gathered}
$$

The distinct values $\left(X_{1}, X_{2}\right)$ and the associated probabilities $\left(F_{1}, F_{2}\right)$ for a normal and lognormal distribution are shown in Table 3-2 (Conciatori et al. 2009b):

Table 3-2: Distinct Values and Associated Probabilities for Normal and Log-normal Distribution. 


\begin{tabular}{ccccc}
\hline \multirow{2}{*}{ Distribution } & \multicolumn{2}{c}{ Points } & \multicolumn{2}{c}{ Associated probabilities } \\
\cline { 2 - 5 } & \multicolumn{1}{c}{$\boldsymbol{X}_{\boldsymbol{1}}$} & $\boldsymbol{X}_{\mathbf{2}}$ & $\boldsymbol{F}_{\boldsymbol{1}}$ & $\boldsymbol{F}_{\mathbf{2}}$ \\
\hline NormalN $(\mu, \sigma)$ & $\mu+\sigma$ & $\mu-\sigma$ & 0.5 & 0.5 \\
$\log -\operatorname{normal} L N(\lambda, \xi)$ & $e^{\lambda-\xi}$ & $e^{\lambda+\xi}$ & $\frac{\alpha_{p}}{\alpha_{p}+\alpha_{m}}$ & $\frac{\alpha_{m}}{\alpha_{p}+\alpha_{m}}$ \\
\hline
\end{tabular}

where $\alpha_{m}=e^{\lambda} \cdot\left(1-e^{\xi}\right), \alpha_{p}=e^{\lambda} \cdot\left(e^{\xi}-1\right)$

The distinct values and associated probabilities are optimal for the estimation of the moments of the random variables and in particular for the mean value and the variance. Estimates of the initial moment of order $n$ for the chloride ion content at time $t$ and depth $d$ are obtained with the following expressions,

$$
\begin{gathered}
Y(t, d)^{n}=\sum_{i=1}^{2^{r}} P_{i} \cdot y(t, d)_{i}^{n} \\
y(t, d)_{i}=f\left(x_{1 \delta_{1}}, x_{2 \delta_{2}}, \cdots, x_{r \delta_{r}}, t, d\right) \\
P_{i}=\prod_{j=1}^{r} p_{\delta_{j}}
\end{gathered}
$$

where $\delta_{j}$ is the point estimate identifier (+,-) for variable $j$, and $P_{i}$ is the probability associated with a given combination of transport properties. The average values of $D_{H R}, D_{C L}$ and $D_{C A P}$, coefficient of variation and distinct values with their associated probabilities are shown in Table 3-3. The average values and coefficient of variation are determined from data bases for concrete typical at the time of construction of the bridges (Conciatori et al. 2009b). Previous studies also indicate the 
lognormal distribution is appropriate for the distribution of the diffusion parameters as well as for the distribution for the chloride content given the duration of exposure and depth into the concrete (Wolofsky 2011a).

Table 3-3: Average Values, Distinct Values, and Associated Probabilities (lognormal).

\begin{tabular}{lllllll}
\hline Parameter & $\boldsymbol{\mu}\left(\mathrm{mm}^{2} / \mathbf{s}\right)$ & $\boldsymbol{C . O} . \boldsymbol{V}$ & $\boldsymbol{X}_{\boldsymbol{1}}\left(\mathbf{m m}^{2} / \mathbf{s}\right)$ & $\boldsymbol{X}_{\mathbf{2}}\left(\mathbf{m m}^{2} / \mathbf{s}\right)$ & $\boldsymbol{F}_{\boldsymbol{1}}$ & $\boldsymbol{F}_{\boldsymbol{2}}$ \\
\hline$D_{H R}$ & $1.3 \times 10^{-4}$ & $30 \%$ & $9.28 \times 10^{-5}$ & $1.67 \times 10^{-4}$ & 0.573 & 0.427 \\
& & & & & & \\
$D_{C A P}$ & $6.5 \times 10^{-4}$ & $30 \%$ & $4.64 \times 10^{-4}$ & $8.34 \times 10^{-4}$ & 0.573 & 0.427 \\
$D_{C L}$ & $4.9 \times 10^{-6}$ & $40 \%$ & $3.09 \times 10^{-6}$ & $6.68 \times 10^{-6}$ & 0.595 & 0.405 \\
\hline
\end{tabular}

The results are obtained as a function of depth in increments of $2 \mathrm{~mm}$ into the concrete for three types of exposure: mist, splash and direct. Figure 3-3 and Figure 3-4 illustrate simulations results from the TransChlor ${ }^{\circledR}$ model for the 8 cases at depths of $26 \mathrm{~mm}$ and $50 \mathrm{~mm}$ for direct exposure. The digits in the legend stand for the distinct points $(0$ or 1 or 2$)$ that are used for each simulation. The first three values respectively stand for $D_{H R}, D_{C A P}$, and $D_{C L}$. For example, the curve (1220) represents the lower value 1 for $D_{H R}$, the higher value 2 for $D_{C A P}$ and $D_{C L}$ and the value 0 for a deterministic value for $D_{\mathrm{CO} 2}$. The simulation was performed for a duration of 16,425 days (approximately 45 years) incorporating hourly climate data (air temperature, relative humidity, precipitation, and solar radiation). The depth of $50 \mathrm{~mm}$ is selected since it is common for the thickness of the concrete cover for reinforced concrete. The depth of $26 \mathrm{~mm}$ is not common and is used to illustrate the increase in deterioration rates when the reinforcement is not properly placed. 


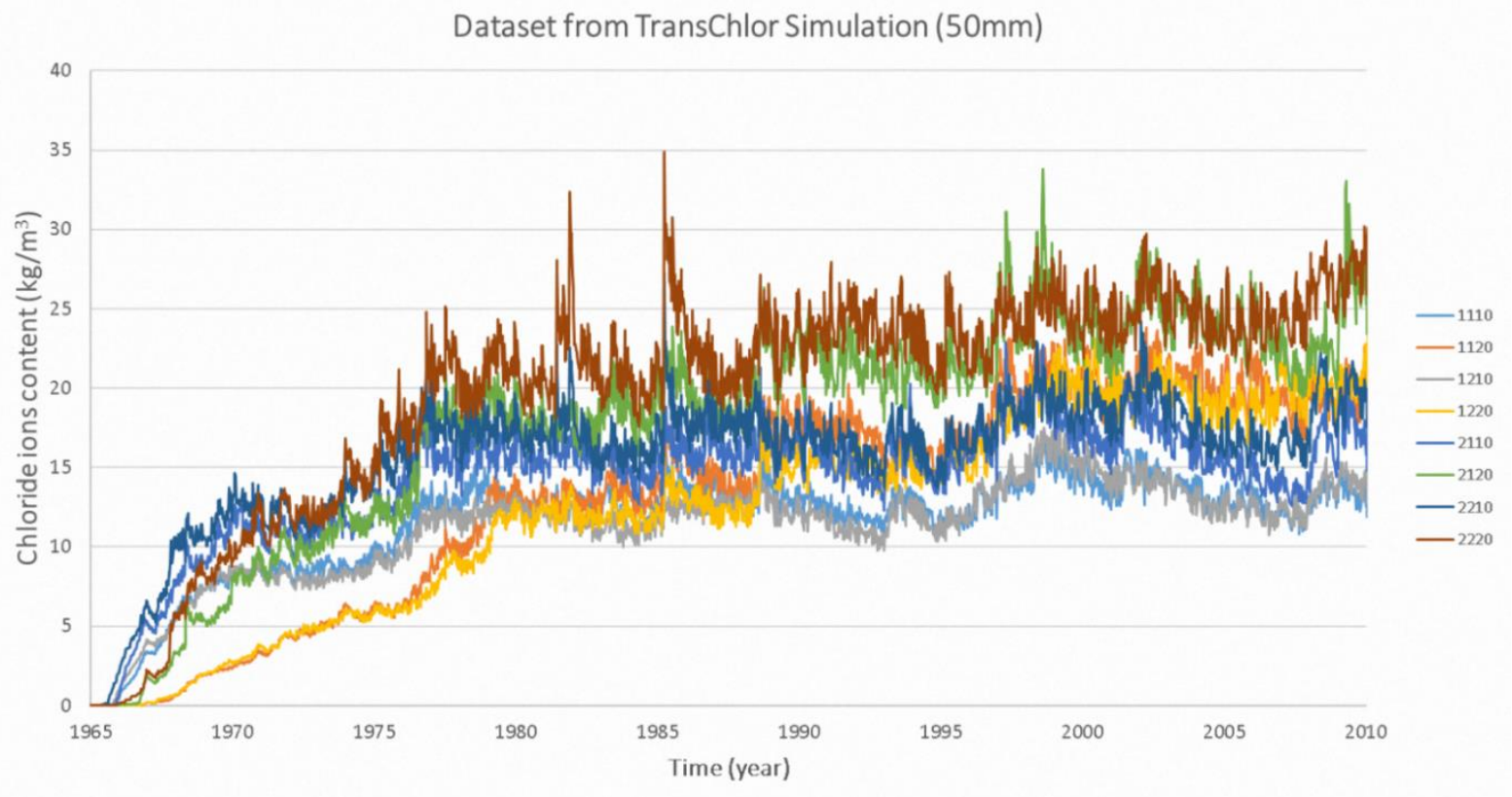

Figure 3-3 Dataset simulated from TransChlor ${ }^{\circledR}$ for $50 \mathrm{~mm}$ depth.

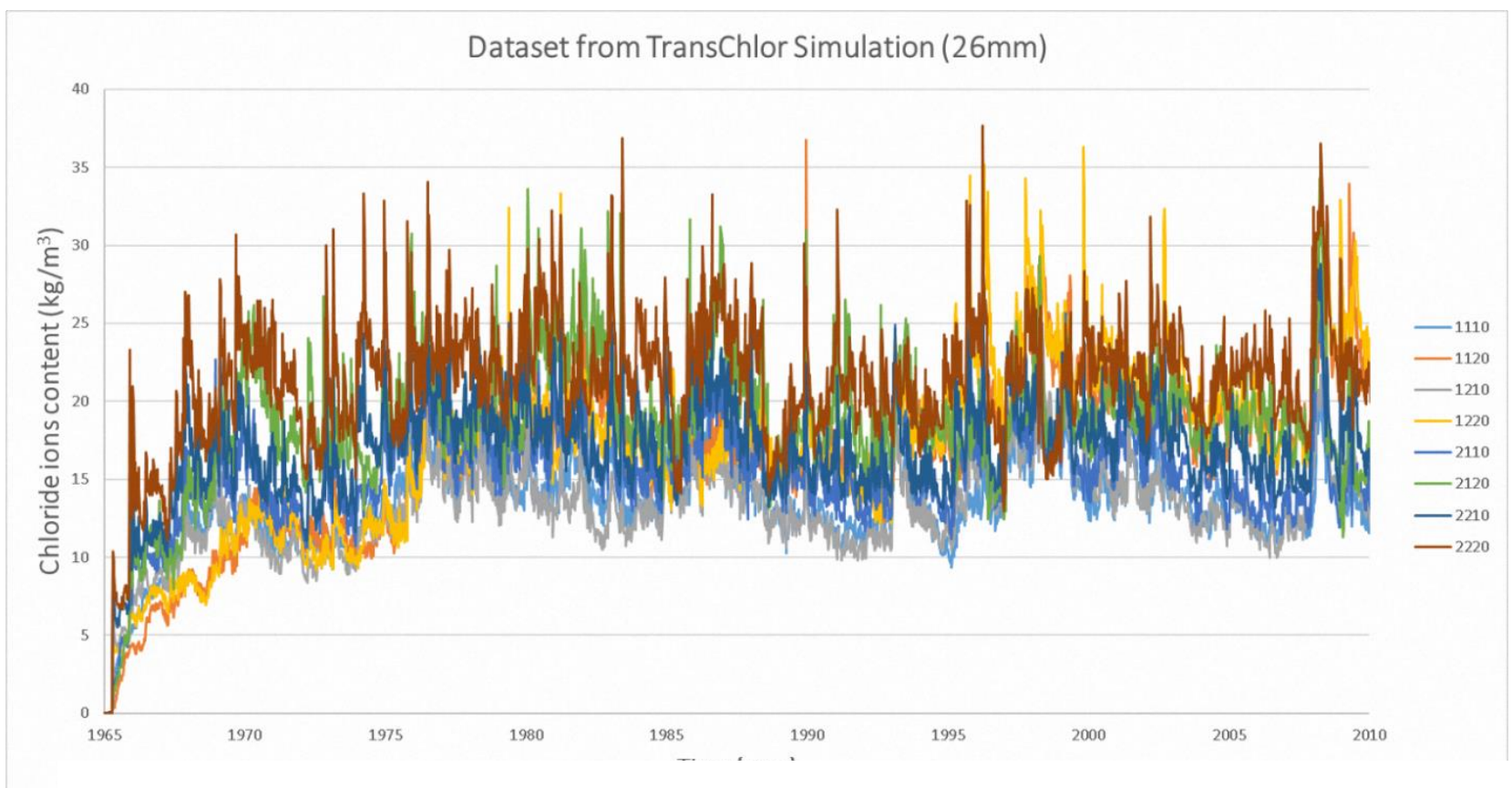

Figure 3-4 Dataset simulated from TransChlor ${ }^{\circledR}$ for $26 \mathrm{~mm}$ depth. 
Figure 3-3 and Figure 3-4 show that the chloride ion content fluctuates significantly as a function of climatic exposure and concrete properties. However, for modeling the deterioration of concrete structures, it may be sufficient to determine the variability in the annual average level of chloride ions. The average annual total chloride ion content is shown in Figure 3-5 and Figure 3-6 at depth of $26 \mathrm{~mm}$ and $50 \mathrm{~mm}$ for each of the 8 simulations. These indicate that the average annual amount of chloride ions increases and reach a steady state after a few decades of service but can fluctuate significantly due to the variability in annual winter conditions. They also indicate that the level of chloride ions is very dependent on material properties which can vary among a population of structures with similar service life.

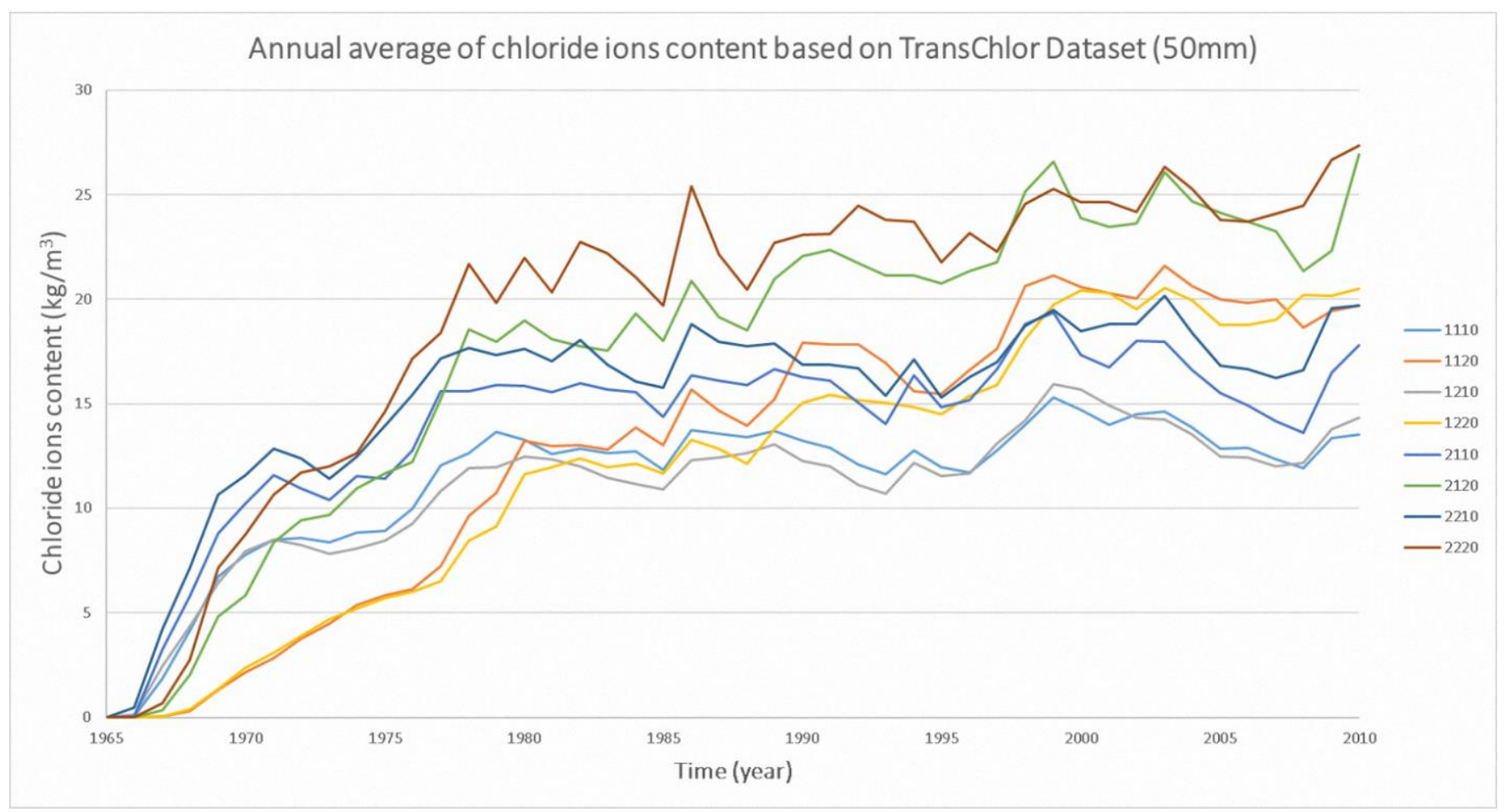

Figure 3-5 Annual average of chloride ions content based on TransChlor ${ }^{\circledR}$ Dataset for $50 \mathrm{~mm}$ depth. 


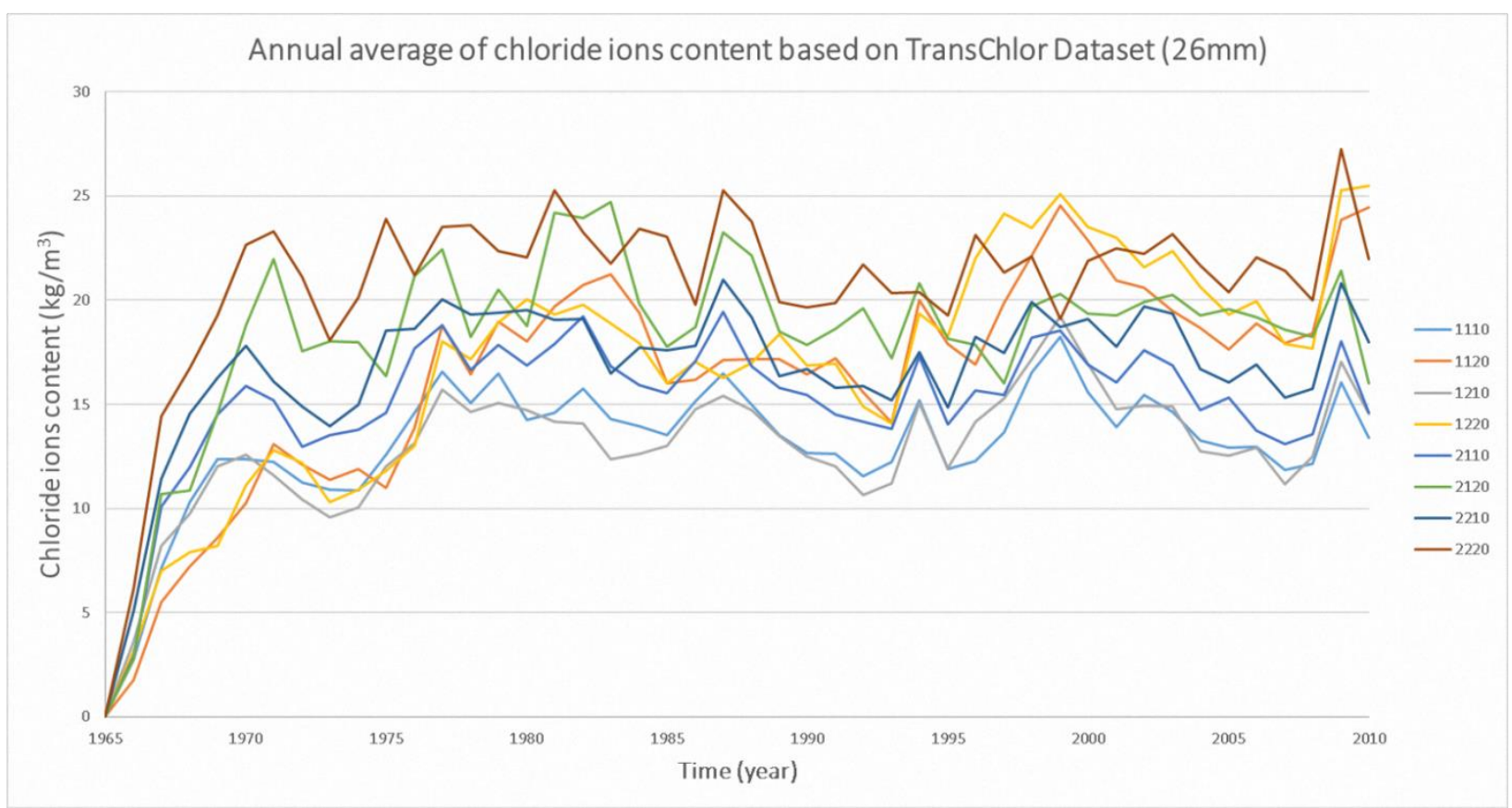

Figure 3-6 Annual average of chloride ions content based on TransChlor ${ }^{\circledR}$ Dataset for $26 \mathrm{~mm}$ depth.

The objective of this work is to use Markov chains to capture the trends and variability observed in chloride ion content for a given location and concrete material properties as predicted by TransChlor $^{\circledR}$. The Markov model can then be used as a surrogate model to the full finite element model to develop optimal strategies for the maintenance and replacement of bridges. The surrogate model is developed for a given climatic region and is applicable to a set of bridges with varying material properties. The transition probabilities of the Markov process are parametrized by using a logistic regression model where concrete properties are the independent variables. 


\subsection{Surrogate Markov chain Model}

\subsubsection{Modeling chloride ions content prediction with Markov Chains}

Markov Chains are adopted to develop prediction models of chloride ions content for reinforced concrete with two concrete cover thicknesses $(26 \mathrm{~mm}$ and $50 \mathrm{~mm})$. The probability of being in a given future chloride state is determined only by the current state. This property is represented by a stochastic process $(X t)$ and a discrete state space as below (Parzen 1962):

$$
P\left(X_{i+1}=i_{i+1} \mid X_{i}=i_{i}, X_{i-1}=i_{i-1, \ldots \ldots, ., X_{1}}=i_{1}, X_{0}=i_{0}\right)=P\left(X_{i+1}=i_{i+1} \mid X_{i}=i_{i}\right)
$$

where $P$ is the transition probabilities and $i$ is the step.

\subsubsection{Computations with Markov Chains}

Given the initial state probabilities vector $q(0)$ the future probability state vector $q(t)$ at the transition periods $t$ can be calculated as the matrix product (Collins 1975):

$$
q(t)=q(0) \times P^{t}
$$

where,

$$
P^{t}=\left[\begin{array}{cccc}
P_{1,1} & P_{1,2} & \ldots & P_{1, \mathrm{n}} \\
P_{2,1} & P_{2,2} & \ldots . & P_{2, \mathrm{n}} \\
. . & . & . . & . . \\
. . & . . & . . & . . \\
. . & . . & . . & . . \\
P_{\mathrm{n}, 1} & P_{\mathrm{n}, 2} & . . & P_{\mathrm{n}, \mathrm{n}}
\end{array}\right]
$$




$$
Q(t)=\left[\begin{array}{cccc}
q_{1}(0) & q_{2}(0) & \ldots & q_{n}(0) \\
q_{1}(1) & q_{2}(1) & \ldots & q_{n}(1) \\
. . & . & \ldots & . . \\
. . & . . & \ldots & . . \\
. & . . & \ldots & . . \\
q_{1}(n) & q_{2}(n) & \ldots & q_{n}(n)
\end{array}\right]
$$

In this application, $q(0)$ is defined as $[1,0,0,0,0,0]$, which states that for the probability that chloride ions content will be in the first category at time zero is $100 \%$, which corresponds to a new structure.

State probabilities for the next time interval can be derived from Eq. 3-11:

$$
\begin{gathered}
q_{1}(1)=q_{1}(0) P_{1,1}+q_{2}(0) P_{2,1}+\cdots+q_{n}(0) P_{n, 1} \\
q_{n}(n)=q_{1}(n-1) P_{1, n}+q_{2}(n-1) P_{2, n}+\cdots+q_{n}(n-1) P_{n, n}
\end{gathered}
$$

The expected chloride ion content at time $\mathrm{t}$ is determined from the calculated transient probabilities, where, $t$ is the time in years as (Butt et al. 1987):

$$
E(C l(t))=\sum_{i=1}^{n} q_{i}(t) \cdot C l_{i}
$$

where $C l_{i}$ is the middle value for state $i$.

The standard derivation is obtained as,

$$
E\left(C l^{2}(t)\right)=\sum_{i=1}^{n} q_{i}(t) \cdot C l_{i}^{2}
$$




$$
S D(C l(t))=\sqrt{E\left(C l^{2}(t)-E(C l(t))^{2}\right)}
$$

\subsection{Parametrization of Transition Probabilities}

In this study, $D_{C L}, D_{C A P}$ and $D_{H R}$ were employed to parametrize transition probabilities for the state probabilities of chloride content using a multinomial logit model (Allison 2012):

$$
\ln \left(\frac{P_{i j}}{1-P_{i j}}\right)=\alpha_{0}+\alpha_{1} D_{H R}+\alpha_{2} D_{C A P}+\alpha_{3} D_{C L}
$$

where $\alpha_{0}$ is a constant and $\alpha_{1}, \alpha_{2}, \alpha_{3}$ are coefficients and $P_{i j}$ are transition probabilities from state $i$ to state $j$ given the initial state $i$. The estimation of the surrogate model is detailed in the following steps:

(1) The range of chloride content is divided into a given number (e.g. 3 or 6) of states (Table 3-4). Results for the chloride content at a given depth (e.g. $26 \mathrm{~mm}$ ) are used to obtain transition counts for each period of reference (e.g. one year). The counts for the initial state 1 are shown in Table 35.

Table 3-4: Transition counts matrix of the chloride ions content for $26 \mathrm{~mm}$ depth.

\begin{tabular}{lcccc}
\hline \multirow{2}{*}{ Categories } & & \multicolumn{3}{c}{ Content at year $n+1$} \\
\cline { 3 - 5 } & & 0 to 10 & 10 to 20 & 20 to 30 \\
\hline \multirow{2}{*}{ Content at } & 0 to 10 & N11 & N12 & N13 \\
year $n$ & 10 to 20 & N21 & N22 & N23 \\
& 20 to 30 & N31 & N32 & N33 \\
\hline
\end{tabular}


Table 3-5: Counts for the initial state 1, 26mm depth.

\begin{tabular}{ccccc}
\hline Response & $\boldsymbol{D}_{\boldsymbol{H R}}$ & $\boldsymbol{D}_{\boldsymbol{C A P}}$ & $\boldsymbol{D}_{\boldsymbol{C L}}$ & Counts \\
\hline 0 to 10 & 1 & 1 & 1 & $\mathrm{~N} 11(1)$ \\
10 to 20 & 1 & 1 & 1 & $\mathrm{~N} 12(1)$ \\
20 to 30 & 1 & 1 & 1 & $\mathrm{~N} 13(0)$ \\
\hline 0 to 10 & 1 & 1 & 2 & $\mathrm{~N} 11(3)$ \\
10 to 20 & 1 & 1 & 2 & $\mathrm{~N} 12(1)$ \\
20 to 30 & 1 & 1 & 2 & $\mathrm{~N} 13(0)$ \\
\hline 0 to 10 & 1 & 2 & 1 & $\mathrm{~N} 11(2)$ \\
10 to 20 & 1 & 2 & 1 & $\mathrm{~N} 12(2)$ \\
20 to 30 & 1 & 2 & 1 & $\mathrm{~N} 13(0)$ \\
\hline 0 to 10 & 1 & 2 & 2 & $\mathrm{~N} 11(3)$ \\
10 to 20 & 1 & 2 & 2 & $\mathrm{~N} 12(1)$ \\
20 to 30 & 1 & 2 & 2 & $\mathrm{~N} 13(0)$ \\
\hline 0 to 10 & 2 & 1 & 1 & $\mathrm{~N} 11(0)$ \\
10 to 20 & 2 & 1 & 1 & $\mathrm{~N} 12(1)$ \\
20 to 30 & 2 & 1 & 1 & $\mathrm{~N} 13(0)$ \\
\hline 0 to 10 & 2 & 1 & 2 & $\mathrm{~N} 11(0)$ \\
10 to 20 & 2 & 1 & 2 & $\mathrm{~N} 12(1)$ \\
20 to 30 & 2 & 1 & 2 & $\mathrm{~N} 13(0)$ \\
\hline 0 to 10 & 2 & 2 & 1 & $\mathrm{~N} 11(0)$ \\
10 to 20 & 2 & 2 & 1 & $\mathrm{~N} 12(1)$ \\
20 to 30 & 2 & 2 & 2 & $\mathrm{~N} 13(0)$ \\
\hline 0 to 10 & 2 & 2 & $\mathrm{~N} 11(0)$ \\
10 to 20 & 2 & 2 & $\mathrm{~N} 12(1)$ \\
20 to 30 & 2 & & 2 & $\mathrm{~N} 13(0)$ \\
\hline
\end{tabular}

(2) Obtain the $\alpha_{0}, \alpha_{1}, \alpha_{2}, \alpha_{3}$ of the Eq. 3-17 using maximum likelihood estimation.

(3) Predicted values $P_{i j}$ as a function of the diffusion parameters are then obtained as.

$$
P_{i j}=\frac{e^{\alpha_{0}+\alpha_{1} D_{H R}+\alpha_{2} D_{C A P}+\alpha_{3} D_{C L}}}{1+e^{\alpha_{0}+\alpha_{1} D_{H R}+\alpha_{2} D_{C A P}+\alpha_{3} D_{C L}}}
$$


Table 3-6 compares the performance of the predicted probabilities for all the cases at 26mm depth from STATISTICA ${ }^{\circledR}$ and Surrogate Markov chain Model and shows good agreement with the data obtained from the finite element model.

Table 3-6: Predicted probabilities from STATISTICA ${ }^{\circledR}$ and Surrogate Markov Chain Model for the cases of $26 \mathrm{~mm}$ depth.

\begin{tabular}{|c|c|c|c|c|}
\hline Cases (26mm) & Categories & 0 to 10 & 10 to 20 & 20 to 30 \\
\hline \multirow{3}{*}{1110} & 0 to 10 & $0.5000(0.5000)$ & $0.5000(0.5000)$ & $0.0000(0.0000)$ \\
\hline & 10 to 20 & $0.0000(0.0000)$ & $0.9970(1.0000)$ & $0.0030(0.0000)$ \\
\hline & 20 to 30 & $0.0000(0.0000)$ & $0.0000(0.0000)$ & $0.0000(0.0000)$ \\
\hline \multirow{3}{*}{1120} & 0 to 10 & $0.7500(0.7500)$ & $0.2500(0.2500)$ & $0.0000(0.0000)$ \\
\hline & 10 to 20 & $0.0000(0.0000)$ & $0.8710(0.9300)$ & $0.1290(0.0700)$ \\
\hline & 20 to 30 & $0.0000(0.0000)$ & $0.3750(0.4760)$ & $0.6250(0.5240)$ \\
\hline \multirow{3}{*}{1210} & 0 to 10 & $0.5000(0.0000)$ & $0.5000(0.5000)$ & $0.0000(0.0000)$ \\
\hline & 10 to 20 & $0.0256(0.0256)$ & $0.9744(0.9670)$ & $0.0000(0.0074)$ \\
\hline & 20 to 30 & $0.0000(0.0000)$ & $0.0000(0.0000)$ & $0.0000(0.0000)$ \\
\hline \multirow{3}{*}{1220} & 0 to 10 & $0.7500(0.7500)$ & $0.2500(0.2500)$ & $0.0000(0.0000)$ \\
\hline & 10 to 20 & $0.0000(0.0000)$ & $0.8966(0.8560)$ & $0.1034(0.1540)$ \\
\hline & 20 to 30 & $0.0000(0.0000)$ & $0.2000(0.1190)$ & $0.8000(0.8810)$ \\
\hline \multirow{3}{*}{2110} & 0 to 10 & $0.0000(0.0000)$ & $1.0000(1.0000)$ & $0.0000(0.0000)$ \\
\hline & 10 to 20 & $0.0000(0.0000)$ & $1.0000(0.9810)$ & $0.0000(0.0190)$ \\
\hline & 20 to 30 & $0.0000(0.0000)$ & $0.0000(0.0000)$ & $0.0000(0.0000)$ \\
\hline \multirow{3}{*}{2120} & 0 to 10 & $0.0000(0.0000)$ & $1.0000(1.0000)$ & $0.0000(0.0000)$ \\
\hline & 10 to 20 & $0.0000(0.0000)$ & $0.7000(0.6690)$ & $0.3000(0.3310)$ \\
\hline & 20 to 30 & $0.0000(0.0000)$ & $0.6667(0.5990)$ & $0.3333(0.4010)$ \\
\hline \multirow{3}{*}{2210} & 0 to 10 & $0.0000(0.0000)$ & $1.0000(1.0000)$ & $0.0000(0.0000)$ \\
\hline & 10 to 20 & $0.0000(0.0000)$ & $0.9250(0.9550)$ & $0.0750(0.0450)$ \\
\hline & 20 to 30 & $0.0000(0.0000)$ & $1.0000(1.0000)$ & $0.0000(0.0000)$ \\
\hline \multirow{3}{*}{2220} & 0 to 10 & $0.0000(0.0000)$ & $1.0000(1.0000)$ & $0.0000(0.0000)$ \\
\hline & 10 to 20 & $0.0000(0.0000)$ & $0.4000(0.4540)$ & $0.6000(0.5460)$ \\
\hline & 20 to 30 & $0.0000(0.0000)$ & $0.1563(0.1816)$ & $0.8438(0.8184)$ \\
\hline
\end{tabular}




\subsection{Results and discussions}

The transition probabilities from the Markov process are used to predict chloride ions content at various depths as a function of time and are compared to the TransChlor ${ }^{\circledR}$ results. Predictions are obtained at depths of $26 \mathrm{~mm}$ and $50 \mathrm{~mm}$ for a period of 45 years. The results show the state probabilities of content of chloride ions as a function of time. The state probabilities are used to obtain the annual average and standard deviation of chloride content as a function of time and compared to the simulated values from TransChlor ${ }^{\circledR}$. The blue and green lines correspond to the 95\% confidence interval for chloride ion content and the yellow line corresponds to the data from the TransChlor ${ }^{\circledR}$ simulation. The results indicate a good agreement between the original and surrogate model.

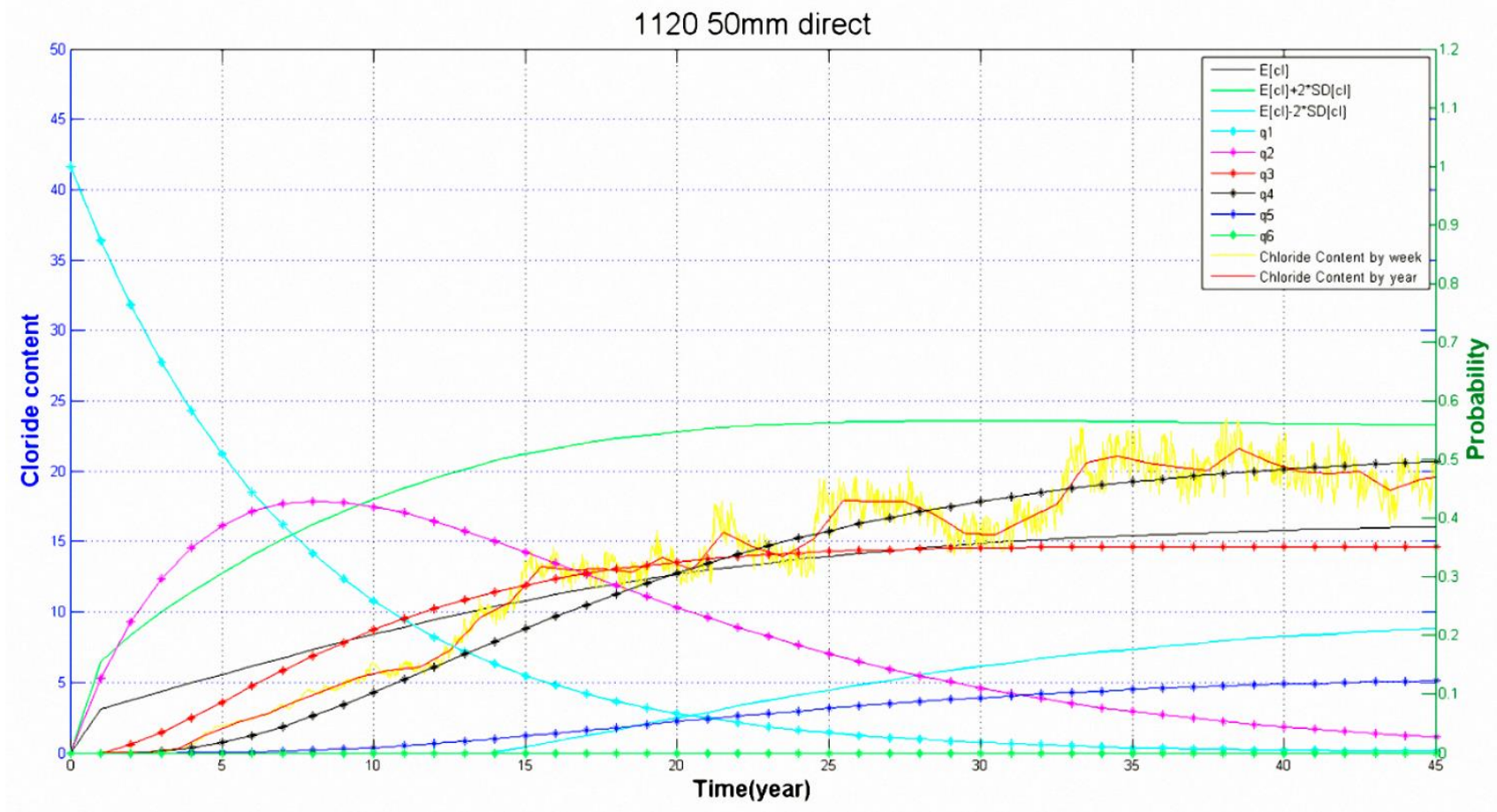

Figure 3-7 Transition probabilities and expected categories of chloride ions content for Case 1120 at $50 \mathrm{~mm}$ considering 45 year period. 


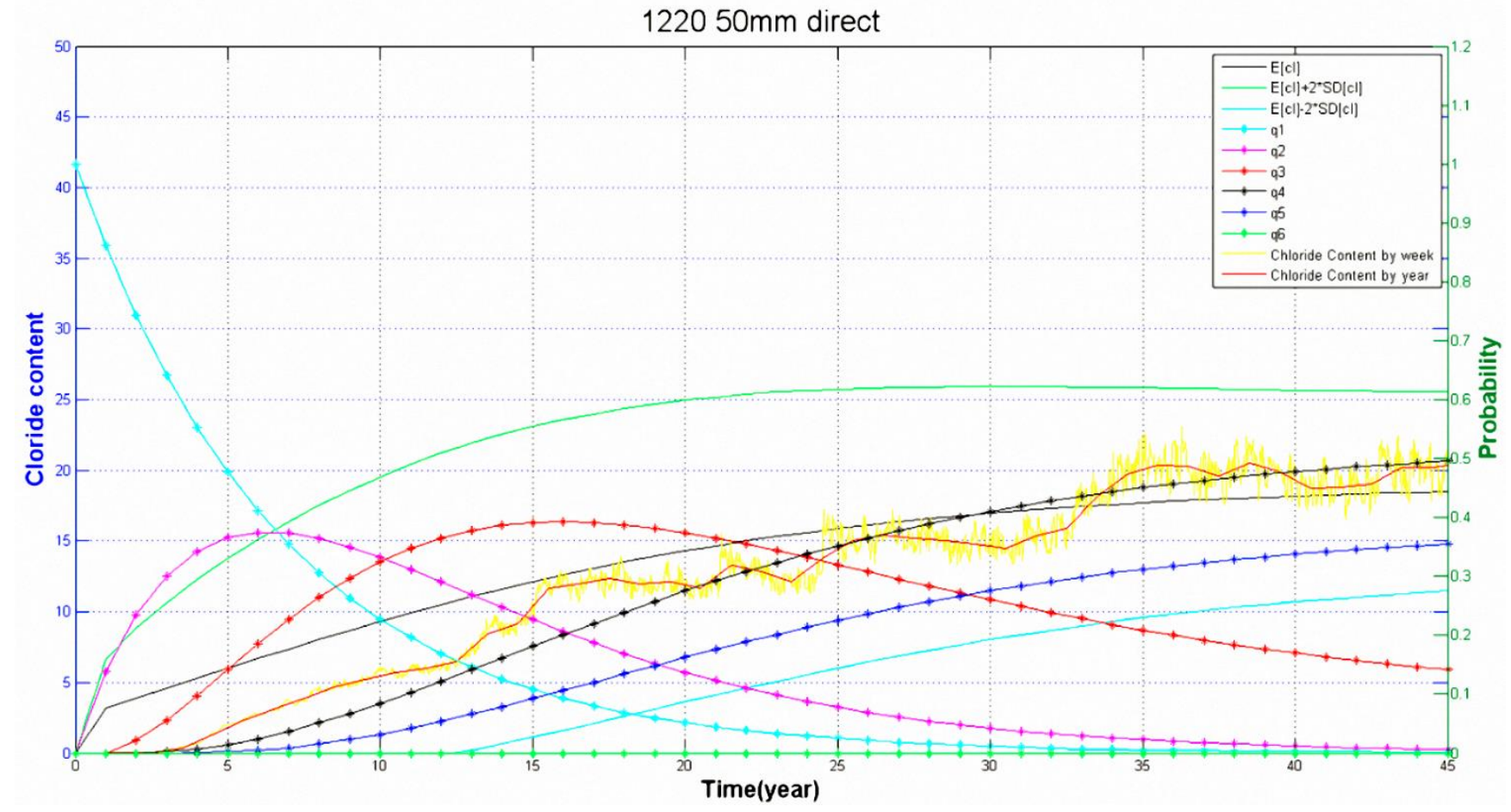

Figure 3-8 Transition probabilities and expected categories of chloride ions content for Case 1220 at $50 \mathrm{~mm}$ considering 45 year period. 


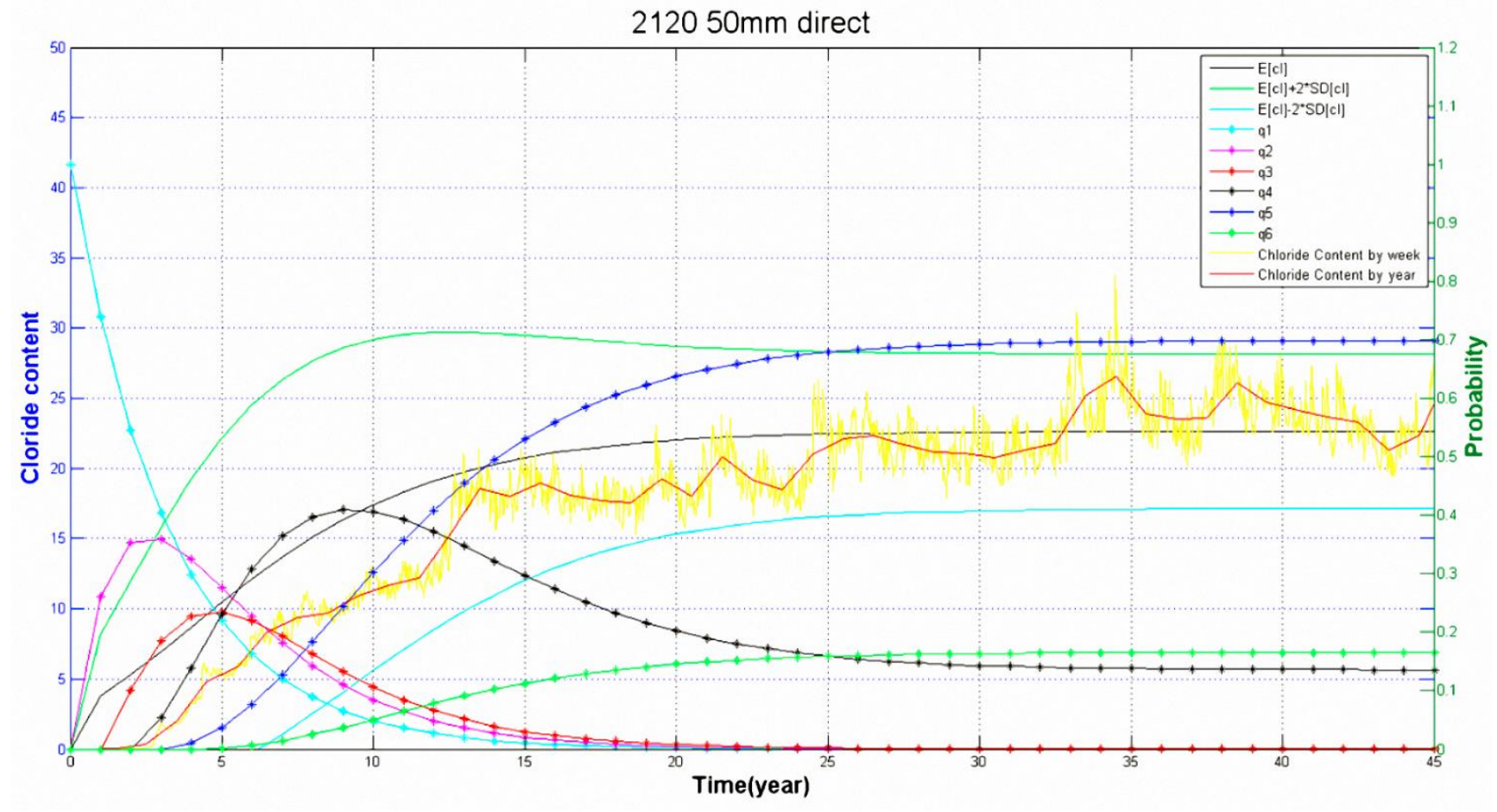

Figure 3-9 Transition probabilities and expected categories of chloride ions content for Case 2120 at $50 \mathrm{~mm}$ considering 45 year period. 


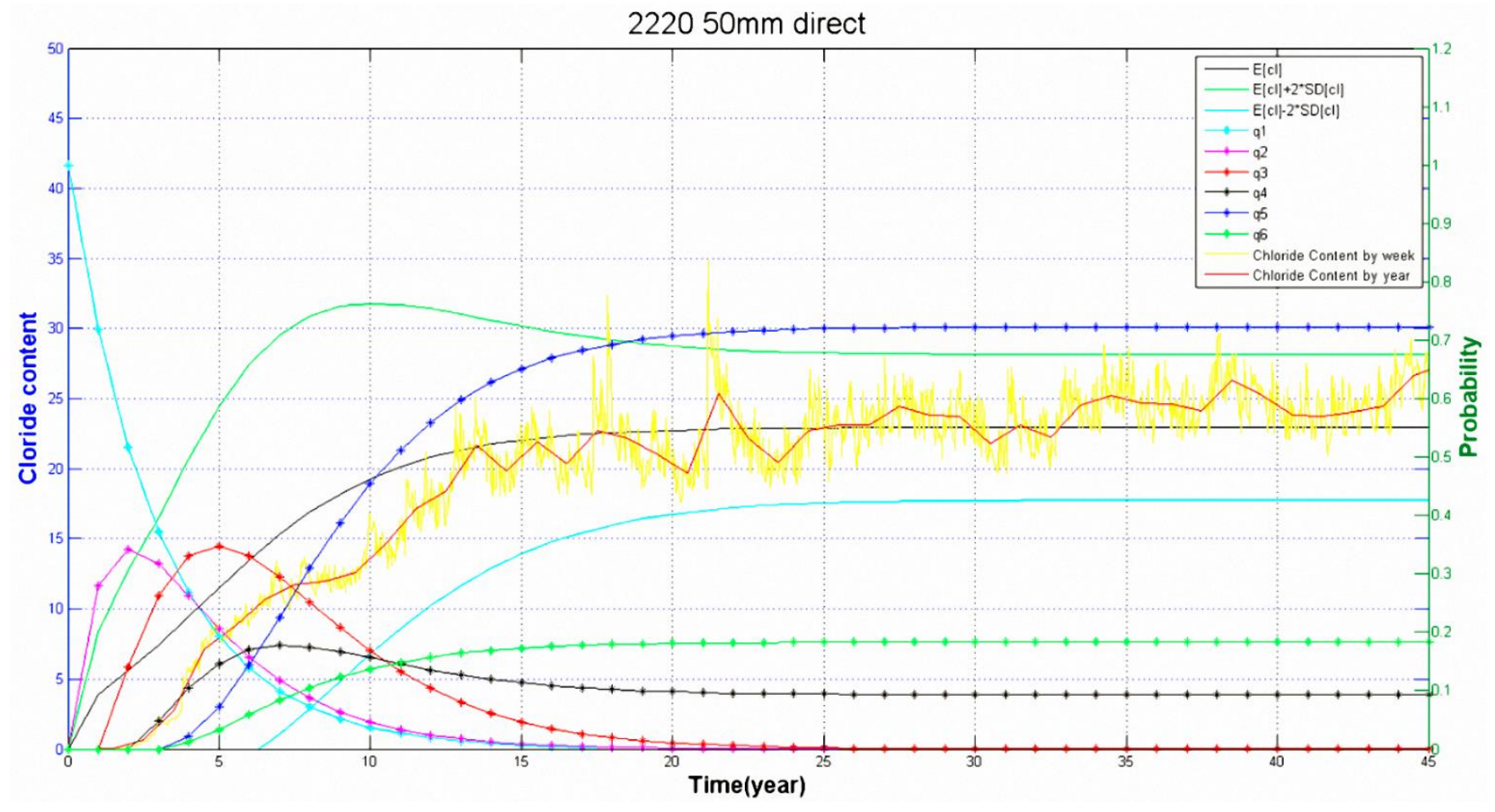

Figure 3-10 Transition probabilities and expected categories of chloride ions content for Case 2220 at $50 \mathrm{~mm}$ considering 45 year period.

Figures 3-7 through 3-10 show results at a depth of $50 \mathrm{~mm}$ with six states over the range of chloride content from 0 to $30 \mathrm{~kg} / \mathrm{m}^{3}$. For the scenarios 2120 and 2220 , the average chloride content increases rapidly from the start of the service life to the seventh year and then slows down until the tenth year. Upon completion of the prediction period of 45 -years, the probabilities for state $q 5$ (20 to $25 \mathrm{~kg} / \mathrm{m}^{3}$ ) is approximately $70 \%$ for both scenarios. The scenarios 1120 and 1220 exhibit a more gradual increase which stabilizes after the twentieth year of service $50 \%$ probability for the 15 to $20 \mathrm{~kg} / \mathrm{m}^{3}$ state. The comparison indicates that the concentrations are very sensitive to values of $D_{H R}$. Conversely, changes in $D_{C L}$ do not significantly affect the evolution and levels of chloride ion content. The effect of $D_{C A P}$ is the least influential among diffusion parameters. Finally, the 
expected chloride content is overestimated for some scenarios in the initial portion of the service life, however, the predictions improve over time and a good match is obtained after the initial stage of the service life.

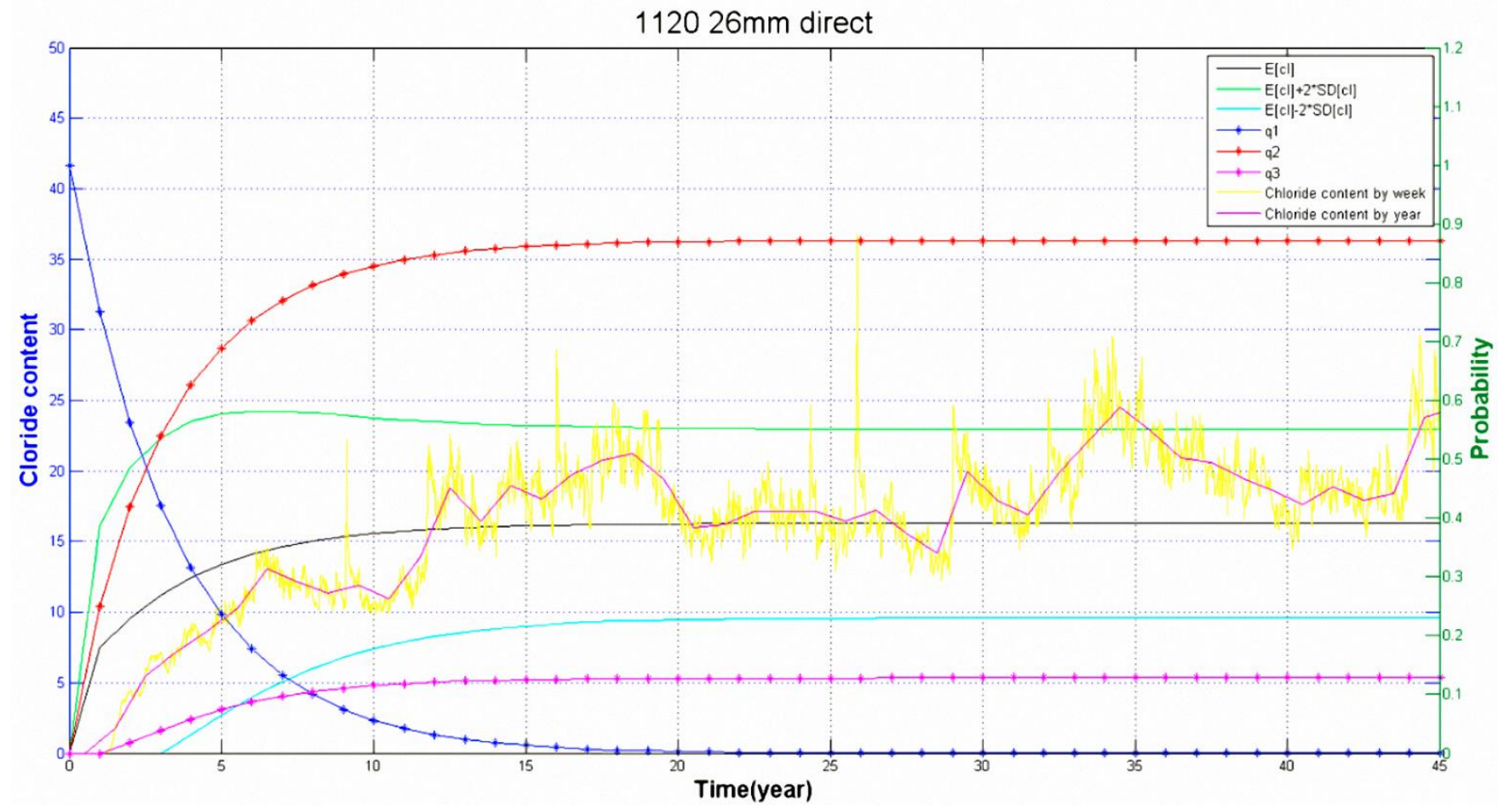

Figure 3-11 Transition probabilities and expected categories of chloride ions content for Case 1120 at $26 \mathrm{~mm}$ considering 45 year period. 


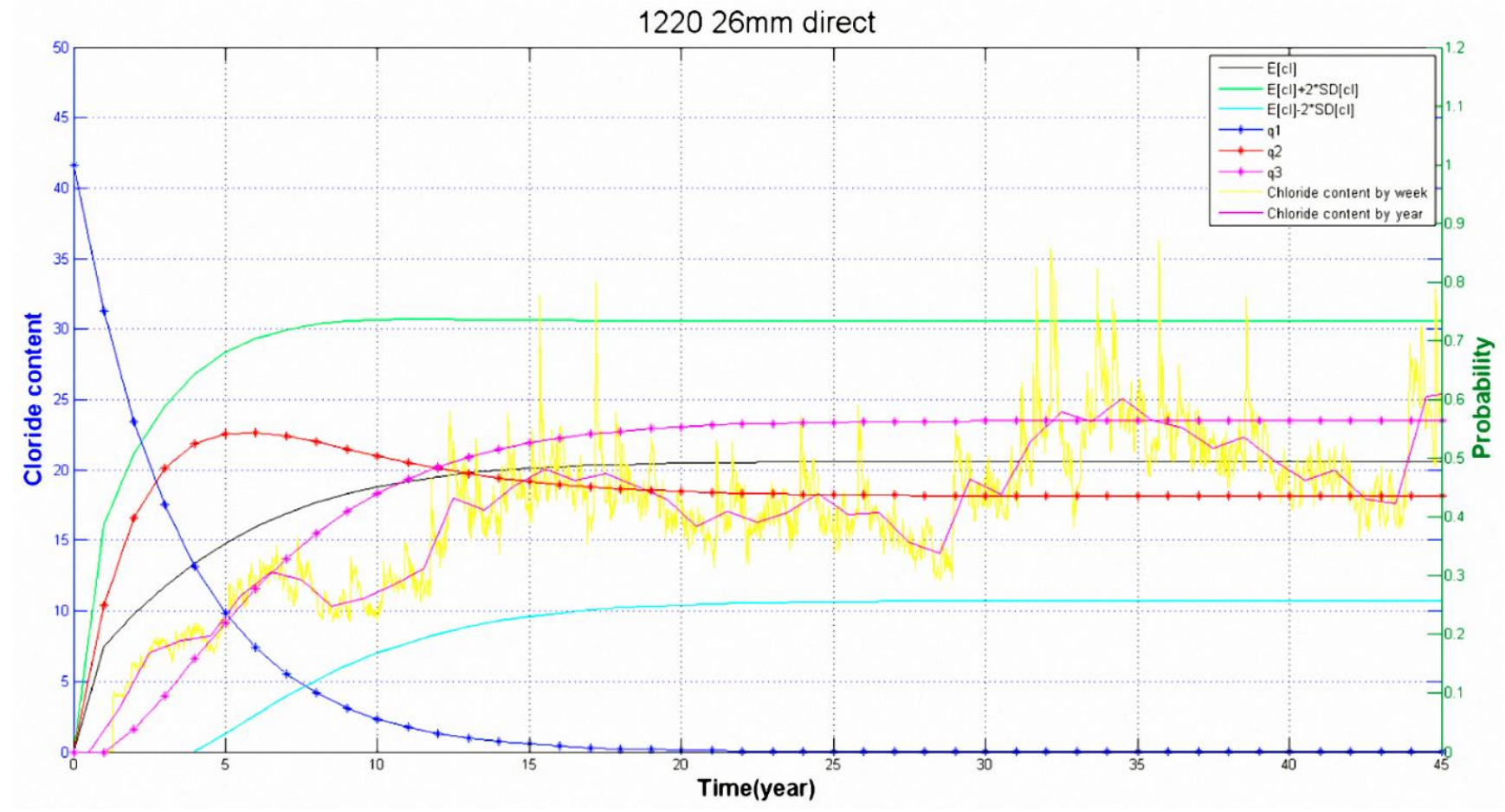

Figure 3-12 Transition probabilities and expected categories of chloride ions content for Case 1220 at $26 \mathrm{~mm}$ considering 45 year period. 


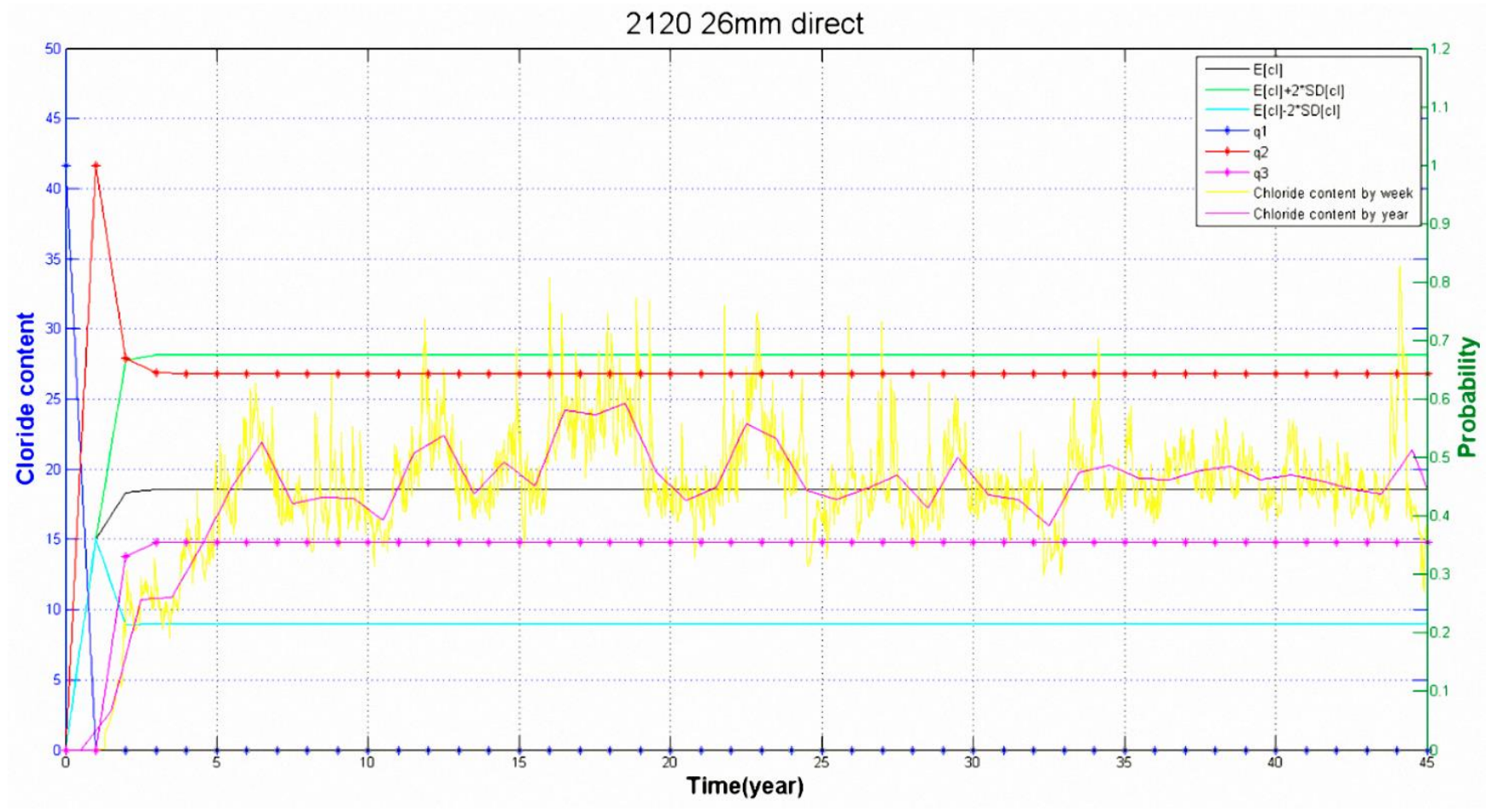

Figure 3-13 Transition probabilities and expected categories of chloride ions content for Case 2120 at $26 \mathrm{~mm}$ considering 45 year period. 


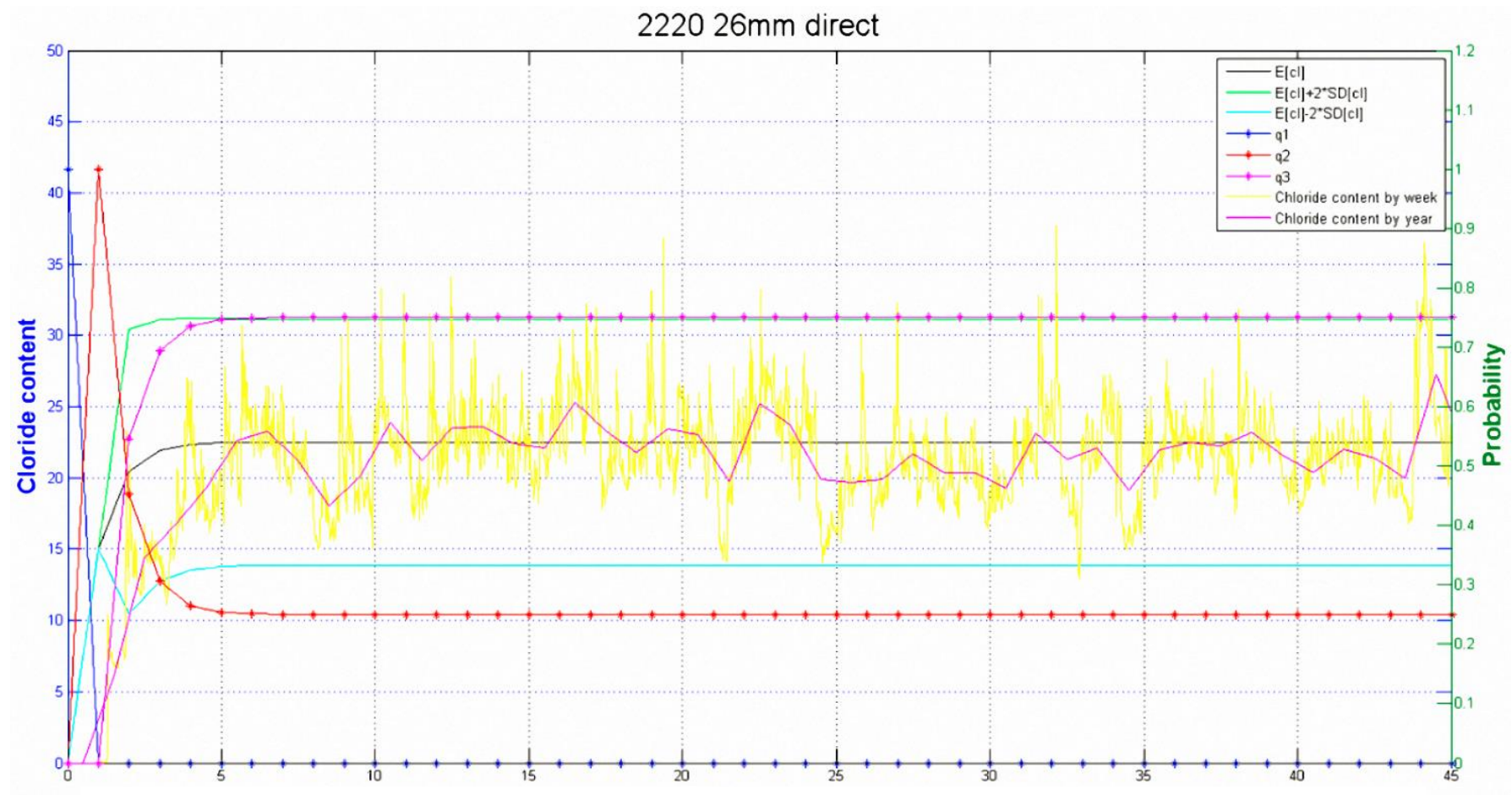

Figure 3-14 Transition probabilities and expected categories of chloride ions content for Case 2220 at $26 \mathrm{~mm}$ considering 45 year period.

Figures 3-11 to 3-14 show results obtained at a depth of $26 \mathrm{~mm}$. In this case, the results are obtained for three states for a range of chloride content from 0 to $30 \mathrm{~kg} / \mathrm{m}^{3}$. A smaller number of states is used in this case given that high levels of chloride content are attained earlier in the service life. For the scenarios 2120 and 2220, the chloride ion content increases rapidly during the first two years of service, and then reaches a steady state after the third year. Upon completion of the 45year prediction period, the probability $(q 2)$ in the state 10 to $20 \mathrm{~kg} / \mathrm{m}^{3}$ is around $65 \%$ for the scenario 2120 and $75 \%$ for the scenario 2220. Meanwhile, for scenarios 1120 and 1220 , the chloride content increases rapidly in the first year and thereafter maintains a relatively steady rate of increase, which starts to stabilize after the fifteenth year. The results indicate that $D_{H R}$ has most effect on the rate of penetration of chloride ions while $D_{C L}$ has an effect mainly on the long-term 
maximum level of chloride ions. The predicted values for the average chloride ion content is slightly underestimated for low values of $D_{H R}$ in the early years of the service life, but are well matched in all cases in the latter part of the service life.

\subsection{Conclusions}

Currently, there are significant concerns over the state of bridges in North America, due to their advanced state of degradation. Thus, it is important to adopt efficient maintenance strategies to ensure that bridges are safe and in working condition for the longest possible period of time. The main mechanism of deterioration of concrete bridges in Canada is due to the widespread use of deicing salts and the ingress of chloride ions and their effect on reinforcing steel. This paper presents a new method of forecasting the chloride ions content based on the Markov Chain-based stochastic model. Transition probabilities for this model are obtained for the states defined as increasing levels of chloride ion content, while simulation data from the TransChlor ${ }^{\circledR}$ model is used to estimate the parameters for the surrogate model. A logistic model is used to predict the transition probabilities between each level as a function of concrete properties. This model can then be used for a wide variety of bridges as well as for different climatic regions. This approach is particularly well-suited to the analysis of maintenance and replacement strategies over a large portfolio of structures located in diverse climatic regions. The deterioration models can also be used in conjunction with inspection data when the latter is available over a sufficient long historical period.

This research demonstrates it is possible to forecast the content of chloride ions in concrete bridges efficiently using Markov Chain models. Future research with this approach can be used to relate 
stages in the process of deterioration to observations from periodic inspection reports as well as from more detailed surveys on the physical state of structural elements. The model can also be extended to other elements of the bridge besides the slab which are not directly exposed to chloride ions. This can be used to develop maintenance and replacement that encompass all elements of the bridge in terms of timing and opportunity costs.

\subsection{Acknowledgments}

The authors acknowledge the financial support by NSERC Discovery Grants and FRQNT Team Grant. 


\section{References}

Allison, P. D. (2012). Logistic regression using SAS: Theory and application: SAS Institute.

Butt, A. A., Shahin, M. Y., Feighan, K. J., \& Carpenter, S. H. (1987). Pavement performance prediction model using the Markov process.

Caner, A., Yanmaz, A. M., Yakut, A., Avsar, O., \& Yilmaz, T. (2008). Service life assessment of existing highway bridges with no planned regular inspections. Journal of Performance of Constructed Facilities, 22(2), 108-114.

Cesare, M. A., Santamarina, C., Turkstra, C., \& Vanmarcke, E. H. (1992). Modeling bridge deterioration with Markov chains. Journal of Transportation Engineering, 118(6), 820833.

Collins, L. (1975). An introduction to Markov chain analysis.

Conciatori, D., Brühwiler, E., \& Morgenthaler, S. (2009). Calculation of reinforced concrete corrosion initiation probabilities using the Rosenblueth method. International Journal of Reliability and Safety, 3(4), 345-362.

Conciatori, D., Grégoire, É., Samson, É., Marchand, J., \& Chouinard, L. (2014). Statistical analysis of concrete transport properties. Materials and structures, 47(1-2), 89-103.

Conciatori, D., Laferrière, F., \& Brühwiler, E. (2010). Comprehensive modeling of chloride ion and water ingress into concrete considering thermal and carbonation state for real climate. Cement and Concrete Research, 40(1), 109-118. 
Conciatori, D., Sadouki, H., \& Brühwiler, E. (2008). Capillary suction and diffusion model for chloride ingress into concrete. Cement and Concrete Research, 38(12), 1401-1408.

Crank, J., \& Gupta, R. S. (1975). Isotherm migration method in two dimensions. International Journal of Heat and Mass Transfer, 18(9), 1101-1107.

CSA. (2014). Canadian Highway Bridge Design Code S6-14 CSA Canadian Standards Association. In: Canada.

Deb, S. (2012). Critical Chloride Content in Reinforced Concrete. The Materbuilder, 9.

Estes, A. C., \& Frangopol, D. M. (2005). Load rating versus reliability analysis. Journal of Structural Engineering, 131(5), 843-847.

Jefremczuk, S. (2005). Chloride ingress and transport in cracked concrete.

Jiang, Y., \& Sinha, K. C. (1989). Bridge service life prediction model using the Markov chain. Transportation research record, 1223, 24-30.

Micevski, T., Kuczera, G., \& Coombes, P. (2002). Markov model for storm water pipe deterioration. Journal of Infrastructure Systems, 8(2), 49-56.

Morcous, G. (2006). Performance prediction of bridge deck systems using Markov chains. Journal of Performance of Constructed Facilities, 20(2), 146-155.

NACE. (2012). A NACE International White Paper. CORROSION CONTROL PLAN FOR BRIDGES. The Corrosion Society. 
O’Connor, A., Sheils, E., Breysse, D., \& Schoefs, F. (2011). Markovian bridge maintenance planning incorporating corrosion initiation and nonlinear deterioration. Journal of Bridge Engineering, 18(3), 189-199.

Parzen, E. (1962). On estimation of a probability density function and mode. The annals of mathematical statistics, 33(3), 1065-1076.

Rosenblueth, E. (1975). Point estimates for probability moments. Proceedings of the National Academy of Sciences, 72(10), 3812-3814.

Samson, E., \& Marchand, J. (2007). Modeling the transport of ions in unsaturated cement-based materials. Computers \& Structures, 85(23), 1740-1756.

Shafei, B., \& Alipour, A. (2015). Estimation of corrosion initiation time in reinforced concrete bridge columns: How to incorporate spatial and temporal uncertainties. Journal of Engineering Mechanics, 141(10), 04015037.

Sobanjo, J. (1997). A neural network approach to modeling bridge deterioration. Paper presented at the Computing in Civil Engineering.

Thomas, O., \& Sobanjo, J. (2016). Semi-Markov models for the deterioration of bridge elements. Journal of Infrastructure Systems, 22(3), 04016010.

Tokdemir, O. B., Ayvalik, C., \& Mohammadi, J. (2000). Prediction of highway bridge performance by artificial neural networks and genetic algorithms. Paper presented at the Proc., 17th Int. Symp. on Automation and Robotics in Construction (ISARC). 
Washington, S. P., Karlaftis, M. G., \& Mannering, F. (2010a). Statistical and econometric methods for transportation data analysis (2 ed. Vol. Part2, Chapter11\&12): CRC press.

Washington, S. P., Karlaftis, M. G., \& Mannering, F. (2010b). Statistical and econometric methods for transportation data analysis (2 ed. Vol. Part2, Chapter10): CRC press.

Wolofsky, R. (2011). Corrosion Initiation of Concrete Bridge Elements Exposed to De-icing Salts: McGill University (Canada).

Wolofsky, R., Chouinard, L., Conciatori, D., \& Bastien, J. (2015). Updating of chloride ingress models using core data measurements. International Journal of Reliability and Safety, 9(4), 291-310.

Yang, J. (2007). Estimation of pavement lifespan using stochastic duration models. Paper presented at the Transportation Research Board 86th Annual Meeting. 


\section{Preface to Chapter 4}

In the previous chapter, numerical models of the diffusion process and chemical reactions of chloride ions in concrete are used to estimate the time to initiation of corrosion and for the progression of corrosion. The main mode of corrosion of concrete bridges in Canada is due to the widespread use of deicing salts and the ingress of chloride ions and their effect on reinforcing steel. The analyses are performed for a variety of typical concrete properties, exposure and climatic conditions. One of the important findings of the previous chapter is related to the efficiency of forecasting the content of chloride ions in concrete bridges using Markov Chain-based models. This approach can be used to relate states in the process of deterioration and thereafter to develop optimal maintenance and replacement strategies to extend service life and optimally allocate financial and technical resources. To this extent, Chapter 4 introduces a framework that incorporates risks in economic benefits and costs by modelling the interactions and uncertainties associated with physical and financial variables in the context of infrastructure management. 


\title{
Chapter 4. Flexible Decision Analysis Procedures for Optimizing the Sustainability of Ageing Infrastructure under Climate Change
}

\begin{abstract}
Currently, there is significant interest in ensuring the sustainability and serviceability of infrastructure systems in the context of climate change. Indeed, a large proportion of existing structures already are in an advanced state of deterioration, thus affecting the sustainability and usefulness of these structures, and highlighting the need for better planning and decision analysis tools. Such tools would benefit from improved models to predict the residual life of structures, to estimate benefits derived from infrastructures, to account for uncertainties associated with physical and financial processes, and to provide more flexibility in decision-making strategies. These concepts are investigated through application of a risk-based decision-making model for reinforced concrete bridge decks in Montreal to estimate the optimal timing for deck repairs. A probabilistic deterioration model is used to predict the residual life of concrete decks as a function of exposure to de-icing salts using historical data and predictions from climate change scenarios. Historical data is used to validate model assumptions by comparing predicted condition states to observations from periodic inspections, while the climate scenarios are used to evaluate the impact of climate change on deterioration rates assuming that current deck design and de-icing salt management strategies are not modified. In this instance, the optimal timing for the first major repair is influenced by the uncertainty involved with climate change predictions and the future availability of funds, while ensuring the safety of users and the required level of service. The proposed framework, based on a cost-benefit analysis, is applicable to any infrastructure project.
\end{abstract}

Keywords: sustainability; infrastructure; deterioration; changing climate; optimal strategies. 


\subsection{Introduction}

\subsubsection{Background}

The management of ageing infrastructures presents many challenges to their owners and operators. Large investments are required to maintain existing infrastructures, to rectify deficiencies, and to eventually replace or upgrade them (Herrmann 2013; OECD 2013; Ottesen 2011). Among these, reinforced concrete (RC) structures represent a significant part of the built environment, which are the focus of the present study. Among the numerous decision analysis tools that have been developed to assist managers, models to estimate the residual life of existing structures are among the most important for identifying the optimal timing of repairs in the lifecycle of a structure. Moreover, financial considerations such as cost functions are important factors affecting decisions. Both physical and financial processes have uncertainties that must be properly integrated in the decision analysis to yield accurate results. The purpose of this paper is to present a novel approach that models the physical deterioration process through a probabilistic chloride ion diffusion model, and that incorporates uncertainties in both physical and financial processes. The model is used to predict the optimal replacement date for the concrete decks of bridges in the context of climate change. A distinctive feature of the model is the inclusion of flexibility in decision-making through an explicit valuation of real options, which take on greater importance in the presence of multiple sources of uncertainty (Power et al. 2015). Improving these models will also contribute to a better understanding of the sustainability of infrastructures. Here a broad definition of sustainability is considered (Leyden et al. 2007). Sustainability is evaluated in relation to impacts on social, human, physical and natural capital. Optimizing strategies of repairs and replacement contribute to increasing the quality and quantity of the infrastructure capital by making these investments last longer. The purpose of this model is to help make better long-run public investments, and by being 
more durable and longer-lasting they will provide sustainable benefits to the population, as well as less environmental impact.

The durability of RC bridge decks is influenced both by environmental and operational conditions. Among these, exposition to chloride ions is one of most important factors that contributes to the premature deterioration of these structures (Bastidas-Arteaga et al. 2011; Breysse et al. 2014; Saetta et al. 1993). Once a RC structure has been exposed to chloride ions, the sequence of events is: 1) initiation of corrosion, 2) expansion of steel due to corrosion products, 3) cracking of the concrete cover and 4) spalling of the concrete cover. The durability of RC structures can be significantly reduced when deterioration processes are combined with high service loads. Climate change can also adversely affect the durability of structures by increasing the number of freezethaw cycles, the level of relative humidity, average temperatures, and frequency of winter precipitation. Talukdar et al. (2012) estimate that climate change has increased carbonation depth by $45 \%$ for concrete structures in Vancouver and Toronto over the past ten decades. Similarly, De Larrard et al. (2014) estimate that climate change has significantly increased the risk of corrosion initiation resulting from carbonation in several French cities. Bastidas-Arteaga and Stewart (2013) propose a probabilistic cost-benefit procedure to analyse two climate change adaptation strategies for new RC structures exposed to chloride ions. The results indicate that the cost effectiveness of specific adaptation strategies is dependent on the climate change scenario, exposure conditions and type of structural system.

\subsubsection{Aims and scope}

Numerous studies have addressed the effect of exposure conditions on the deterioration of concrete structures. However, few studies have examined the effect of climate change on the serviceability of these structures and its impact on infrastructure management strategies. In this setting, the 
optimal timing for the first major repair is influenced by the uncertainty involved with climate change predictions and the future availability of funds, while ensuring the safety of users and the required level of service. The proposed framework, based on cost-benefit analysis, is applicable to any infrastructure project and is illustrated for typical concrete bridge decks in Montreal. This framework incorporates risks in economic benefits and costs by explicitly modelling the interactions and uncertainties associated with physical and financial variables.

\subsection{Modelling of climate change effects and uncertainty}

Since most infrastructures are designed for service lives greater than 50 years, long-term effects associated with climate change should be considered for future designs. Similarly, while the built environment was designed under the implicit assumption that current climate conditions are stationary, the expected durability of these structures could be severely reduced in the future, and could affect the planning and budgeting for major repairs or replacement of infrastructures.

Climate change models can be classified as a function of the spatial resolution of the prediction domain. Global Climate Models (GCMs) cover the entire planet and have a grid resolution of around $200 \mathrm{~km}$, while Regional Climate Models (RCMs) have a spatial resolution below $45 \mathrm{~km}$ (Figure 4-1). Results for a specific location require the use of higher resolution models or statistically downscaled data (Charron 2016). 


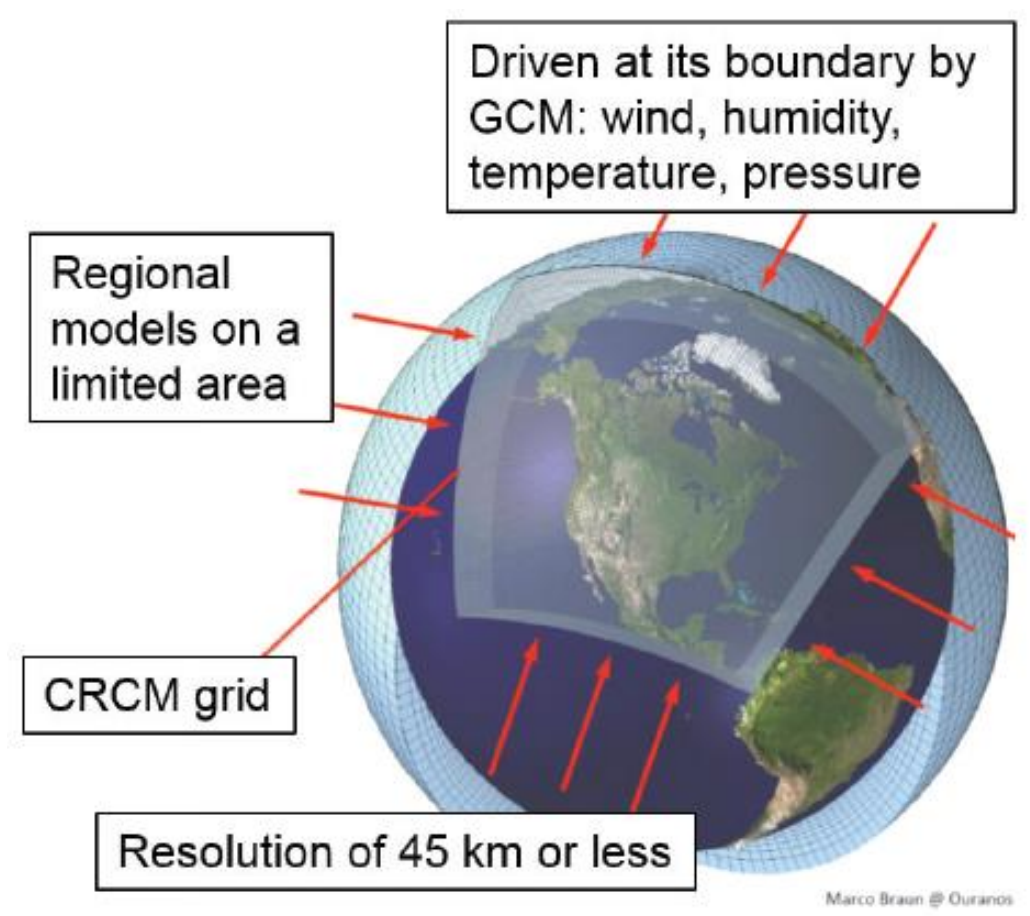

Figure 4-1 GCMs and RCMs (Source: (Charron 2016)).

Climate changes are driven mainly by the emission of greenhouse gases (GHGs). Emissions scenarios describe plausible future releases of greenhouse gases, aerosols, and other anthropogenic gases into the atmosphere on the basis of a coherent and internally consistent set of assumptions about technological change, demographic and socioeconomic development, and their interactions (IPCC 2007). Concentrations of greenhouse gases are described by using Representative Concentration Pathways (RCPs). RCPs are greenhouse gas concentration trajectories adopted by the IPCC for its fifth Assessment Report (AR5) in 2014 which replaced the Special Report on Emissions Scenarios (SRES) projections published in 2000 (Table 4-1). The four scenarios that are generally considered have the designations RCP2.6, RCP4.5, RCP6, and RCP8.5, where the numerical value refers to radiative forcing values $\left(+2.6,+4.5,+6.0\right.$, and $\left.+8.5 \mathrm{~W} / \mathrm{m}^{2}\right)$ in the year 
2100 (Table 4-1). For example, RCP2.6, which corresponds to a scenario with the smallest change in global temperatures, assumes that global greenhouse gases will reach their peak between 2010 and 2020, and that emission of GHGs will then decline. Conversely, RCP8.5 assumes a steady increase in $\mathrm{CO}_{2}$ emissions and corresponds to a scenario with the highest projected changes in global temperatures by the end of this century.

Table 4-1: Key characteristics of RCPs and SRES scenarios (Source: Charron (2016)).

\begin{tabular}{|c|c|c|c|c|c|}
\hline Scenario & $\begin{array}{l}\text { Radioactive } \\
\text { forcing }\end{array}$ & $\begin{array}{c}\mathrm{CO}_{2} \\
\text { equivalent } \\
(\mathbf{p p m}) \\
\end{array}$ & $\begin{array}{c}\text { Temp. } \\
\text { anomaly } \\
\left({ }^{\circ} \mathrm{C}\right) \\
\end{array}$ & Pathway & $\begin{array}{c}\text { SRES temp } \\
\text { anomaly } \\
\text { equivalent }\end{array}$ \\
\hline RCP8.5 & $8.5 \mathrm{~W} / \mathrm{m}^{2}$ in 2100 & $>1370$ & 4.9 & Rising & SRES A1FI* \\
\hline RCP6.0 & $6 \mathrm{~W} / \mathrm{m}^{2}$ post 2100 & $\sim 850$ & 3.0 & $\begin{array}{c}\text { Stabilizing } \\
\text { without } \\
\text { overshoot }\end{array}$ & SRES B2 \\
\hline $\mathrm{RCP} 4.5$ & $\begin{array}{c}4.5 \mathrm{~W} / \mathrm{m}^{2} \text { post } \\
2100\end{array}$ & $\sim 650$ & 2.4 & $\begin{array}{c}\text { Stabilizing } \\
\text { without } \\
\text { overshoot }\end{array}$ & SRES B1 \\
\hline $\begin{array}{c}\mathrm{RCP} 2.6 \\
\text { (RCP3P } \\
\mathrm{D})\end{array}$ & $\begin{array}{c}3 \mathrm{~W} / \mathrm{m}^{2} \text { mid- } \\
\text { century, } \\
\text { decline to } \\
2.6 \mathrm{~W} / \mathrm{m}^{2} \text { by } 2100\end{array}$ & $\sim 490$ & 1.5 & $\begin{array}{l}\text { Peak and } \\
\text { decline }\end{array}$ & None \\
\hline
\end{tabular}

The overall impact of climate change on the future weather of the Montreal area was estimated by using data from the Canadian Regional Climate Model (CanRCMs). Figures 4-2 and 4-3 present the yearly average temperatures and the annual number of rainy days (daily precipitation $>0.1 \mathrm{~mm}$ ) for the past 45 years and the future 90 years predicted from scenarios RCP4.5 and RCP8.5 representing high and medium emissions, respectively. 


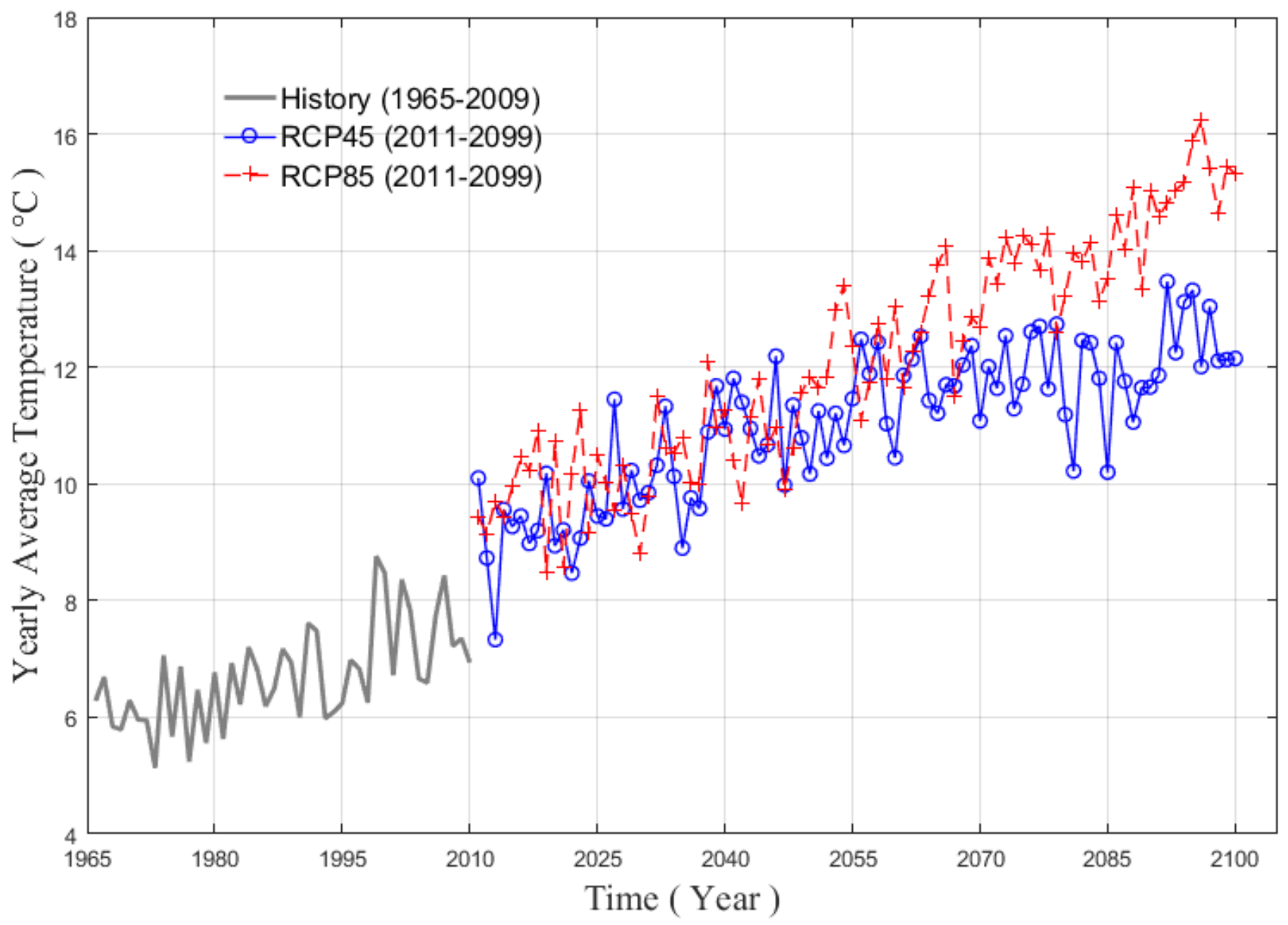

Figure 4-2 Yearly average temperature. Historical Records and projections between RCP8.5 and RCP4.5 


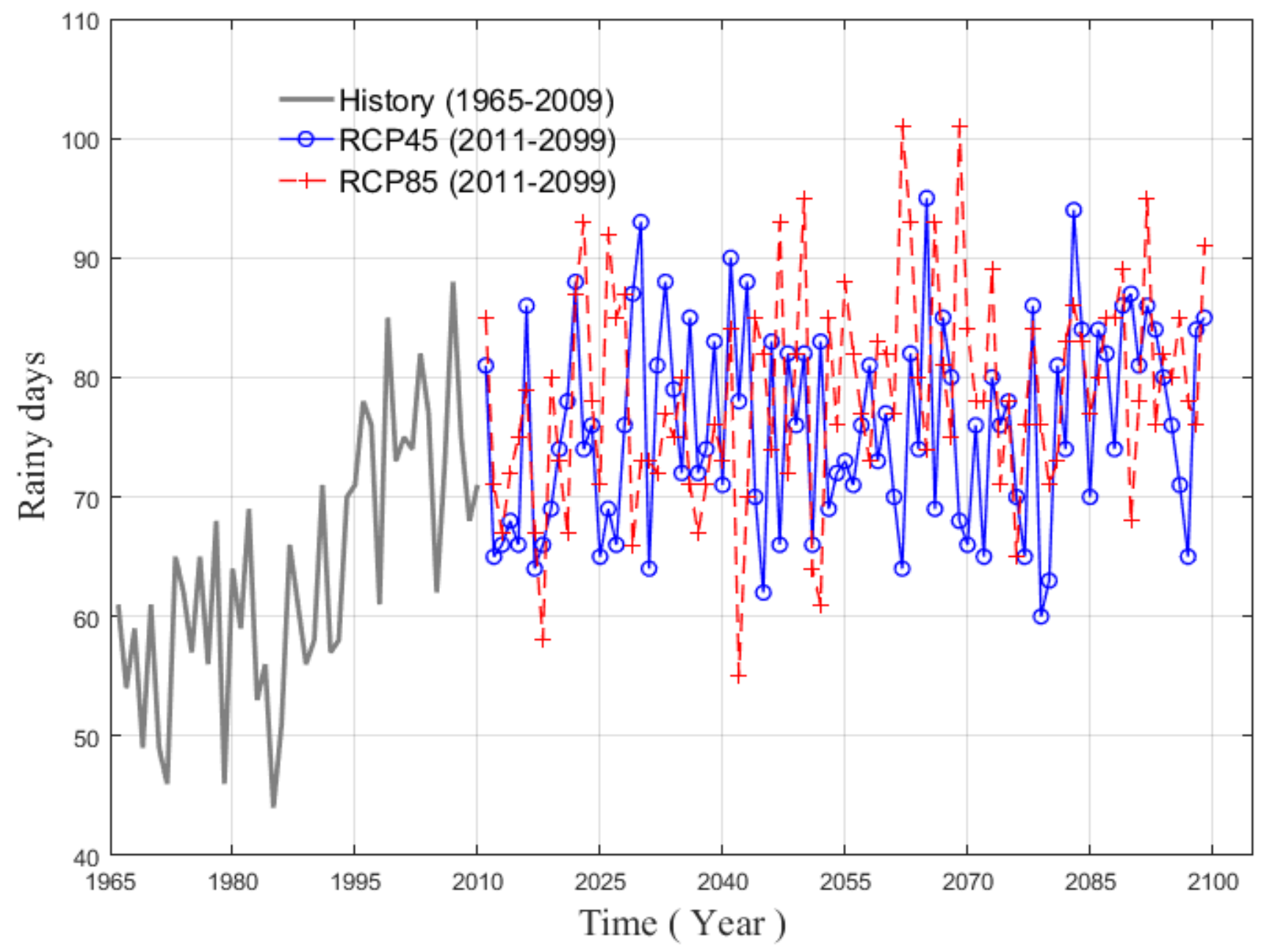

Figure 4-3 Total yearly number of rainy days (daily precipitation $>0.1 \mathrm{~mm}$ ). Historical Records and projections from RCP8.5 and RCP4.5 
Yearly average temperatures were stationary between 1965 to 1980 (Figure 4-2), but have been steadily increasing during recent decades by approximately $1.5^{\circ} \mathrm{C}$. Scenario RCP8.5 indicates that yearly average temperatures would keep increasing with the similar trend, attaining around $15^{\circ} \mathrm{C}$ by the end of this century, which is a $6^{\circ} \mathrm{C}$ increase relative to present. Scenario RCP4.5 on the other hand, reaches a stable level after a steady increase for the first 30 years, and ends up at $12^{\circ} \mathrm{C}$ for a total increase of $3^{\circ} \mathrm{C}$ relative to present. Historical records for the number of annual rainy days show a significant increase over the last 30 years and the trend continues into the next century with a slightly larger trend for scenario RCP8.5. In summary, the number of rain days is expected to increase by more than $25 \%$ in the second half of the century compared to the historical record.

\subsection{Model for the deterioration of concrete bridges}

The main mode of deterioration of RC structures in northern climates is corrosion associated with exposure to chloride ions. Rates of deterioration are dependent on material properties of the concrete (diffusion coefficient), geometrical characteristics (cross-sectional dimensions, depth of cover), exposure conditions (mist, splash or direct) and climate (temperature, humidity and winter precipitation). This study focuses on serviceability limit states and corrosion damage ending with severe cracking and spalling of the concrete cover. The time to the final stage of corrosion damage (spalling, $T_{s p}$ ) is divided into two stages: (i) corrosion initiation $\left(T_{i}\right)$ and, (ii) corrosion propagation ( $T_{p}$, time to onset of spalling) such that, $T_{s p}=T_{i}+T_{p}$. 


\subsubsection{Corrosion initiation}

The time to initiation of corrosion is a function of the amount of de-icing salts used during the winter, the properties of the concrete, the thickness of the concrete cover and the critical level of chloride ions to initiate corrosion. In the following, the concentration of chloride ions is evaluated for thickness covers of $25 \mathrm{~mm}$ and $50 \mathrm{~mm}$. Probabilistic estimates of chloride concentrations as a function of time and depth are obtained with TransChlor ${ }^{\circledR}$, which is a one-dimensional finite element program that models the ingress of chloride ions in concrete as a function of time and depth (Conciatori et al. 2009b). Climate variables that are used as input by TransChlor ${ }^{\circledR}$ are hourly air temperature, relative humidity, precipitation, and solar radiation. The air temperature, relative humidity and precipitation are used to determine the amount and frequency for spreading de-icing salts at the surface of the concrete slab. The exposure to chlorides can be direct, by splashing or by mist depending on the position of the exposed concrete element. In the case of the concrete deck, only direct exposure is considered.

The time to initiation of corrosion is defined as the time required for the chloride ion content (e.g. $\%$ of $C l$ - per weight of cement) to reach a critical level $\left(C_{c r i t}\right)$. The critical chloride content varies with the type of reinforcement and the nature of the corrosion process and can be described probabilistically. In this application, chloride ion thresholds are assumed to follow a lognormal distribution (Figure 4-4). Since there is also uncertainty associated with the material properties of the concrete and model predictions, the chloride ion content as a function of depth and time is also assumed to follow a lognormal distribution (Figure 4-5). The average and standard deviation of the chloride ion content is obtained by assuming that the transport properties of the chloride ions (the diffusion coefficient of chloride ions $D_{C L}$, the diffusion of hydroxides $D_{O H}$ and diffusion by 
capillarity, $D_{C A P}$ ) are lognormally distributed. The propagation of the uncertainty on transport properties is performed by using Rosenblueth point estimates (Conciatori et al. 2009b).
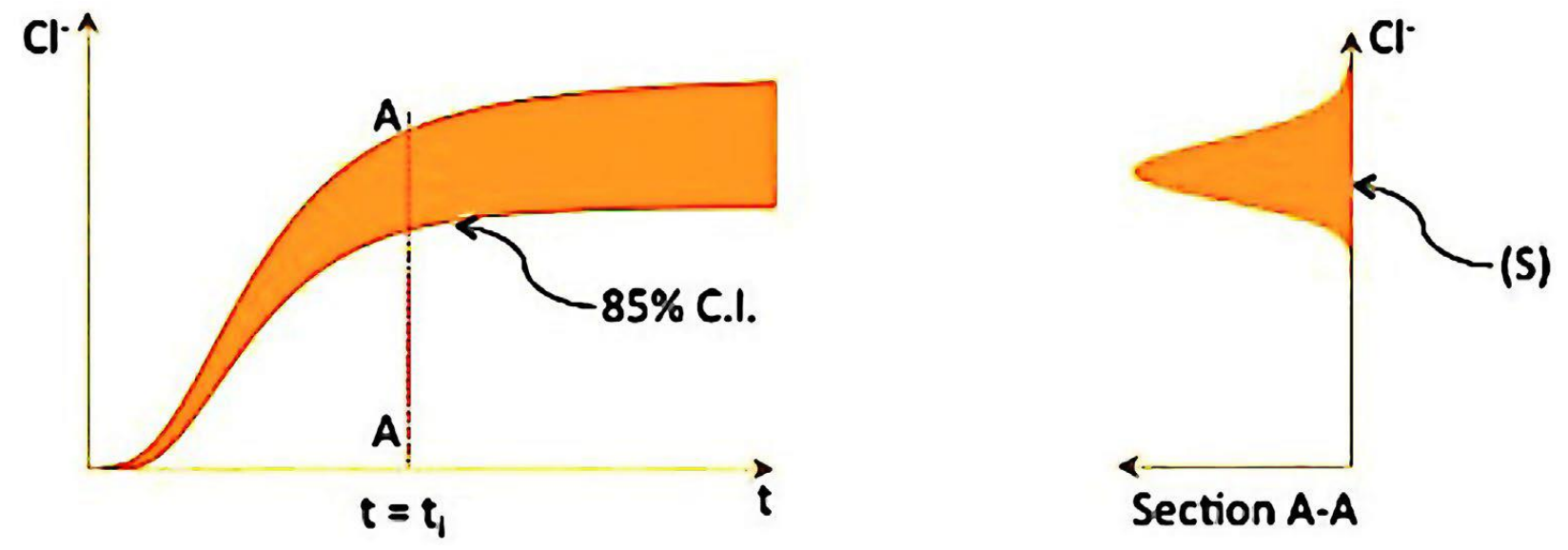

Figure 4-4 Chloride Ion Distribution as a function of time and depth (Wolofsky 2011a).

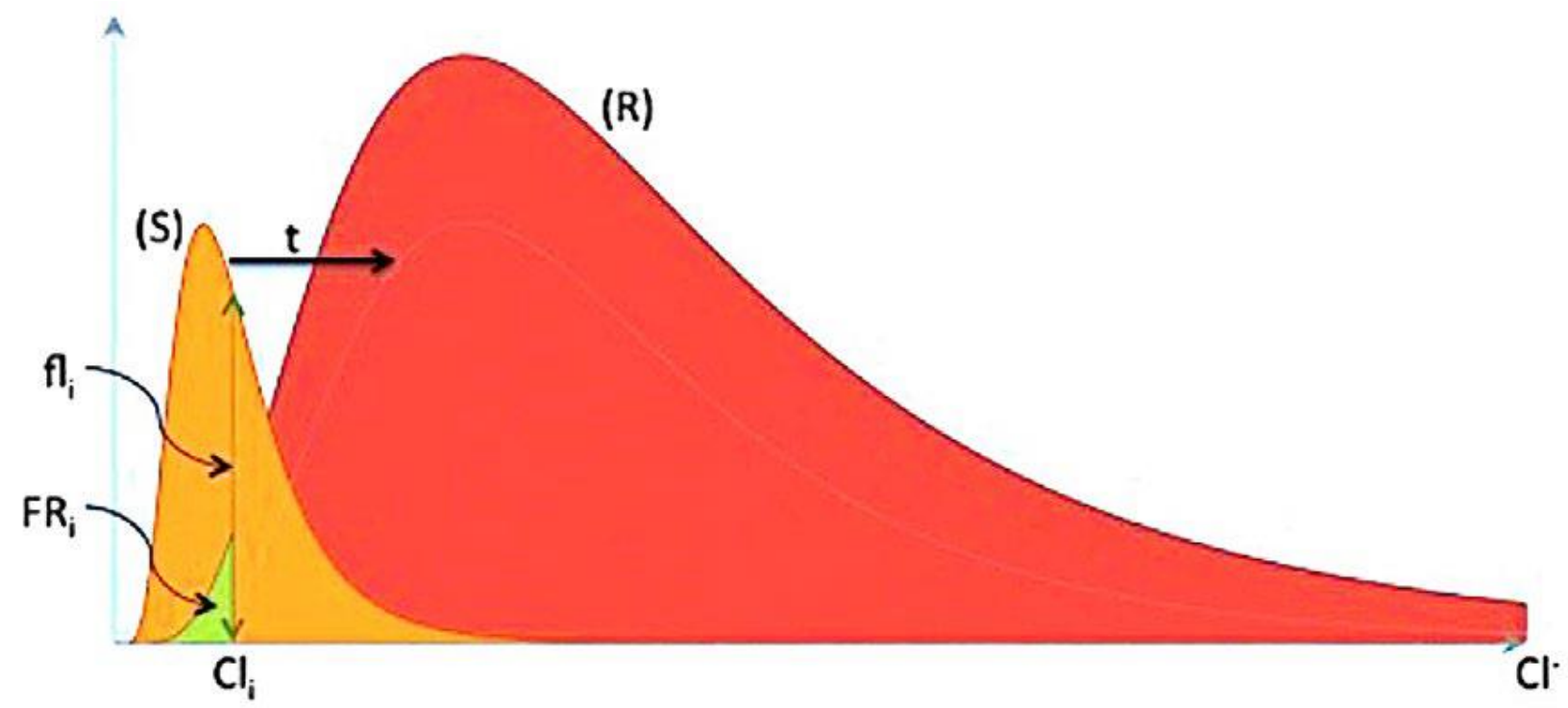

Figure 4-5 Chloride content at a given depth and time and Chloride Threshold level (Wolofsky 2011a). 


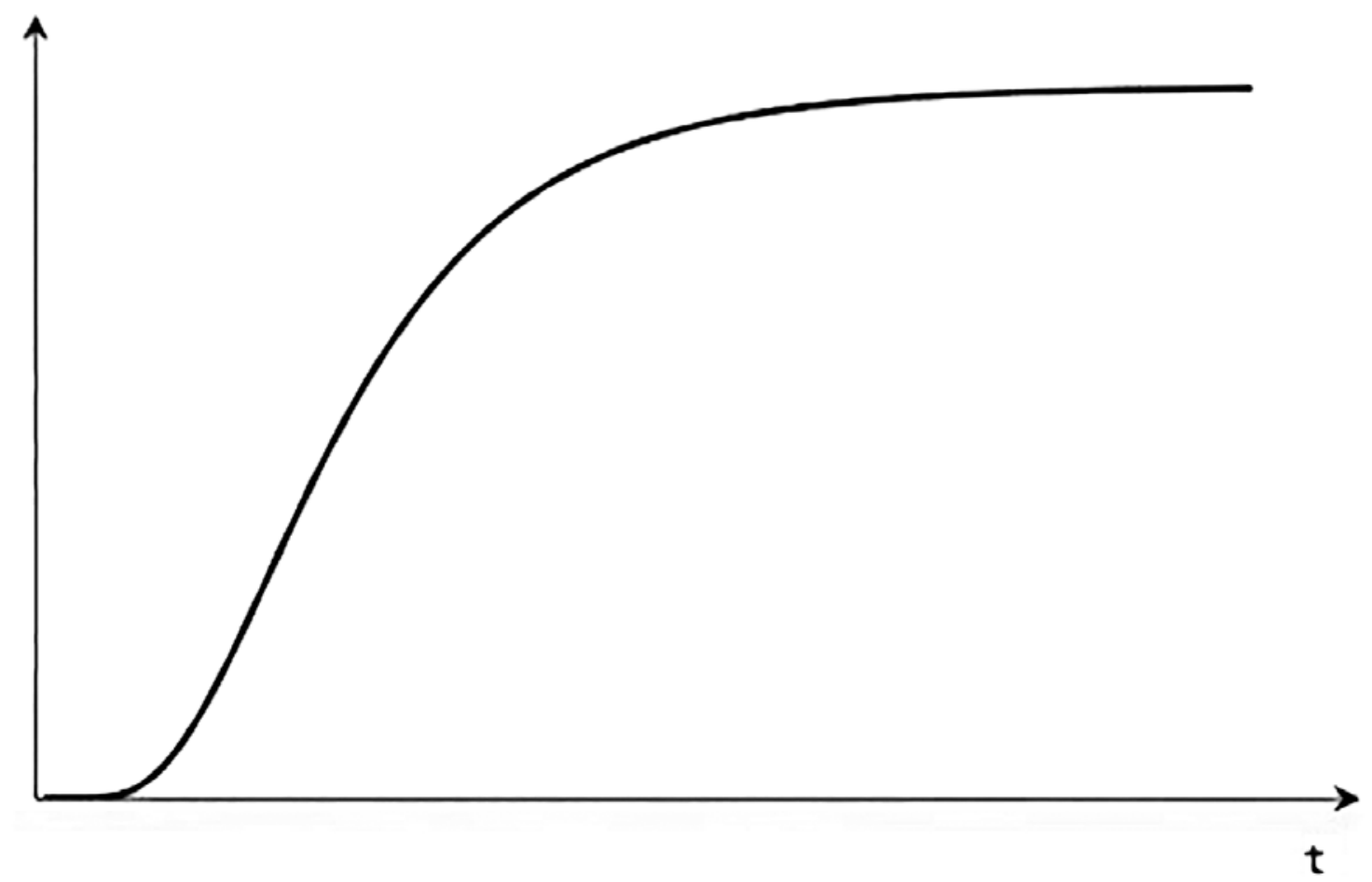

Figure 4-6 Cumulative Probability of time to initiation of corrosion at a given depth (Wolofsky 2011a).

The probability distribution function for the time of initiation of corrosion at a given depth is obtained as a convolution integral of the distribution for the critical chloride ion level and the chloride concentration at a given depth and time (Figures 4-5 and 4-6) (Conciatori et al. 2009b). 


\subsubsection{Corrosion propagation}

The depassivation of the surface layer of the reinforcing steel results in the corrosion of the steel. The corrosion of the reinforcement leads to corrosion products (i.e. rust) and a reduction of the cross-sectional area of steel. The volume of rust is much larger than that of the original steel, leading to expansion and pressure on the concrete. As a result, the concrete cover eventually cracks and spalls and the bond between reinforcement and concrete is compromised which leads to a reduction of the overall strength and ductility of the reinforced concrete element.

The accurate estimation of corrosion rates is difficult since they depend on the presence of oxygen and moisture which are highly variable. Some prediction models use molecular equations for the corrosion reactions to convert rates of oxygen diffusion to steel corrosion rates (Vu and Stewart 2000). However, the corrosion current density obtained from experiments or field measurements are considered to provide among the most accurate estimates of the corrosion rate (Stewart and Rosowsky 1998). In this application, a model where the corrosion rate varies with ambient temperature is adopted (Duracrete 2000):

$$
j_{r}(t)=j_{r, 20}\left[1+K_{c}(T(t)-20)\right]
$$

where $j_{r, 20}$ is the corrosion rate at $20^{\circ} \mathrm{C}, T(t)$ is the temperature at time $t$ (in ${ }^{\circ} \mathrm{C}$ ) and $K_{c}$ is a factor that depends on temperature $\left(K_{c}=0.025\right.$ if $T(t)<20^{\circ} \mathrm{C}$ or $K_{c}=0.073$ if $\left.T(t)>20^{\circ} \mathrm{C}\right)$.

Simplified models for corrosion-induced delamination and spalling of the concrete cover were proposed by Bazant (1979) as well as Lounis and Daigle (2008). Once an internal crack has propagated through the thickness of the concrete cover, the stresses resulting from corrosion products are assumed to remain constant until the cover delaminates or spalls off. Lounis and 
Daigle (2008) propose the following equation for the time between corrosion initiation to the start of spalling (i.e. the propagation time),

$$
t_{p}(s p)=\frac{\pi}{2 S_{r}\left[\frac{1}{\rho_{r}}-\frac{\alpha}{\rho_{s}}\right]}\left[1+v+\frac{d^{2}}{2 c(c+d)}\right] \frac{\left(2 c d+d^{2}\right) f_{t}^{\prime}}{E_{c}}
$$

where $S=$ rebar spacing; $\rho_{r}=$ density of corrosion products (assumed at $3,600 \mathrm{~kg} / \mathrm{m}^{3}$ for $\left.\mathrm{Fe}(\mathrm{OH})\right)_{3}$; $\rho_{s}=$ density of steel $\left(7,860 \mathrm{~kg} / \mathrm{m}^{3}\right) ; \alpha=$ molecular weight ratio of metal iron to the corrosion product (assumed at 0.52); and $j_{r}=$ corrosion production rate per unit area $\left(\mu \mathrm{A} / \mathrm{cm}^{2}\right)$ (Bazant 1979). This model is used to relate changes in the diameter of steel rebars to corrosion-induced damage limit states (Lounis and McAllister 2016). The random variables that are considered in the model are listed in Table 4-2.

Table 4-2: The random variables loading in the propagation model.

\begin{tabular}{ccccc}
\hline Variables & Units & Distribution & Mean & COV \\
\hline Cover thickness, $c_{t}$ & $\mathrm{~mm}$ & Deterministic & $25 / 50 / 70$ & - \\
Bar spacing & $\mathrm{mm}$ & Log-normal & 150 & 5 \\
Bar diameter & $\mathrm{mm}$ & Deterministic & 16 & 20 \\
Concentration threshold for & wt. $(\%)$ cem. & Log-normal & 1.35 & 20 \\
Corrosion initiation, $C_{t h}$ & $\mu \mathrm{A} / \mathrm{cm}^{2}$ & Log-normal & 0.8 \\
Reference corrosion rate, $j_{r, 20}$ & $M P_{a}$ & Normal & 45.5 & 18 \\
28 Day concrete compressive & & & \\
strength, $f_{c}$ & $M P_{a}$ & Normal & $0.53\left(f_{c}\right)^{0.5}$ & 13 \\
Concrete tensile strength, $f_{t \prime}$ & $M P_{a}$ & Normal & $4600\left(f_{c}\right)^{0.5}$ & 12 \\
Concrete elastic modulus, $E_{c}$ & & & \\
\hline
\end{tabular}

Note: $\mathrm{COV}=$ coefficient of variation $(\%)$, 
$f_{c}=$ Concrete compressive strength

The determination of the time-dependent probability of serviceability limit states is complex due to the high level of nonlinearity of the performance functions. In this paper, the total time for the onset of spalling is defined as,

$$
T_{\text {total }}=T_{\text {initiation }}+T_{\text {propagation (to spalling) }}
$$

and its cumulative distribution function is obtained from,

$$
\begin{aligned}
& F_{T_{\text {Total }}}\left(t_{t}\right)=P\left[\left(t_{i}+t_{p}\right)<t\right]=\int_{0}^{t_{t}} f_{T_{\text {propagatia }}}\left(t_{p}\right) \int_{0}^{t_{t}-t_{p}} f_{T_{\text {initiation }}}\left(t_{i}\right) d t_{i} d t_{p} \\
& =\int_{0}^{t_{t}} f_{T_{\text {propagatia }}}\left(t_{p}\right) \cdot F_{T_{\text {initiation }}}\left(t_{t}-t_{p}\right) d t
\end{aligned}
$$

where, $F_{T_{\text {initiation }}}\left(t_{p}\right)$ and $F_{T_{\text {propagatia }}}\left(t_{p}\right)$ are the cumulative distribution functions for the time to initiation of corrosion and the time for corrosion propagation respectively. Since the time from initiation of corrosion to spalling is usually long, and the models for crack growth are mostly linear functions of time, the stages of deterioration are divided into: Stage A) the initial stage, from the start of the service life to the initiation of corrosion, Stage B) the initial stage of corrosion propagation, from the start of the initiation of corrosion to the midpoint until spalling of the concrete cover, Stage C) the final stage of corrosion propagation, for the remainder of time until spalling, and Stage D) spalling of the concrete cover. These four states correspond to the four states used by the MTM (Ministère des Transports, de la Mobilité durable et de l'Électrification des transports) in classifying the state of bridge components following an inspection. 


$$
\begin{gathered}
P_{A}(t)=P\left(t_{i}<t\right) \\
P_{B}(t)=P\left[\left(t_{i}+t_{p} / 2\right)<t\right] \\
P_{C}(t)=P\left[\left(t_{i}+t_{p} / 2\right) \leq t<\left(t_{i}+t_{p}\right)\right] \\
P_{D}(t)=P\left(t>\left(t_{i}+t_{p}\right)\right)
\end{gathered}
$$

\subsection{Decision-Making Model}

The decision model uses the Net Present Value (NPV) of the difference between expected bridge revenues and expected costs of the first major repair to perform a Cost-Benefit Analysis (CBA). Revenues can be either monetary or can represent the value of user time saved. However, as shown in the real option literature, the NPV approach is not a reliable criterion if decision-making flexibility found in investment projects is not considered (see e.g. Myers (1977); McDonald and Siegel (1986); Dixit and Pindyck (1994)). Indeed, Power et al. (2015) show that the option to delay an investment can affect the optimal investment timing in infrastructure projects (see also Bar-Ilan and Strange (1996); Panayi and Trigeorgis (1998) for more details about the importance to consider the delaying option). In the following, the procedure of Power et al. (2015) is included in the investment decision analysis by offering an option to delay a first major deck repair at the time when the economic conditions are most favorable.

The decision-analysis process is modelled using a three-year cycle, which corresponds to the typical inspection cycle of bridges by the MTM. The investment options to the decision-maker are to make repairs early in the service life (in order to avoid larger and more expensive repairs when 
the state of deterioration is more advanced), or to delay the repairs - if, say, current interest rates are high or if there is much uncertainty about the rate of deterioration and climate change scenarios. In northern climates, bridges are generally designed for a service life between 50 to 100 years. However, most bridges show signs of early deterioration after only 20 to 30 years. In this study, simulations are performed over a period of 90 years spanning a historical period of 45 years and the next 45 years in order to capture the effects of climate change scenarios on the durability of existing, as well as of new, structures.

Monte Carlo simulation is used to describe uncertainties in the evolution of bridge deterioration as well as economic factors over time. A total of 10,000 simulations are performed, which represent distinct scenarios for the lifetime of the bridge. The NPV for each path is calculated at intervals of 3 years and the optimal repair date corresponds to the date yielding the maximum NPV for each scenario:

$$
\begin{gathered}
N P V_{s}=\left(\operatorname{Rev}_{t}-C_{t}\right) \times \sum_{t=0}^{T-1} \frac{1}{\left(1+r_{t}\right)^{t}} \\
N \operatorname{Rev}_{t} \times \sum_{t=0}^{T-1} \frac{1}{\left(1+r_{t}\right)^{t}},[-45 \leq T \leq+45]
\end{gathered}
$$

where $N P V_{s}$ is the net present value for scenario $s, N R e v_{t}$ is the Net Revenue which corresponds to the difference between the revenue $\left(\operatorname{Rev}_{t}\right)$ and the costs $\left(C_{t}\right)$ at time $t, T$ is the design lifetime of the structure, and $r_{t}$ is the risk-adjusted interest rate at time $t$ (i.e., yields on Government bonds). Because the model uses the short-term interest rate, the second term in the NPV equation discounts the Net Revenue to the initial time. To compute our NPV in each scenario, the model includes stochastic models for the evolution of demand, prices, inflation, interest rates and rate of deterioration (Power et al. 2015). 


\subsubsection{Estimation of the additional revenue}

Assuming that initial construction costs are considered as sunk costs, the additional revenue from investment $R e v_{t}$ can be defined following Power et al. (2015) and Bastien (2017):

$$
R e v_{t}=M_{t} \times S P_{t} \times H r s_{t} \times Q_{t} \times \exp (\pi \times t)
$$

where $S P_{t}$ is Shadow Price (economic value to the user of one hour saved), $H r s_{t}$ is the number of hours (or fraction) saved by using the infrastructure, $Q_{t}$ is the estimated quantity or volume of traffic on the infrastructure in one year (Šliupas 2006), $\exp (\pi \times t)$ is the Consumer Price Index at time $t$ relative to the starting date time 0 , given that $\pi$ is the continuous rate of inflation. Finally, $M_{t}$ is the adjustment to shadow price due to a lower condition rating of the bridge, such that $0 \leq$ $M_{t} \leq 1$.Indeed, when the condition is below " $\mathrm{A}$ ", regular maintenance is more frequent which increases congestion and delays.

The value of 0.8 is used for condition rating $\mathrm{B}, 0.6$ for condition rating $\mathrm{C}$, and 0 for condition rating D. This parameter can be used to account for user safety in the equation as well as the negative effect on bridge usefulness of increased maintenance needs. In this paper, the shadow price and the time saved by using the bridge are the only fixed parameters. A baseline value of $\$ 14.74$ for the shadow price was estimated from Transport Canada data for the period 1994 to 2011. This shadow price corresponds to the average value (given by a car driver to an hour saved) in the case the purpose of travel is unknown. For the time saved, a baseline value of 5.4 minutes was obtained from data in urban areas of the province of Quebec for bridges having deck areas of $1,000 \mathrm{~m}^{2}$. The total annual number of trips $Q_{t}$ is calculated as follow:

$$
Q_{t}(1-L)=\epsilon_{t}
$$


where $L$ is the lag operator, $\varepsilon_{t}$ is a normally distributed random variable describing the growth rate of $Q$, and we impose that $Q$ cannot exceed twice its initial value due to capacity constraints. The parameters of the normal distribution for $\varepsilon_{t}$ are fitted to the Quebec real GDP growth rate which is a good proxy for the evolution of $Q$.

Since inflation is measured on a quarterly basis, this is the frequency at which we estimate the time series model. To model $\pi_{G, q}$, the quarterly inflation rate, the mean reverting process of OrnsteinUhlenbeck is used (Chang et al. 2013):

$$
\pi_{G, q}=\pi_{G, q-1}+\zeta\left(\xi-\pi_{G, q-1}\right)+\epsilon_{G, q}
$$

where the parameters $\zeta$ and $\xi$ are estimated from Statistics Canada data. In Power et al. (2015) the values are 0.10 and 0.017 respectively. The error term $\epsilon_{G, q}$ is a zero-mean random variable that is distributed normally with variance estimated from the same data.

The annual rate of general inflation (for use with the Consumer Price Index level) is obtained directly from the quarterly frequency using the standard compounding formula.

\subsubsection{Estimation of costs for the first major repair}

When the first major repair is performed, the cost is assumed to be:

$$
C_{t}=\left(1-\text { State }_{t}\right) \times S z \times U C \times \exp \left(\pi_{M} \times t\right)
$$

where State $_{t}$ is the state of the infrastructure (new $=100 \%$ ), $S z$ is the size or area of the deck, $U C$ is the unit cost, and $\exp \left(\pi_{M} \times t\right)$ is the Producer Price Index level at time $t$ relative to starting time 0 and which is based on the materials rate of inflation $\pi \mathrm{m}$. For the baseline model, we consider an area of $1,000 \mathrm{~m}^{2}$ and unit costs of $\$ 1,000$ per $\mathrm{m}^{2}$. 
As with the general rate of inflation, the rate of inflation for materials and labor $\pi_{M, i}$ is estimated using a Ornstein-Uhlenbeck process (Power et al. 2015). The quarterly material and labor costs inflation rate is modelled as:

$$
\pi_{M, q}=\pi_{M, q-1}+\tilde{\zeta}\left(\tilde{\xi}-\pi_{M, q-1}\right)+\epsilon_{G, q}
$$

where the parameters $\tilde{\zeta}$ and $\tilde{\xi}$ are estimated from Statistics Canada data. In (Power et al. 2015) the values are 0.10 and 0.032 respectively. The error term $\epsilon_{M, q}$ is a zero-mean random variable that is distributed normally with variance estimated from the same data. Moreover, we impose a correlation structure between the interest rate, the general rate of inflation, and the materials rate of inflation. These empirical correlations $\left[\rho_{1,2}, \rho_{1,3}, \rho_{2,3}\right]$ are estimated from the same data for Canada.

The annual rate of materials inflation (for use with the Producer Price Index level) is obtained directly from the quarterly frequency using the standard compounding formula.

\subsubsection{The present value of revenues or benefits}

A general version of the short-rate model of the interest rate is provided by Chan et al. (1992) and implemented for infrastructure investments by Power et al. (2015). In the continuous time specification, this interest rate $r$ evolves as an Ornstein-Uhlenbeck stochastic process:

$$
d r_{t}=\alpha\left(\beta-r_{t}\right) d t+\sigma_{t}^{\gamma} d W_{t}
$$

This process can be estimated using data on yields for Canadian Government bonds. We use the parameter values obtained in Power et al. (2015) such that $\alpha=0.135, \beta=-0.0395, \sigma=$ 
0.1463 , and $\gamma=0.1946$. To go from a quarterly to an annual frequency model, the standard compounding formula is used.

The relationships within the model are represented in the relationships diagram in Figure 4-7,

\section{Physical}

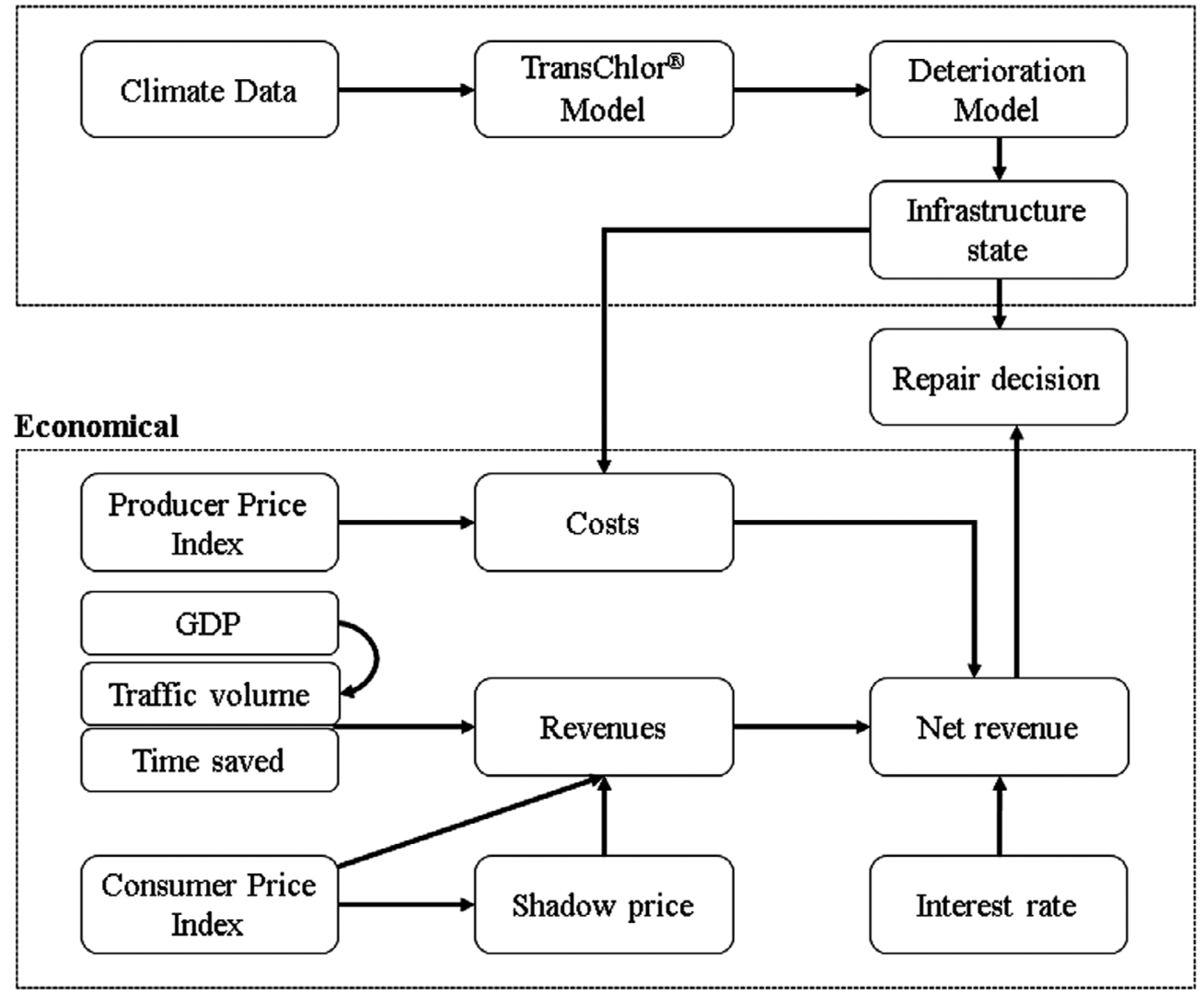

Figure 4-7 Schematic representation of the model. 


\subsection{Discussion of results}

The deterioration model is used to estimate the probability distribution function for the time to reach each of the four stages of deterioration (A to D) defined previously. Estimates are obtained using the historical climatic data during the last 45 years and for the next 45 years using data for climate scenarios RCP4.5 and RCP8.5. The results can be used to compute transition probabilities from one state to another for the specified inspection cycle. The latter can be compared to empirical estimates of transition probabilities obtained from periodic inspection reports for calibration purposes.

Figures 4-8 and 4-9 illustrate the resulting probabilities of the condition states for the three climate scenarios for concrete covers of $25 \mathrm{~mm}$ and $50 \mathrm{~mm}$. The $50 \mathrm{~mm}$ depth is selected since it is common for concrete covers of bridge decks. The $25 \mathrm{~mm}$ depth is not as common and is used to illustrate the effect of a smaller or improperly executed concrete cover on rates of deterioration. For all climate scenarios, the structure is assumed to be initially new and the same salt spreading protocol is used during winter precipitation. 


\section{1) $25 \mathrm{~mm}$ History}

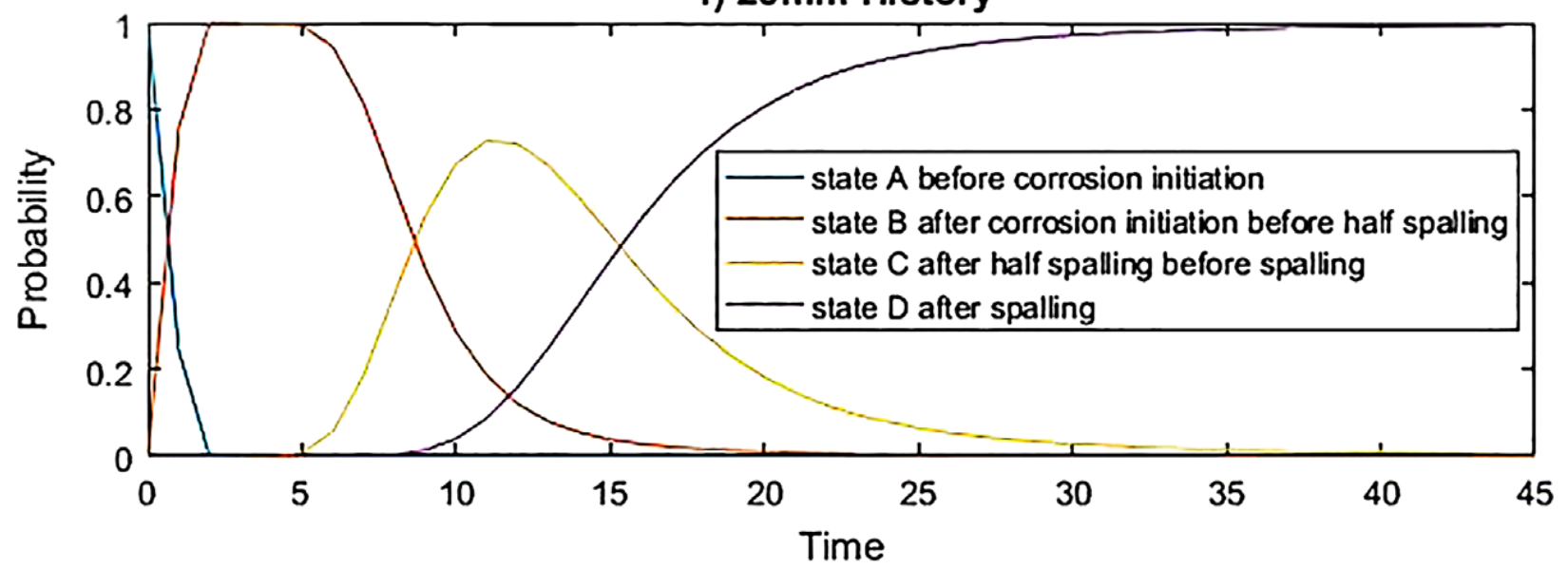

2) $25 \mathrm{~mm}$ RCP4.5

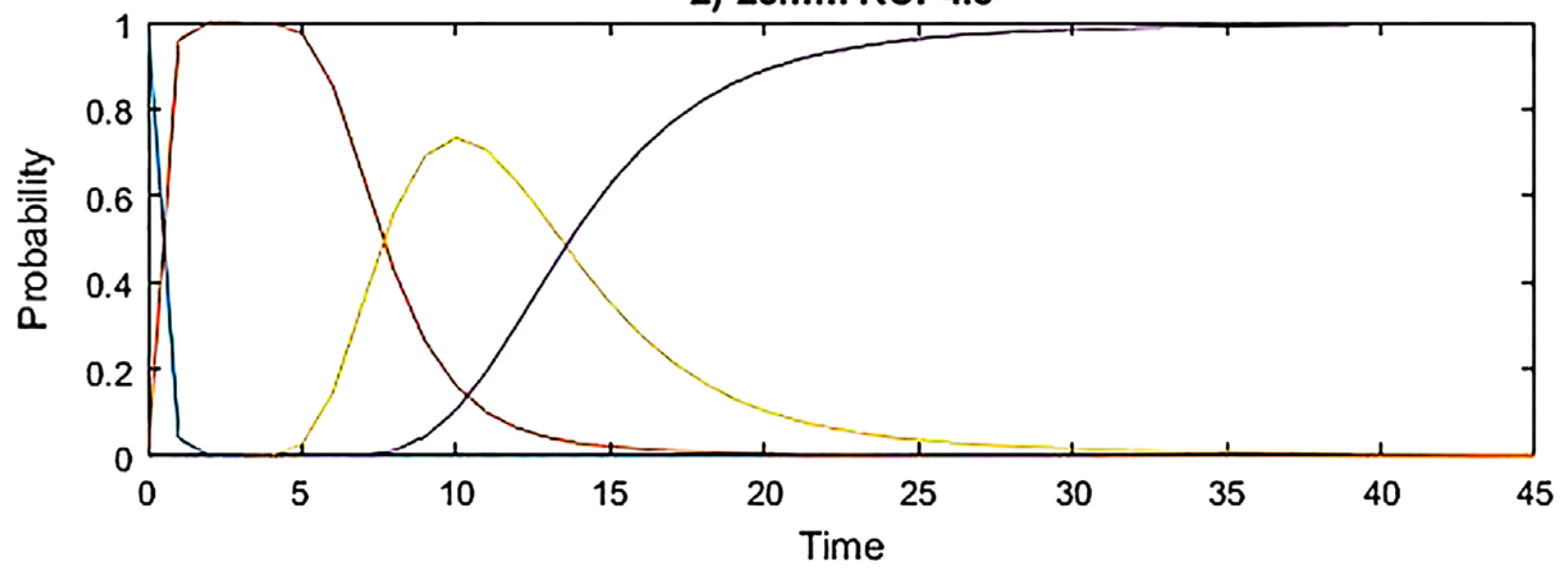

3) $25 \mathrm{~mm}$ RCP8.5

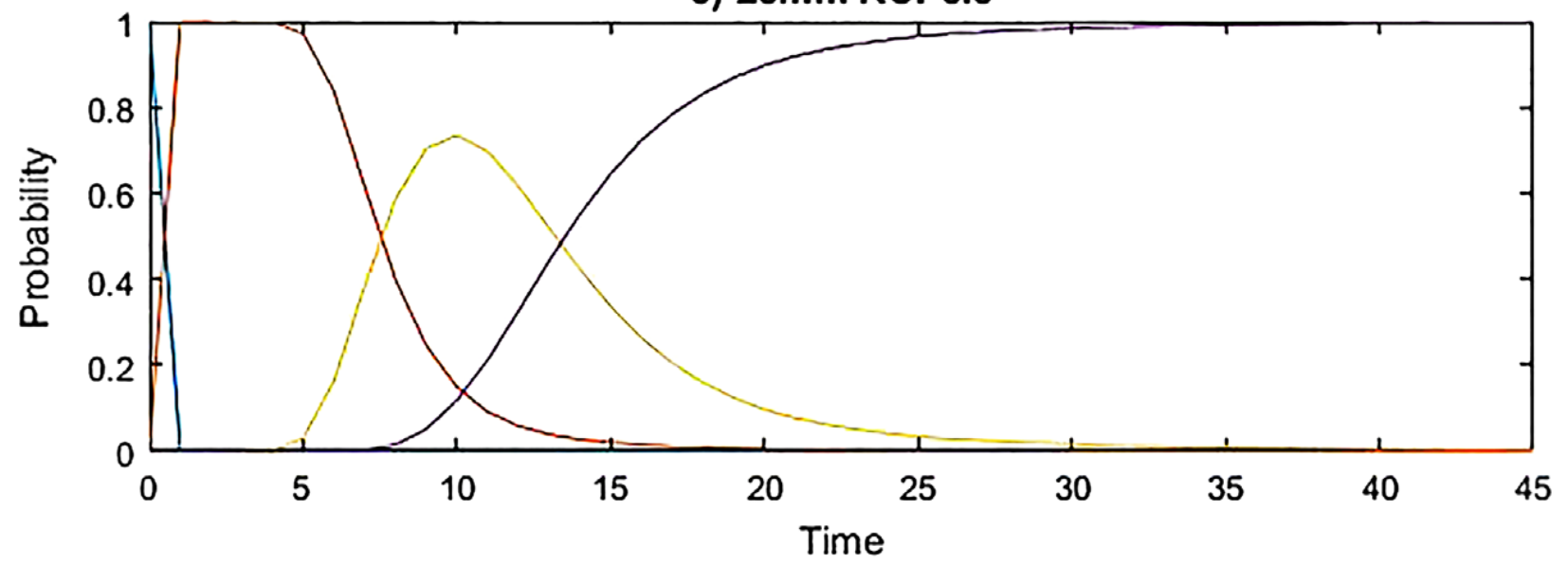

Figure 4-8 Condition state probabilities as a function of time(year) for a concrete cover of 25 mm (1) historical climate, (2) Climate Scenario RCP4.5, (3) Climate Scenario RCP8.5. 

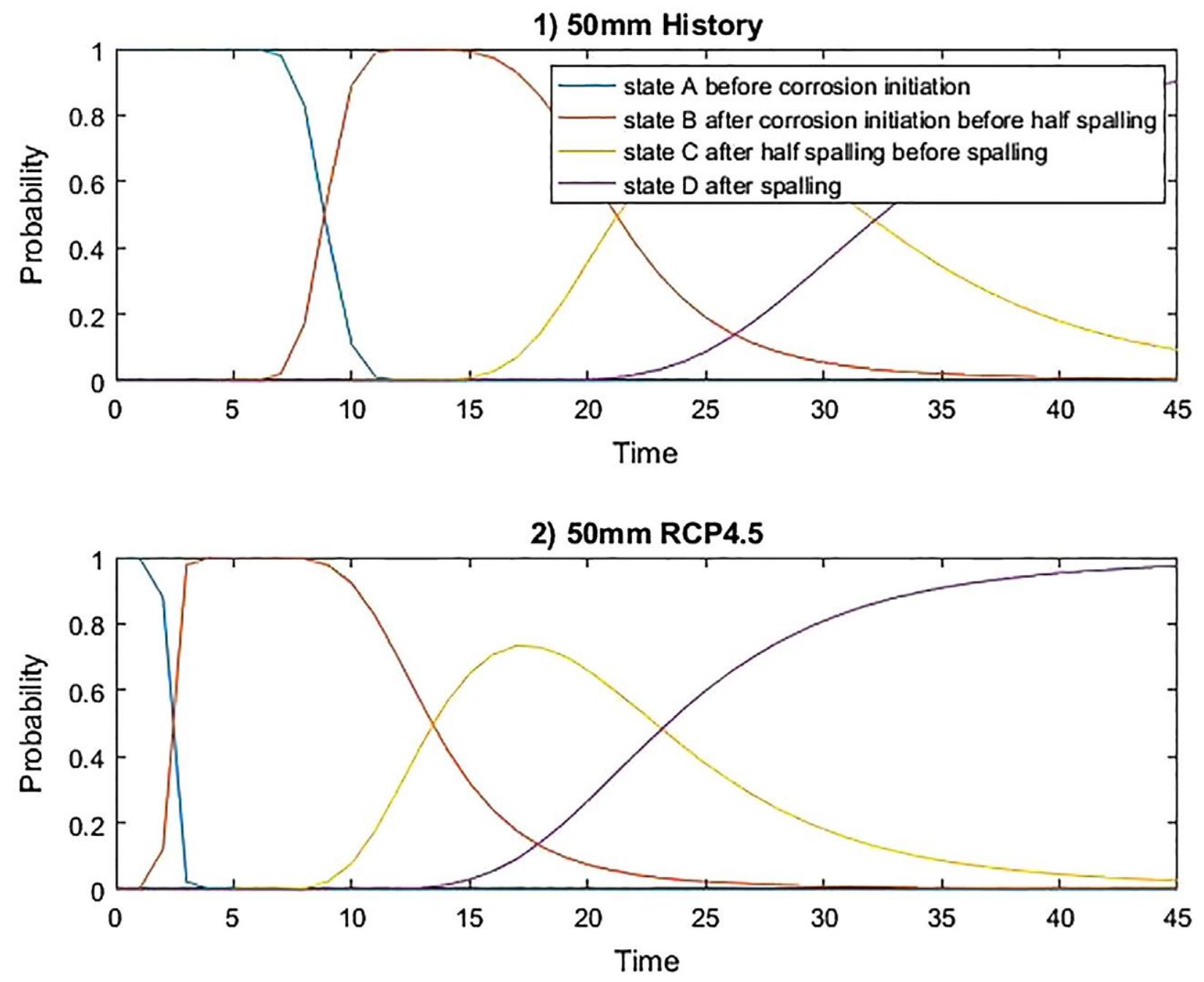

3) $50 \mathrm{~mm}$ RCP8.5

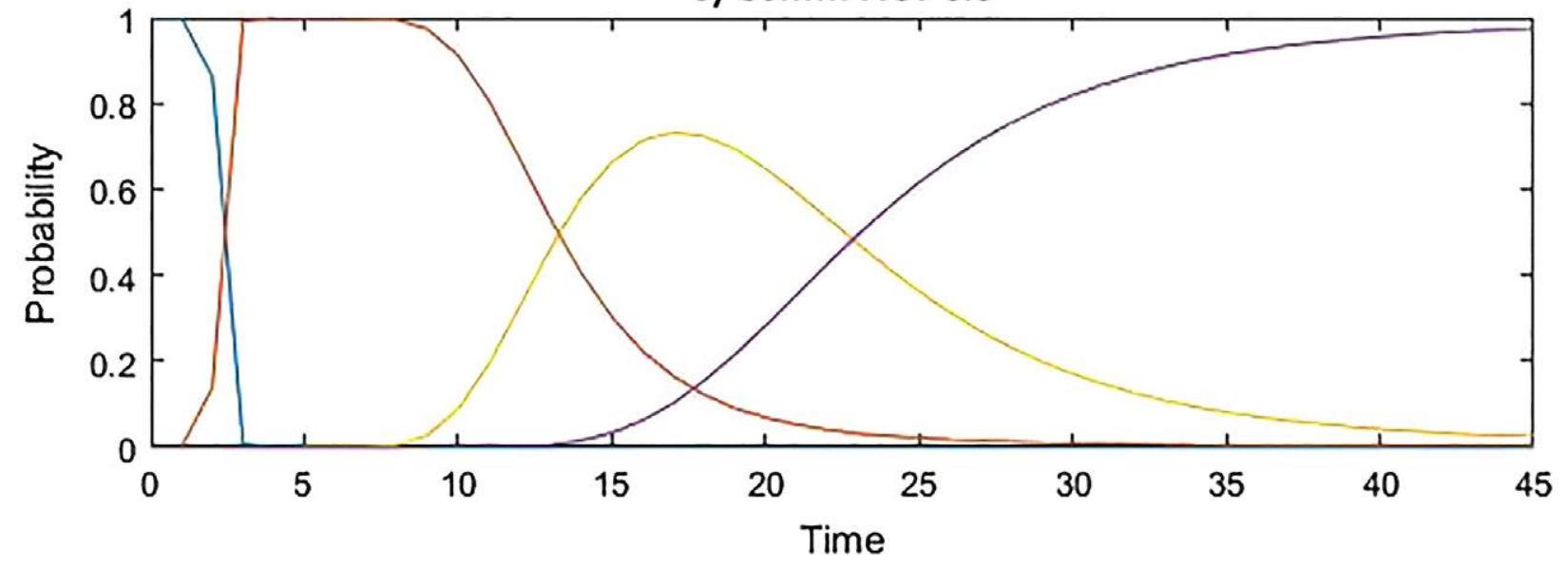

Figure 4-9 Condition state probabilities as a function of time(year) for a concrete cover of 50 mm (1) historical climate, (2) Climate Scenario RCP4.5, (3) Climate Scenario RCP8.5. 
Results show that the time to the initiation of corrosion is highly dependent on the number of precipitation days during the winter which trigger salt usage. Historically, the number of days with winter precipitation have been steadily increasing for the Montreal area over the last decades and the trend is maintained with both climate change scenarios despite an overall increase in average winter temperatures (Figures 4-2 and 4-3). For steel reinforcement with a 50mm cover, time to initiation of corrosion for historical exposures is within the first 10 years of the service life while for both climate change scenarios, time to initiation of corrosion is within the first 5 years of the service life. The model indicates that a large proportion $(\sim 90 \%)$ of the decks that were built 45 years ago have reached their design life (defined as spalling of the cover). This observation is consistent with records of the MTM on the service life of concrete decks. For both climate change scenarios, the warmer temperatures and humidity also contribute to a more rapid deterioration of the concrete deck with $90 \%$ of the decks reaching the end of their service life after 35 years. There is not much difference in the results for the two climate change scenarios despite that scenario RCP8.5 has a slightly larger number of winter precipitation events.

For steel with a $25 \mathrm{~mm}$ concrete cover, the level of chloride ions is on average much higher than at $50 \mathrm{~mm}$; however, capillarity effects and dilution is more prevalent resulting in higher variability in the ions chloride content. The time to initiation of corrosion and to spalling of the concrete cover are much quicker resulting in premature end to the service life. The results for a concrete cover of $25 \mathrm{~mm}$ are more similar for all three scenarios since the time to initiation of corrosion is very short in all cases ( 2 years). Furthermore, the probability for spalling is $90 \%$ after only 20 years of exposure for the two climate change scenarios and only 25 years for the historical scenario. The increase in the corrosion rate between the RCP4.5 and RC8.5 climate change scenarios can be attributed to average temperature levels increasing by $4.5^{\circ} \mathrm{C}$ and $5^{\circ} \mathrm{C}$ by the year 2055 respectively 
compared to the 1965 levels. The impact of changing temperature is considered to be a significant factor in the time-varying corrosion propagation model, as higher temperatures can accelerate corrosion rates.

Cost-benefit analyses are performed for all three climate scenarios and the two concrete covers to determine the optimal time for the first repair of a bridge deck (Figures 4-10 and 4-11). The stacked histograms show the distribution of the optimal dates for deck replacements. The color-coded histograms indicate the state of the bridge deck at the time of the optimal repair.

1) History, 25mm, 1965-2009

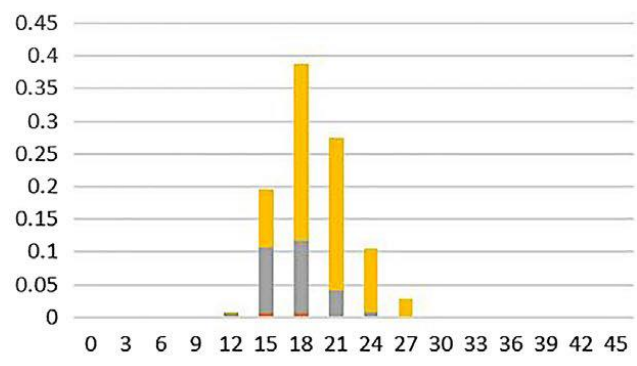

2) RCP4.5, 25mm, 2011-2055

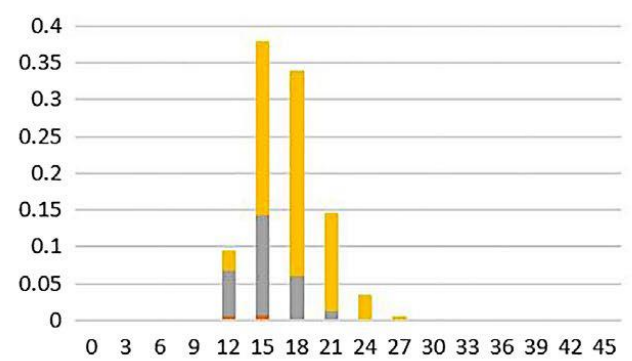

$\square$ State A $\square$ State B $\square$ State C $\square$ State D
3) RCP8.5, 25mm, 2011-2055

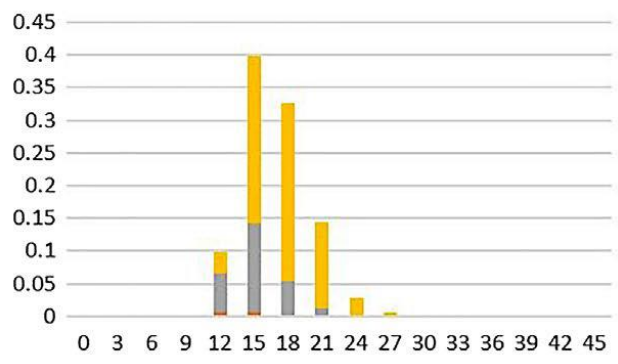

Figure 4-10 Stacked histogram of the optimal date of the bridge deck first repair at $25 \mathrm{~mm}$ (1) historical climate, (2) Climate Scenario RCP4.5, (3) Climate Scenario RCP8.5.

1) History, $50 \mathrm{~mm}, 1965-2009$

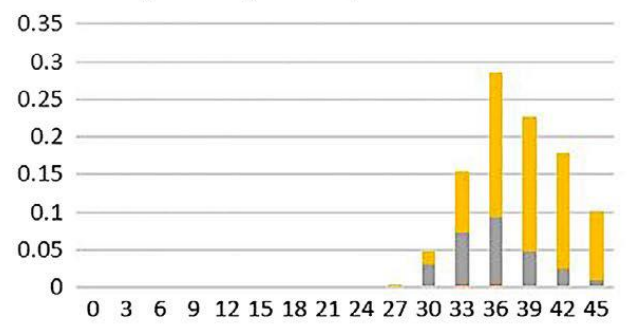

2) RCP4.5, 50mm, 2011-2055

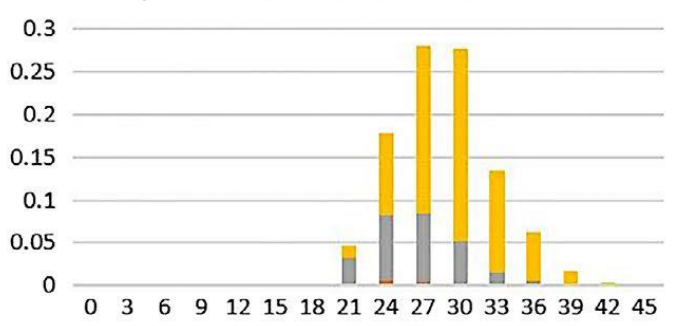

$\square$ State A $\square$ State B $\square$ State C State D
3) RCP8.5, 50mm, 2011-2055

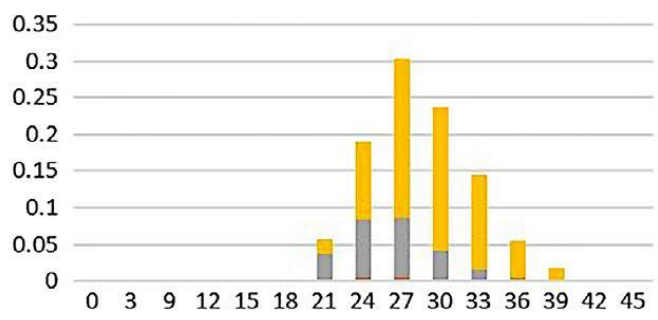

Figure 4-11 Stacked histogram of the optimal date of the bridge deck first repair at $50 \mathrm{~mm}$ (1) historical climate, (2) Climate Scenario RCP4.5, (3) Climate Scenario RCP8.5. 
The results indicate that the most likely time for repair for a $50 \mathrm{~mm}$ concrete cover is year 27 for both climate change scenarios and year 36 for the historical record. For $25 \mathrm{~mm}$ concrete cover, the most likely dates for repair are respectively 15 and 18 years for the climate change and historical scenarios. The dominant factor that dictates the optimal intervention time is the rate of deterioration of the concrete deck, while the uncertainties on the financial variables play a secondary role. The discount rate (interest rate) and its uncertainty contribute to reduce in part the effect of premature deterioration associated with the climate change scenarios. For all scenarios, the optimal time for repairs corresponds mostly to decks that are in State D. This observation suggests that the initiation of spalling could be the signal to implement the first repair.

Table 4-3: Average NPV of 10,000 simulations for each scenario with no repair for each decision year.

\begin{tabular}{ccccccc}
\hline \hline NPVs & RCP8.5,50mm & RCP8.5,25mm & RCP4.5,50mm & RCP4.5,25mm & History,50mm & History,25mm \\
\hline \hline 3 & $\$ 20,279,609$ & $\$ 17,089,178$ & $\$ 20,305,845$ & $\$ 17,163,072$ & $\$ 22,083,822$ & $\$ 17,506,417$ \\
6 & $\$ 36,049,715$ & $\$ 32,557,707$ & $\$ 36,075,952$ & $\$ 32,676,268$ & $\$ 42,462,343$ & $\$ 33,179,933$ \\
9 & $\$ 50,567,362$ & $\$ 44,469,660$ & $\$ 50,599,509$ & $\$ 44,592,302$ & $\$ 60,210,998$ & $\$ 46,014,806$ \\
12 & $\$ 63,247,427$ & $\$ 51,911,830$ & $\$ 63,277,489$ & $\$ 52,223,635$ & $\$ 73,822,814$ & $\$ 55,192,988$ \\
15 & $\$ 73,389,438$ & $\$ 54,977,001$ & $\$ 73,451,602$ & $\$ 55,344,917$ & $\$ 86,222,491$ & $\$ 60,277,382$ \\
18 & $\$ 80,937,518$ & $\$ 54,748,588$ & $\$ 81,157,489$ & $\$ 55,203,208$ & $\$ 97,427,038$ & $\$ 62,155,572$ \\
21 & $\$ 85,941,728$ & $\$ 54,070,145$ & $\$ 86,294,392$ & $\$ 54,328,016$ & $\$ 106,881,167$ & $\$ 62,052,424$ \\
24 & $\$ 88,577,357$ & $\$ 52,772,831$ & $\$ 89,148,939$ & $\$ 52,953,048$ & $\$ 114,416,907$ & $\$ 61,119,504$ \\
27 & $\$ 89,460,841$ & $\$ 51,322,171$ & $\$ 90,367,542$ & $\$ 51,458,036$ & $\$ 120,140,083$ & $\$ 59,845,001$ \\
30 & $\$ 89,336,315$ & $\$ 49,845,543$ & $\$ 90,365,559$ & $\$ 49,962,266$ & $\$ 123,969,896$ & $\$ 58,485,944$ \\
33 & $\$ 88,696,688$ & $\$ 48,408,546$ & $\$ 89,818,444$ & $\$ 48,511,828$ & $\$ 126,051,633$ & $\$ 57,109,351$ \\
36 & $\$ 87,773,818$ & $\$ 47,025,014$ & $\$ 88,982,351$ & $\$ 47,117,936$ & $\$ 127,096,165$ & $\$ 55,768,291$ \\
39 & $\$ 86,744,428$ & $\$ 45,708,547$ & $\$ 88,014,460$ & $\$ 45,786,421$ & $\$ 126,970,897$ & $\$ 54,488,760$ \\
42 & $\$ 85,667,709$ & $\$ 44,455,587$ & $\$ 86,958,347$ & $\$ 44,534,674$ & $\$ 126,809,643$ & $\$ 53,257,121$ \\
45 & $\$ 84,600,952$ & $\$ 43,277,005$ & $\$ 85,909,512$ & $\$ 43,355,382$ & $\$ 126,189,629$ & $\$ 52,097,387$ \\
\hline \hline
\end{tabular}


Table 4-3 presents the average NPV from implementing major repairs as a function of time for each scenario. A general trend can be observed where NPV increases at a rapid rate at the beginning of the service life, and thereafter increases at a slower rate until it reaches its optimal value. After reaching its maximum, the NPV decreases at a slow rate. This result implies that, as expected, it is not optimal to conduct major repairs very early or late in the life of the bridge. However, even sub-optimal repair dates correspond to positive NPV, meaning the repairs are nonetheless a good investment. Another observation from this data is that the difference between the NPV for the historical and climate change scenarios increases with time. This suggests that climate change has the effect of bringing forward the optimal date for repairs and moreover accelerates the post-optimal date decrease in NPV. Therefore, if a bridge stays in a fairly good rating for a long period of time (historical scenarios), it generates greater benefits in the absence of repairs, unlike the case of a bridge that is deteriorating rapidly (predicted scenarios), and therefore is in greater need of repairs to generate benefits. It is important to keep in mind that the NPVs presented above are for a stylized problem, and should not be considered as applicable for all possible situations. Moreover, the benefits identified are for the bridge deck with a life span of 45 years. Future research could explore a more thorough analysis accounting for repair costs for other elements of the bridge.

Life-cycle costs include multiple other costs that are not currently accounted for in the model such as initial construction costs, cost of maintenance, repairs, replacements and disposal and could be used in future applications. Obsolescent or outdated assets, can be evaluated in this framework when costs associated with the service life or the services provided by the structure cannot meet expected performance levels. 


\subsection{Conclusions}

Improving the sustainability and serviceability of infrastructures in the most economical way are important objectives for decision-makers given the current state of uncertainty with climate change and the general state of the infrastructure. This study applies a risk-based decision-making model for optimizing the time for the first major intervention of a structure. The method is demonstrated for reinforced concrete bridge decks in Montreal. Features of the procedure are the modelling of both the physical and financial variables that affect the costs and benefits associated with infrastructures and allowing for some flexibility for managers in the timing of their funding decision to account for a context of high uncertainty for both physical and financial processes. The method is demonstrated for reinforced concrete bridge decks in Montreal, for which detailed data are available, for current structures using historical climate data and for new bridges using data for two climate change scenarios.

The results show that the model can accurately predict the distribution of the service life for current concrete decks given the historical climate. The results also indicate that under climate change scenarios, the service life of new structures designed using current procedures and subjected to current policies for the use of de-icing salts would be significantly reduced. The reduction in the service life is mainly due to an increase in the number days with precipitation during the winter despite an increase in average temperatures. The decision analysis model indicates that the optimal replacement time for current concrete decks is between 27 and 36 years after the start of their service, while it would be significantly reduced under climate change scenarios.

The optimal decision for the replacement of the concrete indicates that it is generally close to the end of the service life of the deck. However, the rate in the change of the NPV is quite slow when 
we are close to the optimal repair date, indicating that there is flexibility in either carrying out or delaying a replacement. The probability distribution in optimal dates reflects both the uncertainties in the physical process of deterioration as well as in the financial variables.

\subsection{Acknowledgments}

The authors acknowledge the financial support by NSERC, FONCER, CRIB, FRQSC and SSHRC.

\section{References}

Bar-Ilan, A., \& Strange, W. C. (1996). Investment lags. The American Economic Review, 86(3), $610-622$.

Bastidas-Arteaga, E., Chateauneuf, A., Sánchez-Silva, M., Bressolette, P., \& Schoefs, F. (2011). A comprehensive probabilistic model of chloride ingress in unsaturated concrete. Engineering Structures, 33(3), 720-730.

Bastidas-Arteaga, E., \& Stewart, M. G. (2013). Probabilistic cost-benefit analysis of climate change adaptation strategies for new RC structures exposed to chloride ingress. Paper presented at the 11th International Conference on Structural Safety \& Reliability.

Bastien, J., Fortin, J.S., Power, G.J., Tandja M., C. (2017). Optimal timing of bridge deck repairs. Working paper. Université Laval.

Bazant, Z. P. (1979). Physical model for steel corrosion in concrete sea structures--theory. Journal of the Structural Division, 105(ASCE 14651 Proceeding). 
Breysse, D., Chaplain, M., Marache, A., \& Rodney, E. (2014). Simulation of synthetic climate at local scale as a mean to assess the impact of climate change on infrastructures. Civil Engineering and Environmental Systems, 31(2), 165-178.

Chan, K. C., Karolyi, G. A., Longstaff, F. A., \& Sanders, A. B. (1992). An empirical comparison of alternative models of the short-term interest rate. The journal of finance, 47(3), 12091227.

Chang, T., Ranjbar, O., \& Tang, D. (2013). Revisiting the mean reversion of inflation rates for 22 OECD countries. Economic Modelling, 30, 245-252.

Charron, I. (2016). A Guidebook on Climate Scenarios: Using Climate Information to Guide Adaptation Research and Decisions, 2016 Edition. Retrieved from

Conciatori, D., Brühwiler, E., \& Morgenthaler, S. (2009). Calculation of reinforced concrete corrosion initiation probabilities using the Rosenblueth method. International Journal of Reliability and Safety, 3(4), 345-362.

De Larrard, T., Bastidas-Arteaga, E., Duprat, F., \& Schoefs, F. (2014). Effects of climate variations and global warming on the durability of RC structures subjected to carbonation. Civil Engineering and Environmental Systems, 31(2), 153-164.

Dixit, A. K., \& Pindyck, R. S. (1994). Investment under uncertainty: Princeton university press.

Duracrete. (2000). Probabilistic calculations. DuraCrete-probabilistic performance based durability design of concrete structures. EU-brite EuRam III. Contract BRPR-CT95-0132. Project BE95-1347/R12-13. Retrieved from

Herrmann, A. W. (2013). ASCE 2013 Report Card for America's Infrastructure. Paper presented at the IABSE Symposium Report. 
IPCC. (2007). Climate Change 2007: Synthesis Report. Contribution of Working Groups I, II and III to the Fourth Assessment Report of the Intergovernmental Panel on Climate Change [Core Writing Team, Pachauri, R.K and Reisinger, A. (eds.)] (1462-9011). Retrieved from Geneva, Switzerland:

Leyden, K., Healy, D., Douthwaite, R., Lumley, I., Gibbons, M., Murray, A., . . Johnston, P. (2007). Sustainable Development Evaluation of Road Infrastructure Programmes and Projects. A sustainability assessment process for road-building and other development in Ireland.

Lounis, Z., \& Daigle, L. (2008). Reliability-based decision support tool for life cycle design and management of highway bridge decks. Paper presented at the Annual Conference of the Transportation Association of Canada.

Lounis, Z., \& McAllister, T. P. (2016). Risk-based decision making for sustainable and resilient infrastructure systems. Journal of Structural Engineering, 142(9), F4016005.

McDonald, R., \& Siegel, D. (1986). The value of waiting to invest. The Quarterly Journal of Economics, 101(4), 707-727.

Myers, S. C. (1977). Determinants of corporate borrowing. Journal of financial economics, 5(2), $147-175$.

OECD. (2013). Spending on transport infrastructure 1995-2011: trends, policies, data. Paper presented at the International Transport Forum, Paris.

Ottesen, F. (2011). Infrastructure Needs and Pension Investments. OECD Journal: Financial Market Trends, 2011(1), 97-109. 
Panayi, S., \& Trigeorgis, L. (1998). Multi-stage real options: The cases of information technology infrastructure and international bank expansion. The Quarterly Review of Economics and Finance, 38(3), 675-692.

Power, G. J., Tandja M, C. D., Bastien, J., \& Grégoire, P. (2015). Measuring infrastructure investment option value. The Journal of Risk Finance, 16(1), 49-72.

Saetta, A. V., Scotta, R. V., \& Vitaliani, R. V. (1993). Analysis of chloride diffusion into partially saturated concrete. Materials Journal, 90(5), 441-451.

Šliupas, T. (2006). Annual average daily traffic forecasting using different techniques. Transport, 2l(1), 38-43.

Stewart, M. G., \& Rosowsky, D. V. (1998). Time-dependent reliability of deteriorating reinforced concrete bridge decks. Structural safety, 20(1), 91-109.

Talukdar, S., Banthia, N., Grace, J., \& Cohen, S. (2012). Carbonation in concrete infrastructure in the context of global climate change: Part 2-Canadian urban simulations. Cement and Concrete Composites, 34(8), 931-935.

Vu, K. A. T., \& Stewart, M. G. (2000). Structural reliability of concrete bridges including improved chloride-induced corrosion models. Structural safety, 22(4), 313-333.

Wolofsky, R. (2011). Corrosion Initiation of Concrete Bridge Elements Exposed to De-icing Salts: McGill University (Canada). 


\section{Preface to Chapter 5}

The previous chapter introduces a single framework combining a rich description of both the physical and economic variables and their stochastic evolution over time, which also allows different climate change scenarios to better capture the true long run uncertainty facing decisionmakers in infrastructure. The model was illustrated for the case of the first intervention on a bridge. Therefore, there are interesting possible extensions of the model to pay closer attention to the cycle of renewals, such as the optimization problem of multiple preventive maintenances and major repairs during the lifetime of the bridge, and moreover better understanding the link between minor and major repairs. In Chapter 5, the Meta-heuristic algorithms in conjunction with the deterioration model are then used to optimize the DM for RC bridge decks in Montreal. Based on the Pareto optimal solutions, a decision-maker can acquire a wealth of pertinent information from a sequence of M\&R strategies through the consideration of all specified policies and constraints. 


\title{
Chapter 5. Multi-objective optimization for maintenance strategies of infrastructure projects under the influence of climate change
}

\begin{abstract}
Infrastructure asset management is an important research area concerned with efficient and sustainable utilization and maintenance of infrastructure. Considering the numerous sources of uncertainties associated with the performance of structures and economics over their life cycle, a risk-informed decision-making process is proposed to identify the most effective strategies to satisfy performance requirements at minimal cost. The decision problem is formulated as a multiobjective optimization problem for targeted performance levels and total costs and solved using both Multi-Objective Particle Swarm Optimization (MOPSO) and a Non-dominated sorting genetic algorithm II (NSGA-II). Solutions are presented in the form of a Pareto front, which corresponds to a set of optimal solutions satisfying both objectives at varying degrees. The presentation of optimal solutions as a Pareto Front defines a spectrum of solutions that provides flexibility as a function of the priorities of the decision-maker. The primary goal of this study is to determine the type and optimal sequence of maintenance/repair/replacement activities over the service life of a structure and moreover, have a better understanding of the effectiveness and interaction between minor and major repairs. The results indicate that annual budget constraints have a significant effect on the Pareto front and the schedule associated to individual solutions. The findings also show that under climate change scenarios, the service life of infrastructure facilities that are designed according to current practices could be greatly reduced without proper adjustments.
\end{abstract}


Keywords: decision-making; infrastructure; deterioration; climate change; Multi-objective optimization.

\subsection{Introduction and Background}

Infrastructure assets, such as bridges, roads, pipelines, etc., provide essential services to society as well as a support for economic activities. Infrastructure asset management is an important area of research to promote an efficient use of these resources and their long-term sustainability. This objective is getting more challenging since an increasingly large proportion of infrastructure assets are in need of repair and replacement (Chen and Bai 2019). The sheer magnitude of this task requires state-of-the-art procedures to schedule appropriate activities both in time and in space. In this article, procedures are proposed to optimize repair and replacement strategies for reinforced concrete bridges in northern climates where the main contributor to deterioration is the application

of de-icing salts and the ingress of chloride ions into the concrete (Bastidas-Arteaga et al. 2011; Breysse et al. 2014; Saetta et al. 1993). For long term planning, consideration should also be given to potential climate change effects that may affect the rate of deterioration. Such effects include increasing average air temperature, winter precipitation frequency and amount, number of freezethaw cycles, and relative humidity levels (Zhang, Chouinard, Power, Tandja M, et al. 2018; Palko and Lemmen 2017). In planning and optimizing activities, consideration should be given to economic factors as well to societal impacts such as level of safety, noise, environmental impacts and traffic delays (Menon et al. 2009). Maintenance scheduling and budgeting can affect users and the economy for periods of time that extend beyond the lifecycle of individual infrastructure 
components. Therefore, an optimized infrastructure management strategy is essential for sustainability and efficiency purposes (Marlow et al. 2010; Santos et al. 2017).

\subsubsection{Optimization procedures with conflicting objectives}

Decision-making is an essential part of infrastructure asset management. This involves selecting intervention strategies for multiple projects by specifying maintenance/repair/replacement tasks and timing of activities that minimize costs and increase infrastructure performance. It is not an easy task since a number of constraints must be considered, such as limited resources and multiple goals, in a context of uncertainty. With the recent development of machine learning algorithms, more reliable optimization techniques can be efficiently applied for such problems (Ng et al. 2011). Generally, optimization techniques can be classified as single-objective optimization (SOO) and multi-objective optimization (MOO) techniques (Hillier 2012). SOO targets the minimization (maximization) of one objective with multiple constraints, whereas MOO uses trade-offs between multiple objectives to find optimal solutions. One common use of SOO is to minimize the cost of management interventions while satisfying the required service level (Zhang et al. 2017). Although SOO can present a variety of solutions by altering the constraints, a large amount of computation time is required for each solution. MOO is preferable since it is possible to compare a set of optional solutions that are feasible and obtained under various conditions. Moreover, MOO techniques usually do not provide unique solutions and provide instead a set of multiple Pareto solutions (non-dominated solutions) or Pareto front satisfying all constraints (Horn et al. 1994). Policy-makers can select solutions along the Pareto front according to their objectives or priorities (Chen and Bai 2019). 
In many instances, multiple objective functions may be incompatible, which increases the difficulty of solving the MOO problem. For instance, a large expense for maintenance and repair reduces the deficiencies of the structure, thereby improving the level of service. Thus, the two objective functions of (maximizing) service and (reducing) cost for interventions are two objective functions that are contradictory to each other. Assigning weights to different objectives in terms of their priorities enables the creation of a single composite objective function. This approach is usually called scalar optimization and is one of the most effective methods to minimize contradictory objectives (Bhatti 2012). Recently, Shim and Lee (2017) proposed a framework for a multi-objective problem of bridge deck interventions using transportation data obtained from the Wyoming Department of Transportation. Their model has two objective functions: (1) minimization of the structurally deficient deck area and (2) minimization of the budget of maintenances and repairs. However, it has limited application since the definition of weights is arbitrary and specific to their case. Santos et al. (2018) developed a tri-objective optimization framework for pavements that includes a comprehensive assessment of life-cycle costs from the production and transportation of materials, construction, maintenance, traffic management of the work-zone during construction and maintenance and usage up to end-of-life. The objective functions are: (1) Minimization of the present value of the total life cycle road costs; (2) Maximization of the pavement performance during the project analysis period; and (3) minimization of the life cycle environmental liabilities arising from all pavement life cycle stages. 
A Pareto Solution Set (PSS) provides information on the relations between objectives, objective values and trade-offs between objectives thereby leading to better-informed decisions (Chen et al. 2015; Rifai et al. 2016; Santos et al. 2019; Chen and Bai 2019). The concept of Pareto optimality is illustrated in Figure 5-1 in the case of two objectives $f_{1}$ and $f_{2}$. The region of feasibility represents all feasible solutions for the set of objective functions. Feasible solutions respect the constraints on the system; however, optimal solutions based on minimization of the objectives are located on the outer lower left edge of the feasible region.

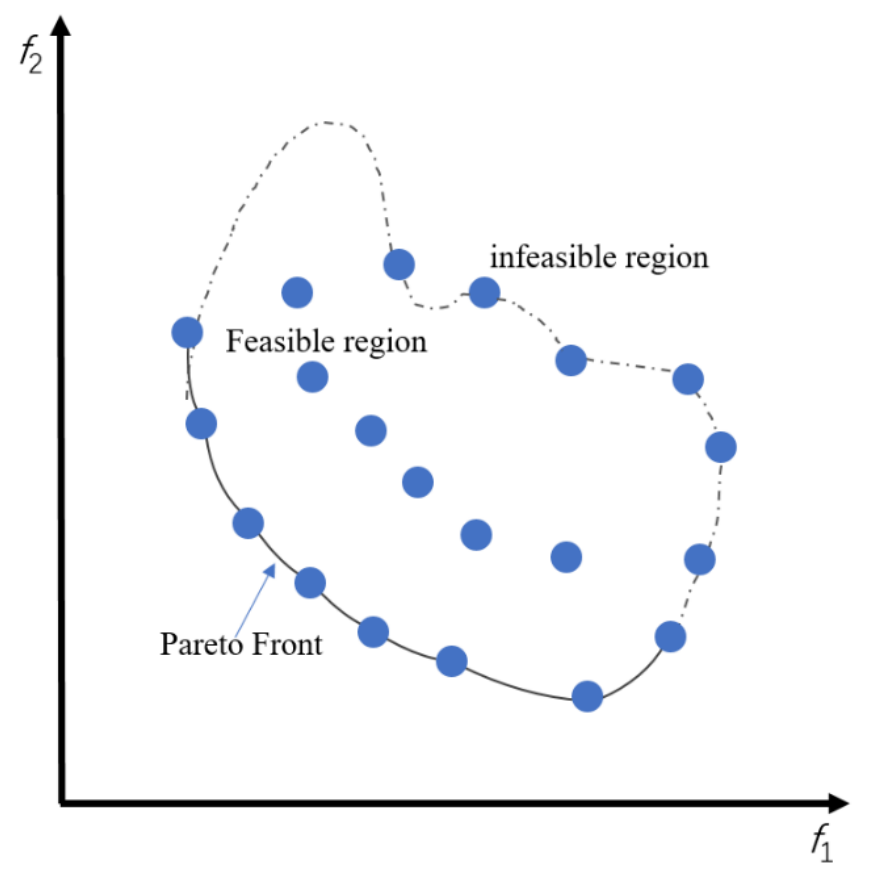

Figure 5-1 The concept of Pareto front.

In multi-objective optimization, sorting the Pareto front can be used to measure the suitability of a solution in a specific iteration. By means of this sorting, the set of non-dominated solutions that define the Pareto front is identified and it is assigned a rank of one. These solutions are then separated, and the solutions that remain are compared in order to identify a new set of non- 
dominated solutions with a rank of two. This procedure is continued until there is a ranking of the whole population (Elhadidy et al. 2015), as shown in Figure 5-2.

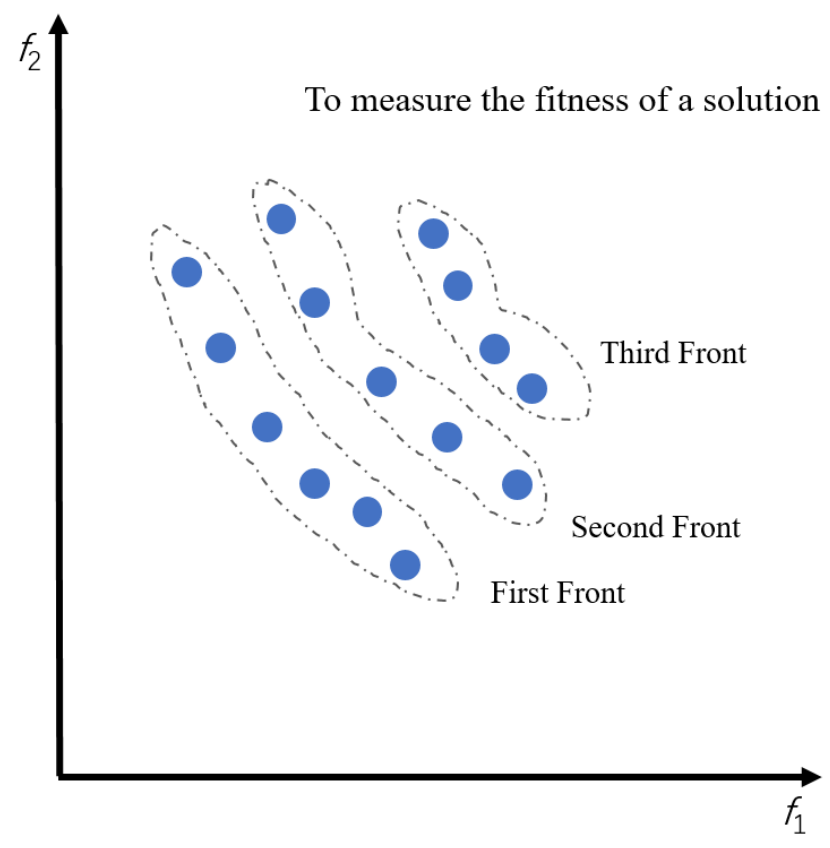

Figure 5-2 Pareto front Sorting.

\subsubsection{Optimization procedures classified by solution approach}

Optimization methods can also be classified in terms of the algorithm type used to solve the problem. Solution methods can be categorized as heuristic, deterministic and other. Silver et al. (1980) describe heuristics as an intuitive approach in which intelligent interpretation of the objectives to obtain a reasonable solution is the optimization solution. On the other hand, Moteleb (2010) describes deterministic methods as those where optimal solutions are obtained based on corollaries and mathematical theorems. Other than these two basic methods, hybrid methods have also been proposed. Wu et al. (2008) proposed a hybrid model for the optimization of pavement 
preservation strategies on the basis of an analytic hierarchy process for priority setting under multiple principles, and goal programming for achieving multiple objectives. The model aims to maximize the service life of the pavement while minimizing the total preservation cost.

Note that other types of solution-method classification also exist in the literature (e.g., for nonlinear global optimization (Bierlaire et al. 2010), for combinatorial optimization (Blum and Roli 2003). In addition, some solution approaches are sometimes combined with filtering techniques for reducing the solution space without losing any optimality (Hertz et al. 2005).

Priority-based methods are some of the most common deterministic methods which specify the management outcomes by defining the decision criteria of management. Rules are defined according to perceived or stated priorities either before or during the optimization process (Lin et al. 2012). Numerical solution techniques are common in solving deterministic objectives. Examples of these techniques are dual, dynamic, linear, branch and bound programming. Such methods usually follow strict standards and algorithms, which lead to a limited scope of application. These methods are commonly used in large-sized decision-making problems with simple outcome relationships (Anastasopoulos et al. 2013; Chen and Bai 2019; Kale et al.).

One of the most popular choices for MOO is genetic algorithms (GA). Here, possible outcomes, such as sequences of management interventions and strategies, are modeled as genes undergoing crossover and mutation in order to create the solutions (Schmitt 2001). GA methods are easy to control and flexible for solving complex decision-making problems (Belevičius et al. 2013; Morcous and Lounis 2005; Elhadidy et al. 2015; Hadiwardoyo et al. 2017). GA as a global search and optimization approach has a broad range of applications and provides accurate solutions and high efficiency. GA also has been applied in bridge rehabilitation and pavement management systems (Elhadidy et al. 2015; Santos et al. 2018). Farran and Zayed (2012) use GA along with 
Markov Chains to determine the profile of optimal rehabilitation sequences of the Metro system of Montreal. Pavement maintenance strategies for road networks in Indonesia have been investigated through a GA structure to optimize the road services while minimizing costs (Hadiwardoyo et al. 2017).

Particle Swarm Optimization (PSO) is a powerful stochastic optimization technique developed by Eberhart and Kennedy (1995). PSO mimics numerically the social behavior of animals, like fish in schools and birds in flocks. The initial population of solutions consists of random individuals or particles "flying" in the search space to find the optimal solution. Each particle is characterized by its location and velocity. The number of parameters to specify for the optimization is small and their effect on the optimal solutions is not very significant in comparison with other techniques of optimization (Poli et al. 2007). PSO has been used to optimize building maintenance strategies based on cost (AL-Smadi 2019), for forest road vertical alignment optimization (Babapour et al. 2018), and to assess the cost-effectiveness of trade-offs in flexible pavement maintenance strategies (Chou and Le 2011).

Multi-Objective PSO (MOPSO) is a growing field to solve MOO problems, with applications in electrical engineering, industrial engineering and civil engineering (Lalwani et al. 2013). MOPSO techniques have been used by (Chou and Le 2011) to assess the cost-effectiveness of trade-offs in a flexible strategy of pavement maintenance. AL-Smadi (2019) applies the MOPSO algorithm to find the optimal treatment action among eight maintenance actions for the EV building of Concordia University.

Recently, the prediction of service life for infrastructure has been performed by using probabilistic concepts and approaches for single objective optimization. This is due to the inherent random and uncertain nature of deterioration processes from initiation to propagation. A generalized 
probabilistic framework was proposed by (Kim et al. 2013) for planning optimal inspection and maintenance activities for deteriorating structures. More recently, Zhang, Chouinard, Power, Tandja, et al. (2018) presented a novel framework that optimizes the date for the first major replacement of a concrete deck with a model that considers time-dependent deterioration processes as well as financial uncertainties.

\subsubsection{Common decision-making maintenance, repair and replacement strategies}

Maintenance, repair and replacement strategies can be formulated as an optimization problem under constraints. Sarma and Adeli (1998) and Frangopol (2011) review research on the cost optimization of concrete structures and argue that life-cycle cost optimization should replace initial cost optimization. Zhang and Wang (2017) develop a decision model for determining a prioritized maintenance schedule for a deteriorated bridge network. It uses network analysis methods and meta-heuristic optimization algorithms to integrate the rating of bridge capacity and condition, traffic impacts as well as the location parameters into one global objective function that defines the whole maintenance cost and network reliability. Maintenance actions must be effectively planned throughout the life cycle of infrastructures to optimize budget allocation under the constraints of functionality and safety (Frangopol and Soliman 2016). A proper maintenance plan can reduce the degree of damage and provide the required level of service of a deteriorating structure.

Several methodologies have been proposed to model the deterioration of infrastructure and to assess underlying risks. Among them, Markov chain models have been widely used to predict the 
evolution of the state of a large group of deteriorating structures and to select optimum $M \& R$ strategies (Jiang and Sinha 1989; Cesare et al. 1992; Thomas and Sobanjo 2016). The parameters (transition probabilities) for these models are derived primarily from statistics computed from databases of past inspection and condition assessment reports. Transition probabilities have also been derived from physical simulation models that have been correlated to defined performance levels (O'Connor et al. 2011; Zhang, Chouinard, and Conciatori 2018). However, it is a difficult task to predict the remaining service life of a structure due to uncertainties on initial conditions, time to initiation of corrosion and propagation of deterioration (Frangopol 2011). Visual inspections remain the primary source of information for evaluating and monitoring the condition of typical bridge structures. An accurate prediction model can be used in conjunction with visual inspections to improve the assessment of the infrastructure present and future state.

\subsubsection{Motivation}

The main objective of this paper is to develop a general and simplified framework to determine optimal Maintenance and Rehabilitation (M\&R) interventions that maximize benefits and minimize probabilities of disruptions during a given period of analysis for a single structure. The expected cost of $M \& R$ strategies for the bridge should take into account economic considerations, timing of implementation, as well as serviceability and sustainability. M\&R activities should be planned and scheduled in order to minimize disruptions of operations in the transportation network. The corresponding set of Pareto optimal solutions can be used by the decision-maker to better understand the relationships between the multiple objectives and trade-offs involved for optimal solutions. 
This study attempts to develop a system of decision support that is able to provide numerous alternative plans of maintenance through the application of MOO. The optimization procedures are then demonstrated for typical bridges located in Montreal, Canada. The results are demonstrated for a sequence of M\&R strategies for the concrete deck. Historic climate data is used to evaluate the current condition of existing bridges, while climate change scenarios are used to predict the residual life of both existing bridges and newly constructed bridges.

\subsection{TransChlor ${ }^{\circledR}$ model}

Corrosion is the key mode of deterioration of reinforced concrete (RC) structures in Northern climates, and this is related to the use of de-icing salts. Deterioration is affected by geometrical properties (thickness of concrete cover, cross-sectional dimensions), material characteristics (diffusion coefficients), climate (humidity, temperature, and winter precipitation), and exposure conditions (splash, mist or direct) (Angst 2018; Cao et al. 2019; Zhang, Chouinard, Power, Tandja M, et al. 2018). Fick's second diffusion law has often been used to derive profiles of chloride ions concentration in concrete (Nilsson et al. 1996), (Hunkeler 2005). The critical chloride content ( $\left.\mathrm{C}_{\text {crit }}\right)$ is a material property and is defined as the level above which the corrosion of the reinforcement is initiated. $\mathrm{C}_{\text {crit }}$ is highly variable and is affected by the binder type, w/c ratio, steel surface condition (Angst 2011).

In this application, the TransChlor $^{\circledR}$ software is used to simulate the transport of chloride ions in the concrete. The framework and the main steps of the TransChlor ${ }^{\circledR}$ are illustrated in Figure 5-3. Historical hourly climate data (or climate change scenarios) are used to simulate the exposure of the structures to de-icing salts in the winter. The transport model uses the finite element method 
and a finite difference method to simulate the evolution of chloride ions profile respectively in space and time. The program also incorporates probabilistic analyses to estimate the distribution of the chloride ions content as a function of time and depth to account for uncertainties on concrete and steel properties. A more detailed description of the model is provided in (Conciatori et al. 2018).

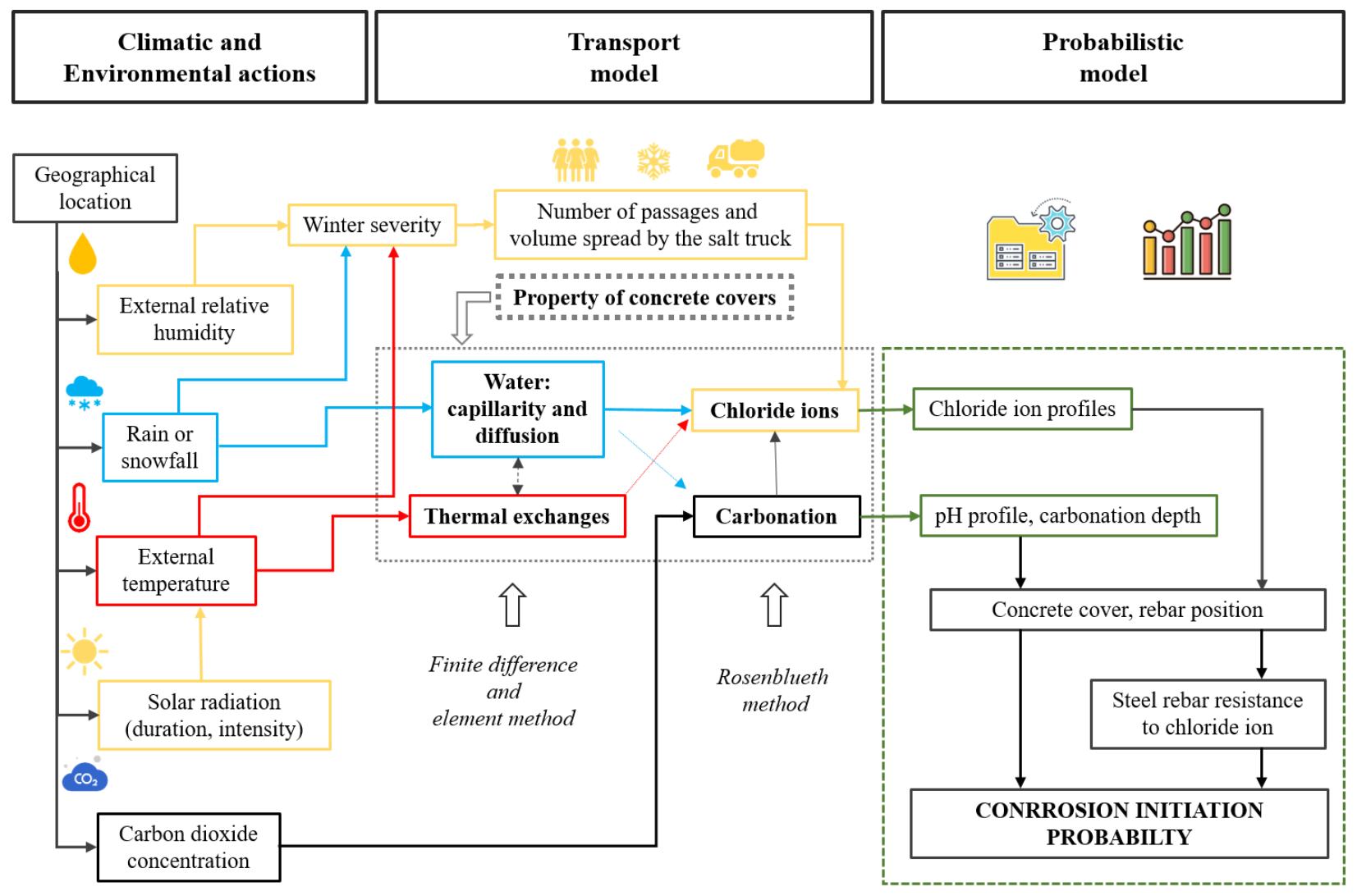

Figure 5-3 Flowchart of computations in TransChlor ${ }^{\circledR}$. 


\subsection{Test case for Montreal, Canada}

The bridge for the case study was built in 1959, it has four traffic lanes and consists of a portico with two symmetrical spans (each free span is $11.4 \mathrm{~m}$ in length). The thickness of the deck is $1 \mathrm{~m}$ at the supports and $0.60 \mathrm{~m}$ at the centre. Field investigations of the bridge include a visual inspection and Torrent ${ }^{\circledR}$ permeability and resistivity tests performed at several locations on the underside of the slab and the wing walls (Figure 5-4). Locations 1 to 4 are located underneath the slab, while locations 5 to 7 are located on the wing wall. The Torrent ${ }^{\circledR}$ method was used to determine the air permeability $k_{T}$ of the concrete (Torrent 1992). Table 5-1 provides the correspondence between the subjective descriptions of the concrete quality as a function of $k_{T}$ for non-saturated mature concrete. When the concrete is wet or partially saturated, an electric resistivity $(\rho)$ test is also performed to correct measurements since these are reduced in the presence of water (Torrent and Frenzer 1995; Adámek and Juránková 2010). Both parameters $\left(k_{T}, \rho\right)$ are combined to determine the quality of the concrete from a chart (Figure 5-5). The results of the tests indicate that the overall permeability of the concrete for the bridge is high or that the concrete is of poor quality. The transport of substances in concrete directly depends on the material permeability (Conciatori et al. 2010). By testing the permeability, we are able to determine the transport parameters of TransChlor ${ }^{\circledR}$ Model, so as to simulate the chloride profile as accurately as possible. 


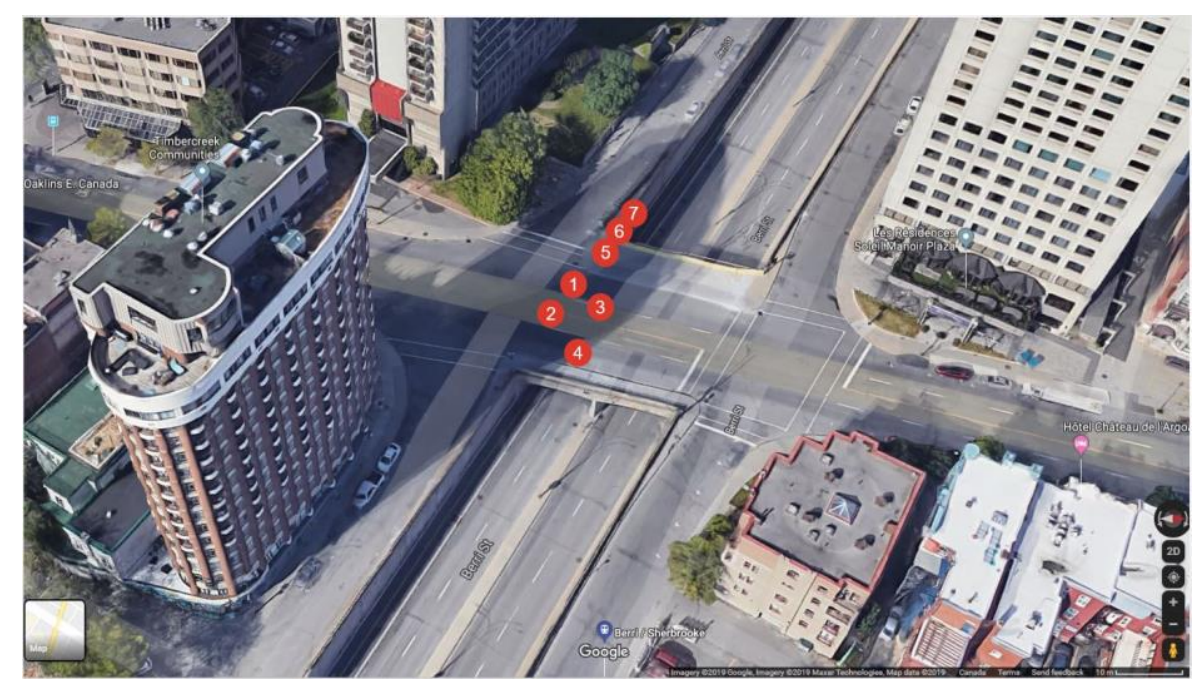

Figure 5-4 Locations of field tests performed on the bridge

Table 5-1: Quality Classes of Cover Concrete for non-saturated concrete (Proceq 2005).

Quality of cover concrete $\quad$ Index $\quad k T\left(10^{-16} \mathrm{~m}^{2}\right)$

\begin{tabular}{ccc}
\hline Very bad & 5 & $>10$ \\
bad & 4 & $1.0-10$ \\
normal & 3 & $0.1-1.0$ \\
good & 2 & $0.01-0.1$ \\
Very good & 1 & $<0.01$ \\
\hline
\end{tabular}




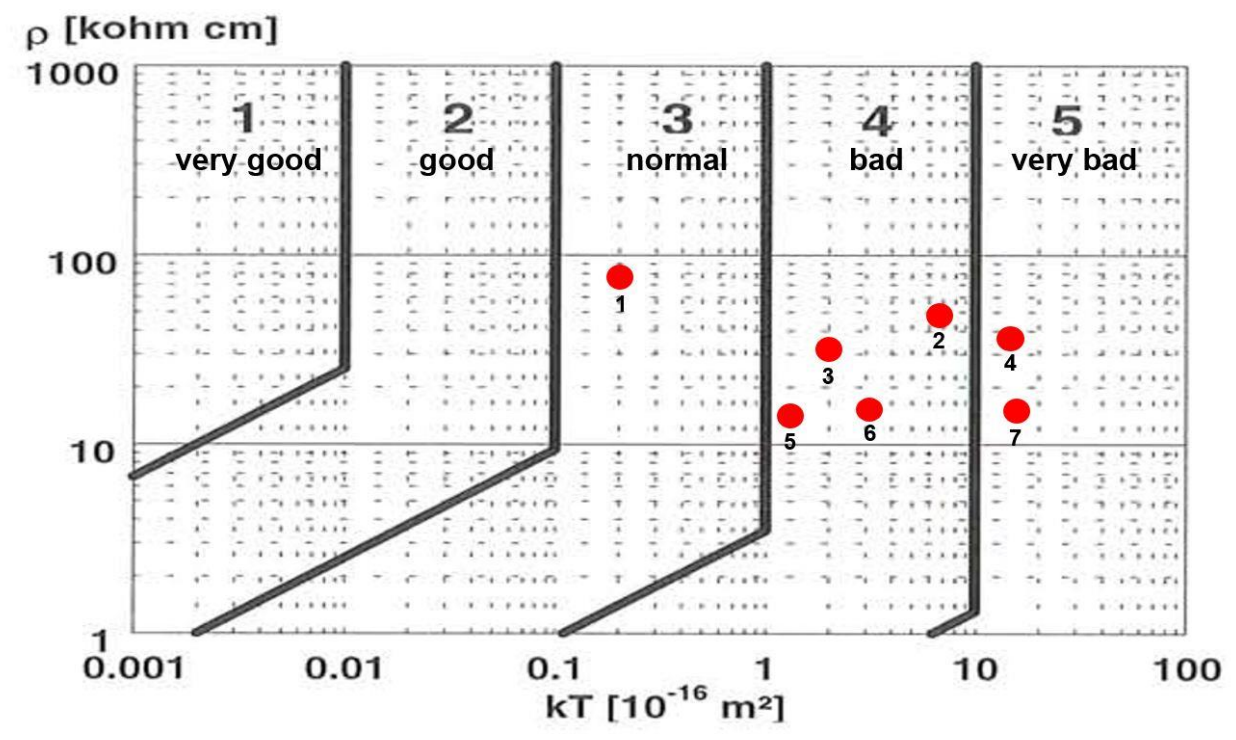

Figure 5-5 Nomogram for determining the quality classes of concrete as a function of air permeability and resistivity (test results are shown as red dots) (Proceq 2005).

\subsection{Optimization model for maintenance and repairs}

\subsubsection{Optimization methodologies}

The process of optimization for bridge maintenance and repairs requires the inclusion of a deterioration model. The computational effectiveness of the proposed technique for optimizing the sequence and timing of maintenance and repairs activities is implemented by the effective heuristic algorithm, MOPSO. A multi-objective Genetic Algorithm (MOGA) was also used for bi-objective optimization for the purposes of validation and comparison. The proposed technique provides schedules of bridge maintenance that account for two objectives of conflicting objectives, minimization the cost of $M \& R$ interventions and minimization of disruptions to users. 
PSO has been used as an effective algorithm of optimization in a wide range of applications (Parsopoulos and Vrahatis 2002). PSO is a technique based on the evolution of an initial population of solutions, and in some respects is similar to algorithms that are evolutionary (e.g. EA), apart from the fact that, as opposed to evolving, each possible solution (particle) are characterized by its location and velocity in the search space.

This technique is initialized with a set of randomly generated particles and the optima is sought based on the update of the particle position at each iteration. Two optimum values are used to update the position of each particle: the Global Best (gbest) and the Personal Best (pbest) solutions. Pbest corresponds to the optimal value reached at a given iteration by a given particle, while gbest is the optimized solution achieved by the swarm at the current iteration, which leads other particles to its location. The particles flight in the solution is defined as follows:

$$
\begin{aligned}
& V_{T}^{S}(i+1)=w V_{T}^{S}(i)+c_{1} r_{1}\left(\text { pbest }_{T}^{S}(i)-X_{T}^{S}(i)\right)+c_{2} r_{2}\left(\text { gbest }-X_{T}^{S}(i)\right) \\
& X_{T}^{S}(i+1)=X_{T}^{S}(i)+V_{T}^{S}(i+1)
\end{aligned}
$$

where $V_{T}^{S}$ is the velocity of the particle $T$ with $S$ dimension, $i$ is the iteration; $w$ is the inertia weight of particle movement, which is used to regulate the impact of the prior velocity on the current velocity. Large values of $w$ maintain previous particle velocities and increases the velocity, which minimizes the possibility of confinement to a local optimum. Conversely, small values of $w$ reduce the velocity of particles and promotes a local search in the solution space; $c_{l}$ is the cognitive acceleration coefficient, $c_{2}$ is the social acceleration coefficient; both $r_{1}$ and $r_{2}$ are independent uniformly distributed random variables between 0 and $1 ; \operatorname{pbest}_{T}^{S}(i)$ is the best solution achieved by the $T^{\text {th }}$ particle at the $i^{\text {th }}$ iteration, gbest is the optimal solution achieved by the swarm at the $i^{\text {th }}$ iteration, $X_{T}^{S}(i)$ is the current position of $T^{\text {th }}$ particle in iteration $i$ and $V_{T}^{S}(i+1)$ is the velocity of 
the $T^{\text {th }}$ particle at iteration $i+1$ (Lalwani et al. 2013). The equations, parameters, velocity and position updates of the MOPSO are similar to those of PSO, except for the objective functions. The steps of MOPSO can be summarised as follow: (1) Randomly define the location of each particle in the solution space between the specified minimum and maximum values, (2) Randomly define the initial velocity of each particle within the specified minimum and maximum values, (3) Update the velocity of each particle using Equation 1, (4) Update the best solution (pbest) for each particle, (5) Add all non-dominated solutions into the current archive; (6) Delete the dominated archived solution, (7) Update the overall best solution (gbest), which is chosen from the archived member that dominates the fewest feasible solutions in the current iteration. The flowchart of MOPSO algorithm is shown in Figure 5-6: 


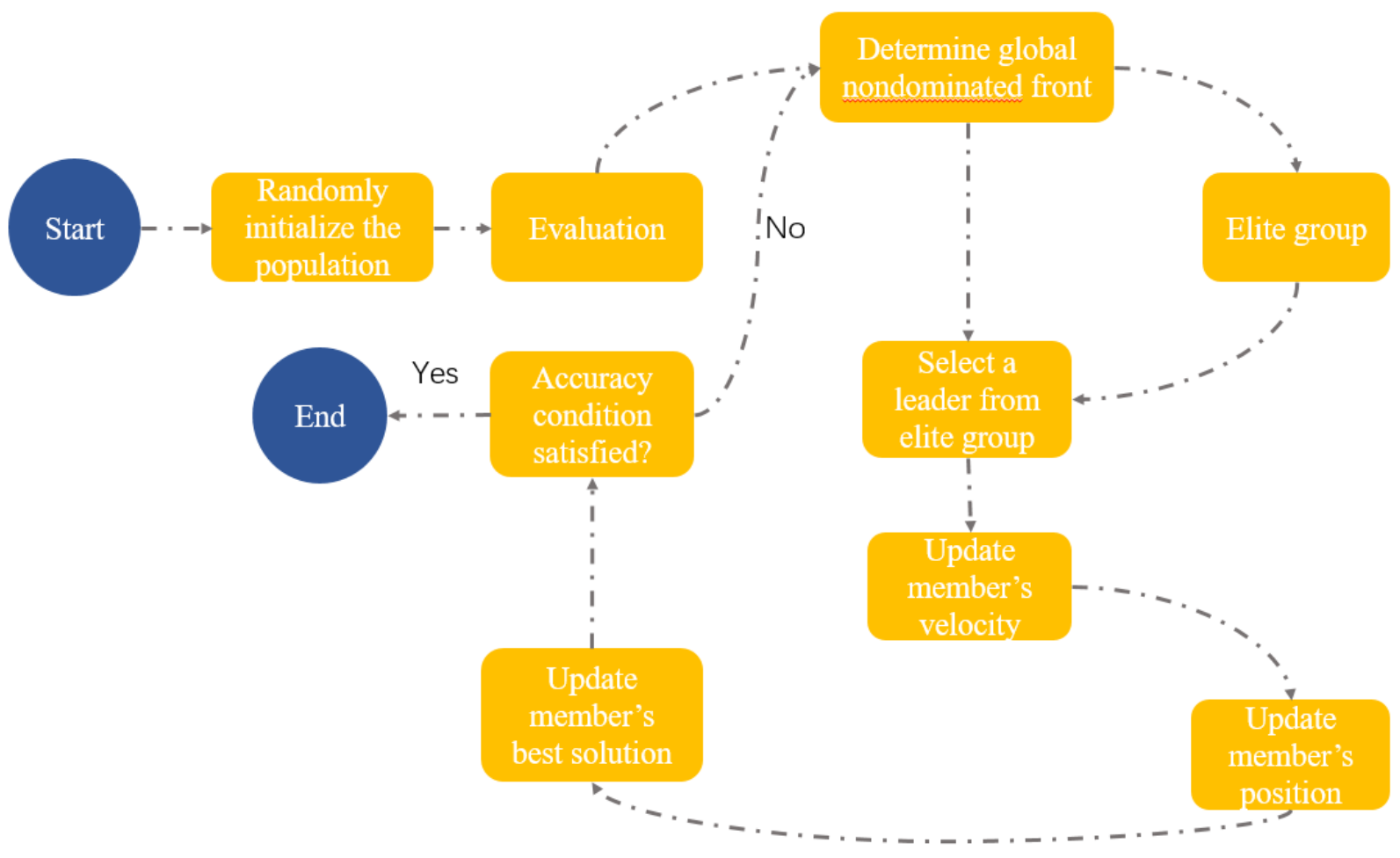

Figure 5-6 MOPSO algorithm.

Genetic algorithms (GA) are classified as stochastic search tools and emulate natural selection mechanisms, which usually are simple but robust and powerful processes (Goldberg and Holland 1988). They start with a random initial population of solutions that are defined as "chromosomes", where each chromosome is comprised of a sequence of units that form "genes" that encrypt specific components of a solution. In the optimization or search process, chromosomes advance over consecutive iterations or "generations", unless the problem congregates with chromosomes that reflect the approximate or optimal solution to the problem (Gen and Cheng 2000). The reproduction operations are primarily crossovers and mutations. Crossover combines genes from the chromosomes of two predecessors and produces an offspring from each pair of parents (Figure 5-7(a)), while mutations generate offspring by introducing a variation in individual chromosome 
of a predecessor (Figure 5-7(b)).

Predecessor A

Chromosome

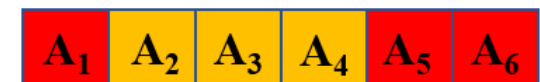

Predecessor B

Chromosome

Random Gene Exchange

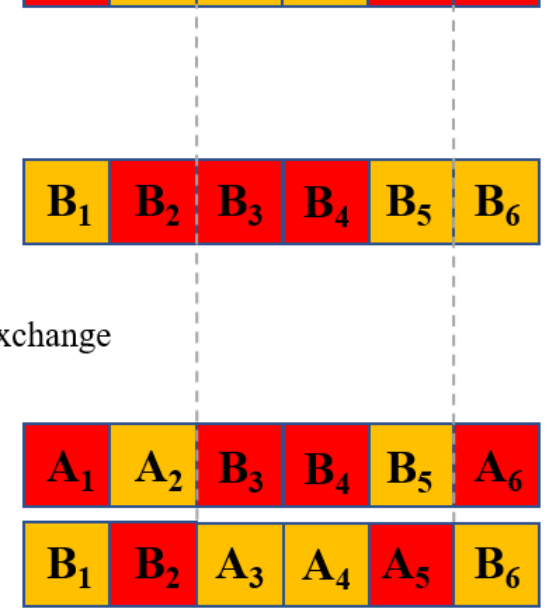

Predecessor X

Chromosome

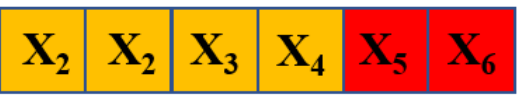

Offspring 1

Chromosome

Offspring 2

Chromosome

Offspring

Chromosome

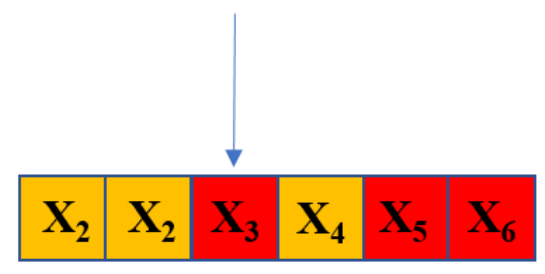

(a)

(b)

Figure 5-7 Reproduction operation: (a) crossover and (b) mutation operations.

In this study, NSGA-II, one of the most effective heuristic methods in MOGA's family (Deb et al. 2002), was used. The differences between simple GA and NSGA-II lie in GA's process of 'selection'. For each generation in NSGA-II, the parent and offspring populations are combined to create a new population. The evaluation of dominance ranking is subsequently conducted for the combined population set. In the evaluation of dominance ranking, the number of alternative solutions that are dominant over that solution is determined for each solution of the new population; the solutions are then ranked in accordance with the amount of solutions that are dominant over them. Basic steps of the NSGA-II algorithm are shown in Figure 5-8. 


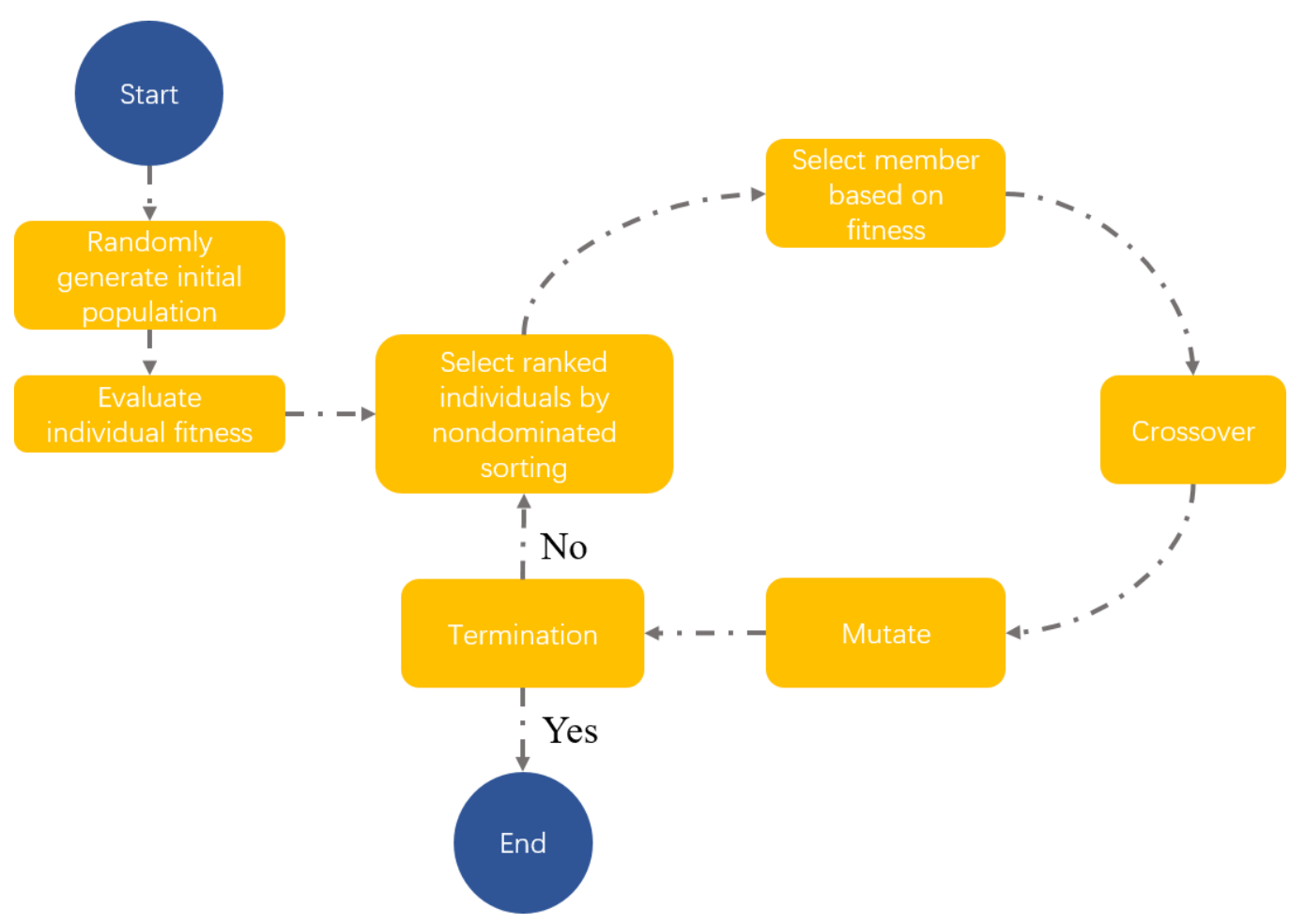

Figure 5-8 NSGA-II algorithm.

\subsubsection{Deterioration Model}

(Zhang, Chouinard, Power, Tandja, et al. 2018) use a probabilistic deterioration model for concrete decks derived from chloride ion transport models and climate change scenarios. In this research, the deterioration model is defined using a similar methodology for durability limit states consistent with CSA S408-11 (2011). The time to the final stage of the design service life (Spalling, $T_{s p}$ ) is divided into two stages: 1) corrosion initiation $\left(T_{i}\right)$ and, 2) corrosion propagation $\left(T_{t}\right)$ thus, $T_{t}=T_{i}$ $+T_{p}$ 
The determination of the probability of serviceability limit states that are time-dependent is complex due to the nonlinearity of the performance functions. The time to the onset of spalling is defined as,

$$
T_{t}=T_{i}+T_{p}
$$

and its cumulative distribution function is obtained from Equation 4,

$$
\begin{aligned}
& F_{T_{t}}\left(t_{t}\right)=P\left[\left(t_{i}+t_{p}\right)<t\right]=\int_{0}^{t_{t}} f_{T_{p}}\left(t_{p}\right) \int_{0}^{t_{t}-t_{p}} f_{T_{i}}\left(t_{i}\right) d t_{i} d t_{p} \\
& =\int_{0}^{t_{t}} f_{T_{p}}\left(t_{p}\right) \cdot F_{T_{i}}\left(t_{t}-t_{p}\right) d t
\end{aligned}
$$

where, $f_{T_{i}}\left(t_{i}\right)$ and $f_{T_{p}}\left(t_{p}\right)$ are the probability density functions for the time to the initiation of corrosion and the time of corrosion propagation up to the onset of spalling of the concrete cover respectively. Since the time from corrosion initiation to spalling is usually long, and the crack growth models are mainly linear functions in time, the deterioration is divided into four stages. Stage 1 is the initial period, from the beginning of the service life to the initiation of corrosion. Stage 2 is defined from the beginning of the corrosion initiation until the crack widths reach $0.8 \mathrm{~mm}$. Stage 3 is the final phase of the propagation of corrosion, from the previous stage to the onset of concrete cover spalling, which corresponds to Stage 4 (Figure 5-9). The four states defined herein can be related to current visual inspection and condition assessment procedures and is applicable to a wide range of structures.

$$
\text { Stage 1: } P_{1}(t)=P\left(t_{i}<t\right)
$$


Stage 3: $P_{3}(t)=P\left[\left(t_{i}+t_{p} / 2\right) \leq t<\left(t_{i}+t_{p}\right)\right]$

Stage 4: $P_{4}(t)=P\left(t>\left(t_{i}+t_{p}\right)\right)$

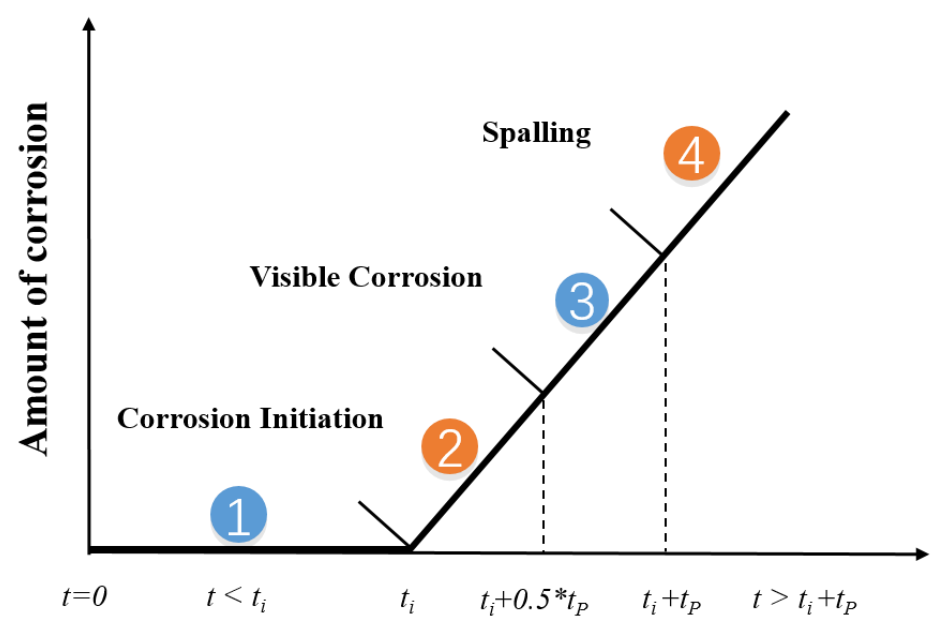

Time $t$

Figure 5-9 Definition of durability condition states.

Estimates of the concentration of chloride as a function of depth and time in the concrete deck are obtained with TransChlor ${ }^{\circledR}$ as described previously. The time to the corrosion initiation $\left(t_{i}\right)$ is defined as the length of time needed for chloride ion levels to reach the critical level for corrosion for the corresponding type of reinforcing steel. The length of time between the initiation of corrosion to the onset of spalling $\left(t_{p}\right)$ is estimated using the expression proposed by (Lounis and Daigle 2008), 


$$
t_{p}(s p)=\frac{\pi}{2 S j_{r}\left[\frac{1}{\rho_{r}}-\frac{\alpha}{\rho_{s}}\right]}\left[1+v+\frac{d^{2}}{2 c(c+d)}\right] \frac{\left(2 c d+d^{2}\right) f_{t}^{\prime}}{E_{c}}
$$

where $S=$ rebar spacing; $\rho_{r}=$ density of corrosion products (assumed at $3,600 \mathrm{~kg} / \mathrm{m}^{3}$ for $\left.\mathrm{Fe}(\mathrm{OH})_{3}\right)$; $\rho_{s}=$ density of steel $(7,860 \mathrm{~kg} / \mathrm{m} 3) ; \alpha=$ molecular weight ratio of metal iron to the corrosion product (assumed at 0.52$)$; and $j_{r}=$ corrosion production rate per unit area $\left(\mu \mathrm{A} / \mathrm{cm}^{2}\right)(\mathrm{Bazant}$ 1979). The model is utilized to relate the increase in rebar diameter due to corrosion build-up to corrosion-induced limit states (Lounis and McAllister 2016). The random variable that are used in the model are summarized in Table 5-2.

Table 5-2: Variables of the propagation model.

\begin{tabular}{|c|c|c|c|c|}
\hline Variables & Units & Distribution & Mean & $\mathrm{COV}$ \\
\hline Cover thickness, $c_{t}$ & $\mathrm{~mm}$ & Deterministic & $25 / 50 / 70$ & - \\
\hline Bar spacing & $\mathrm{mm}$ & Log-normal & 150 & 5 \\
\hline Bar diameter & $\mathrm{mm}$ & Deterministic & 16 & - \\
\hline $\begin{array}{l}\text { Concentration threshold for } \\
\text { Corrosion initiation, } C_{t h}\end{array}$ & wt. $(\%)$ cem. & Log-normal & 1.35 & 20 \\
\hline Reference corrosion rate, $j_{r, 20}$ & $\mu \mathrm{A} / \mathrm{cm}^{2}$ & Log-normal & 0.8 & 20 \\
\hline $\begin{array}{c}28 \text { Day concrete compressive } \\
\text { strength, } f_{c}\end{array}$ & $\mathrm{MP}_{\mathrm{a}}$ & Normal & 45.5 & 18 \\
\hline Concrete tensile strength, $f_{t}^{\prime}$ & $\mathrm{MP}_{\mathrm{a}}$ & Normal & 3.58 & 13 \\
\hline Concrete elastic modulus, $E_{c}$ & $\mathrm{MP}_{\mathrm{a}}$ & Normal & 31029 & 12 \\
\hline
\end{tabular}

Note: $\mathrm{COV}=$ coefficient of variation $(\%)$, $f_{c}=28$ Day concrete compressive strength 
The elements of the yearly transition probabilities matrix (TPM $\left.\left(P^{t}\right)\right)$ are by definition null except for the elements on and above the diagonal. Given the initial state probabilities vector $q(0)$, the future probability state vector $q(t)(t=1,2, \ldots, T)$ after $t$ years is (Collins 1975):

$$
q(t)=q(0) \times P^{t}
$$

where,

$$
\begin{gathered}
P=\left[\begin{array}{cccc}
P_{1,1} & P_{1,2} & \ldots & P_{1, \mathrm{j}} \\
P_{2,1} & P_{2,2} & \ldots & P_{2, \mathrm{j}} \\
\ldots & \ldots & \ldots & \ldots \\
P_{i, 1} & P_{i, 2} & \ldots & P_{i, \mathrm{j}}
\end{array}\right] \\
q(t)=\left[\begin{array}{cccc}
q_{1}(0) & q_{2}(0) & q_{3}(0) & q_{4}(0) \\
q_{1}(1) & q_{2}(1) & q_{3}(1) & q_{4}(1) \\
\ldots & \ldots & \ldots & \ldots \\
\ldots & \ldots & \ldots & \ldots \\
\ldots & \ldots & \ldots & \ldots \\
q_{1}(T) & q_{2}(T) & q_{3}(T) & q_{4}(T)
\end{array}\right]
\end{gathered}
$$

In this application, $q(0)$ is defined as $[1,0,0,0]$, which states that the structure is new at time zero. In this application, TPMs were estimated for three climate scenarios and three concrete covers. The transition probabilities are obtained by minimizing the sum of absolute differences between $q(t)$ and $Q(t)$, where $Q(t)$ is the vector of state probabilities at time $t\left[P_{1}(t) P_{2}(t) P_{3}(t) P_{4}(t)\right](t=1$, $2, \ldots, T)$ predicted from the deterioration model.

$$
\operatorname{Minimize} \sum_{t=1}^{T}|q(t)-Q(t)|
$$

Subject to: $0 \leq p_{i j} \leq 1$ for $i, j=1,2,3,4$ 


$$
\sum_{j=1}^{4} p_{i j}=1
$$

The use of the absolute differences prompts a faster optimization routine and does not induce significant losses in the final solution relative to that obtained from the quadratic loss function (Portnoy and Koenker 1997). The Optimization was carried out in MATLAB ${ }^{\circledR}$ environment and using the FMINCON function (Byrd et al. 2000).

\subsubsection{Problem formulation}

In this application, four basic types of M\&R activities are considered, "Do-Nothing" (A), "Minor Maintenance" (B), "Major Maintenance" (C), and "Replacement" (D) and used to define sequences of activities during the lifetime of the structure. "Minor maintenance" includes cleaning and the sealing of joints and repair of cracks and superficial local repairs on the slab (above the reinforcement). "Major maintenance" primarily comprises localized repair of the concrete to a depth below the reinforcement as well as the sealing of joints and the use of epoxy injection to fill racks. Often, quick setting concrete will be used for both minor and major repairs to minimize the length of disruptions in the transportation network. The "Replacement" entails the construction of a new slab including new reinforcement.

The cost data for each M\&R activity as a function of the condition states are obtained from a sample of maintenance, repair and replacement activities in the Montreal area (Table 5-3). For example, at Condition state 3, Action B (minor maintenance) has a cost of $\$ 800$ per $\mathrm{m}^{2}$. 
Table 5-3: Cost matrix of M\&R strategies $\left(\mathrm{C} \$ / \mathrm{m}^{2}\right)$.

\begin{tabular}{c|cccc}
\hline \multirow{2}{*}{ Condition state } & \multicolumn{4}{|c}{ M\&R activities } \\
& A & B & C & D \\
\hline 1 & 0 & 0 & 0 & 0 \\
2 & 0 & 800 & 0 & 0 \\
3 & 0 & 800 & 1500 & 2000 \\
4 & 0 & 0 & 1500 & 2000 \\
\hline
\end{tabular}

M\&R activities are assumed to be performed at the start of each fiscal year and transition states are observed at the end of the fiscal year. In this study, only discrete states are considered since the inspection and maintenance activities are assumed to be performed on an annual basis. The yearly TPMs for the four actions are proposed in Table 5-4. For the "Do-nothing" option, Equation 13 is used to calculate the TPM (Table 5-5), which is utilized to describe the stochastic process of deterioration. For minor repairs, the TPM is defined such that given a bridge is initially in state 3 , it will be in state 2 after the minor repair. Minor repairs are not performed if the bridge deck is in state 4. In this instance, the state of deterioration is considered too severe for minor repairs. For major maintenance actions, the TPM is defined such that a bridge deck in either state 3 or 4 will be in state 2 after repair, which implies that the reinforcing steel has not been replaced after a major repair. For deck replacements, the state after replacement is assumed to be 1 (new state) regardless of the current state.

Table 5-4: Yearly Transition Probability Matrices (at the time of actions).

$$
\text { Action A: Do Nothing }
$$

Condition state

\begin{tabular}{l|ccc}
1 & $P_{11}$ & $P_{12}$ & 0 \\
2 & 0 & $P_{22}$ & $P_{23}$
\end{tabular}

Action B: Minor Maintenance

$\begin{array}{llll}1 & 2 & 3 & 4 \\ 1 & 0 & 0 & 0 \\ 0 & 1 & 0 & 0\end{array}$




\begin{tabular}{|c|c|c|c|c|c|c|c|c|}
\hline 3 & 0 & 0 & $P_{33}$ & $P_{34}$ & 0 & 1 & 0 & 0 \\
\hline 4 & 0 & 0 & 0 & 1 & 0 & 0 & 0 & 1 \\
\hline & \multicolumn{4}{|c|}{ Action C: Major Maintenance } & \multicolumn{4}{|c|}{ Action D: Replacement } \\
\hline Condition state & 1 & 2 & 3 & 4 & 1 & 2 & 3 & 4 \\
\hline 1 & 1 & 0 & 0 & 0 & 1 & 0 & 0 & 0 \\
\hline 2 & 0 & 1 & 0 & 0 & 1 & 0 & 0 & 0 \\
\hline 3 & 0 & 1 & 0 & 0 & 1 & 0 & 0 & 0 \\
\hline 4 & 0 & 1 & 0 & 0 & 1 & 0 & 0 & 0 \\
\hline
\end{tabular}

The current condition state at any time is random and is represented by a vector where the elements are the probabilities $q_{i}$ for each state. The expected current state of the deck at time $t$ is:

$$
E(X(t))=\sum_{i=1}^{4} q_{i}(t) *(i) \text { for } i=1 \ldots 4
$$

In the optimization process, each possible solution is comprised of a sequence of yearly $M \& R$ tasks (A, B, C or D) over a time horizon of $T$ years.

\subsubsection{Objective functions}

The multi-objective optimization is to identify M\&R strategies that minimize Net Present Value of cost (NPVC) and minimize probabilities of disruptions during the lifetime of the bridge. Thus, the first objective is defined as:

$$
N P V C=\sum_{t=0}^{T-1} \frac{S z \cdot U C \cdot e^{\pi_{m} t}}{\left(1+r_{t}\right)^{t}}-\frac{R V}{\left(1+r_{t}\right)^{t}}
$$

where, $T$ is the time period of analysis, and $r_{t}$ is the discount rate at time $t$ (i.e., yields on Government bonds), $S z$ is the area of the deck, and $U C$ is the unit costs for the different M\&R 
strategies. Moreover, to capture rising costs over time we use $e^{\pi_{m} t}$ as the Producer Price Index level at time $t$ where $\pi_{m}$ is rate of inflation for the cost of materials. Unit costs for M\&R actions are listed in Table 5-3 for the baseline model and a deck area of 1,000 $\mathrm{m}^{2} . R V$ is the residual value of the infrastructure asset and is calculated as:

$$
R V=\text { State }_{50} \cdot \text { Cost }_{\text {replacement }}
$$

where State $_{50}$ is the residual state of the bridge at year 50 and Cost $_{\text {replacement }}$ is the cost for reconstruction of the new deck. The argument is that if a given strategy leaves the infrastructure in better shape than a different strategy after 50 years of service life, the first one is better (other things equal) as it will have lower costs in future periods.

For a RC bridge deck, the end of life is determined as the date when the critical level of deck spalling and delamination is reached (FHWA 1995; Lounis et al. 2006). Therefore, the second objective function is defined to minimize the probability of spalling (failure) during the service life:

$$
\text { Min. } P_{\text {spalling }}
$$

An overview of the proposed framework is shown in Figure 5-10. 


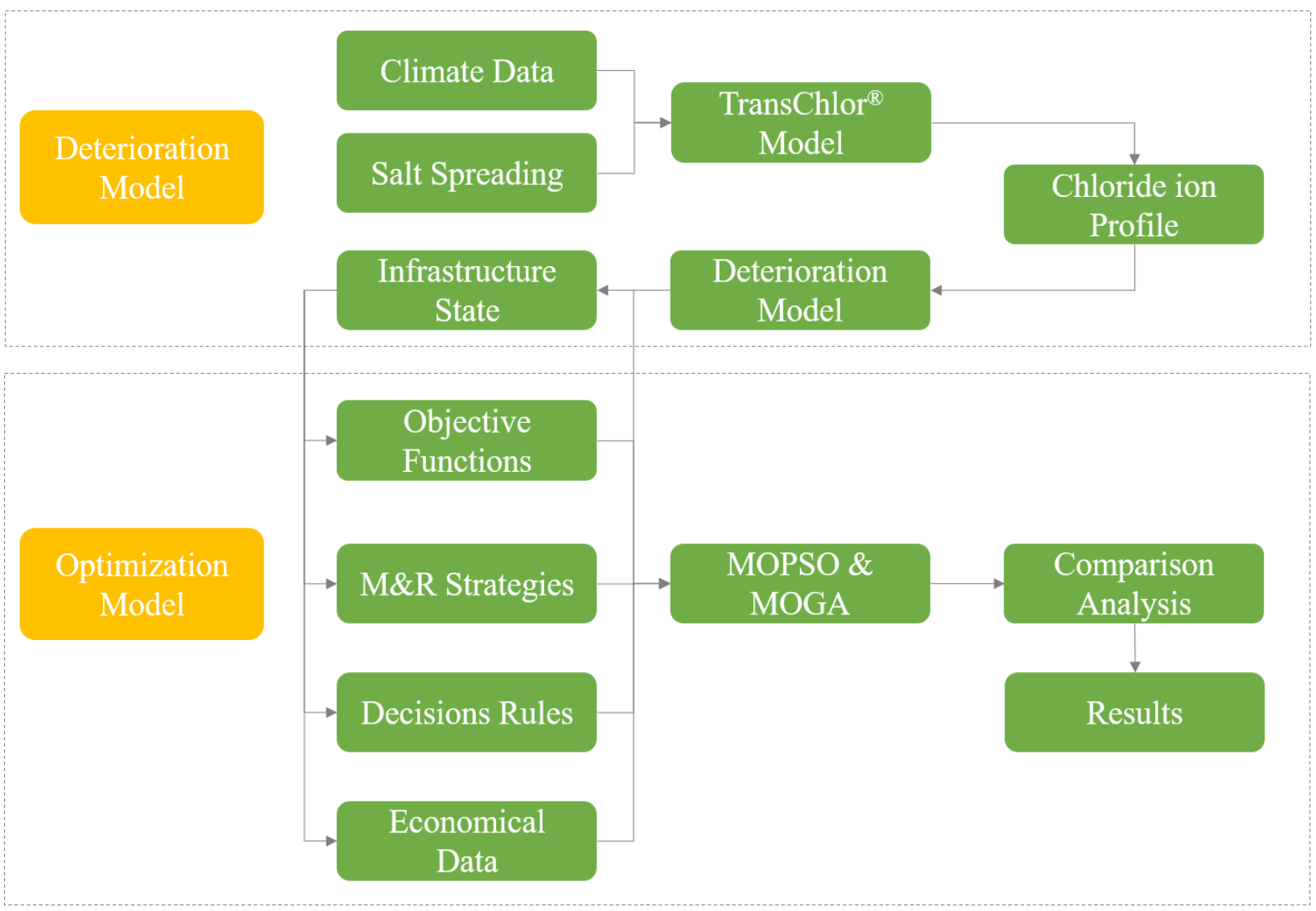

Figure 5-10 An overview of the proposed framework.

\subsection{Application of the model and discussion of the results}

The deterioration model is used to evaluate the probability distribution function for the time to reach each of the four condition states (A to D) defined previously. Historical climatic data from Environment Canada (Canada 2019) is used over the period 1959-2009 to model the current state of the bridge while climate change scenarios RCP 8.5 and RCP 4.5 from the Canadian Regional Climate Model (CanRCMs) are used to generate predictions over the next 50 years (2009-2059). The results are then used to determine the TPM for the three climate scenarios and (historical, RCP 8.5 and RCP 4.5$)$ to model the deterioration process for the optimization analysis. 
Historical records for the number of annual winter precipitation days reveal a considerable increase over the period 1979 to 2009 compared to the period from 1959 to 1979 . The predictions from RCP8.5 and RCP4.5 of winter precipitation for the period 2009 to 2059 remain at the high levels of 1999 to 2009 (Figure 5-11). To summarize, the number of winter precipitation day is anticipated to rise by over $30 \%$ during the next 50 years in comparison to the historical record.

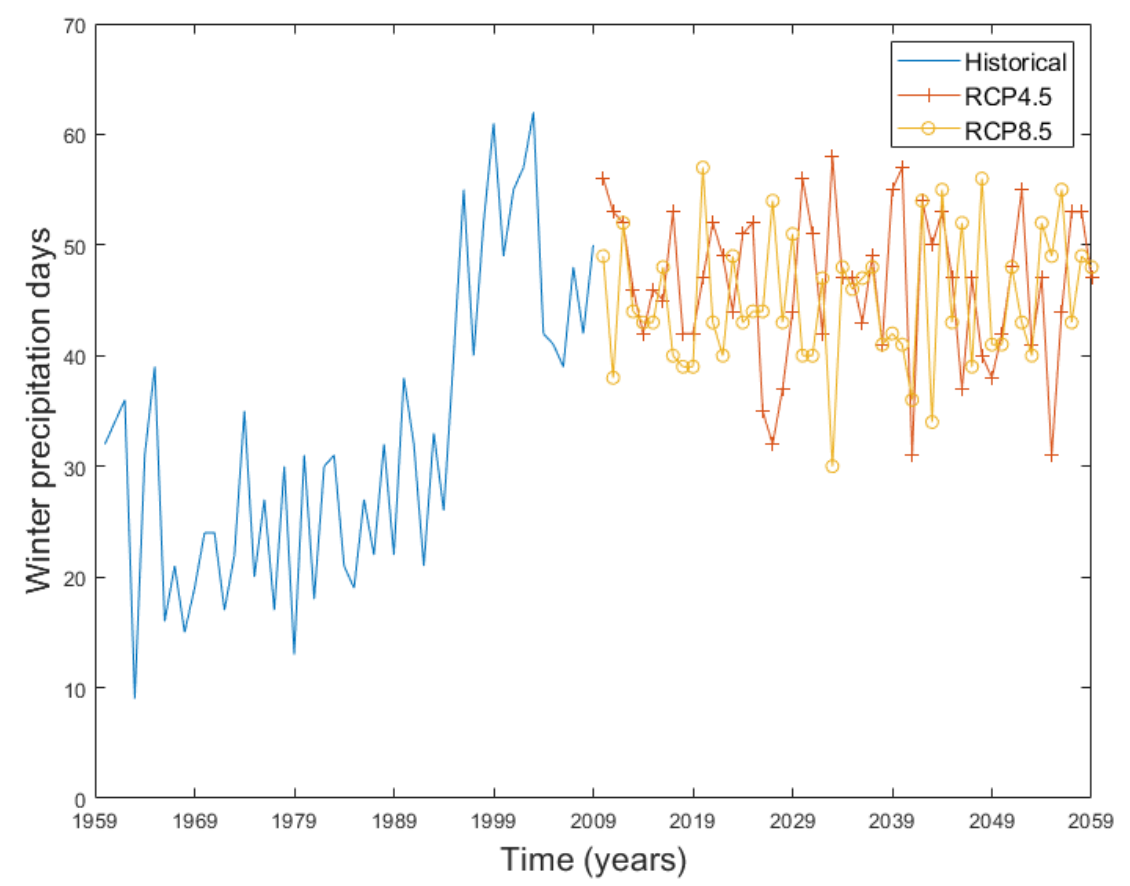

Figure 5-11 Total yearly number of winter precipitation days (daily precipitation $>.1 \mathrm{~mm}$ ).

Historical Records and projections from RCP8.5 and RCP4.5.

Figure 5-12 presents the resulting transition probabilities of the condition states for concrete covers of $25 \mathrm{~mm}, 50 \mathrm{~mm}$ and $70 \mathrm{~mm}$, for the three climate scenarios. The $70 \mathrm{~mm}$ concrete cover corresponds to the average concrete cover for the bridge under study, while the $50 \mathrm{~mm}$ depth is the concrete cover for most existing bridges and the $25 \mathrm{~mm}$ cover is used to assess the effect of 
improperly placed reinforcement on deterioration rates. For all climate change scenarios, the salt spreading protocol in future years is assumed to remain the same as the current protocol.

The simulation results show that the initiation time to corrosion is mainly dependent on the number of days of precipitation during the winter. With $70 \mathrm{~mm}$ concrete cover, the initiation time to corrosion for historical exposure is within the first 30 years of the service life, while the initiation time to corrosion is approximately 10 years under both climate change scenarios due to the significant increase in the number of days with precipitation during the winter.

The model also shows that $40 \%$ of the decks constructed 50 years ago that had no or little preventive maintenance (which corresponds to the current practice in many cities) have decks that have reached the end of their service life (i.e., concrete cover is spalling). If a similar lack of maintenance practices were followed for new constructions, the simulations indicate that for both climate change scenarios, due to higher temperatures and more frequent winter precipitation, the proportion of concrete decks that have reached the end of their service life after 50 year increases to $80 \%$.

Results for concrete covers of $50 \mathrm{~mm}$ and $25 \mathrm{~mm}$ are similar for the historical and climate change scenarios since initiation times are short (around 5 years and 2 years for $50 \mathrm{~mm}$ and $25 \mathrm{~mm}$ cases, respectively). The probability for spalling is $90 \%$ after 20 years of service for $25 \mathrm{~mm}$ covers and 35 to 40 years for $50 \mathrm{~mm}$ covers. Note that the climate scenario RCP 8.5 is associated with the most rapid deterioration processes due to higher temperatures during the winter, which increase the corrosion rate. 

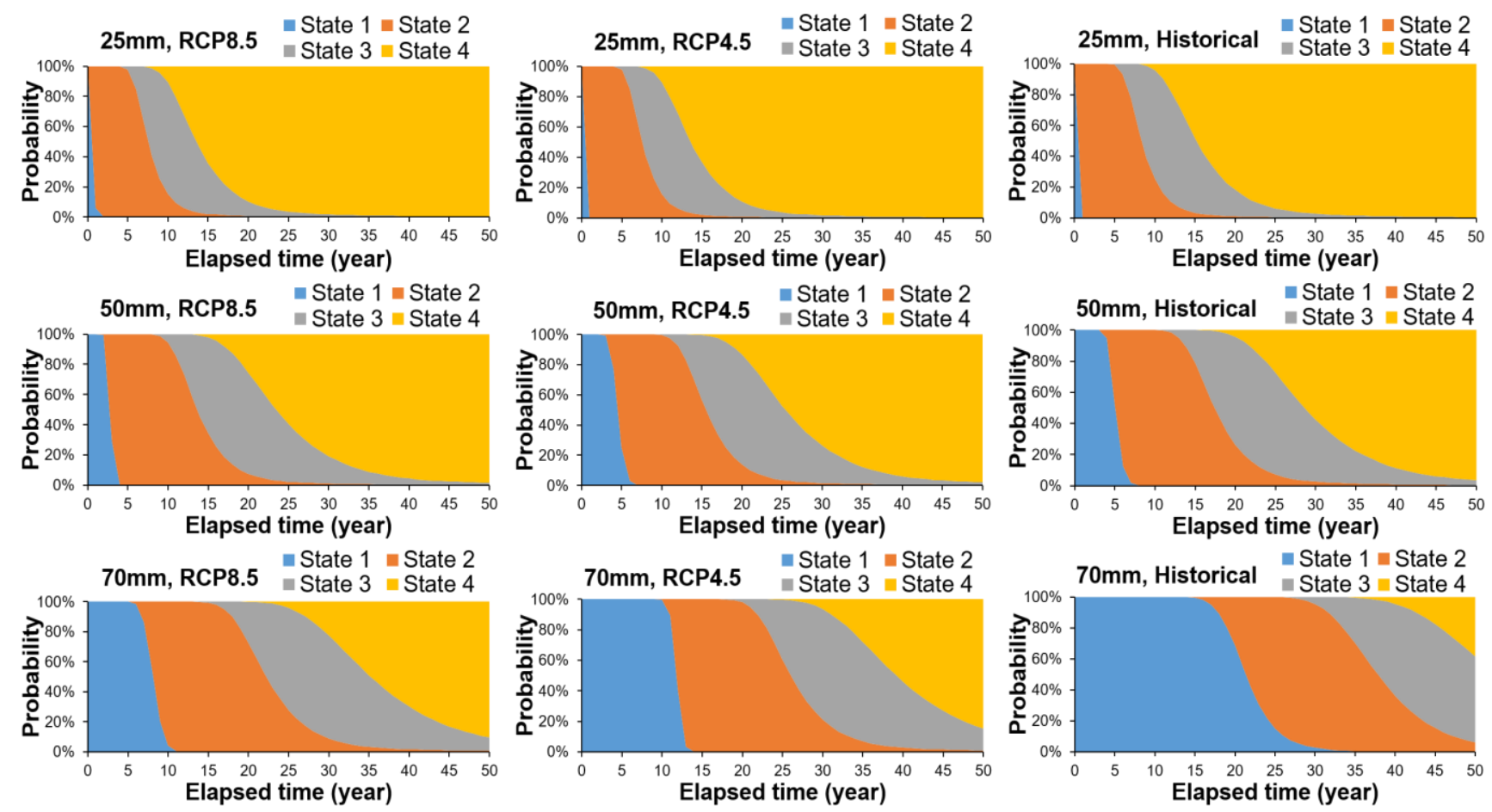

Figure 5-12 Condition state probabilities as a function of time (year) for three climate scenarios

(Historical, RCP4.5 and RCP8.5) and concrete cover thickness (25mm, 50mm and 70mm).

Table 5-5: Yearly Transition Probability Matrices for three climate scenarios (Historical, RCP4.5 and RCP8.5) and concrete cover thickness (25mm, 50mm and 70mm).

\section{Concrete cover thickness}

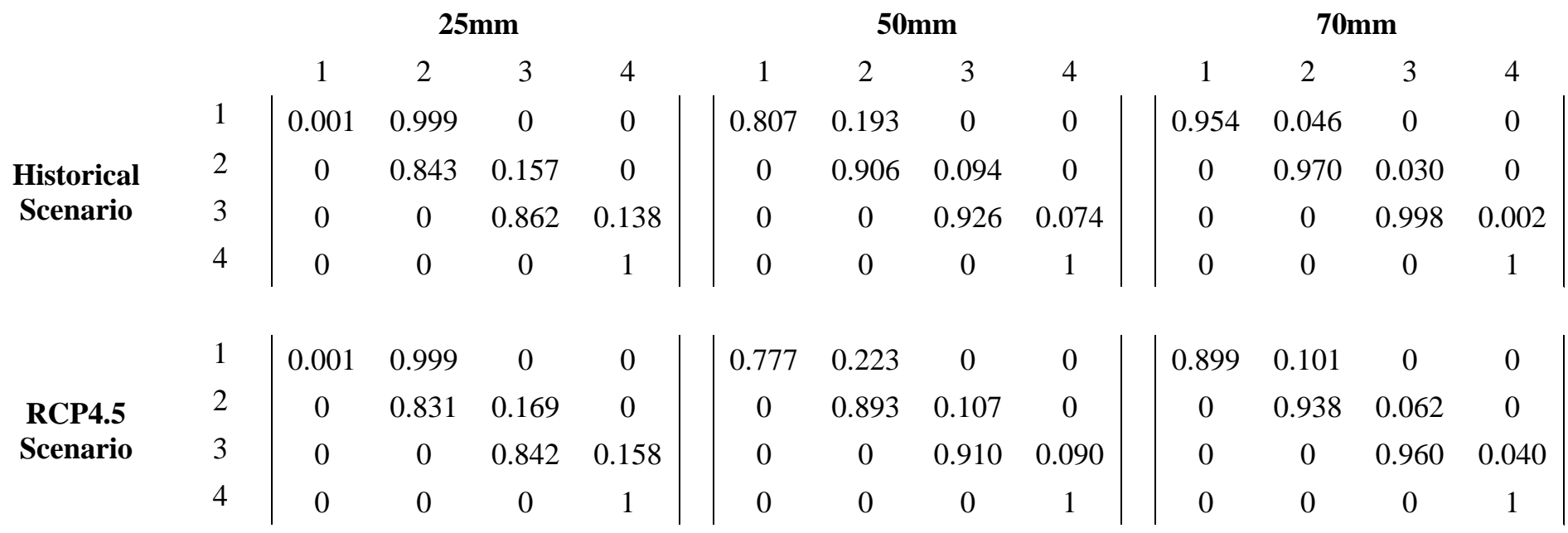




\begin{tabular}{cc|cccc|c|ccc|cccc} 
& 1 & 0.060 & 0.940 & 0 & 0 \\
RCP8.5 & 2 & 0 & 0.831 & 0.169 & 0 & 0.679 & 0.321 & 0 & 0 \\
0 & 0.889 & 0.111 & 0 \\
Scenario & 3 & 0 & 0 & 0.838 & 0.162 & 0 & 0 & 0.910 & 0.090 \\
& 4 & 0 & 0 & 0 & 1 & 0 & 0 & 0 & 1 & 0.861 & 0.139 & 0 & 0 \\
0 & 0.930 & 0.070 & 0 \\
0 & 0 & 0.948 & 0.052 \\
0 & 0 & 0 & 1
\end{tabular}

The MOPSO and NSGA-II algorithms were programmed into MATLAB ${ }^{\circledR}$ subroutines (MATLAB, 2018), and ran using a desktop version of the Windows 10 Enterprise operating system and Intel Core i7-8700HQ 3.20 GHz processor with $64.00 \mathrm{~GB}$ of RAM. The parameter settings for a trial study of the MOPSO algorithm are as follows: (1) number of iterations: 300; (2) number of particles in swarm: 300; (3) initial weight: 0.5 (according to Eberhart and Kennedy (1995), who recommended an initial weight between 0 to 1 ); (4) acceleration rates: $\mathrm{c} 1=2$ and $\mathrm{c} 2=2$ (as suggested by Babapour et al. (2018)); and (5) velocity boundary (Vmax): 0 and 4; The GA settings were set-up at the condition where population was 300 , crossover rate was 0.8 , mutation rate was 0.1 (the almost optimum rate for mutation and cross over indicated by Babapour et al. (2018), and the number of generations was 300 .

Figures 13 to 18 illustrate the Pareto-optimal front following 300 iterations in the objective space over the planning horizon for the two optimization techniques. Figures 13 to 15 compare the tradeoff solutions for different concrete cover thicknesses while Figures 16 to 18 illustrate the differences among climate scenarios for given concrete cover thicknesses. Each color-coded triangle and dot in these figures represent a bridge deck M\&R strategy using MOPSO and NSGAII respectively, and accordingly, provides a unique and optimal solution.

A common problem during analysis is choosing a solution from the Pareto front. In general, when one objective of maintenance strategies is optimized, the other objective is often suboptimal. For example, examining the results of MOPSO and NSGA-II for climate scenario RCP4.5 with a 
concrete cover with a thickness of 50mm (Figure 5-14), assuming that decision-makers are economically motivated, or that the budget is limited, solution $\mathrm{S}_{1}$ should be chosen because it minimizes the probability of spalling at the minimum NPVC. However, if the level of performance of the bridge deck is favored over cost, the solution $\mathrm{S}_{2}$ is optimal because it provides the highest performance (e.g., no spalling during the service life).

Lounis et al. (2006) propose that the end of the service life of RC decks in corrosive environments is reached when an estimated $30 \%$ of the deck area has spalled. In this case, optimal maintenance strategies corresponding to this criterion is represented beneath the horizontal red line in Figure 514(a). Similarly, if the budget is set as $\$ 5 \mathrm{M}$, the optimal solutions which satisfy this limit are shown on the left side of the vertical red line in Figure 5-14(a). As a consequence, an optimum set of generated results are available in the marked region. It would make sense in this case to select the points at the boundary (minimum cost at $30 \%$ spalling or minimum spalling at $\$ 5 \mathrm{M}$ ).

The six representative long-term maintenance plans extracted from the solutions of both optimization techniques are presented in Figure 5-14(b). Each rectangle corresponds to an interval of one year and each color-coded rectangular represents a possible action at that year. Choosing solution $\mathrm{X}_{1}$ for example, the $\mathrm{M} \& \mathrm{R}$ strategies are two major maintenances at year 14 and year 26, and one replacement at year 38, respectively. The digit (e.g., 1 to 4 ) above the rectangular indicates the expected state of the bridge deck being in that year. The results for maintenance plans $\mathrm{X}_{1}, \mathrm{X}_{2}$, $\mathrm{X}_{3}$ from MOPSO and $\mathrm{Y}_{1}, \mathrm{Y}_{2}, \mathrm{Y}_{3}$ from NSGA-II, are very close for both objectives. However, they exhibit differences in the sequence of maintenance activities. Looking more closely at the maintenance plan indicates that the two algorithms provide a different pattern of $M \& R$ actions. Specifically, Plans $\mathrm{Y}_{1}, \mathrm{Y}_{2}$ and $\mathrm{Y}_{3}$ of NSGA-II suggest more minor maintenance instead of major maintenance and replacement compared to $\mathrm{X}_{1}, \mathrm{X}_{2}$ and $\mathrm{X}_{3}$ of MOPSO, respectively. The 
combination of frequent minor and major maintenances can prove to be equally effective as replacement (Action D).

Furthermore, one of the most effective ways to optimize the life cycle cost-performance trade-off, when the expected level of the objective (NPVC or probability of spalling) varies, is to obtain a flexible solution. The Pareto front in Figure 14 (a) can logically be divided into three parts. Part 1 includes solutions that have higher probabilities of spalling than solution $\mathrm{X}_{1}$ and $\mathrm{Y}_{1}$ (above $\mathrm{X}_{1}$ and $\mathrm{Y}_{1}$ ), Part 2 includes solutions (to the right of $\mathrm{X}_{3}$ and $\mathrm{Y}_{3}$ ) that have greater NPVC than solution $\mathrm{X}_{3}$ and $\mathrm{Y}_{3}$, and Part 3 (in the lower left of the figure) includes solutions that have lower probabilities of spalling than solutions $\mathrm{X}_{1}$ and $\mathrm{Y}_{1}$ and lower NPVC than solutions $\mathrm{X}_{3}$ and $\mathrm{Y}_{3}$. In Part $1, \mathrm{NPVC}$ slightly decreases as probability of failure increases significantly while in Part 2, NPVC substantially increases as the probability of spalling decreases. Moreover, we find that in the region of Part 2, the results from both algorithms are similar. However, in the Part 1 area, in most cases MOPSO has a slightly advantage over NSGA-II. Thus, at the same level of probability of spalling, MOPSO provides lower NPVC than NSGA-II. If the two objectives are equally important to the decision-makers, the solutions located in Part 3 could become appropriate trade-offs. Therefore, if no economic constraints exist, further $M \& R$ actions will reduce the probability of failure to a very low level (close to $0 \%$ ). When there are constraints on budgets and performance level of the structure, solutions from the bi-objective optimization can provide optimal compromises between different objectives. Thus, the results show that the proposed method can lead to multiple useful solutions that provide some flexibility to decision-makers in practice. 


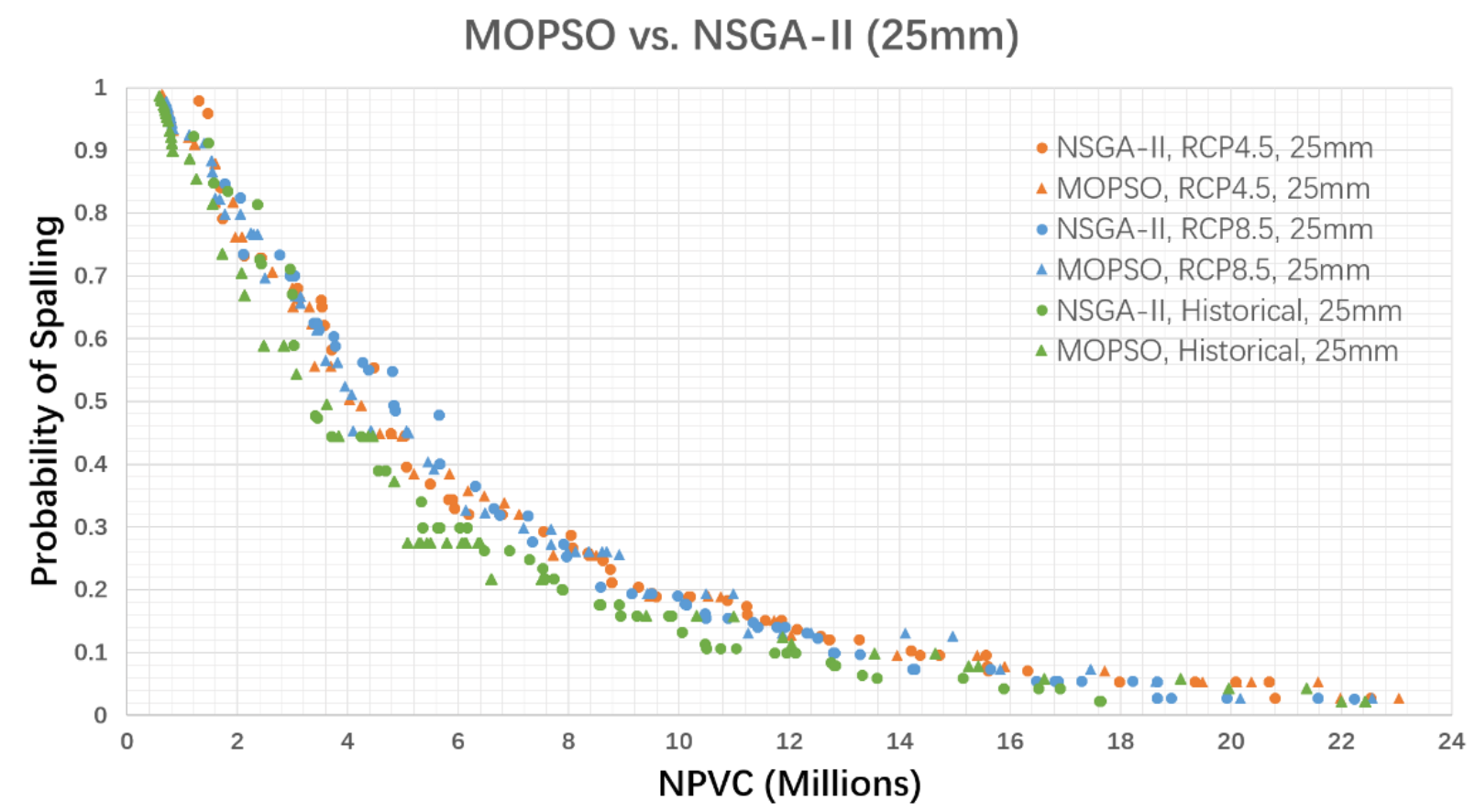

Figure 5-13 Optimal solutions for three climate scenario and a concrete cover thickness of $25 \mathrm{~mm}$. 


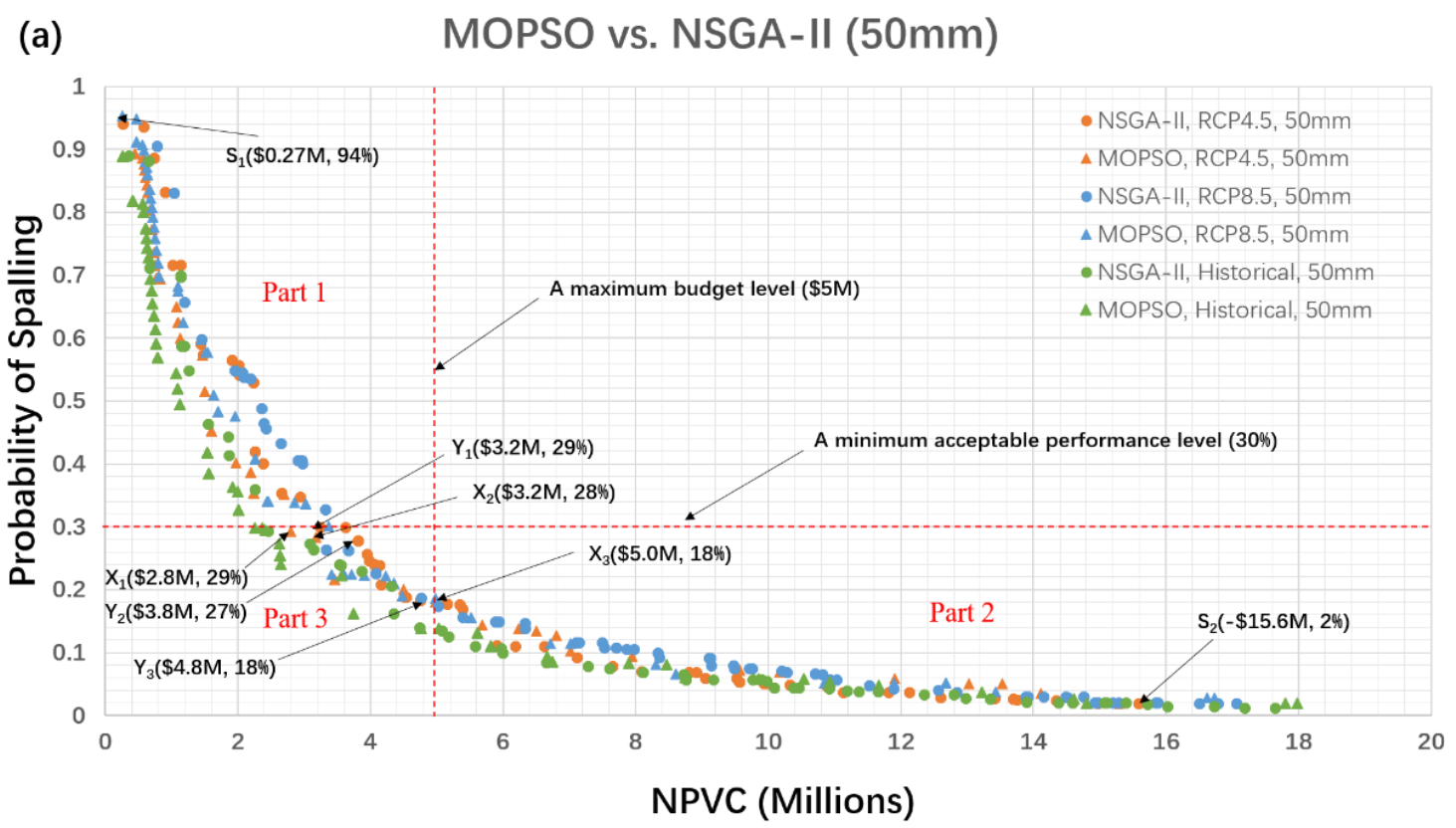

(b) $\longrightarrow \begin{aligned} & \text { Action A: Do } \\ & \text { nothing }\end{aligned} \longrightarrow \begin{aligned} & \text { Action B: Minor } \\ & \text { Maintenance }\end{aligned} \longrightarrow \begin{aligned} & \text { Action C: Major } \\ & \text { Maintenance }\end{aligned} \longrightarrow \begin{aligned} & \text { Action D: } \\ & \text { Replacement }\end{aligned}$

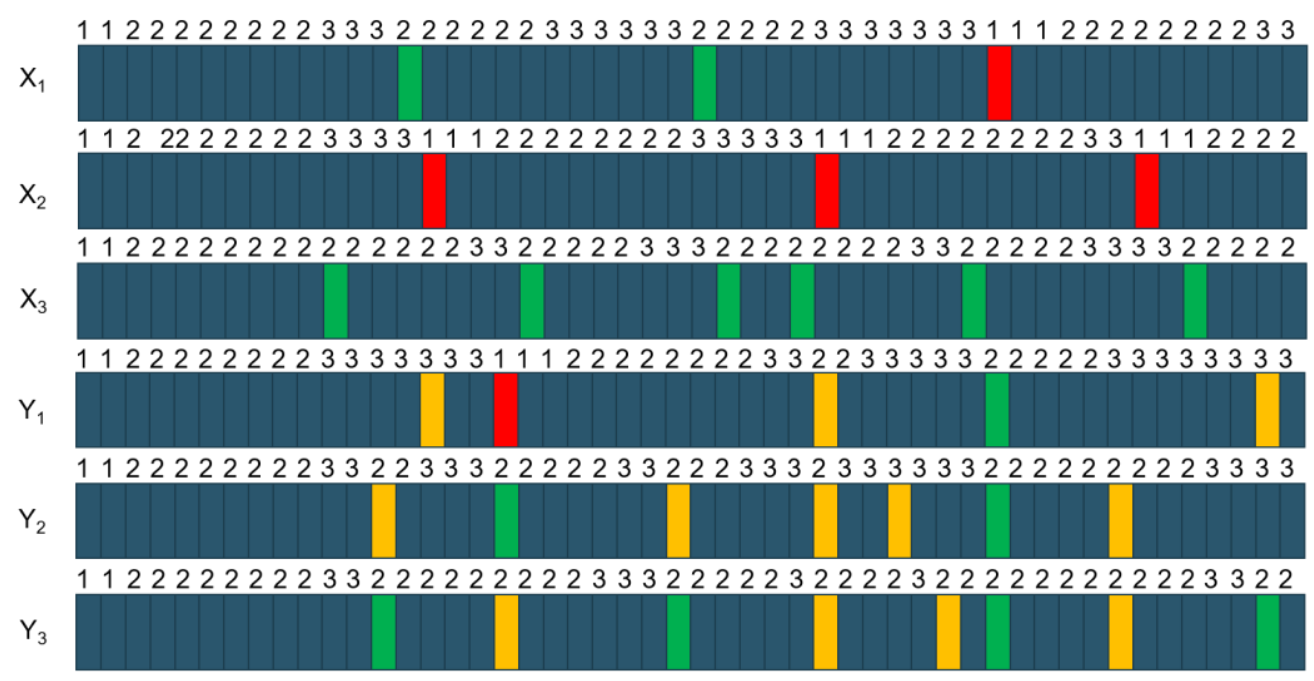

Figure 5-14 (a) Optimal solutions for three climate scenarios and a concrete cover thickness of 50mm; (b) Comparison of Maintenance Plan for the considered optimization techniques. 
MOPSO vs. NSGA-II (70mm)

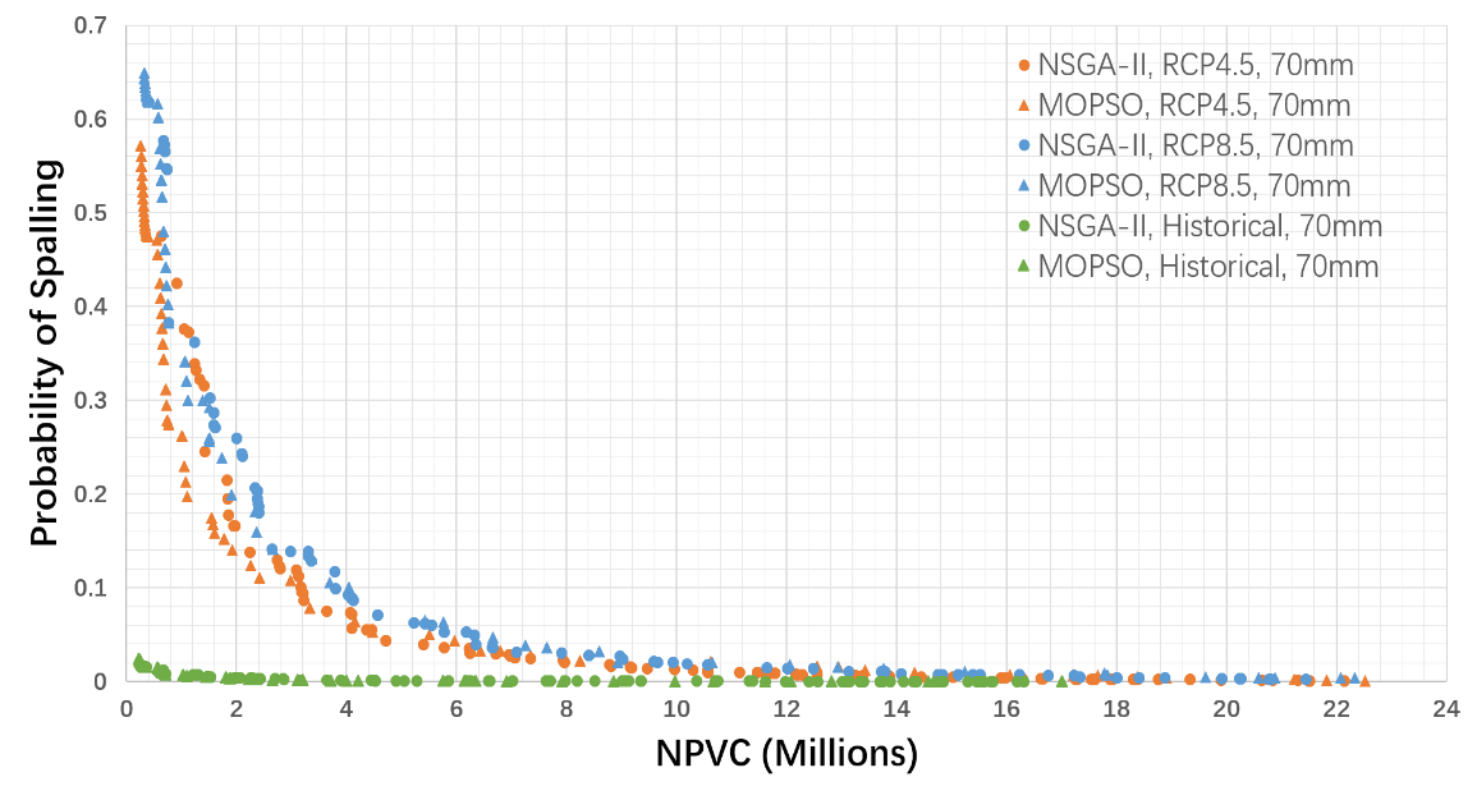

Figure 5-16 Optimal solutions for three climate scenario and a concrete cover thickness of 70mm.

MOPSO vs. NSGA-II (RCP8.5)

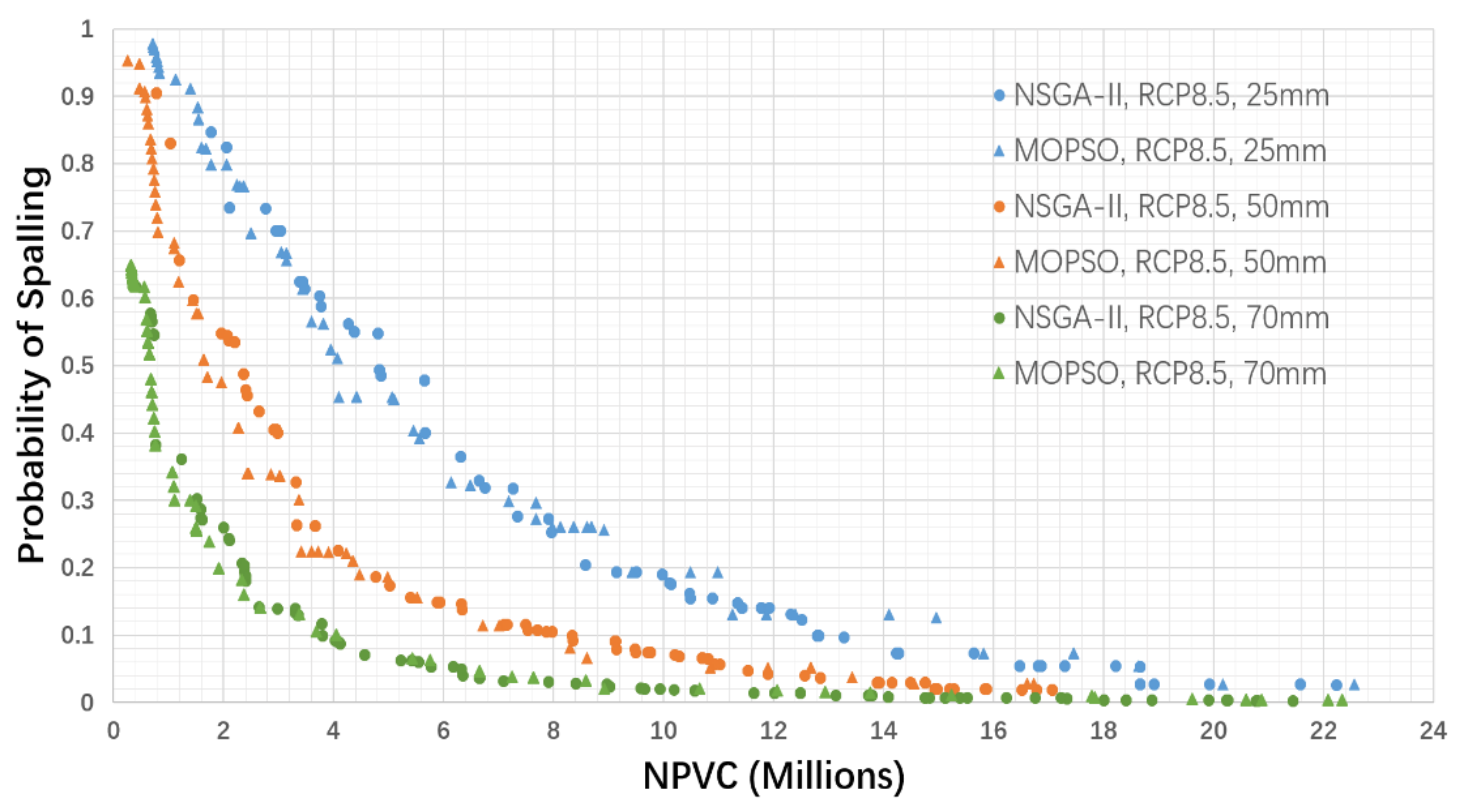

Figure 5-15 Optimal solutions for three concrete cover thickness for the RCP8.5 climate change scenario. 
MOPSO vs. NSGA-II (RCP4.5)

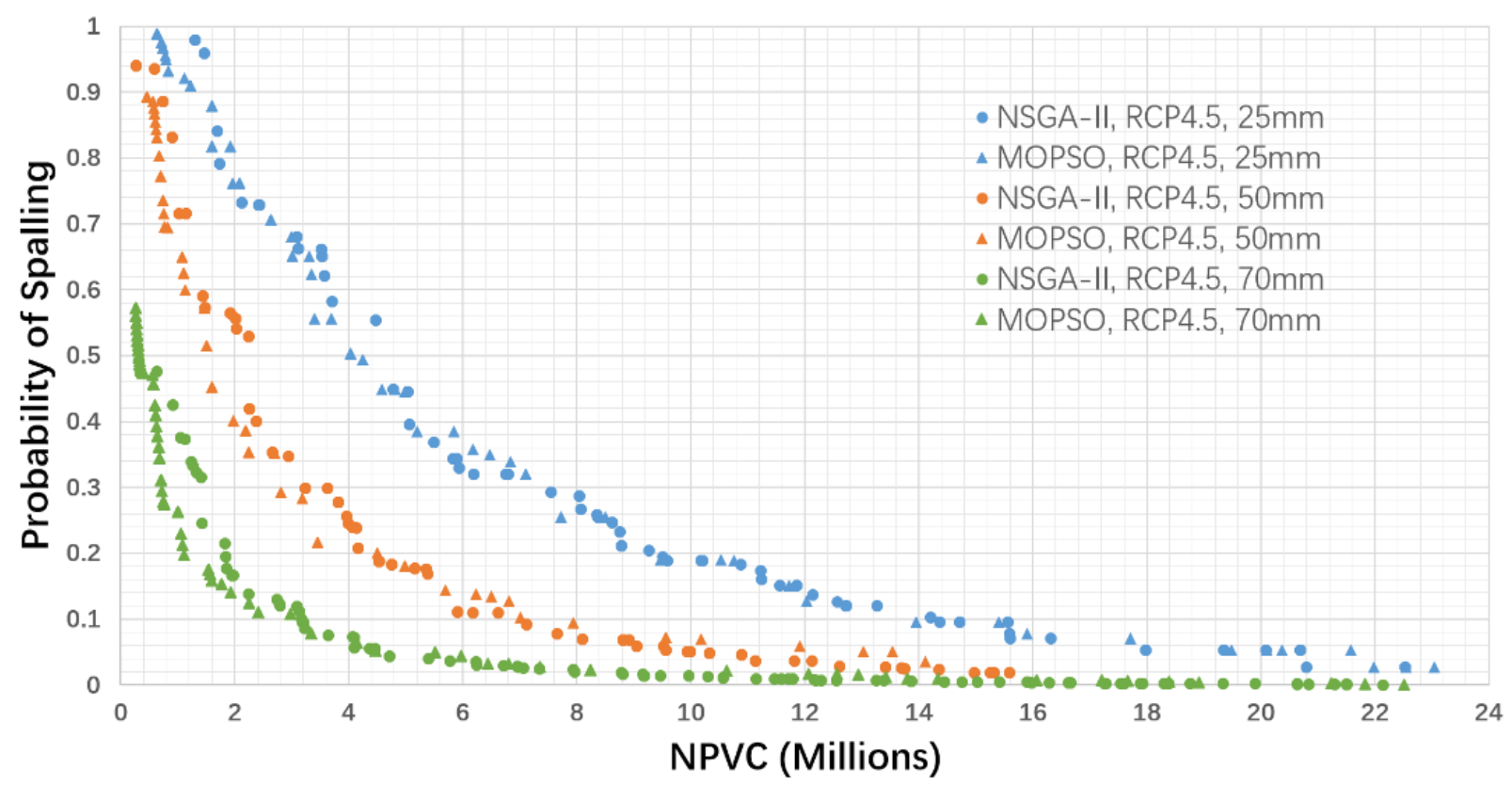

Figure 5-17 Optimal solutions for three concrete cover thickness for the RCP4.5 climate change scenario.

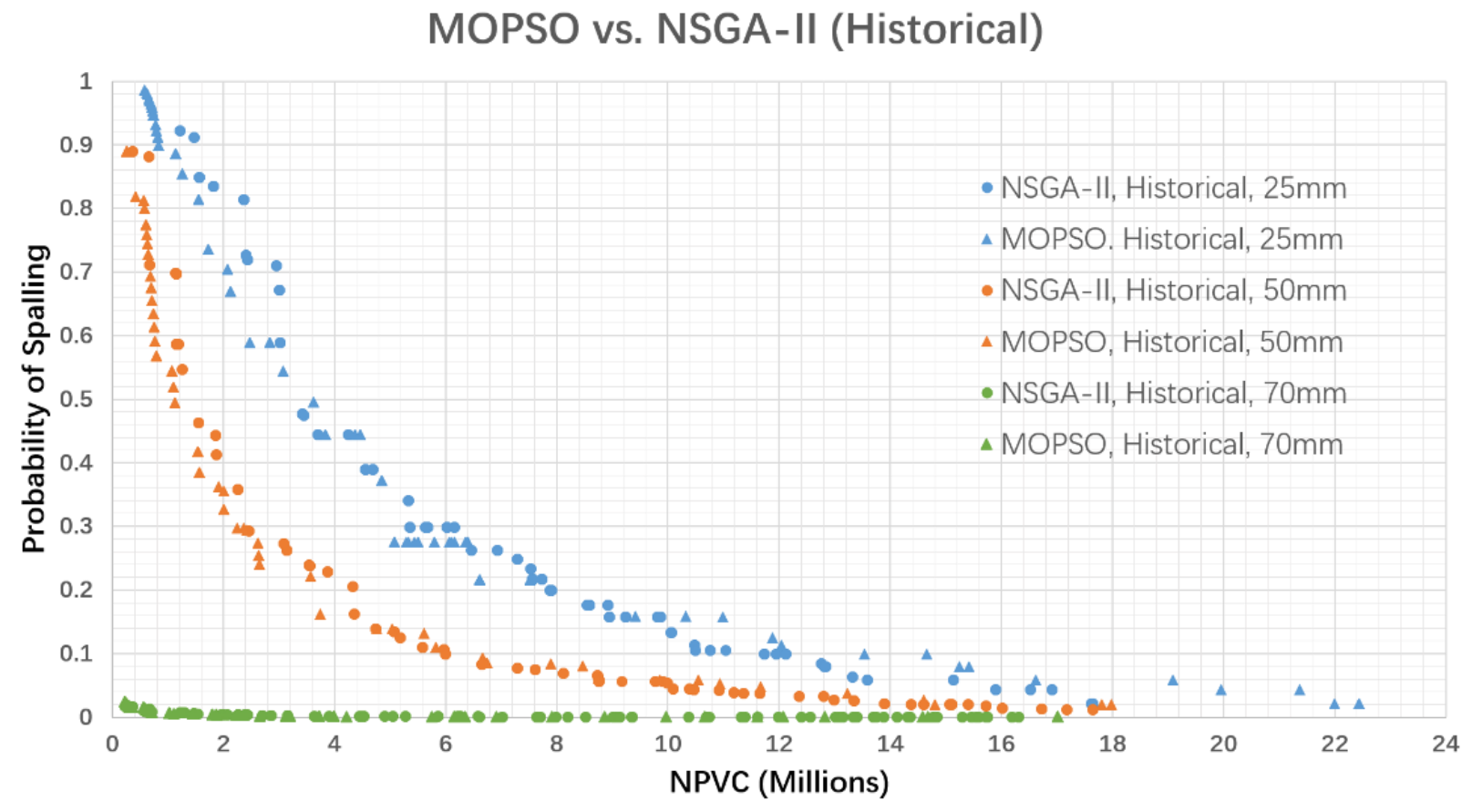

Figure 5-18 Optimal solutions for three concrete cover thickness for the Historical climate change scenario. 
Figure 5-19 compares the deterioration patterns of the bridge deck (in accordance with the six representative solutions shown in Figure 5-14). Every solution should comply with all of the requirements already noted in the optimization model. Note that the process of aging has an enormous impact on the rate of deterioration. The optimized solutions show that the condition state at year 50 lies between State 2 to State 3, which is the expected result for optimal utilization of the bridge infrastructure. Moreover, the solutions that we obtain, while always optimal, provide different choices of the decision boundaries. For example, if a minor maintenance strategy is favored in the optimal decision sequence, the optimal solution prompts continuous repair operations throughout the second half of the bridge lifetime. On the other hand, options for a major maintenance decision strategy will reduce the frequency of maintenance operations but may not be cost-effective and in addition cause more downtime of the bridge during the repair in a realworld setting. 
(a)

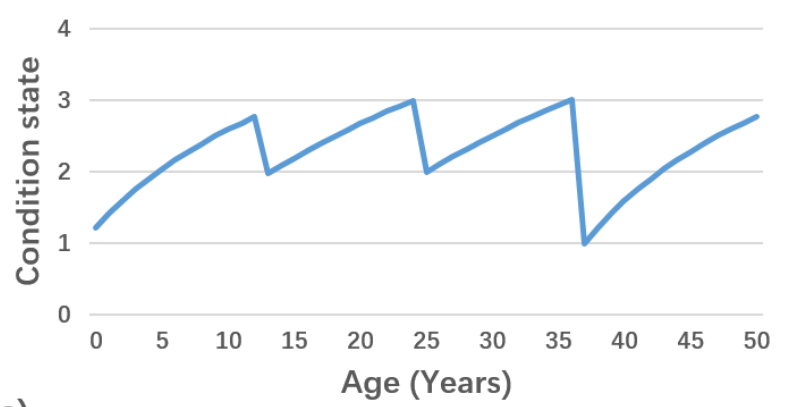

(c)

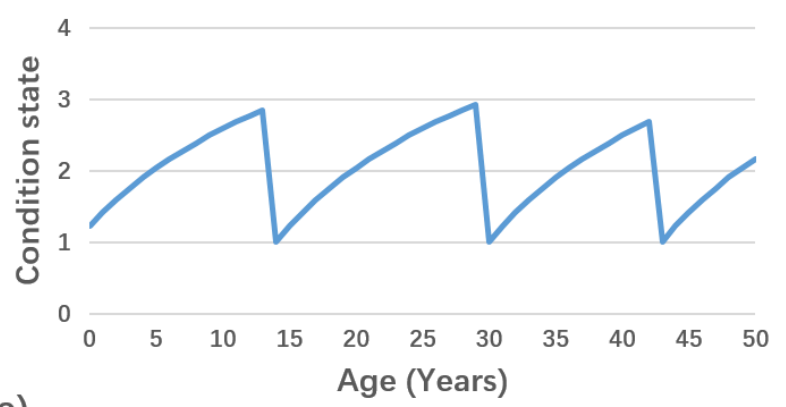

(e)

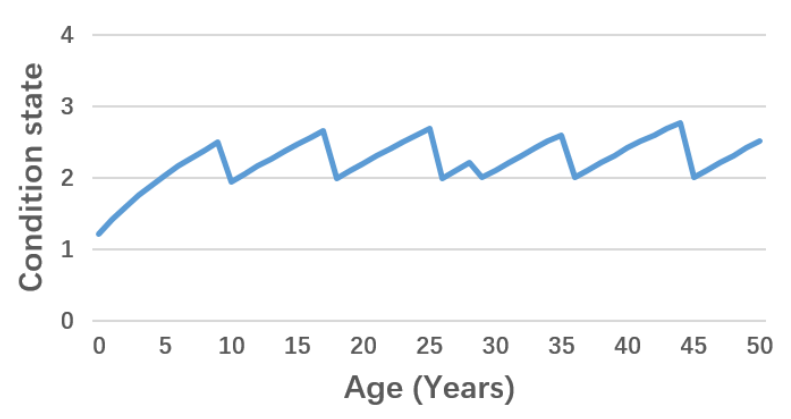

(b)

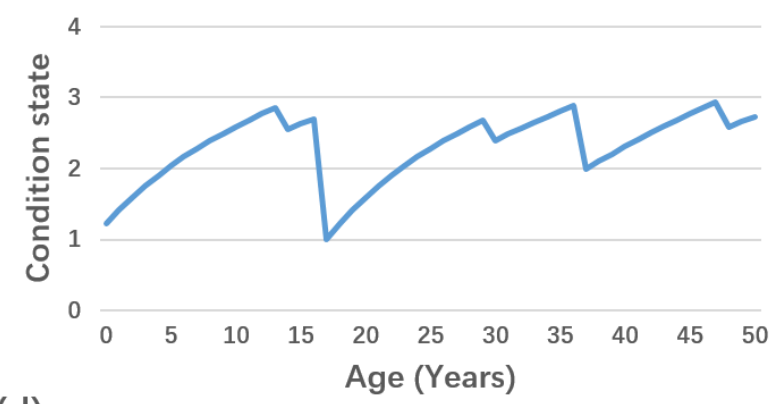

(d)

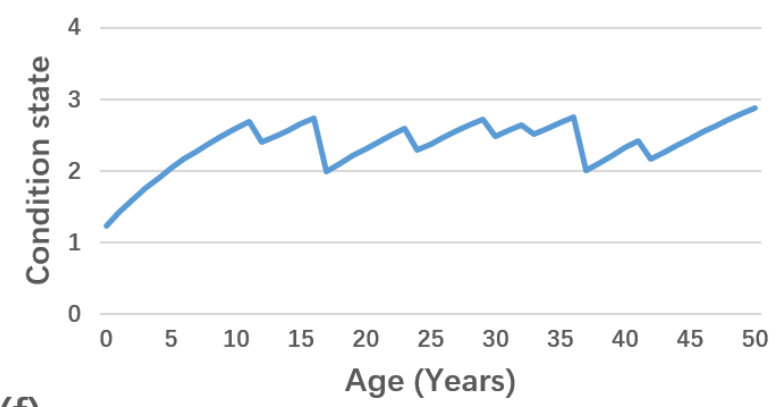

(f)

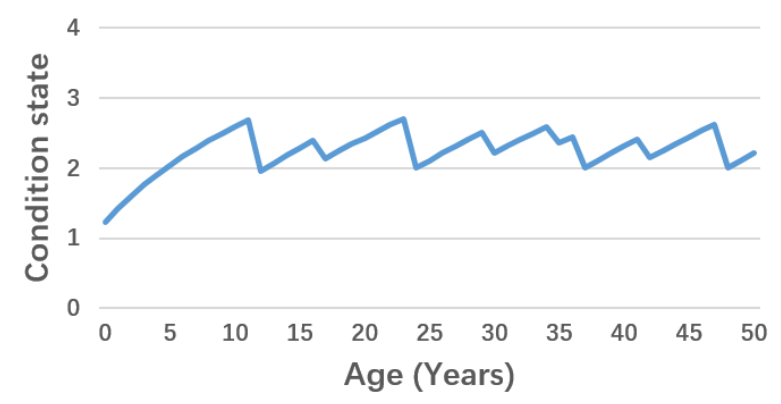

Figure 5-19 Optimized deterioration pattern for the six representative M\&R actions of the bridge deck showing different action spread and level throughout the bridge lifetime. (a) two major maintenances and one replacement $\left(\mathrm{X}_{1}\right)$; (b) three replacements $\left(\mathrm{X}_{2}\right)$; (c) six major repairs $\left(\mathrm{X}_{3}\right)$; (d) three minor maintenances, one major maintenance and one replacement ( $\mathrm{Y}_{1}$ ); (e) five minor maintenances and two major maintenances $\left(\mathrm{Y}_{2}\right)$; (f) four minor maintenances and four major maintenances. 
(a)

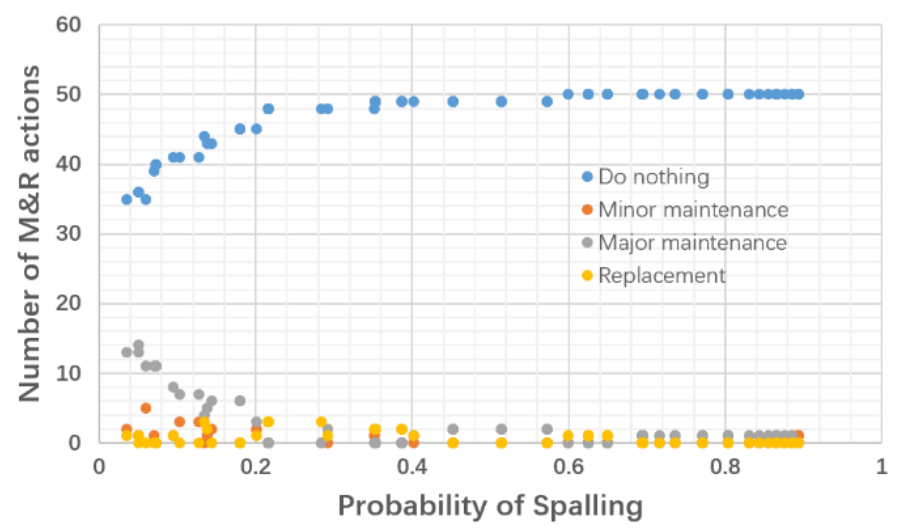

(b)

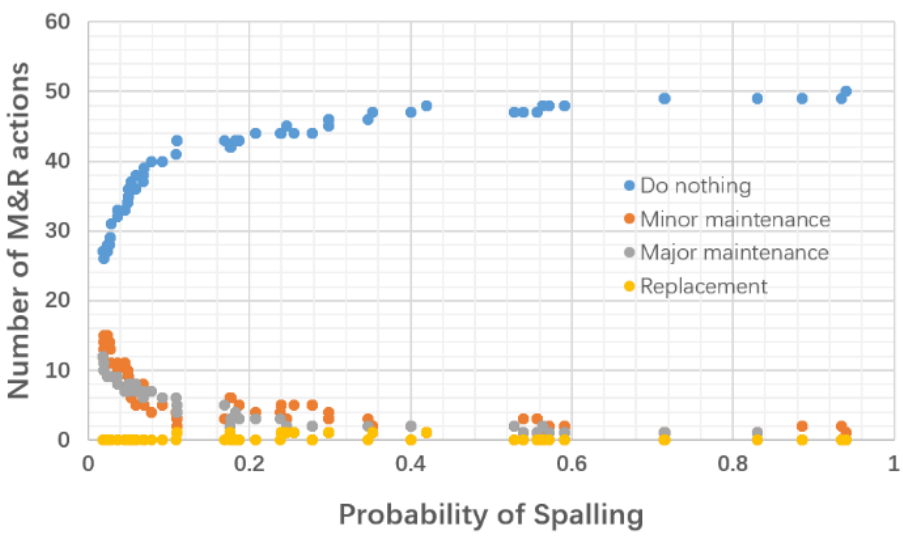

Figure 5-21 Number of M\&R actions as a function of Probability of Spalling for two optimization methods. (a) MOPSO, RCP4.5, 50mm; (b) NSGA-II, RCP4.5, 50mm.

(a)

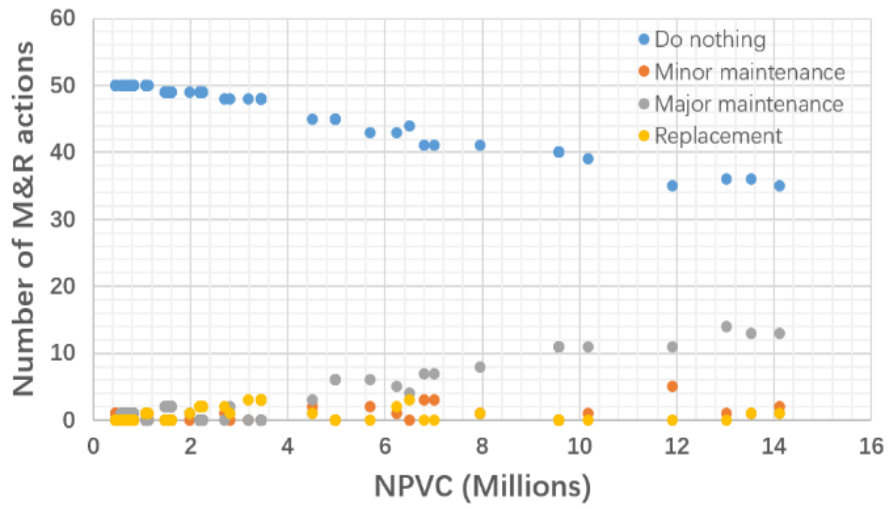

(b)

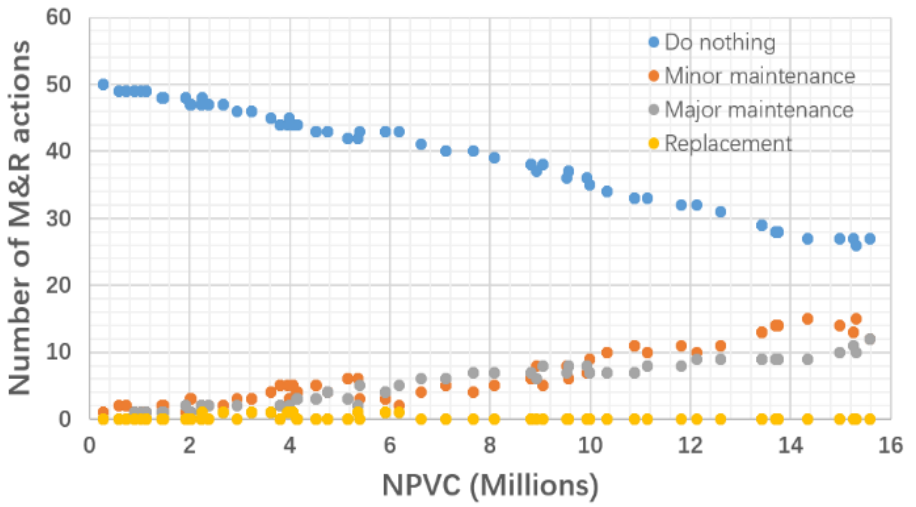

Figure 5-20 Number of M\&R actions as a function of NPVC for two optimization methods (a) MOPSO, RCP4.5, 50mm; (b) NSGA-II, RCP4.5, 50mm. 
Figures 20 and 21 show the number of M\&R actions as a function of the Probability of spalling and NPVC, respectively. We can see clear differences between the two optimization approaches in terms of favorability to execute M\&R actions. MOPSO prompts the "do nothing" action slightly more often than NSGA-II. In addition, at a 0.6 probability of spalling, MOPSO's "do nothing" decision reaches saturation, which is faster than that obtained from NSGA. This behavior can be seen as an advantage of MOPSO over the NSGA-II. Additional sensitivity analysis shows the advantage of MOPSO, as depicted in Figure 5-21. While the slope of "do nothing" decision is similar in solutions obtained from both optimization approaches, when considering the NPVC, the slopes of action decisions are slightly higher in the case of NSGA-II solutions. This indicates that MOPSO solutions are able to return lower number of maintenance activities to achieve an optimal solution at the same NPVC. Moreover, the results shown in Figures 20 and 21 can help decisionmakers obtain the information about the number of different $M \& R$ actions that need to be performed during the 50 years when considering specific policy and better understand the relationship between different actions. It is important to note that changing the population size and other optimization parameters may affect the obtained results, but this is beyond the scope of the present work.

Similar findings can be observed in other scenarios. The results also show that improper quality control at the time of construction for the placement of reinforcing steel (small concrete cover thickness) have a strong negative impact on durability. This will further lead to more M\&R actions during the lifetime of the bridge to maintain the deck at the required performance level. Moreover, climate change is expected to negatively affect the durability of concrete structures in Montreal, and it needs to be taken into account when considering future allocations of the funds for infrastructure management. 


\subsection{Conclusions and future directions}

Improving the sustainability and serviceability of infrastructures in the most economical way are important objectives for decision-makers given the current state of uncertainty with climate change and the general state of the infrastructure.

An inverse relationship generally exists between condition of bridge and profit during the operation. It means whenever bridge condition improves, the cost of maintenances will considerably increase. A proper trade-off strategy in these objectives is critical for facility managers.

Therefore, a real case study on bridge in Montreal is conducted to demonstrate the availability of the optimization problem through the application of the two efficient Meta heuristic algorithms. For a single facility, the developed novel MOO model helps in determination of the sequence of M\&R actions over a certain study period "N", and by minimizing NPVC of the rehabilitations in making sure the acceptable level of performance of the infrastructure during the service life.

The optimization techniques are used by developed methodology with Markov chain principles for infrastructure deterioration modelling. The first step is of identification of the data, then two individual models are made for Meta heuristic algorithms structure and Markov chain deterioration process. Then, under the single platform, the novelty also arises through considering the uncertainties with financial, climate change and the exposure to de-icing salts that integrated in the decision model. The results reveal that the deterioration model can accurately predict the service life distribution for current RC bridge decks taking into consideration the climate on a historical basis. The findings also show that under climate change scenarios, the service life of new RC facilities that have been designed utilising current procedures and that are subject to current 
policies for using de-icing salts would be considerably reduced. The service life reduction is due in main to an increase in the number of precipitation days throughout the winter in despite of an increase in temperatures. The model of intervention effect is by nature dynamic, which means, certain intervention techniques and methods could be implemented with different levels of improvement effects. The analysis of the generated trade-offs between objectives shows that the model was able to generate a wide range of optimal trade-off solutions through the consideration of all specified policies and constraints, and therefore the decision-makers could select based on the available budget for bridge maintenance and the reliability.

Note that it is necessary to determine the target failure probability in terms of durability for the structure and individual components on the basis of: a) the design life of the structure; b) the design life of components; c) maintenance complexity and costs; and d) limiting the state-dependent consequences of any failure. A consensus should be reached between the relevant authority with jurisdiction and the owners in terms of the criteria regarding a suitable level of reliability and serviceability. NSGA-II and MOPSO, which are efficient dealing with computationally complex optimization problems as techniques of MOO are implemented and compared. The findings also show that over NSGA-II, MOPSO has an advantage according to the optimal solutions in terms of NPVC and the probability of spalling.

Future works can extend this work by considering M\&R plans for different type of components of bridge over different time in management period. As certain results are subject to change in cost models, the systematic sensitivity analysis of cost models is recommended. Additionally, the detailed policies such as the time interval of the $M \& R$ actions can be introduced along with environmental and social effects of the NPVC model. 


\section{Acknowledgments}

The authors would like to acknowledge the financial support from a NSERC-CREATE grant.

\section{References}

Adámek, Jirí, and Vlasta Juránková. 2010. "Evaluation of durability of concrete by measurement of permeability for air and water." In Modern Building Materials, Structures and Techniques. Proceedings of the International Conference, 1. Vilnius Gediminas Technical University, Department of Construction Economics ....

AL-Smadi, Huthaifa. 2019. 'Space-Based Maintenance Management for Architectural Building Systems using Multi-Objective Optimization', Concordia University.

Anastasopoulos, Panagiotis Ch, John E Haddock, and Srinivas Peeta. 2013. 'Improving systemwide sustainability in pavement preservation programming', Journal of Transportation Engineering, 140: 04013012.

Angst, Ueli. 2011. 'Chloride induced reinforcement corrosion in concrete', Doctoral theses, Norwegian University of Science and Technology, Trondheim.

Angst, Ueli M. 2018. 'Challenges and opportunities in corrosion of steel in concrete', Materials and Structures, 51: 4.

Babapour, Razieh, Ramin Naghdi, Ismael Ghajar, and Zahra Mortazavi. 2018. 'Forest road profile optimization using meta-heuristic techniques', Applied Soft Computing, 64: 126-37.

Bastidas-Arteaga, Emilio, Alaa Chateauneuf, Mauricio Sánchez-Silva, Ph Bressolette, and Franck Schoefs. 2011. 'A comprehensive probabilistic model of chloride ingress in unsaturated concrete', Engineering Structures, 33: 720-30. 
Bazant, Zdenek P. 1979. 'Physical model for steel corrosion in concrete sea structures--theory', Journal of the Structural Division, 105.

Belevičius, Rimantas, Donatas Jatulis, and Dmitrij Šešok. 2013. 'Optimization of tall guyed masts using genetic algorithms', Engineering Structures, 56: 239-45.

Bhatti, M Asghar. 2012. Practical Optimization Methods: With Mathematica ${ }^{\circledR}$ Applications (Springer Science \& Business Media).

Bierlaire, Michel, Michaël Thémans, and Nicolas Zufferey. 2010. 'A heuristic for nonlinear global optimization', INFORMS Journal on Computing, 22(1): 59-70.

Blum, Christian, and Andrea Roli. 2003. 'Metaheuristics in Combinatorial Optimization: Overview and Conceptual Comparison', ACM Computing Surveys, 35(3): 268-308.

Breysse, Denys, Myriam Chaplain, Antoine Marache, and Elodie Rodney. 2014. 'Simulation of synthetic climate at local scale as a mean to assess the impact of climate change on infrastructures', Civil Engineering and Environmental Systems, 31: 165-78.

Byrd, Richard H, Jean Charles Gilbert, and Jorge Nocedal. 2000. 'A trust region method based on interior point techniques for nonlinear programming', Mathematical programming, 89: $149-85$.

Canada, Environment. 2019. "Environment and Climate Change Canada." In.

Cao, Yin, Christoph Gehlen, Ueli Angst, Ling Wang, Zhendi Wang, and Yan Yao. 2019. 'Critical chloride content in reinforced concrete-An updated review considering Chinese experience', Cement and Concrete Research, 117: 58-68.

Cesare, Mark A, Carlos Santamarina, Carl Turkstra, and Erik H Vanmarcke. 1992. 'Modeling bridge deterioration with Markov chains', Journal of Transportation Engineering, 118: 820-33. 
Chen, Lin, and Qiang Bai. 2019. 'Optimization in Decision Making in Infrastructure Asset Management: A Review', Applied Sciences, 9: 1380.

Chen, Lin, Theunis FP Henning, Andrea Raith, and Asaad Y Shamseldin. 2015. 'Multiobjective optimization for maintenance decision making in infrastructure asset management', Journal of Management in Engineering, 31: 04015015.

Chou, Jui-Sheng, and Thanh-Son Le. 2011. 'Reliability-based performance simulation for optimized pavement maintenance', Reliability engineering \& system safety, 96: 1402-10.

Collins, Lyndhurst. 1975. "An introduction to Markov chain analysis." In.: Geo Abstracts Ltd.

Deb, Kalyanmoy, Amrit Pratap, Sameer Agarwal, and TAMT Meyarivan. 2002. 'A fast and elitist multiobjective genetic algorithm: NSGA-II', IEEE transactions on evolutionary computation, 6: 182-97.

Eberhart, Russell, and James Kennedy. 1995. "Particle swarm optimization." In Proceedings of the IEEE international conference on neural networks, 1942-48. Citeseer.

Elhadidy, Amr A, Emad E Elbeltagi, and Mohammad A Ammar. 2015. 'Optimum analysis of pavement maintenance using multi-objective genetic algorithms', HBRC Journal, 11: 10713.

Farran, Mazen, and Tarek Zayed. 2012. 'New life-cycle costing approach for infrastructure rehabilitation', Engineering, Construction and Architectural Management, 19: 40-60.

FHWA. 1995. 'coding guide for the structure inventory and appraisal of the nation's bridges', Federal Highway Administration Report FHWA-PD-96-001.

Frangopol, Dan M. 2011. 'Life-cycle performance, management, and optimisation of structural systems under uncertainty: accomplishments and challenges 1', Structure and Infrastructure Engineering, 7: 389-413. 
Frangopol, Dan M, and Mohamed Soliman. 2016. 'Life-cycle of structural systems: recent achievements and future directions', Structure and infrastructure engineering, 12: 1-20.

Gen, Mitsuo, and Runwei Cheng. 2000. 'Genetic algorithms and engineering optimization. 2000', John Wiley\&Sons, New York (USA).

Goldberg, David E, and John H Holland. 1988. 'Genetic algorithms and machine learning', Machine learning, 3: 95-99.

Hadiwardoyo, Sigit P, A Gomes Correia, and Paulo Pereira. 2017. 'Pavement maintenance optimization strategies for national road network in indonesia applying genetic algorithm', Procedia engineering, 210: 253-60.

Hertz, Alain, David Schindl, and Nicolas Zufferey 2005. 'Lower bounding and tabu search procedures for the frequency assignment problem with polarization constraints', 4OR, 3(2): $139-161$.

Hillier, Frederick S. 2012. Introduction to operations research (Tata McGraw-Hill Education).

Horn, Jeffrey, Nicholas Nafpliotis, and David E Goldberg. 1994. "A niched Pareto genetic algorithm for multiobjective optimization." In Proceedings of the first IEEE conference on evolutionary computation. IEEE world congress on computational intelligence, 82-87. Ieee.

Hunkeler, F. 2005. 'Corrosion in reinforced concrete: processes and mechanisms', Corrosion in reinforced concrete structures: $1-45$.

Jiang, Yi, and Kumares C Sinha. 1989. 'Bridge service life prediction model using the Markov chain', Transportation research record, 1223: 24-30.

Kale, Rajesh F, NG Gore, and PJ Salunke. 'Applications of matlab in optimization of bridge superstructures', International Journal of Research in Engineering and Technology, 3. 
Kim, Sunyong, Dan M Frangopol, and Mohamed Soliman. 2013. 'Generalized probabilistic framework for optimum inspection and maintenance planning', Journal of Structural Engineering, 139: 435-47.

Lalwani, Soniya, Sorabh Singhal, Rajesh Kumar, and Nilama Gupta. 2013. 'A comprehensive survey: Applications of multi-objective particle swarm optimization (MOPSO) algorithm', Transactions on Combinatorics, 2: 39-101.

Lin, Ming-Hua, Jung-Fa Tsai, and Chian-Son Yu. 2012. 'A review of deterministic optimization methods in engineering and management', Mathematical Problems in Engineering, 2012.

Lounis, Z, B Martin-Perez, L Daigle, and J Zhang. 2006. 'Decision Support Tools for Service Life Prediction and Rehabilitation of Concrete Bridge Decks-Final Report', Institute for Research in Construction, National Research Council Canada (B5318. 2).

Lounis, Zoubir, and L Daigle. 2008. "Reliability-based decision support tool for life cycle design and management of highway bridge decks." In Annual Conference of the Transportation Association of Canada, 1-19.

Lounis, Zoubir, and Therese P McAllister. 2016. 'Risk-based decision making for sustainable and resilient infrastructure systems', Journal of Structural Engineering, 142: F4016005.

Marlow, DR, DJ Beale, and Stewart Burn. 2010. 'A pathway to a more sustainable water sector: sustainability-based asset management', Water Science and Technology, 61: 1245-55.

Menon, Saraswathi, Judith Karl, and Kanni Wignaraja. 2009. 'Handbook on planning, monitoring and evaluating for development results', UNDP Evaluation Office, New York, NY.

Morcous, George, and Zoubir Lounis. 2005. 'Maintenance optimization of infrastructure networks using genetic algorithms', Automation in Construction, 14: 129-42. 
Moteleb, Moustafa. 2010. Risk based decision making tools for sewer infrastructure management (University of Cincinnati).

Ng, ManWo, Zhanmin Zhang, and S Travis Waller. 2011. 'The price of uncertainty in pavement infrastructure management planning: An integer programming approach', Transportation Research Part C: Emerging Technologies, 19: 1326-38.

Nilsson, LO, E Poulsen, P Sandberg, HE Sørensen, and O Klinghoffer. 1996. 'HETEK, Chloride penetration into concrete, State-of-the-Art, Transport processes, corrosion initiation, test methods and prediction models', Denmark, ISSN/ISBN: 0909-4288.

O'Connor, AJ, E Sheils, Denys Breysse, and Franck Schoefs. 2011. 'Markovian bridge maintenance planning incorporating corrosion initiation and nonlinear deterioration', Journal of Bridge Engineering, 18: 189-99.

Palko, K, and Donald Stanley Lemmen. 2017. 'Climate risks and adaptation practices for the Canadian transportation sector 2016'.

Parsopoulos, Konstantinos E, and Michael N. Vrahatis. 2002. 'Recent approaches to global optimization problems through particle swarm optimization', Natural computing, 1: 235306.

Poli, Riccardo, James Kennedy, and Tim Blackwell. 2007. 'Particle swarm optimization', Swarm intelligence, 1: 33-57.

Portnoy, Stephen, and Roger Koenker. 1997. 'The Gaussian hare and the Laplacian tortoise: computability of squared-error versus absolute-error estimators', Statistical Science, 12: 279-300.

Proceq. 2005. "Permeability Tester TORRENT." In Operating Instructions. 
Rifai, Andri Irfan, Sigit Pranowo Hadiwardoyo, António Gomes Correia, and PAULO Pereira. 2016. "Genetic Algorithm Applied for Optimization of Pavement Maintenance under Overload Traffic: Case Study Indonesia National Highway." In Applied Mechanics and Materials, 369-78. Trans Tech Publ.

Saetta, Anna V, Roberto V Scotta, and Renato V Vitaliani. 1993. 'Analysis of chloride diffusion into partially saturated concrete', Materials Journal, 90: 441-51.

Santos, João, Adelino Ferreira, and Gerardo Flintsch. 2017. 'A multi-objective optimization-based pavement management decision-support system for enhancing pavement sustainability', Journal of cleaner production, 164: 1380-93.

Santos, João, Adelino Ferreira, and Gerardo Flintsch. 2019. 'An adaptive hybrid genetic algorithm for pavement management', International Journal of Pavement Engineering, 20: 266-86.

Santos, João, Adelino Ferreira, Gerardo Flintsch, and Veronique Cerezo. 2018. 'A multi-objective optimisation approach for sustainable pavement management', Structure and Infrastructure Engineering, 14: 854-68.

Sarma, Kamal C, and Hojjat Adeli. 1998. 'Cost optimization of concrete structures', Journal of structural engineering, 124: 570-78.

Schmitt, Lothar M. 2001. 'Theory of genetic algorithms', Theoretical Computer Science, 259: 161.

Shim, Hyung Seop, and Seung Hyun Lee. 2017. 'Balanced allocation of bridge deck maintenance budget through multi-objective optimization', KSCE Journal of Civil Engineering, 21: 1039-46.

Silver, Edward A, R Victor, V Vidal, and Dominique de Werra. 1980. 'A tutorial on heuristic methods', European Journal of Operational Research, 5: 153-62. 
Thomas, Omar, and John Sobanjo. 2016. 'Semi-Markov models for the deterioration of bridge elements', Journal of Infrastructure Systems, 22: 04016010.

Torrent, R, and G Frenzer. 1995. "A method for the rapid determination of the coefficient of permeability of the "covercrete"." In International Symposium Non-Destructive Testing in Civil Engineering (NDT-CE), 985-92.

Torrent, Roberto J. 1992. 'A two-chamber vacuum cell for measuring the coefficient of permeability to air of the concrete cover on site', Materials and structures, 25: 358-65.

Wu, Zheng, Gerardo W Flintsch, and Tanveer Chowdhury. 2008. 'Hybrid multiobjective optimization model for regional pavement-preservation resource allocation', Transportation research record, 2084: 28-37.

Zhang, Le, Liangliang Fu, Weihua Gu, Yanfeng Ouyang, and Yaohua Hu. 2017. 'A general iterative approach for the system-level joint optimization of pavement maintenance, rehabilitation, and reconstruction planning', Transportation Research Part B: Methodological, 105: 378-400.

Zhang, Weili, and Naiyu Wang. 2017. 'Bridge network maintenance prioritization under budget constraint', Structural safety, 67: 96-104.

Zhang, Yan, Luc E Chouinard, and David Conciatori. 2018. 'Markov chain-based stochastic modeling of chloride ion transport in concrete bridges', Frontiers in Built Environment, 4: 12.

Zhang, Yan, Luc E Chouinard, Gabriel J Power, Charli D Tandja M, and Josée Bastien. 2018. 'Flexible decision analysis procedures for optimizing the sustainability of ageing infrastructure under climate change', Sustainable and Resilient Infrastructure: 1-12. 


\section{Preface to Chapter 6}

In the previous chapter, probabilistic models have been developed to propagate uncertainties and to estimate the probability distribution of the chloride ion content as a function of time and space, and for the time to the initiation of corrosion. In many instances, the degree of uncertainties on predictions can be very large which reduces the usefulness of the predictions in practical applications. A measure of decreasing these uncertainties is to obtain core samples in order to determine the chloride content at various depths from the concrete cover to update distribution parameters. In the next chapter, an efficient and novel system identification procedure based on a surrogate model and a Bayesian procedure for chloride ion levels as a function of time and space is proposed for updating the distribution of model parameters. Surrogate models are used to get an appropriate representation of the chloride ion transport model and to facilitate computations. This novel approach can be used in combination with single or multiples core samples obtained on a structure. 


\section{Chapter 6. Bayesian Estimation of Model Parameters for Chloride Ion Ingress in Concrete Using Core Sample Data}

\section{Abstract}

Several models for predicting the residual life of concrete structures have been developed in recent years in response to the need to optimize inspection, repairs and replacement strategies for existing bridges and for the design of more durable structures. The dominant mode of deterioration of concrete bridge structures in northern climates is corrosion associated with the ingress of chloride ions from salt spreading. Finite element and finite difference models can be used to predict the concentration of chloride ions as a function of time and space in concrete and to estimate the time to the initiation of corrosion of the reinforcing steel. The input parameters to these models include environmental exposure data, salt spreading protocols and concrete properties. Data on environmental exposure and salt spreading protocols can be obtained from meteorological stations and roadway operators respectively such that the remaining uncertainties are mainly related to concrete properties. Prior distributions on concrete diffusion properties can be specified using compiled data bases of experimental data. Probabilistic methods are used to propagate uncertainties on concrete properties in the models and to derive the prior probability distribution function of chloride ion content as a function of time and depth. When chloride content is obtained from core samples, Bayesian updating procedures are proposed to update the probability distribution functions of concrete properties considering the type of exposure, the chloride ion profile and time of sampling. The proposed procedure can be applied for any number of core samples sampled at different times and accounts for correlations between chloride content 
predictions at different times and depths. The proposed procedure is demonstrated for an existing bridge located in Montreal, Canada.

Keywords: Bayesian updating; chloride ion; deterioration; core sample data; concrete bridge.

\subsection{Introduction}

The techniques for modelling deterioration processes for infrastructures have evolved rapidly over the last decades. This has been in response to the increasingly large number of ageing structures and the need to better predict their residual life and develop timely and economically optimal intervention plans for infrastructure portfolios. Corrosion of reinforcing steel due to exposure to chloride ions is the main cause of deterioration of concrete bridges in northern climates. The corrosion of reinforcing steel leads to concrete cracking, delamination and spalling of the concrete cover, reduction of reinforcement cross section, and loss of bond between the reinforcing steel and concrete, which result in a reduction in strength and ductility of both structural and non-structural elements.

Several models for the transport of chloride ions in concrete have been proposed in the literature that account with varying degrees of detail and accuracy for the chemical interactions between concrete materials and chloride ions as well as for the type and level of environmental exposure. A probabilistic approach in the application of these models is favored since it explicitly accounts for the random nature of exposure, the uncertainties in the prediction models and the uncertainty on concrete properties (Bastidas-Arteaga et al. 2011; Saassouh and Lounis 2012; Zhang, Chouinard, and Conciatori 2018). Probabilistic approaches have been implemented through Monte Carlo simulation (Lounis and Mirza 2001), first-order or second-order reliability methods (Enright 
and Frangopol 1998), and point-estimation methods and crossing theory (Stewart and Rosowsky 1998; Conciatori et al. 2009b). In general, more advanced deterioration models require a large number of input parameters and are computationally more demanding, which limits the types of probabilistic analyses that can be performed efficiently.

In this work, uncertainties associated with concrete properties, modelling of chloride ions ingress, and environmental exposure are considered. The application of the proposed probabilistic model is illustrated for a chloride-contaminated concrete bridge located in Montreal that was exposed to de-icing salts for over forty years and for which environmental and core sample data are available. First, the model used to predict the chloride content as a function of time and depth is described. Next, given prior distributions on concrete properties, point estimation methods are used to derive prior distribution of chloride content as a function of time and depth. Finally, given core sample data, a Bayesian updating procedure is proposed that can account for correlations in predictions as a function of time and space.

\subsection{Model for Chloride Ions Transport in Concrete}

The time to initiation of corrosion is the most critical parameter in the estimation of the residual life of a structure in northern climates exposed to de-icing salts. The time to initiation to corrosion can be estimated by using models for the propagation of chloride ions in concrete and data on the critical chloride ion content to initiate corrosion for a given type of reinforcing steel. In this application, the TransChlor ${ }^{\circledR}$ model was selected to provide estimates of chloride ion content as a function of time and depth into the concrete (Conciatori et al. 2008; Conciatori et al. 2010). This model uses the time history of climate data to simulate the application of de-icing salts at the 
surface of concrete elements, and the penetration of the chloride ions into the concrete as a function of the type of exposure (direct, splash and mist). These features are important for updating model parameters using core sample data since simulation results can account for both the time history and type of exposure. The TransChlor ${ }^{\circledR}$ model is briefly described in the next section. A more detailed description of the model can be found in (Conciatori et al. 2018).

The TransChlor ${ }^{\circledR}$ model accounts for two primary chemical reactions: carbonation and adsorption of chloride ions by the cement paste. The second chemical reaction is a reversible transformation and therefore can adsorb or release chloride ions into the concrete pore structure. The TransChlor ${ }^{\circledR}$ uses a finite element method to solve for the ion propagation in space within the concrete and a finite difference method to solve for the progression as a function of time. The transport modes include thermal and vapor transfers, liquid water transport with and without chloride ions, capillary suction, chloride ion diffusion in water, and carbon dioxide diffusion in concrete. Movements of substances in the concrete depend directly on the concrete permeability for all transport modes, except for thermal transfers. The time step used in the simulation is 1 hour. This time interval provides the required level of accuracy to properly account for precipitation history and wetting/drying cycles.

Concrete properties that are considered as random variables are the water vapor diffusion coefficient $\left(D_{H R}\right)$, the free chloride ion diffusion coefficient $\left(D_{C L}\right)$ and the capillarity coefficient $\left(D_{C A P}\right)$. The exposure model used in the TransChlor ${ }^{\circledR}$ simulations is illustrated in Figure 6-1. 


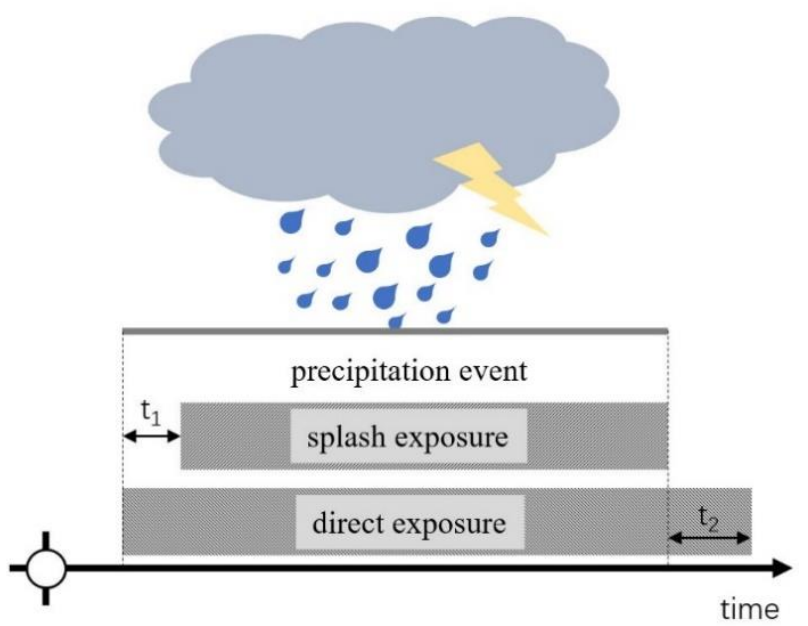

Figure 6-1 Exposure Types and Periods for TransChlor ${ }^{\circledR}$.

In the event of a precipitation event, the concrete surface is completely saturated, and the relative humidity reaches $100 \%$. Depending on the location of concrete elements, three types of exposure are possible: Direct, Splash and Mist (Figure 6-2). Direct exposure starts right after the precipitation event while splash exposure is delayed by $t_{1}$ hours to allow for water accumulation, and ends with $t_{2}$, the time required for drying the surface after the precipitation event. Mist exposure is only a function of relative humidity.

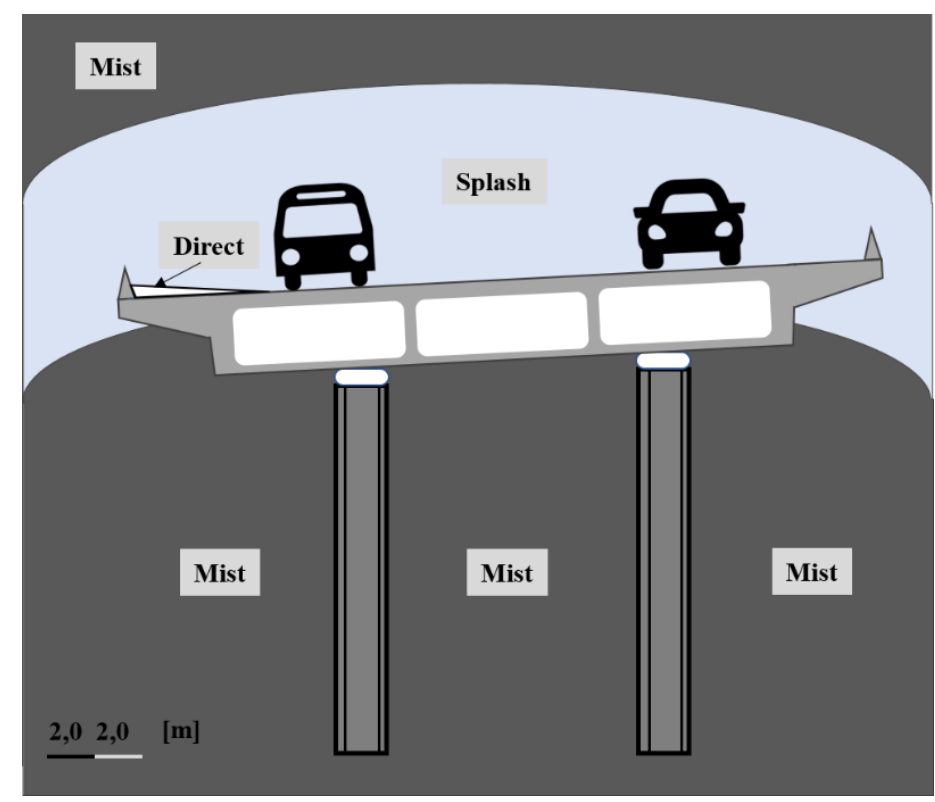

Figure 6-2 Types of exposures for bridge components. 
De-icing salts are applied on the road surface if any of the four following conditions are met:

1. ( $\left.T \leq T_{\text {lim }}\right)$ and $\left(H \geq H_{\text {lim }}\right)$, where $T$ is air temperature, $T_{\text {lim }}$ is temperature below which deicing salts are applied and similarly, $H$ and $H_{\text {lim }}$ are the relative humidity and the relative humidity above which de-icing salts are applied. In this application $H_{\text {lim }}$ is set at $95 \%$ while the $T_{\text {lim }}$ is obtained through iterative procedure to match annual amounts of de-icing salts used;

2. Rain and $\left(T \leq T_{\text {lim }}\right)$, when a precipitation event coincides with air temperatures below $T_{\text {lim }}$.

3. Snow, during snowing events;

4. $t_{\text {event }} \geq t_{\text {interval }}$, where $t_{\text {event }}$ is the duration of an event after the passage of a de-icing truck and $t_{\text {interval }}$ is the time interval between trucks.

The program also incorporates a probabilistic analysis to derive the probability distribution function of chloride ion content as a function of depth and time. Uncertainties in predictions are due to uncertainties in exposure conditions and material properties of the concrete. The relationships between the various components of the model are represented in Figure 6-3. 


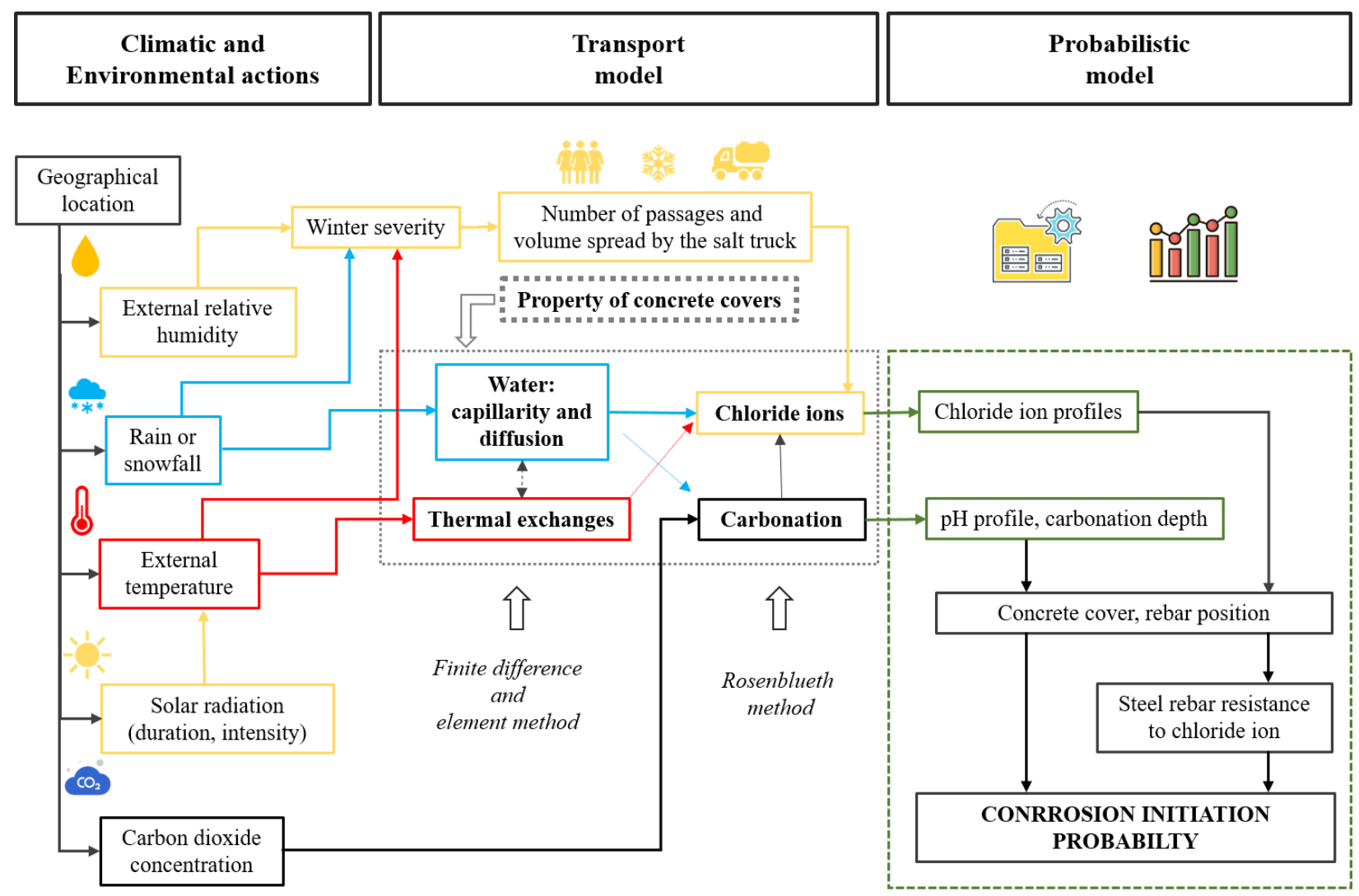

Figure 6-3 Flowchart of computations in TransChlor ${ }^{\circledR}$

In this application, the hourly environmental data observed during the service life of a given structure is used to model exposure, which greatly reduces this source of uncertainty. The residual uncertainty on exposure is related to the salt spreading rate. The salt spreading strategy is obtained from city records and/or from specifications for the salting equipment. For the purposes of this study, the rate of salt application for each salting operation is estimated from historical data (Wolofsky 2011b) and is assumed constant for the entire duration of the service life.

The three diffusion material properties that are considered random by the TransChlor ${ }^{\circledR}$ model are water vapor transport $\left(D_{H R}\right)$, liquid water transport by capillary suction $\left(D_{C A P}\right)$, and chloride ion 
transport $\left(D_{C L}\right)$. The relation between the diffusion parameters and the chloride content is a monotonic function of the diffusion parameters for a given time $(t)$ and depth $(d)$ of concrete cover.

$$
C l(t, d)=g\left(D_{H R}, D_{C A P}, D_{C L} \mid t, d\right)=g(\underline{D} \mid t, d)
$$

Under these conditions, the probability density function of the chloride content can de derived from the joint distribution of the diffusion parameters, assumed to be independent, $f_{\underline{D}}(\underline{d})=f_{D_{H R}} \cdot f_{D_{C A P}} \cdot f_{D_{C L}}$,

$$
\begin{gathered}
f_{C l}(c l \mid t, d)=|J|^{-1} f_{\underline{D}}\left(\underline{g}^{-1}(C l \mid t, d)\right) \\
f_{C l}(c l \mid t, d)=|J|^{-1} f_{D_{H R}}\left(g^{-1}(C l \mid t, d)\right) \cdot f_{D_{C A P}}\left(g^{-1}(C l \mid t, d)\right) \\
\cdot f_{D_{C L}}\left(g^{-1}(C l \mid t, d)\right)
\end{gathered}
$$

where

$$
|J|=\left|\frac{\partial g}{\partial D_{H R}} \quad \frac{\partial g}{\partial D_{C A P}} \quad \frac{\partial g}{\partial D_{C L}}\right|_{\left(D_{H R}, D_{C A P}, D_{C L}\right)=g^{-1}(C l)}
$$

In TransChlor ${ }^{\circledR}$ the chloride content for a given time and depth has been shown to be lognormally distributed though Monte Carlo simulation given that the diffusion parameters are also lognormally distributed (Conciatori et al. 2009b). Since the lognormal distribution is preserved, this implies that the relations between the diffusion coefficients and chloride content are approximately conditionally linear for a given time and depth. Under this assumption, the conditional distribution of chloride content $(\mathrm{Cl})$ can be fully characterized through its mean and variance, 


$$
\begin{gathered}
E[C l(t, d)]=\iiint g(\underline{D} \mid t, d) \cdot f_{\underline{D}}(\underline{d}) d \underline{D} \\
V A R[C l(t, d)]=\iiint(g(\underline{D} \mid t, d)-E[C l(t, d)])^{2} \cdot f_{\underline{D}}(\underline{d}) d \underline{D}
\end{gathered}
$$

A two-point Rosenblueth method is used to propagate the uncertainty and estimate probabilistic moments for chloride ion concentrations as a function of time and depth (Conciatori et al. 2009b). Details of the procedure and comparisons with results from Monte Carlo simulations (MCS) are presented in (Conciatori et al. 2014). Considering a real function $Y$ of a real variable $X$, it can be shown (Rosenblueth 1981) that the estimation of $n^{\text {th }}$ moment of $Y$ can be calculated from point estimators of $X$ independently of the distribution of the variable. The point estimators of $X\left(X_{+}\right.$and $\left.X_{-}\right)$and their associated weights $\left(p_{+}\right.$and $\left.p_{-}\right)$are defined as,

$$
\begin{gathered}
X_{+}=m_{X}+\zeta_{+} \sigma_{X} \quad X_{-}=m_{X}-\zeta_{-} \sigma_{X} \\
p_{+}=\frac{\zeta_{-}}{\zeta_{-}+\zeta_{+}} \quad p_{-}=1-p_{+} \\
\text {where } \quad \zeta_{+}=\frac{\gamma_{X}}{2} \sqrt{1+\left(\frac{\gamma_{X}}{2}\right)^{2}} \quad \zeta_{-}=\zeta_{+}-\gamma_{X}
\end{gathered}
$$

and $m_{X}, \sigma_{X}$ and $\gamma_{X}$ are respectively the mean, standard deviation and skewness of $X$. In the case where $Y$ is a function of $\mathrm{r}$ independent variables, a set of two-point estimates are defined for each variable. An estimate for the $n^{\text {th }}$ moment of $X$ is obtained by considering simulation result $\left(y_{i}\right)$ from all possible combinations $\left(c=2^{\mathrm{r}}\right)$ of the two-point estimates for the $r$ random variables, 


$$
\begin{gathered}
Y^{n}=\sum_{i=1}^{2^{r}} P_{i} \cdot y_{i} Y^{n}=\sum_{i=1}^{2^{r}} P_{i} \cdot y_{i} \\
y_{i}=f\left(x_{1 \delta_{1}}, x_{2 \delta_{2}}, \ldots, x_{r \delta r}\right) \\
P_{i}=\prod_{j=1}^{r} p_{\delta_{j}}
\end{gathered}
$$

where $\delta_{j}$ is the identifier $(+,-)$ of the point estimate for variable $j$, and $P_{i}$ is the probability associated with a given combination (out of $2^{\mathrm{r}}$ combinations) of transport properties. In this case, the Rosenblueth point estimation method performs well given that the function is close to linear as a function of the diffusion parameters for a given time and depth of concrete cover (Christian and Baecher 1999).

\subsection{Bayesian Updating Procedure}

The probabilistic estimation procedure described in the previous paragraph provides estimates of the conditional distribution of chloride ion content at a given time and depth using prior distributions on concrete diffusion parameters. The prior distributions of diffusion parameters are assumed to be independent and are obtained from databases on concrete properties for the type of concrete used in the structure under study. The uncertainty on chloride ion concentrations as a function of time and depth can be fairly large given the variability associated with concrete properties for a given mixture and adversely affect predictions of residual life used for optimizing maintenance and repair activities (Conciatori et al. 2009a). The uncertainty (standard deviation) on predictions also increase linearly as a function of time, which impacts the ability to properly 
plan future interventions. When core samples are available after given periods of service, this information can be used to update the probabilistic model and greatly reduce uncertainties on predictions of the residual life. Bastidas-Arteaga et al. (2012) and Richard et al. (2012) propose an approach based on Bayesian Networks for parameter identification from core sample data. They use a priori uniform distributions for the concentration of chloride ions at the surface $\left(C_{S}\right)$ and the effective chloride diffusion coefficient $(D)$. A Monte Carlo simulation procedure is used to obtain the conditional probability of chloride content as a function of the parameters $D$ and $C_{s}$ for the $\operatorname{erf}$ diffusion model. However, Monte Carlo procedures are computationally too demanding with TransChlor $^{\circledR}$, which uses coupled non-linear finite element and finite difference models to generate the hourly time-histories of ion propagation as a function of time and depth. An alternative procedure that requires much fewer model evaluations is developed below.

The posterior distribution for concrete parameters is defined as,

$$
f_{\left[\begin{array}{c}
D_{H R} \\
D_{C A P} \\
D_{C L}
\end{array}\right]}^{\prime \prime l}\left([\underline{C l}] \mid\left(D_{H R}, D_{C A P}, D_{C L}\right)\right) \cdot f_{\left[\begin{array}{c}
D_{H R} \\
D_{C A P} \\
D_{C L}
\end{array}\right]}^{\prime}
$$

where $f_{\left[\begin{array}{c}D_{H R} \\ D_{C A P} \\ D_{C l}\end{array}\right]}^{\prime}=f^{\prime}{ }_{D_{H R}} \cdot f^{\prime}{ }_{D_{C A P}} \cdot f^{\prime}{ }_{D_{C L}}$ is the joint prior distribution for the three random variables and $l\left([\underline{C l}] \mid\left(D_{H R}, D_{C l}, D_{C A P}\right)\right)$ is the likelihood of the chloride ion concentrations observed in the core samples as a function of diffusion parameters,

$$
l\left([\underline{C l}] \mid\left(D_{H R}, D_{C l}, D_{C A P}\right)\right)=\prod_{i=1}^{n_{\text {core }}} \prod_{j=1}^{n_{i}} f\left(C_{i, j} \mid t_{i}, d_{i, j},\left(D_{H R}, D_{C l}, D_{C A P,}\right)\right)
$$


where $n_{\text {core }}$ is the number of core samples available on the bridge, $n_{i}$ is the number of chloride content measurements performed on the $i^{t h}$ core sample, $t_{i}$ is the time at which the core sample was sampled, $d_{i j}$ is the depth of $j^{\text {th }}$ chloride ion measurement on core sample $i$, and where $f\left(C_{i, j} \mid t_{i}, d_{i, j},\left(D_{H R}, D_{C l}, D_{C A P}\right)\right)$ is the conditional distribution of chloride ion content given the diffusion parameters. Uncertainty on model predictions are represented by random variables for model and sampling uncertainty,

$$
C_{i, j(\text { core })}=C_{i, j(\text { pred })} \cdot \varepsilon_{m} \cdot \varepsilon_{s}
$$

where the variables $\varepsilon_{m}$ and $\varepsilon_{s}$ are assumed to be lognormally distributed. In most instance, the computational requirements to evaluate the likelihood function is prohibitive and a simplified version of the numerical model has to be used. Chen et al. (2004) review uncertainty propagation in numerical models and suggest performing MCS on meta-models such as Response Surface Models (RSM). However, the recommended number of simulations required to estimate an RSM with three input parameters is greater than 100 .

An alternative is to perform the analysis with a locally linearized since the numerical model is close to linear as a function of the diffusion parameters for a given time and depth. For example, considering a conditional second moment analysis for the chloride content $(\mathrm{Cl})$ at a given time and depth, the mean value vector and covariance matrix between chloride content and diffusion parameters are as follows, 


$$
\left[\begin{array}{c}
C l \\
D_{H R} \\
D_{C A P} \\
D_{C l}
\end{array}\right] \sim\left[\begin{array}{c}
\mu_{C l} \\
\mu_{D_{H R}} \\
\mu_{D_{C A P}} \\
\mu_{D_{C l}}
\end{array}\right],\left[\begin{array}{cccc}
\sigma_{C l}^{2} & \sigma_{C l, D_{H R}} & \sigma_{C l, D_{C A P}} & \sigma_{C l, D_{C l}} \\
\sigma_{C l, D_{H R}} & \sigma_{D_{H R}}^{2} & 0 & 0 \\
\sigma_{C l, D_{C A P}} & 0 & \sigma_{D_{C A P}}^{2} & 0 \\
\sigma_{C l, D_{C l}} & 0 & 0 & \sigma_{D_{C l}}^{2}
\end{array}\right]
$$

The elements of the mean value vector and covariance matrix are evaluated using prior distributions that reflect the large initial uncertainties associated with material properties. The conditional mean value for the chloride content given the diffusion parameter is then for the linearized model,

$\mu_{C l \mid D_{H R}, D_{C A P}, D_{C l}}=\mu_{C l}+\left[\begin{array}{lll}\sigma_{C l, D_{H R}} & \sigma_{C l, D_{C A P}} & \sigma_{C l, D_{C l}}\end{array}\right]\left[\begin{array}{ccc}\sigma_{D_{H R}}^{2} & 0 & 0 \\ 0 & \sigma_{D_{C A P}}^{2} & 0 \\ 0 & 0 & \sigma_{D_{C l}}^{2}\end{array}\right]^{-1}\left(\left[\begin{array}{c}D_{H R} \\ D_{C A P} \\ D_{C l}\end{array}\right]-\right.$ $\left.\left[\begin{array}{c}\mu_{D_{H R}} \\ \mu_{D_{C A P}} \\ \mu_{D_{C l}}\end{array}\right]\right)$

$$
\mu_{C l \mid D_{H R}, D_{C A P}, D_{C l}}=\mu_{C l}+\left[\begin{array}{lll}
\frac{\sigma_{C l, D_{H R}}}{\sigma_{D_{H R}}^{2}} & \frac{\sigma_{C l, D_{C A P}}}{\sigma_{D_{C A P}}^{2}} & \frac{\sigma_{C l, D_{C l}}}{\sigma_{D_{C l}}^{2}}
\end{array}\right]\left(\left[\begin{array}{c}
D_{H R}-\mu_{D_{H R}} \\
D_{C A P-} \mu_{D_{C A P}} \\
D_{C l}-\mu_{D_{C l}}
\end{array}\right]\right)
$$

$\mu_{C l \mid D_{H R}, D_{C A P}, D_{C l}}=\mu_{C l}+$

$\left[\frac{\rho_{C l, D_{H R}} \sigma_{C l}}{\sigma_{D_{H R}}} \cdot\left(D_{H R}-\mu_{D_{H R}}\right)+\frac{\rho_{C l, D_{C A P}} \sigma_{C l}}{\sigma_{D_{C A P}}} \cdot\left(D_{C A P-} \mu_{D_{C A P}}\right)+\frac{\rho_{C l, D_{C l}} \sigma_{C l}}{\sigma_{D_{C l}}} \cdot\left(D_{C l}-\mu_{D_{C l}}\right)\right]$

This last equation is equivalent to a multilinear regression as a function of the diffusion parameters and each term of the equation can be evaluated efficiently using the Rosenblueth point estimation 
procedure. The mean chloride content is obtained from equation 10 with $n=1$, while the slope parameter for each diffusion parameter (e.g. $\frac{\rho_{C l, D_{H R}} \sigma_{C l}}{\sigma_{D_{H R}}}$ for $D_{H R}$ ) is estimated as,

$$
\frac{\rho_{C l, D_{H R}} \sigma_{C l}}{\sigma_{D_{H R}}} \cong \frac{E\left[C l \mid D_{H R_{+}}\right]-E\left[C l \mid D_{H R_{-}}\right]}{D_{H_{+}}-D_{H R_{-}}}
$$

where $D_{H R_{+}}$and $D_{H R_{-}}$are define in Eq. 7. The conditional variance of the chloride content is obtained as,

$$
\begin{gathered}
\sigma_{C l \mid D_{H R}, D_{C A P}, D_{C l}}^{2}=\sigma_{C l}^{2}-\left[\begin{array}{lll}
\sigma_{C l, D_{H R}} & \sigma_{C l, D_{C A P}} & \sigma_{C l, D_{C l}}
\end{array}\right]\left[\begin{array}{ccc}
\frac{1}{\sigma_{D_{H R}}^{2}} & 0 & 0 \\
0 & \frac{1}{\sigma_{D_{C A P}}^{2}} & 0 \\
0 & 0 & \frac{1}{\sigma_{D_{C l}}^{2}}
\end{array}\right]\left[\begin{array}{c}
\sigma_{C l, D_{H R}} \\
\sigma_{C l, D_{C A P}} \\
\sigma_{C l, D_{C l}}
\end{array}\right] \\
\sigma_{C l \mid D_{H R}, D_{C A P}, D_{C l}}^{2}=\sigma_{C l}^{2}-\left[\frac{\left(\sigma_{C l, D_{H R}}\right)^{2}}{\sigma_{D_{H R}}^{2}}+\frac{\left(\sigma_{C l, D_{C A P}}\right)^{2}}{\sigma_{D_{C A P}}^{2}}+\frac{\left(\sigma_{C l, D_{C l}}\right)^{2}}{\sigma_{D_{C l}}^{2}}\right]
\end{gathered}
$$

$$
\sigma_{C l \mid D_{H R}, D_{C A P}, D_{C l}}^{2}=\sigma_{C l}^{2}\left(1-\rho_{C l, D_{H R}}{ }^{2}-\rho_{C l, D_{C A P}}{ }^{2}-{\rho_{C l, D_{C l}}}^{2}\right)
$$

The conditional second moment analysis assumes that the conditional variance is constant as a function of predictor variables. This last equation can also be evaluated efficiently by using the Rosenblueth point estimation procedure. For example, 


$$
\sigma_{C l \mid D_{H R}}^{2}=\sigma_{C l}^{2}\left(1-\rho_{C l, D_{H R}}^{2}\right) \cong \sigma_{C l \mid D_{H R_{+}}}^{2} \cdot P_{+}+\sigma_{C l \mid D_{H R_{-}}}^{2} \cdot P_{-}
$$

where $P_{+}$and $P_{-}$are defined in Eq. 8 .

The first-order second-moment models for the conditional mean and standard deviation are used to compute the likelihood of the diffusion parameters given core sample data. The prior distributions are used to estimate the conditional distributions and to compute the likelihood function of the diffusion parameters given the observations from core samples, for example, in the case of $D_{H R}$,

$$
\operatorname{lik}\left(D_{H R}\right) \propto \prod_{i=1}^{n_{\text {core }}} \prod_{j=1}^{n_{i}} f\left(C l_{i j} \mid E\left[C I \mid d_{i j}, t_{i}, D_{H R}\right], \sigma\left[C I \mid d_{i j}, t_{i}, D_{H R}\right]\right)
$$

where the probability density function is the lognormal distribrution with the conditional mean and the condtional variance defined in Eqs 19 and 23 respectively. Similar expressions are derived for the likehilood functions for $D_{C L}$ and $D_{C A P}$.

If data from a core is available at different depths (e.g. $25 \mathrm{~mm}$ and $50 \mathrm{~m}$ ), the procedure can be used to determine optimal model parameters for each depth separately or jointly for all depths and type of exposure. In the latter case, the joint conditional distribution for chloride content at two depths is used for the likelihood function. The mean value vector and covariance matrix for the variables is then, 


$$
\left[\begin{array}{c}
C l_{25} \\
C l_{50} \\
D_{H R} \\
D_{C A P} \\
D_{C l}
\end{array}\right] \sim\left[\begin{array}{c}
\mu_{C l_{25}} \\
\mu_{C l_{50}} \\
\mu_{D_{H R}} \\
\mu_{D_{C A P}} \\
\mu_{D_{C l}}
\end{array}\right],\left[\begin{array}{ccccc}
\sigma_{C l_{25}}^{2} & \sigma_{C l_{25}, C l_{50}} & \sigma_{C l_{25}, D_{H R}} & \sigma_{C l_{25}, D_{C A P}} & \sigma_{C l_{25}, D_{C l}} \\
\sigma_{C l_{25}, l_{50}} & \sigma_{C l_{50}}^{2} & \sigma_{C l_{50}, D_{H R}} & \sigma_{C l_{50}, D_{C A P}} & \sigma_{C l_{50}, D_{C l}} \\
\sigma_{C l_{25}, D_{H R}} & \sigma_{C l_{50}, D_{H R}} & \sigma_{D_{H R}}^{2} & 0 & 0 \\
\sigma_{C l_{25}, D_{C A P}} & \sigma_{C l_{50}, D_{C A P}} & 0 & \sigma_{D_{C A P}}^{2} & 0 \\
\sigma_{C l_{25}, D_{C l}} & \sigma_{C l_{50}, D_{C l}} & 0 & 0 & \sigma_{D_{C l}}^{2}
\end{array}\right]
$$

The conditional mean vector is then,

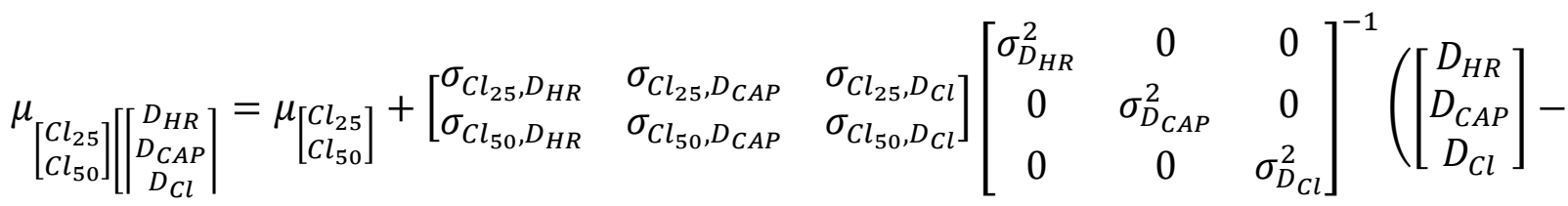

$\left.\left[\begin{array}{c}\mu_{D_{H R}} \\ \mu_{D_{C A P}} \\ \mu_{D_{C l}}\end{array}\right]\right)$

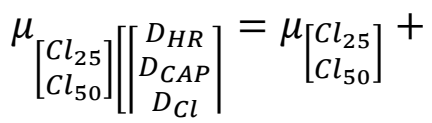

$\left[\begin{array}{lll}\frac{\rho_{C l_{25}, D_{H R}} \sigma_{C l_{25}}}{\sigma_{D_{H R}}} \cdot\left(D_{H R}-\mu_{D_{H R}}\right)+ & \frac{\rho_{C l_{25}, D_{C A P} \sigma_{C l_{25}}}}{\sigma_{D_{C A P}}} \cdot\left(D_{C A P-} \mu_{D_{C A P}}\right)+ & \frac{\rho_{C l_{25}, D_{C l}} \sigma_{C l_{25}}}{\sigma_{D_{C l}}} \cdot\left(D_{C l}-\mu_{D_{C l}}\right) \\ \frac{\rho_{C l_{50}, D_{H R}} \sigma_{C l_{50}}}{\sigma_{D_{H R}}} \cdot\left(D_{H R}-\mu_{D_{H R}}\right)+ & \frac{\rho_{C l_{50}, D_{C A P} \sigma_{C l_{50}}}}{\sigma_{D_{C A P}}} \cdot\left(D_{C A P-} \mu_{D_{C A P}}\right)+ & \frac{\rho_{C l_{50}, D_{C l}} \sigma_{C l_{50}}}{\sigma_{D_{C l}}} \cdot\left(D_{C l}-\mu_{D_{C l}}\right)\end{array}\right]$

Similarly, the conditional covariance matrix can be derived as,

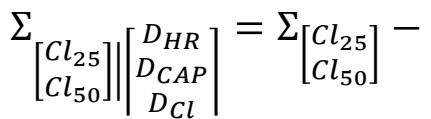

$\left[\begin{array}{lll}\sigma_{C l_{25}, D_{H R}} & \sigma_{C l_{25}, D_{C A P}} & \sigma_{C l_{25}, D_{C l}} \\ \sigma_{C l_{50}, D_{H R}} & \sigma_{C l_{50}, D_{C A P}} & \sigma_{C l_{50}, D_{C l}}\end{array}\right]\left[\begin{array}{ccc}\frac{1}{\sigma_{D_{H R}}^{2}} & 0 & 0 \\ 0 & \frac{1}{\sigma_{D_{C A P}}^{2}} & 0 \\ 0 & 0 & \frac{1}{\sigma_{D_{C l}}^{2}}\end{array}\right]\left[\begin{array}{cc}\sigma_{C l_{25}, D_{H R}} & \sigma_{C l_{50}, D_{H R}} \\ \sigma_{C l_{25}, D_{C A P}} & \sigma_{C l_{50}, D_{C A P}} \\ \sigma_{C l_{25}, D_{C l}} & \sigma_{C l_{50}, D_{C l}}\end{array}\right]$ 


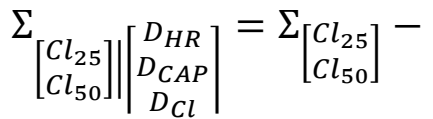

$$
\begin{aligned}
& {\left[\begin{array}{cc}
\frac{\left(\sigma_{C l_{25}, D_{H R}}\right)^{2}}{\sigma_{D_{H R}}^{2}}+\frac{\left(\sigma_{C l_{25}, D_{C A P}}\right)^{2}}{\sigma_{D_{C A P}}^{2}}+\frac{\left(\sigma_{C l_{25}, D_{C l}}\right)^{2}}{\sigma_{D_{C l}}^{2}} & \frac{\sigma_{C l_{25}, D_{H R}} \sigma_{C l_{50}, D_{H R}}}{\sigma_{D_{H R}}^{2}}+\frac{\sigma_{C l_{25}, D_{C A P}} \sigma_{C l_{50}, D_{C A P}}}{\sigma_{D_{C A P}}^{2}}+\frac{\sigma_{C l_{25}, D_{C l}} \sigma_{C l_{50}, D_{C l}}}{\sigma_{D_{C l}}^{2}} \\
s y m & \frac{\left(\sigma_{C l_{50}, D_{H R}}\right)^{2}}{\sigma_{D_{H R}}^{2}}+\frac{\left(\sigma_{C l_{50}, D_{C A P}}\right)^{2}}{\sigma_{D_{C A P}}^{2}}+\frac{\left(\sigma_{C l_{50}, D_{C l}}\right)^{2}}{\sigma_{D_{C l}}^{2}}
\end{array}\right]}
\end{aligned}
$$

Given the vector of the conditional mean chloride content and the conditional covariance matrix, the likelihood function is then evaluated for the multivariate lognormal distribution. In this case,

$$
\left[\begin{array}{l}
\ln \left(C l_{25} \mid D_{H R}\right) \\
\ln \left(C l_{50} \mid D_{H R}\right)
\end{array}\right] \sim N\left[\left[\begin{array}{l}
\mu_{\ln \left(C l_{25} \mid D_{H R}\right)} \\
\mu_{\ln \left(C l_{50} \mid D_{H R}\right)}
\end{array}\right],\left[\begin{array}{cc}
\sigma_{\ln \left(C l_{25} \mid D_{H R}\right)}^{2} & \left.\sigma_{\ln \left(C l_{25} \mid D_{H R}\right), \ln \left(C l_{50} \mid D_{H R}\right)}\right) \\
s y m & \sigma_{\ln \left(C l_{50} \mid D_{H R}\right)}^{2}
\end{array}\right]\right]
$$

where

$$
\begin{aligned}
\sigma_{\ln \left(C l_{25} \mid D_{H R}\right), \ln }\left(C l_{50} \mid D_{H R}\right) \\
=\ln \left(E\left[C l_{25} \cdot C l_{50}\right] \mid D_{H R}\right)-\mu_{\ln \left(C l_{25} \mid D_{H R}\right)} \\
-\mu_{\ln \left(C l_{50} \mid D_{H R}\right)}-\left(\frac{\sigma_{\ln \left(C l_{25} \mid D_{H R}\right)}^{2}+\sigma_{\ln \left(C l_{50} \mid D_{H R}\right)}^{2}}{2}\right)
\end{aligned}
$$

and

$$
\rho=\ln \left(\frac{\sigma_{C l_{25 \mid D_{H R}}, C l_{50 \mid D_{H R}}}}{E\left[C l_{25 \mid D_{H R}}\right] \cdot E\left[C l_{50 \mid D_{H R}}\right]}+1\right) \cdot \frac{1}{\sigma_{l n C l_{25 \mid D_{H R}}} \cdot \sigma_{l n C l_{50 \mid D_{H R}}}}
$$

The likelihood function for the observations at $25 \mathrm{~mm}$ and $50 \mathrm{~mm}$ depth on core samples is, 


$$
\begin{aligned}
& \operatorname{lik}\left(\ln C l_{25},{\left.\ln C l_{50}\right)}^{n} \prod_{i=1}^{n} \frac{1}{2 \pi \sigma_{l n C l_{25}} \cdot \sigma_{l n C l_{50}} \cdot \ln C l_{25} \cdot \ln C l_{50} \sqrt{1-\rho^{2}}} \exp \left[-\frac{1}{2\left(1-\rho^{2}\right)}\left\{\left(\frac{\ln C l_{25}-\mu_{l n C l_{25}}}{\sigma_{l n C l_{25}}}\right)^{2}\right.\right.\right. \\
& \left.\left.-2 \rho\left(\frac{\ln C l_{25}-\mu_{l n C l_{25}}}{\sigma_{l n C l_{25}}}\right)\left(\frac{\ln C l_{50}-\mu_{l n C l_{50}}}{\sigma_{l n C l_{50}}}\right)+\left(\frac{\ln C l_{50}-\mu_{\operatorname{lnCl} l_{50}}}{\sigma_{l n C l_{50}}}\right)^{2}\right\}\right]
\end{aligned}
$$

\subsection{Application to Bridges in Montreal}

Among North American cities, Montreal has one of the most severe climates for the environmental exposure of its infrastructures and in particular bridges. A large proportion of the bridges in Montreal were constructed between 1960 and 1970. Materials used during that time period were predominantly cement type I at $350 \mathrm{~kg} / \mathrm{m}^{3}$ with water/cement ratios of 0.5 , an air content of $1.5 \%$ of mass of cement, and limestone aggregates. The distribution for the diffusion parameters for this type of concrete are listed (Table 6-1) and are derived from a compilation of concrete properties by (Conciatori et al. 2009a)

The input parameters that control salt spreading in the simulations with TransChlor ${ }^{\circledR}$ are the average quantity of sodium chloride spread per intervention, and the time between two spreading operations $\left(t_{\text {interval }}\right)$ during a precipitation event. The application rate of sodium chloride per intervention is set at $140 \mathrm{~kg} / \mathrm{Lane}-\mathrm{km}$ (Morin and Perchanok 2000) which is the mean application rate for expressways and bare pavement conditions in Eastern Canada. The mean value also matches the recommended application rate provided in the CEPA Priority Substance List Assessment Report (Canada 2001). The salt dissolution is very influential on numerical results and 
is a highly uncertain parameter. Indeed the outcome of salt that has been spread is random and depends on factors such as traffic level and speed, and snow removal operations.

Figure 6-4 illustrates the influence of the application rate of sodium chloride on chloride ion concentration as a function of depth from the exposed surface after 45 years of exposure for a structure in Montreal (Wolofsky 2011b). The time between salting operations during a winter storm is set at 8 hours for typical bridges. The analysis simulates exposure for the last 45 years of service life using hourly climatic data for Montreal. The climate data obtained from Environment Canada was in $1 / 10^{\circ} \mathrm{C}$ (Figure 6-5). The concrete is modelled with finite elements (1D) with a resolution of $2 \mathrm{~mm}$ and for a maximum depth of $400 \mathrm{~mm}$. This thickness is larger than the actual thickness of the slab but has been selected to avoid numerical issues with open boundary conditions. Note that since the deck is part of a box girder, the internal face of the slab is not exposed to the environment or salt.

A probabilistic analysis is performed to account for the uncertainty on material properties. The TransChlor ${ }^{\circledR}$ model allows the user to consider up to four variables for concrete properties in the probabilistic approach 1) the hydraulic transport of water by diffusion $\left.\left(D_{H R}\right), 2\right)$ the hydraulic transport of water by capillary suction $\left.\left(D_{C A P}\right), 3\right)$ the ionic transport of chlorides $\left(D_{C L}\right)$, and 4$)$ the carbonation $\left(D_{\mathrm{CO} 2}\right)$. The temperature of concrete influences the hydraulic transport properties $\left(D_{H R}\right.$, and $\left.D_{C A P}\right)$, as well as the ionic transport of chlorides $\left(D_{C L}\right)$ and water concentration influences the ionic transport of chlorides, $\left(D_{C L}\right)$, and carbonation, $\left(D_{C O 2}\right)$. These dependencies are incorporated directly in the TransChlor ${ }^{\circledR}$ software (Conciatori et al. 2010). For the probabilistic analysis, all the parameters except for carbonation were selected, since analyses indicate that the depth of carbonation for all exposure conditions did not exceed $10 \mathrm{~mm}$ after 45 years. Therefore, only three variables were considered which requires $8\left(=2^{3}\right)$ simulations for the application of the 
Rosenblueth point-estimation procedure. The exposure conditions selected for the simulations correspond to splash and direct exposures, which are representative of exposure conditions where core samples were collected. For the probabilistic approach, mean and standard deviations for the three parameters are specified and used to compute the mean and standard deviation of the chloride ion concentration as a function of time and depth (Table 6-1). As discussed in (Conciatori et al. 2009b; Conciatori et al. 2014) the lognormal distribution is used for all the random variables. During the winter months, the concentrations of chloride ions fluctuate greatly near the concrete surface (i.e. within the breathing zone). This is due to capillary action and from alternating periods of high surface concentrations of chloride ions (during and shortly after salting operations) followed by low surface concentrations of chloride ions. Comparing the simulation results at 25 $\mathrm{mm}$ and $50 \mathrm{~mm}$ depths indicates that the chloride ion concentration at $25 \mathrm{~mm}$ depth is much more variable in time than the corresponding measurements at $50 \mathrm{~mm}$ depth and that predictions are dependent on meteorological conditions prior to sampling (Figure 6-4 and Table 6-2). The peaks in the figures correspond to salting operations while the downward trends correspond to summer months when chloride ions slowly diffuse deeper into the concrete. In this case, all core samples were obtained outside the winter period. In this case, the simulations with TransChlor ${ }^{\circledR}$ correspond to the same time during the service of the structures when core samples were obtained. If core samples are obtained at different times during the service life, results should be compiled for each time of sampling. In this case, it is important to note that the core samples were obtained during the summer months, long after the concrete surface was exposed to the application of de-icing salts. 

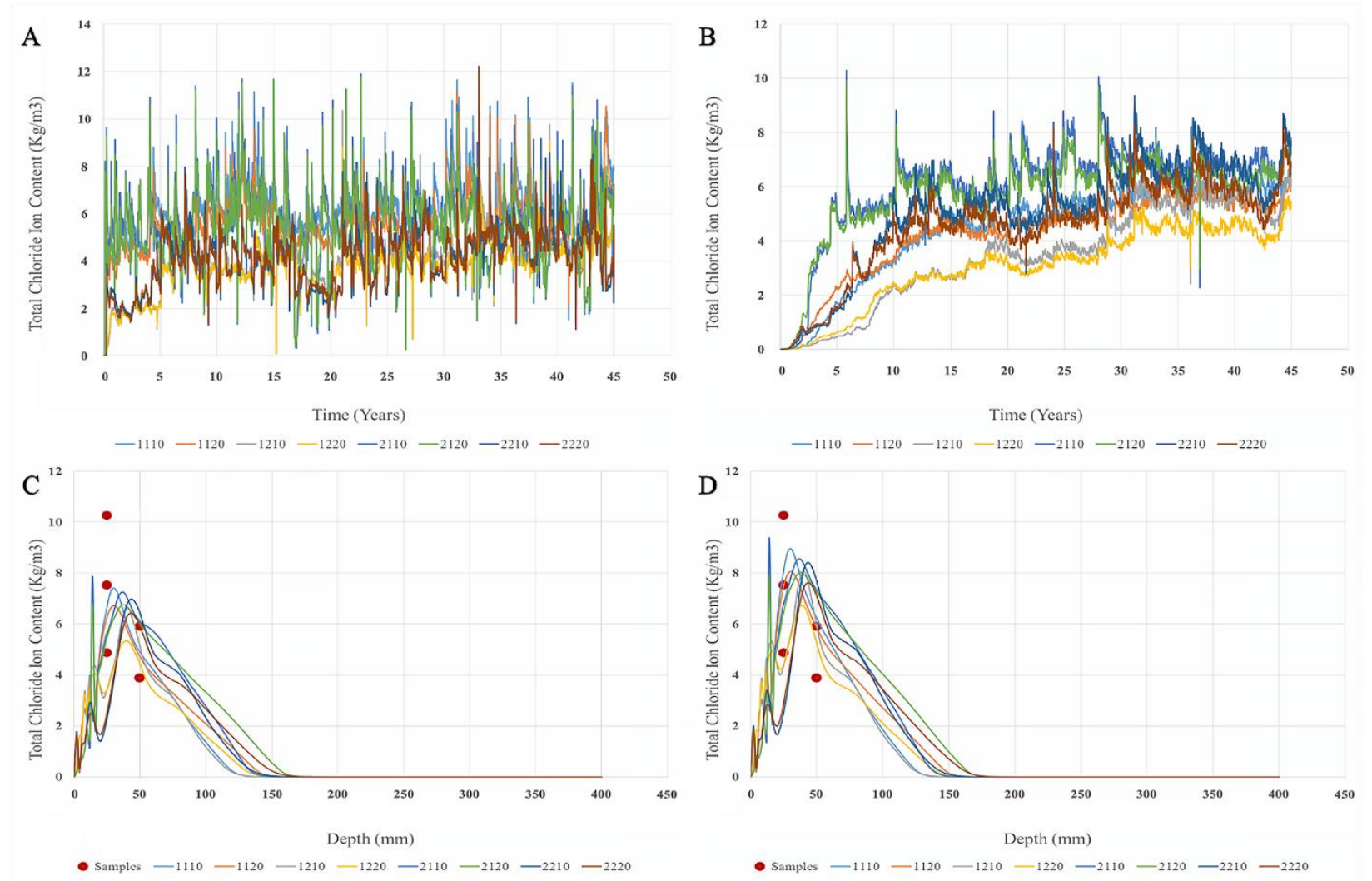

Figure 6-4 Chloride ion distribution at the depth of A) $25 \mathrm{~mm}$ and B) $50 \mathrm{~mm}$ in 45 years with the salt/water dissolution ratio of $8 \%$. Chloride ion profiles after 45 years for salt/water dissolution ratio of C) $6 \%$ and D) $8 \%$. 

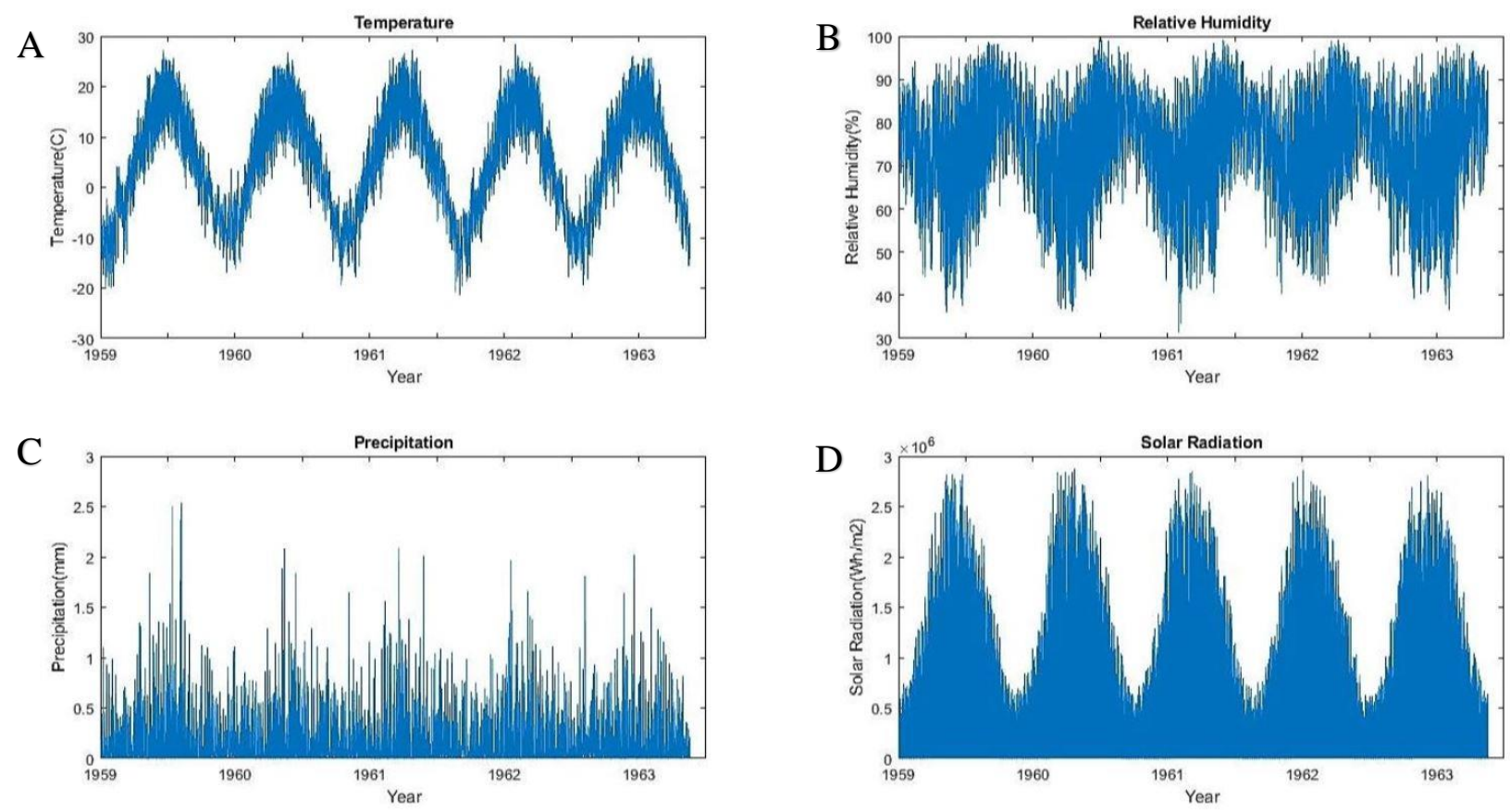

Figure 6-5 Typical Data on Exposure Conditions for Montreal. (A) Air temperature, (B) Relative humidity, (C) Precipitation, and (D) Solar radiation.

Table 6-1: Average values, distinct values, and weights for Rosenblueth point estimation.

\begin{tabular}{|c|c|c|c|c|c|c|c|c|}
\hline Parameter & $\mu(\mathrm{mm} 2 / \mathrm{s})$ & $\mu(\ln )$ & $s(\ln )$ & $\begin{array}{c}\text { C.O.V } \\
(\%)\end{array}$ & $\begin{array}{c}X- \\
(\mathrm{mm} 2 / \mathrm{s})\end{array}$ & $X+(\mathrm{mm} 2 / \mathrm{s})$ & $p-$ & $p+$ \\
\hline $\begin{array}{c}D_{H R} \\
\left(\mathrm{~mm}^{2} / \mathrm{s}\right)\end{array}$ & $1.3 \times 10^{-4}$ & -8.99 & 0.294 & 30 & $9.28 \times 10^{-5}$ & $1.67 \times 10^{-4}$ & 0.573 & 0.427 \\
\hline $\begin{array}{c}D_{C A P} \\
(\mathrm{~mm} / \mathrm{s})\end{array}$ & $6.5 \times 10^{-4}$ & -7.38 & 0.294 & 40 & $4.64 \times 10^{-4}$ & $8.34 \times 10^{-4}$ & 0.573 & 0.427 \\
\hline $\begin{array}{c}D_{C L} \\
\left(\mathrm{~mm}^{2} / \mathrm{s}\right)\end{array}$ & $4.9 \times 10^{-6}$ & -12.3 & 0.385 & 10 & $3.09 \times 10^{-6}$ & $6.68 \times 10^{-6}$ & 0.595 & 0.405 \\
\hline
\end{tabular}


Results from measurements on core samples are compared with predictions for direct exposures at depths of $25 \mathrm{~mm}$ and $50 \mathrm{~mm}$. The measurements of chloride ion content on cores are quite variable, which can be attributed to the spatial variability of concrete properties and of local exposure conditions (Suo and Stewart 2009).

Table 6-2: Chloride content after 45 years at $25 \mathrm{~mm}$ and $50 \mathrm{~mm}$ depth for direct exposure (run: $\left.i j k, i: D_{H R}, j: D_{C A P}, k: D_{C L}\right)$.

\begin{tabular}{c|ccc|cc}
\hline \hline \multirow{2}{*}{$\begin{array}{c}\text { Run } \\
(i j k)\end{array}$} & \multicolumn{3}{|c|}{ Parameter } & \multicolumn{2}{c}{ Chloride ion content } \\
\cline { 2 - 6 } & $D_{H R}$ & $D_{C A P}$ & $D_{C L}$ & $25 \mathrm{~mm}$ & $50 \mathrm{~mm}$ \\
\hline 111 & $9.280 \times 10^{-5}$ & $4.460 \times 10^{-4}$ & $3.090 \times 10^{-6}$ & 9.987 & 5.212 \\
112 & $9.280 \times 10^{-5}$ & $4.460 \times 10^{-4}$ & $6.680 \times 10^{-6}$ & 9.011 & 4.984 \\
121 & $9.280 \times 10^{-5}$ & $8.340 \times 10^{-4}$ & $3.090 \times 10^{-6}$ & 6.136 & 5.301 \\
122 & $9.280 \times 10^{-5}$ & $8.340 \times 10^{-4}$ & $6.680 \times 10^{-6}$ & 6.152 & 4.612 \\
211 & $1.670 \times 10^{-4}$ & $4.460 \times 10^{-4}$ & $3.090 \times 10^{-6}$ & 8.118 & 6.390 \\
212 & $1.670 \times 10^{-4}$ & $4.460 \times 10^{-4}$ & $6.680 \times 10^{-6}$ & 7.822 & 6.302 \\
221 & $1.670 \times 10^{-4}$ & $8.340 \times 10^{-4}$ & $3.090 \times 10^{-6}$ & 2.912 & 6.710 \\
\hline \hline
\end{tabular}

Table 6-3: Rosenblueth point estimates for the conditional mean and standard deviation of chloride content at $25 \mathrm{~mm}$ and $50 \mathrm{~mm}$ depth.

\begin{tabular}{|c|c|c|c|c|c|c|c|c|}
\hline \multirow{2}{*}{$\begin{array}{c}\text { Depth } \\
D_{H R}\end{array}$} & \multicolumn{4}{|c|}{$25 \mathrm{~mm}$} & \multicolumn{4}{|c|}{ "50mm } \\
\hline & $\mu_{\mathrm{cl} \mid} \mid D_{H R}$ & $\overline{\sigma_{\mathrm{cl}} \mid D_{H R}}$ & $\mu_{\text {lncl }} \mid D_{H R}$ & $\sigma_{\text {lncl }} \mid D_{H R}$ & $\mu_{\mathrm{cl} \mid} \mid D_{H R}$ & $\overline{\sigma_{\mathrm{cl}} \mid D_{H R}}$ & $\mu_{\text {lncl }} \mid D_{H R}$ & $\sigma_{\text {lncl }} \mid D_{H R}$ \\
\hline $1.670 \times 10^{-4}$ & 5.920 & 2.416 & 1.701 & 0.392 & 6.415 & 0.185 & 1.858 & 0.029 \\
\hline $9.280 \times 10^{-5}$ & 8.119 & 1.744 & 2.072 & 0.212 & 5.078 & 0.241 & 1.624 & 0.048 \\
\hline$D_{C A P}$ & $\mu_{\mathrm{cl}} \mid D_{C A P}$ & $\sigma_{\mathrm{cl}} \mid D_{C A P}$ & $\mu_{\text {lncl }} \mid D_{C A P}$ & $\sigma_{\text {lncl }} \mid D_{C A P}$ & $\mu_{\mathrm{cl}} \mid D_{C A P}$ & $\sigma_{\mathrm{cl}} \mid D_{C A P}$ & $\mu_{\text {lncl }} D_{C A P}$ & $\sigma_{\text {lncl }} \mid D_{C A P}$ \\
\hline $8.340 \times 10^{-4}$ & 4.857 & 1.499 & 1.535 & 0.302 & 5.652 & 0.791 & 1.722 & 0.139 \\
\hline $4.460 \times 10^{-4}$ & 8.911 & 0.873 & 2.183 & 0.098 & 5.647 & 0.617 & 1.725 & 0.109 \\
\hline$D_{C L}$ & $\mu_{\mathrm{cl}} \mid D_{C L}$ & $\sigma_{\mathrm{cl}} \mid D_{C L}$ & $\mu_{\text {lncl }} \mid D_{C L}$ & $\sigma_{\text {lncl }} \mid D_{C L}$ & $\mu_{\mathrm{cl}} \mid D_{C L}$ & $\sigma_{\mathrm{cl}} \mid D_{C L}$ & $\mu_{\text {lncl }} \mid D_{C L}$ & $\sigma_{\text {lncl }} \mid D_{C L}$ \\
\hline $3.090 \times 10^{-6}$ & 7.298 & 2.524 & 1.931 & 0.336 & 5.795 & 0.641 & 1.751 & 0.110 \\
\hline $6.680 \times 10^{-6}$ & 7.006 & 1.992 & 1.908 & 0.279 & 5.435 & 0.720 & 1.684 & 0.132 \\
\hline
\end{tabular}


The conditional distribution of the chloride content as a function of diffusion parameters is obtained at first by neglecting the modelling and the sampling uncertainty in order to evaluate the sensitivity of the model to the diffusion parameters. The conditional distribution of the chloride content as a function of $D_{H R}$ shows different tendancies at $25 \mathrm{~mm}$ and $50 \mathrm{~mm}$ depths (Figure 6-6). $\mathrm{Cl}$ decreases with increasing $D_{H R}$ at shallow depths since a higher $D_{H R}$ promotes higher mobility of water down into the concrete as shown by the large fluctuations of $\mathrm{Cl}$ with each precipitation event. At $50 \mathrm{~mm}$ depth, the $\mathrm{Cl}$ increases with $D_{H R}$ since more of the $\mathrm{Cl}$ is transported inside the concrete and concnetratinos are less sensitive to precipitation events. Note that since the core samples are taken during the summer months, the $D_{H R}$ at $25 \mathrm{~mm}$ depth influences the flushing of the $\mathrm{Cl}$ out of the concrete with precipitation events while at $50 \mathrm{~mm}$, it promotes the migration of $\mathrm{Cl}$ from the shallow locations to deeper locations within the concrete. The results at $50 \mathrm{~mm}$ also indicates that $D_{H R}$ is the most influential parameter since there is very little varaibility in the chloride content as a function of $D_{H R}$. For the chloride ion content at $25 \mathrm{~mm}$, the likelihood function of $D_{H R}$ given core sample data is very close to the the prior distrituion such that the posterior distribution is similar to the prior but with less uncertainty with a mode close to $1.1 \times 10^{-}$ ${ }^{4}$. For the chloride content at $50 \mathrm{~mm}$, the likelihood function is very narrow and shifted towards low values of $D_{H R}$. The mode of the posterior distribution is close to $0.7 \times 10^{-4}$. The conditional distribution of chlroide content at $50 \mathrm{~mm}$ has a small conditional variance indicting that $D_{C A P}$ and $D_{C L}$ have little effect. Combining the data at both depths by assuming independence results in a posterior distribution with a mode at $8.0 \times 10^{-4}$ (Figure 6-7). The difference observed between predictions and core sample data is attributed to modelling and sampling uncertainty, which is modelled as a combined lognormal random variable with mean of 1 and a coefficient of variation 
of 0.20 . When considering these uncetainties, the mode of the posterior distribution are more consistent and have a joint posterior mode at $1.05 \times 10^{-4}$ and a large variance.
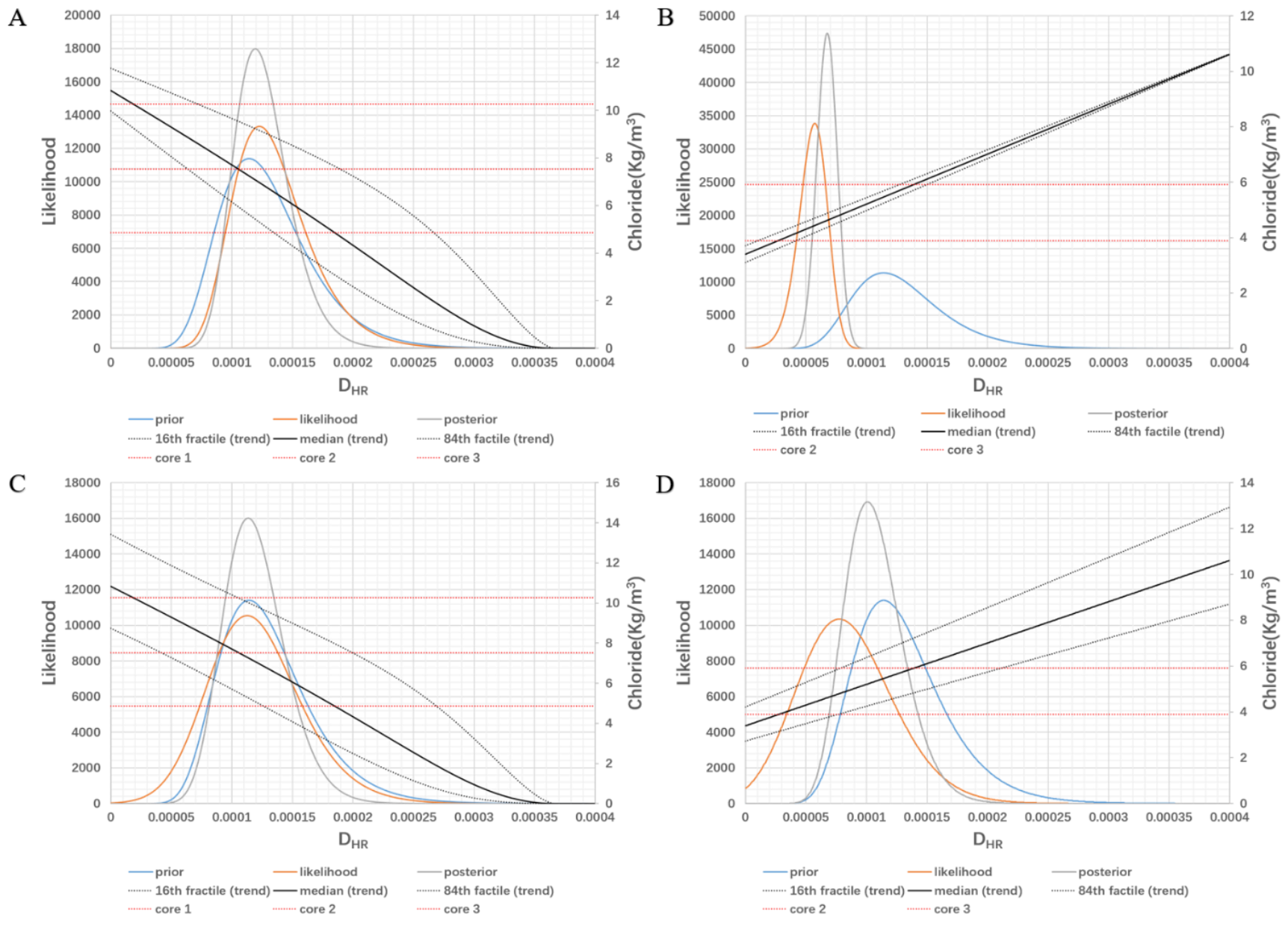

Figure 6-6 Prior, likelihood and posterior distributions of $D_{H R}$ at A) $25 \mathrm{~mm}$ and B) $50 \mathrm{~mm}$ depth; C) $25 \mathrm{~mm}$ (with model and sampling uncertainties) and D) $50 \mathrm{~mm}$ depth (with model and sampling uncertainties) (the black lines correspond to the conditional distribution of $\mathrm{Cl}$ as a function of DHR, the red lines corresponds to the core sample data). 

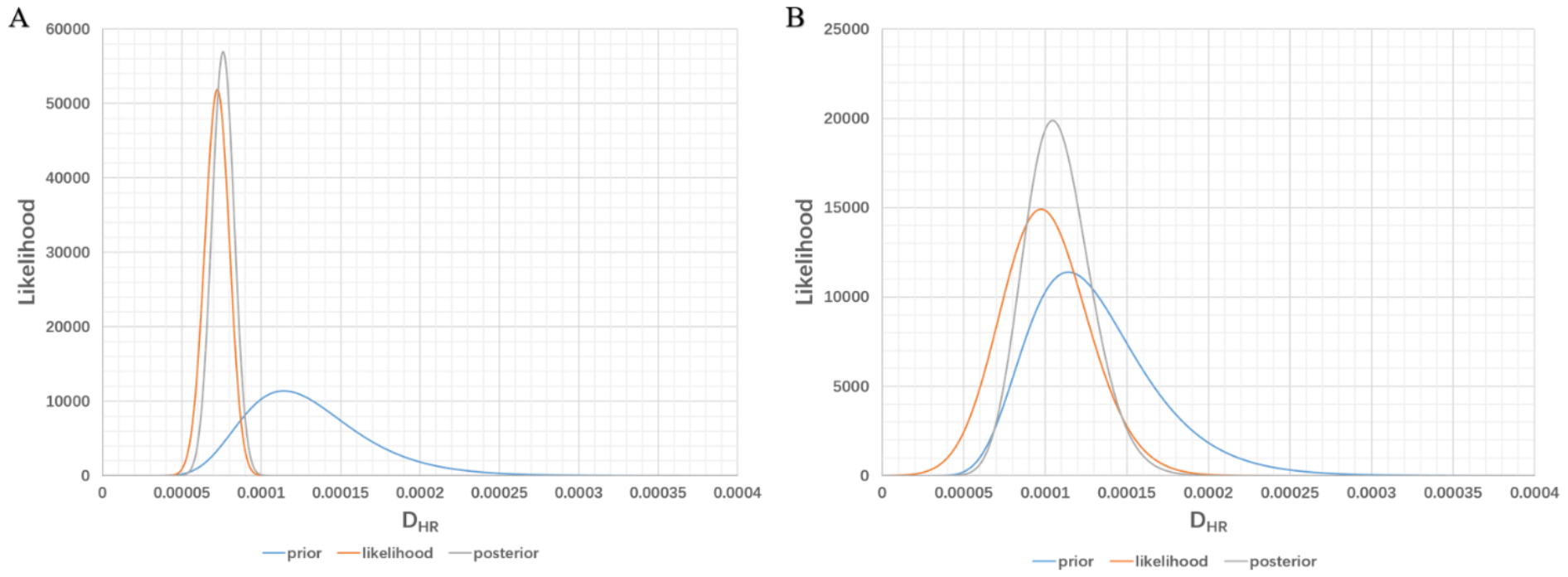

Figure 6-7 Prior, likelihood and posterior distributions of $D_{H R}$ for the combined likelihoods assuming independence: A) No model and no sampling uncertainty; B) With model and sampling uncertainties.

Figure 6-8 shows that the diffusion coefficient by capillarity is the most influential parameter for the chloride ion concentration at $25 \mathrm{~mm}$ depth, which decreases significantly with an increase in $D_{C A P}$. As expected, this parameter is not influential for the chloride ion content at greater depths (> $50 \mathrm{~mm}$ ). The $\mathrm{Cl}$ at $25 \mathrm{~mm}$ is highly depenedent on $D_{C A P}$ since it is greatly affected by capillarity due to its proximity to the surface, the $\mathrm{Cl}$ at $50 \mathrm{~mm}$ is almost constant with $D_{C A P}$ because capillarity effect are negligible at these depths. The likelihood funtion is almost uniform and the posterior distribution at $50 \mathrm{~mm}$ is similar to the prior distribution. For a depth of $25 \mathrm{~mm}$, the mode of the posterior distribution is shifted to higher values and is equal to 0.0065 and has smaller uncertainty. As would be expected the likelihood function when combining the data at the two depths is dominated by the results at $25 \mathrm{~mm}$ (Figure 6-9). The results are very similar when he sampling and modelling uncertainties are consisdered. 

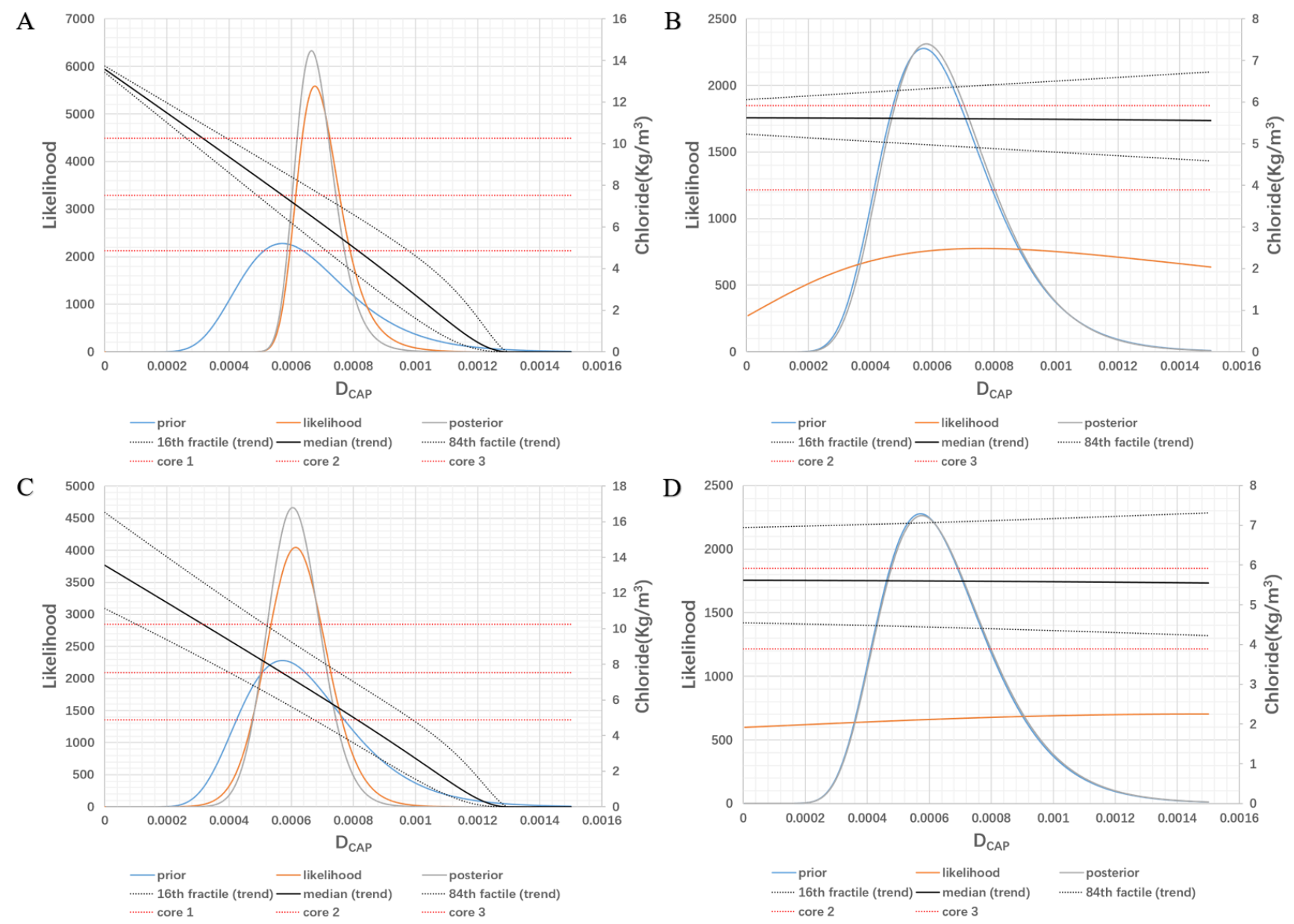

Figure 6-8 Prior, likelihood and posterior distributions of $D_{C A P}$ at A) $25 \mathrm{~mm}$ and B) $50 \mathrm{~mm}$ depth; C) $25 \mathrm{~mm}$ (with model and sampling uncertainties) and D) $50 \mathrm{~mm}$ depth (with model and sampling uncertainties) (the black lines correspond to the conditional distribution of $\mathrm{Cl}$ as a function of $D_{C A P}$, the red lines corresponds to the core sample data). 

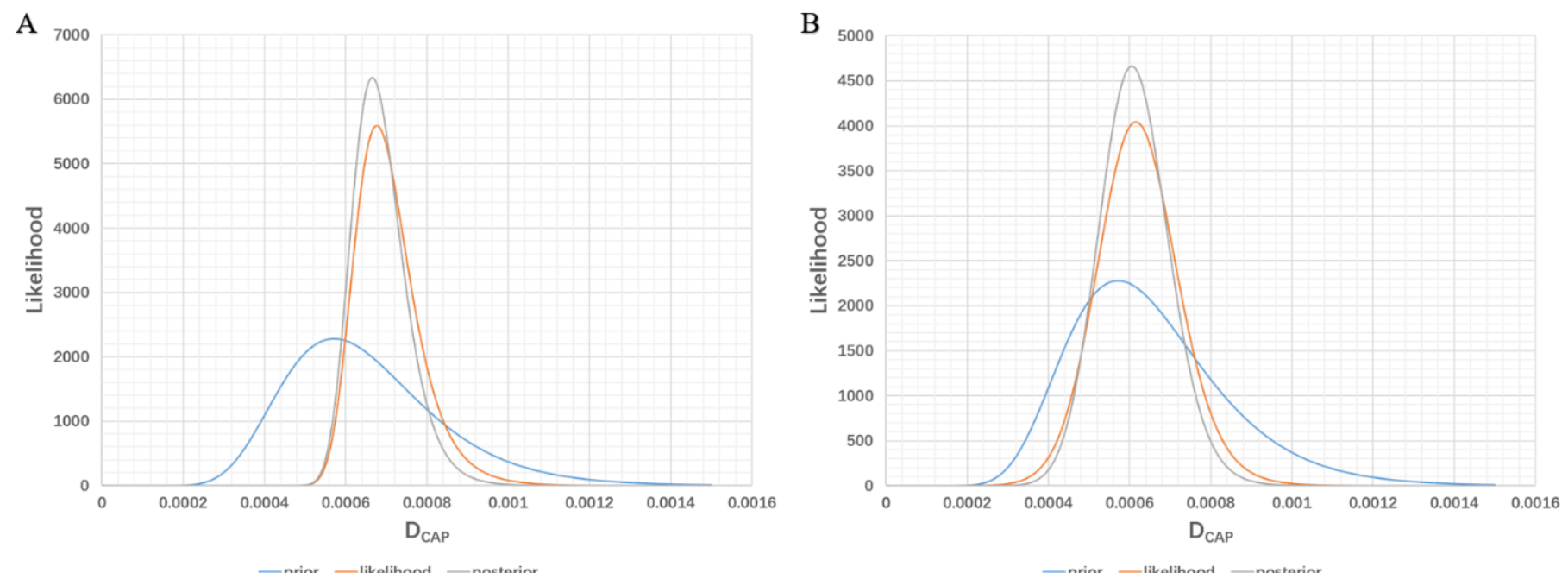

Figure 6-9 Prior, likelihood and posterior distributions of $D_{C A P}$ for the combined likelihoods assuming independence: A) No model and no sampling uncertainty; B) With model and sampling uncertainties.

Figure 6-10 shows that the choride ion diffusion coefficient $\left(D_{C L}\right)$ has very little influence on the chloride ion content at both $25 \mathrm{~mm}$ and $50 \mathrm{~mm}$ depths as compared to the other two coefficients. 

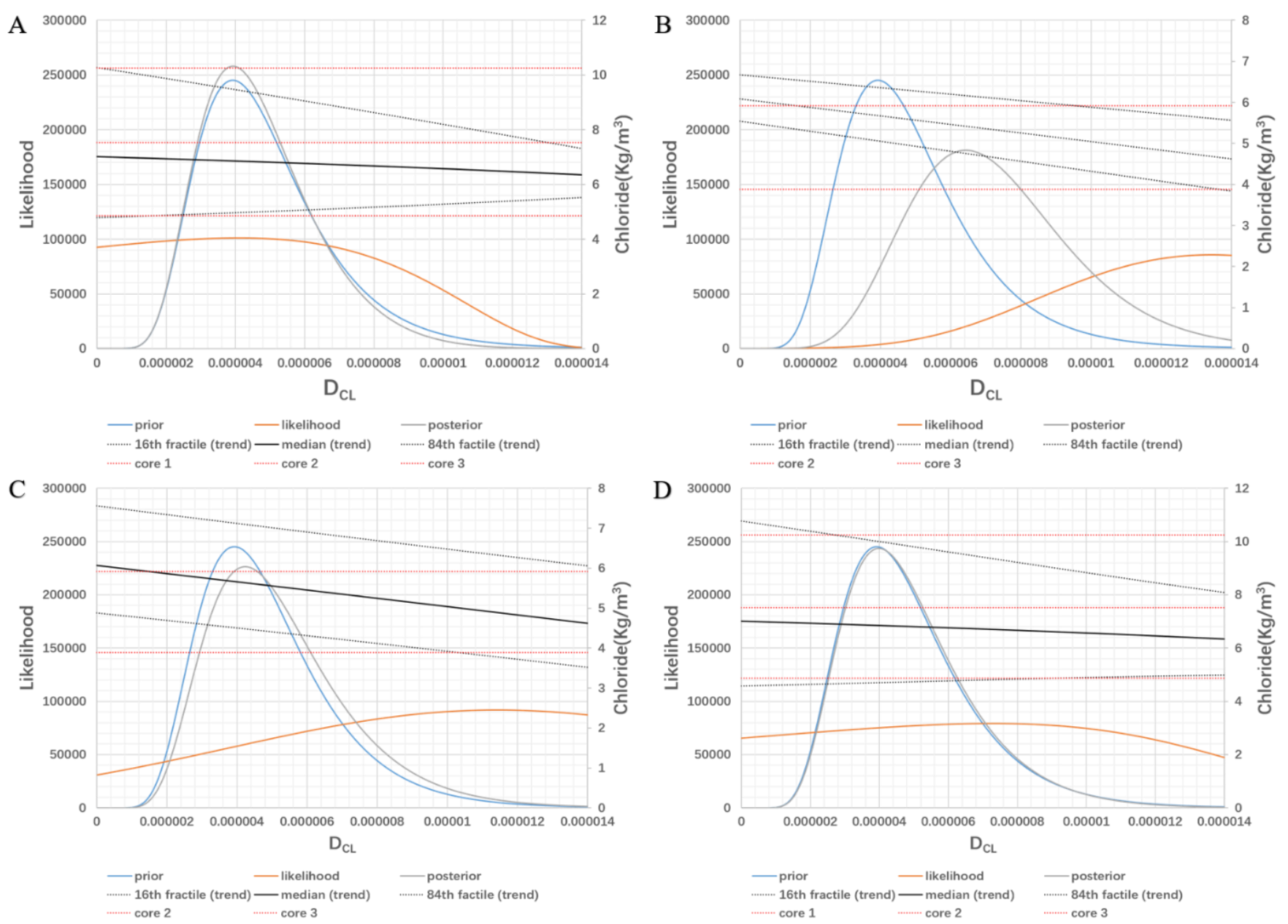

Figure 6-10 Prior, likelihood and posterior distributions of $D_{C L}$ at A) $25 \mathrm{~mm}$ and B) $50 \mathrm{~mm}$ depth; C) $25 \mathrm{~mm}$ (with model and sampling uncertainties) and D) $50 \mathrm{~mm}$ depth (with model and sampling uncertainties) (the black lines correspond to the conditional distribution of $\mathrm{Cl}$ as a function of $D_{C L}$, the red lines corresponds to the core sample data).

The posterior distribution for the combined likelihoods is very similar to the one obtained for $50 \mathrm{~mm}$ (Figure 6-11). 

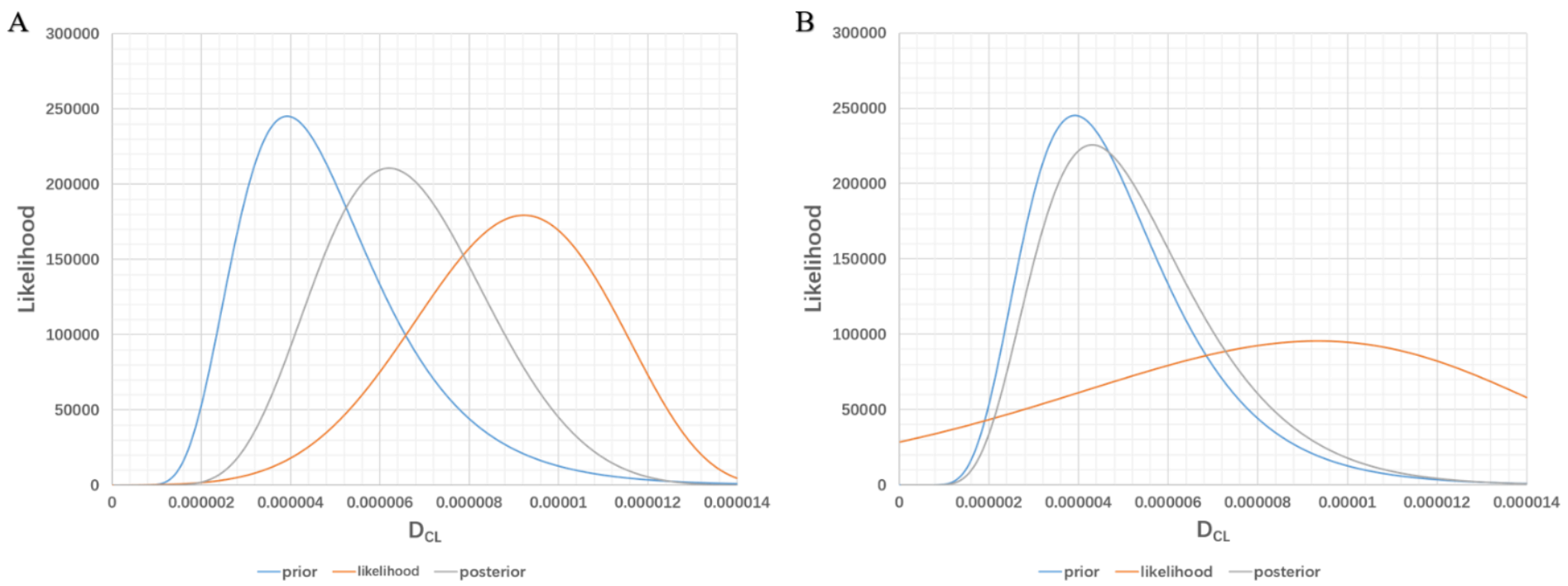

Figure 6-11 Prior, likelihood and posterior distributions of $D_{C L}$ for the combined likelihoods assuming independence: A) No model and no sampling uncertainty; B) With model and sampling uncertainties.

Next, the updating procedure is implemented such that the likelihood function is based by considering the best diffusion parameters given observations on a core at multiple depths. The correlation coefficients for the chlroride ion content at $25 \mathrm{~mm}$ and $50 \mathrm{~mm}$ are computed for each of the diffusion parameters and are presented in Table 6-4. The coefficients indicate that the chloride content at the two depths are negatively correlated.

Table 6-4: Correlation coefficients (lognormal and normal) for the conditional distributions of Chloride ion content at $25 \mathrm{~mm}$ and $50 \mathrm{~mm}$ given $D_{H R}, D_{C A P}$ and $D_{C L}$.

\begin{tabular}{|c|c|c|c|}
\hline & & $\rho_{C l_{25} C l_{50}}$ & $\rho_{\operatorname{lnCl}} l_{25} \operatorname{lnCl} l_{50}$ \\
\hline$D_{H R}$ & $1.670 \times 10^{-4}$ & -0.436 & -0.455 \\
\hline
\end{tabular}




\begin{tabular}{llll} 
& $9.280 \times 10^{-5}$ & -0.180 & -0.182 \\
\hline & $8.340 \times 10^{-4}$ & -0.942 & -0.988 \\
$D_{C A P}$ & & & \\
& $4.460 \times 10^{-4}$ & -0.523 & -0.527 \\
\hline & $3.090 \times 10^{-6}$ & -0.610 & -0.637 \\
$D_{C L}$ & & & \\
& $6.680 \times 10^{-6}$ & -0.305 & -0.314 \\
\hline \hline
\end{tabular}

The mode of the posterior of $D_{H R}$ is similar to the one obtained previously under the assumption of independence (Figure 6-12).
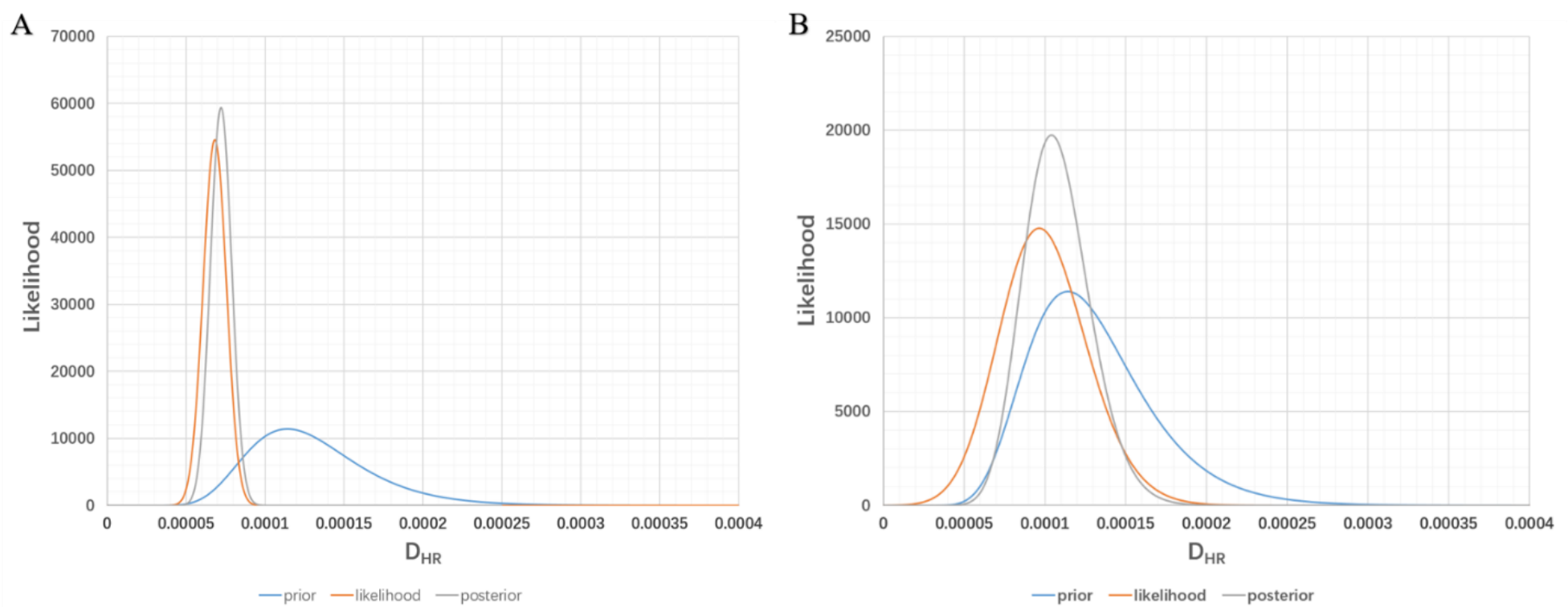

Figure 6-12 Prior, likelihood and posterior distributions of $D_{H R}$ for the joint distribution of chloride ions at $25 \mathrm{~mm}$ and $50 \mathrm{~mm}$ jointly: A) No model and no sampling uncertainty; B) With model and sampling uncertainties.

In the case of $D_{C A P}$, the mode of the distribution is similar to the one obtained previously under the assumption of independence but the uncertainty of $D_{C A P}$ is greatly reduced because the chloride contents at $25 \mathrm{~mm}$ and $50 \mathrm{~mm}$ are strongly negatively correlated (Figure 6-13). 

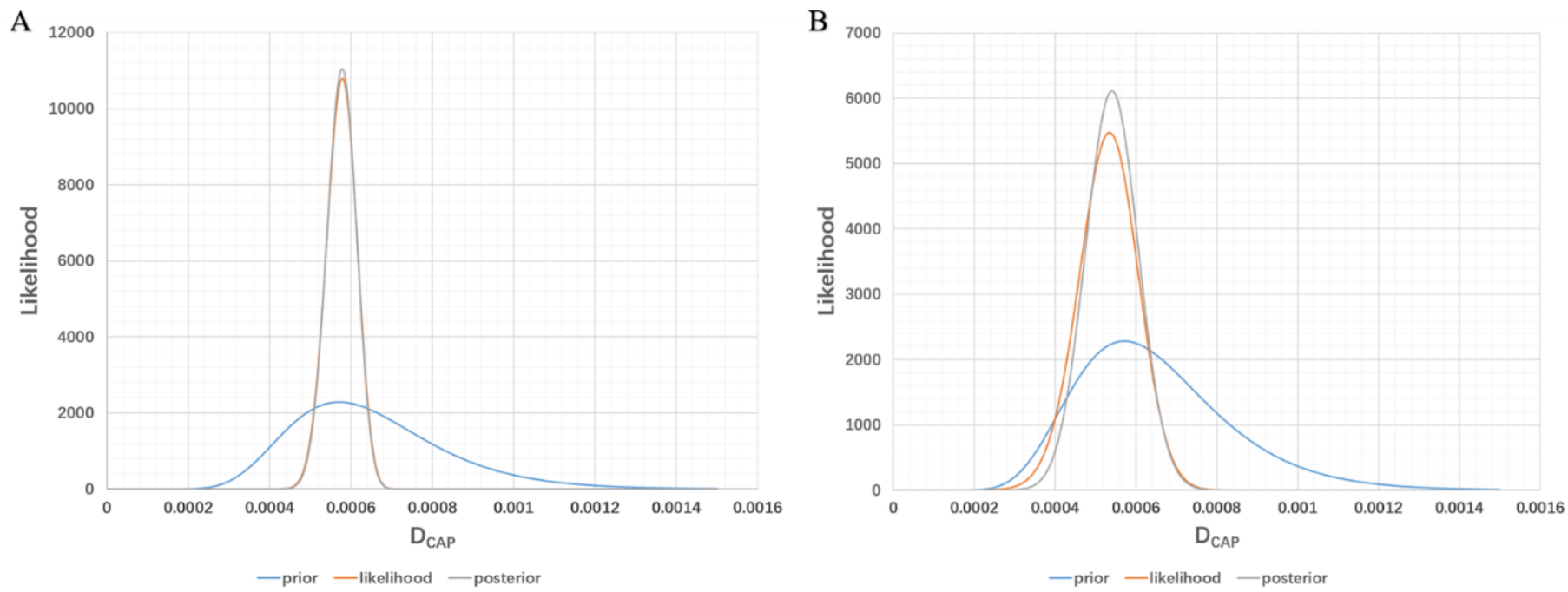

Figure 6-13 Prior, likelihood and posterior distributions of $D_{C A P}$ for the joint distribution of chloride ions at $25 \mathrm{~mm}$ and $50 \mathrm{~mm}$ jointly: A) No model and no sampling uncertainty; B) With model and sampling uncertainties.

In the case of $D_{C L}$, the effect of the negative correlation between chloride concentrations at $25 \mathrm{~mm}$ and $50 \mathrm{~mm}$ depths is to shift the posterior distribution to slightly values of $D_{C L}$ but effect is negligible when both sampling and model uncertainties are considered (Figure 6-14).
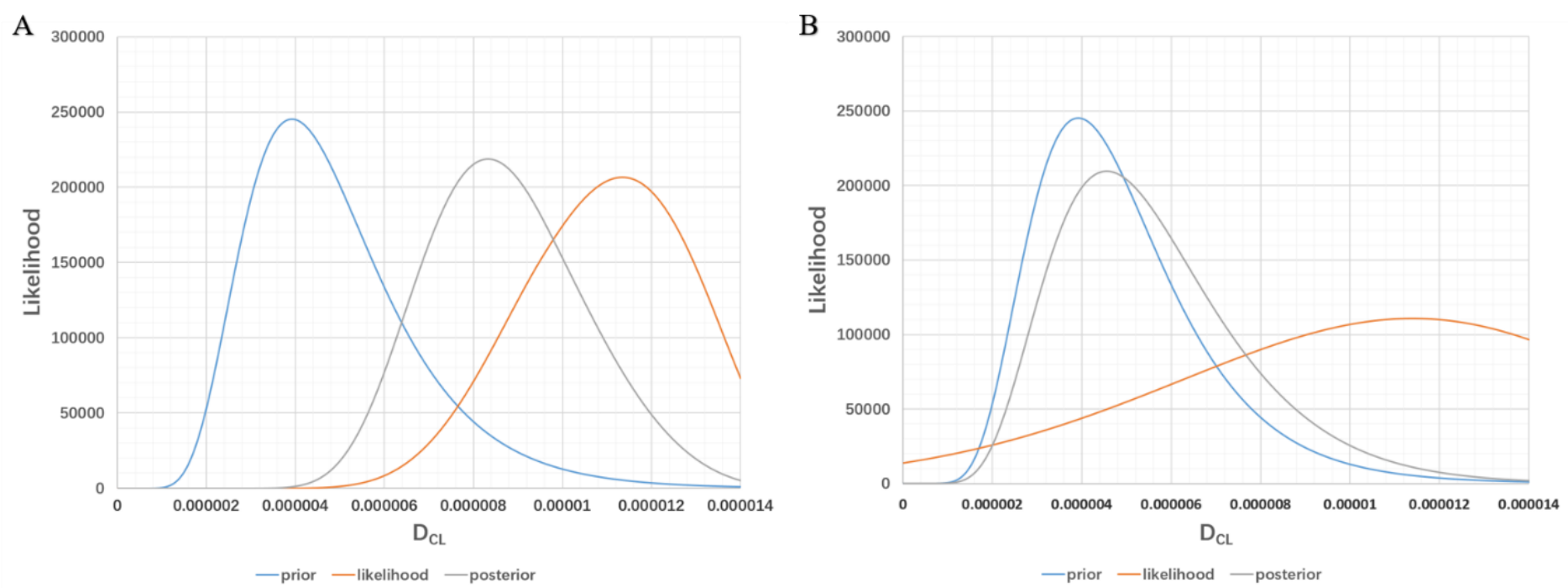

Figure 6-14 Prior, likelihood and posterior distributions of $D_{C L}$ for the joint distribution of chloride ions at $25 \mathrm{~mm}$ and $50 \mathrm{~mm}$ jointly: A) No model and no sampling uncertainty; B) With model and sampling uncertainties. 


\subsection{Conclusions and Recommendations}

The techniques for modelling deterioration processes for infrastructures have evolved rapidly over the last decades in the context of the increasing number of ageing structures and the need to predict their residual life as accurately as possible in order to maintain an acceptable level of reliability for existing structures and for developing timely and economically optimal intervention plans. For structures located in northern climates, the dominant mode of deterioration of concrete is corrosion associated with the ingress of chloride ions from salt spreading. Given the uncertainty and variability in these parameters, the analysis of chloride ion ingress is best performed probabilistically. Prior distributions on concrete parameters can be generally obtained from databases for similar concretes. When core samples with chloride content are available, this information can be used to reduce the uncertainty on model parameters through Bayesian updating and improve residual life predictions.

The main contribution of this work is the development of an efficient updating procedure to reduce the uncertainty on diffusion parameters of concrete, using observations from core sample data. A reduction in this uncertainty allows for improved estimates of the residual life of structures, which is the most important input in planning and allocating funds for maintenance/repair/replacement of bridges. The procedure can be applied for multiple core samples as well as for observations of chloride content at different depths.

The likelihood function given core sample data is derived using a conditional surrogate model for the time and depth at which core sample data is available. The surrogate model is based on the conditional mean and the conditional variance, which are estimated efficiently with Rosenblueth point estimators, and the assumption of the lognormal distribution for the chloride content. The 
model can also account for the spatial correlation between predictions at different depths. The updating procedure is illustrated for a bridge located in Montreal that has been in service for forty years with data available from 3 core samples at depths of $25 \mathrm{~mm}$ and $50 \mathrm{~mm}$.

Moreover, the likelihood function provides a means of evaluating the predictive ability of the model by comparing the range of optimal diffusion parameters for different depths. Results can also be used to analyze the sensitivity of the predictions in relation to each of the random variables. In this case, the results indicate that at shallow depths $(25 \mathrm{~mm})$ the chloride content is mainly controlled by diffusion capillarity diffusion coefficient $\left(D_{C A P}\right)$ with little uncertainty contributed by the other two diffusion parameters. Conversely, at $50 \mathrm{~mm}$ depth, the chloride content is controlled mainly by the hydraulic diffusion coefficient $\left(D_{H R}\right)$ with little uncertainty contributed by the other coefficients. For both depths, the chloride diffusion coefficient plays a minor role. The results also show that sampling uncertainty can be fairly large and could be attributed to the spatial variability of the penetrating chloride ions, for example due to local pounding of water at the surface of a slab.

The results that were presented was for core samples collected on the deck of a bridge. The next step would be apply the procedure to a bridge with a larger number of core samples obtained at different times during the service life of the bridge and at locations with exposure associated with the splash zone and with mist exposures (e.g. under an overpass), which often exhibit more severe degradations due to the large number of wet/dry cycles.

\section{Acknowledgments}

The authors would like to acknowledge the financial support from a NSERC-CREATE grant. 


\section{References}

AL-Smadi, Huthaifa. 2019. 'Space-Based Maintenance Management for Architectural Building Systems using Multi-Objective Optimization', Concordia University.

Angst, Ueli. 2011. 'Chloride induced reinforcement corrosion in concrete', Doctoral theses, Norwegian University of Science and Technology, Trondheim.

Babapour, Razieh, Ramin Naghdi, Ismael Ghajar, and Zahra Mortazavi. 2018. 'Forest road profile optimization using meta-heuristic techniques', Applied Soft Computing, 64: 126-37.

Bastidas-Arteaga, Emilio, Alaa Chateauneuf, Mauricio Sánchez-Silva, Ph Bressolette, and Franck Schoefs. 2011. 'A comprehensive probabilistic model of chloride ingress in unsaturated concrete', Engineering Structures, 33: 720-30.

Bazant, Zdenek P. 1979. 'Physical model for steel corrosion in concrete sea structures--theory', Journal of the Structural Division, 105.

Belevičius, Rimantas, Donatas Jatulis, and Dmitrij Šešok. 2013. 'Optimization of tall guyed masts using genetic algorithms', Engineering Structures, 56: 239-45.

Bhatti, M Asghar. 2012. Practical Optimization Methods: With Mathematica ${ }^{\circledR}$ Applications (Springer Science \& Business Media).

Bierlaire, Michel, Michaël Thémans, and Nicolas Zufferey. 2010. 'A heuristic for nonlinear global optimization', INFORMS Journal on Computing, 22(1): 59-70.

Blum, Christian, and Andrea Roli. 2003. 'Metaheuristics in Combinatorial Optimization: Overview and Conceptual Comparison', ACM Computing Surveys, 35(3): 268-308.

Breysse, Denys, Myriam Chaplain, Antoine Marache, and Elodie Rodney. 2014. 'Simulation of synthetic climate at local scale as a mean to assess the impact of climate change on infrastructures', Civil Engineering and Environmental Systems, 31: 165-78. 
Byrd, Richard H, Jean Charles Gilbert, and Jorge Nocedal. 2000. 'A trust region method based on interior point techniques for nonlinear programming', Mathematical programming, 89: $149-85$.

Chen, Lin, and Qiang Bai. 2019. 'Optimization in decision making in infrastructure asset management: A review', Applied Sciences, 9: 1380.

Chou, Jui-Sheng, and Thanh-Son Le. 2011. 'Reliability-based performance simulation for optimized pavement maintenance', Reliability engineering \& system safety, 96: 1402-10.

Collins, Lyndhurst. 1975. "An introduction to Markov chain analysis." In.: Geo Abstracts Ltd.

Conciatori, David, Eugen Brühwiler, and Christian Linden. 2018. 'Numerical simulation of the probability of corrosion initiation of RC elements made of reinforcing steel with improved corrosion performance', Structure and Infrastructure Engineering, 14: 1446-54.

Conciatori, David, Francine Laferrière, and Eugen Brühwiler. 2010. 'Comprehensive modeling of chloride ion and water ingress into concrete considering thermal and carbonation state for real climate', Cement and Concrete Research, 40: 109-18.

Deb, Kalyanmoy, Amrit Pratap, Sameer Agarwal, and TAMT Meyarivan. 2002. 'A fast and elitist multiobjective genetic algorithm: NSGA-II', IEEE transactions on evolutionary computation, 6: 182-97.

Eberhart, Russell, and James Kennedy. 1995. "Particle swarm optimization." In Proceedings of the IEEE international conference on neural networks, 1942-48. Citeseer.

Elhadidy, Amr A, Emad E Elbeltagi, and Mohammad A Ammar. 2015. 'Optimum analysis of pavement maintenance using multi-objective genetic algorithms', HBRC Journal, 11: 10713.

Environment Canada. 2019. "Environment and Climate Change Canada." In. 
Environment Canada. 2020. "CanRCM4 Model Output." In.

Farran, Mazen, and Tarek Zayed. 2012. 'New life-cycle costing approach for infrastructure rehabilitation', Engineering, Construction and Architectural Management, 19: 40-60.

Frangopol, Dan M. 2011. 'Life-cycle performance, management, and optimisation of structural systems under uncertainty: accomplishments and challenges 1', Structure and Infrastructure Engineering, 7: 389-413.

Frangopol, Dan M, and Mohamed Soliman. 2016. 'Life-cycle of structural systems: recent achievements and future directions', Structure and infrastructure engineering, 12: 1-20.

Gen, Mitsuo, and Runwei Cheng. 2000. 'Genetic algorithms and engineering optimization. 2000', John Wiley\&Sons, New York (USA).

Goldberg, David E, and John H Holland. 1988. 'Genetic algorithms and machine learning', Machine learning, 3: 95-99.

Hadiwardoyo, Sigit P, A Gomes Correia, and Paulo Pereira. 2017. 'Pavement maintenance optimization strategies for national road network in indonesia applying genetic algorithm', Procedia engineering, 210: 253-60.

Hertz, Alain, David Schindl, and Nicolas Zufferey 2005. 'Lower bounding and tabu search procedures for the frequency assignment problem with polarization constraints', 4OR, 3(2): $139-161$.

Hillier, Frederick S. 2012. Introduction to operations research (Tata McGraw-Hill Education).

Horn, Jeffrey, Nicholas Nafpliotis, and David E Goldberg. 1994. "A niched Pareto genetic algorithm for multiobjective optimization." In Proceedings of the first IEEE conference on evolutionary computation. IEEE world congress on computational intelligence, 82-87. Ieee. 
Hunkeler, F. 2005. 'Corrosion in reinforced concrete: processes and mechanisms', Corrosion in reinforced concrete structures: 1-45.

Kim, Sunyong, Dan M Frangopol, and Mohamed Soliman. 2013. 'Generalized probabilistic framework for optimum inspection and maintenance planning', Journal of Structural Engineering, 139: 435-47.

Lalwani, Soniya, Sorabh Singhal, Rajesh Kumar, and Nilama Gupta. 2013. 'A comprehensive survey: Applications of multi-objective particle swarm optimization (MOPSO) algorithm', Transactions on Combinatorics, 2: 39-101.

Lin, Ming-Hua, Jung-Fa Tsai, and Chian-Son Yu. 2012. 'A review of deterministic optimization methods in engineering and management', Mathematical Problems in Engineering, 2012.

Lounis, Z, B Martin-Perez, L Daigle, and J Zhang. 2006. 'Decision Support Tools for Service Life Prediction and Rehabilitation of Concrete Bridge Decks-Final Report', Institute for Research in Construction, National Research Council Canada (B5318. 2).

Lounis, Zoubir, and L Daigle. 2008. "Reliability-based decision support tool for life cycle design and management of highway bridge decks." In Annual Conference of the Transportation Association of Canada, 1-19.

Lounis, Zoubir, and Therese P McAllister. 2016. 'Risk-based decision making for sustainable and resilient infrastructure systems', Journal of Structural Engineering, 142: F4016005.

Menon, Saraswathi, Judith Karl, and Kanni Wignaraja. 2009. 'Handbook on planning, monitoring and evaluating for development results', UNDP Evaluation Office, New York, NY.

Moteleb, Moustafa. 2010. Risk based decision making tools for sewer infrastructure management (University of Cincinnati). 
Ng, ManWo, Zhanmin Zhang, and S Travis Waller. 2011. 'The price of uncertainty in pavement infrastructure management planning: An integer programming approach', Transportation Research Part C: Emerging Technologies, 19: 1326-38.

Palko, K, and Donald Stanley Lemmen. 2017. 'Climate risks and adaptation practices for the Canadian transportation sector 2016'.

Parsopoulos, Konstantinos E, and Michael N. Vrahatis. 2002. 'Recent approaches to global optimization problems through particle swarm optimization', Natural computing, 1: 235306.

Poli, Riccardo, James Kennedy, and Tim Blackwell. 2007. 'Particle swarm optimization', Swarm intelligence, 1: 33-57.

Portnoy, Stephen, and Roger Koenker. 1997. 'The Gaussian hare and the Laplacian tortoise: computability of squared-error versus absolute-error estimators', Statistical Science, 12: 279-300.

Proceq. 2005. "Permeability Tester TORRENT." In Operating Instructions.

Rifai, Andri Irfan, Sigit Pranowo Hadiwardoyo, António Gomes Correia, and PAULO Pereira. 2016. "Genetic Algorithm Applied for Optimization of Pavement Maintenance under Overload Traffic: Case Study Indonesia National Highway." In Applied Mechanics and Materials, 369-78. Trans Tech Publ.

Santos, João, Adelino Ferreira, and Gerardo Flintsch. 2017. 'A multi-objective optimization-based pavement management decision-support system for enhancing pavement sustainability', Journal of Cleaner Production, 164: 1380-93. 
Santos, João, Adelino Ferreira, Gerardo Flintsch, and Veronique Cerezo. 2018. 'A multi-objective optimisation approach for sustainable pavement management', Structure and Infrastructure Engineering, 14: 854-68.

Sarma, Kamal C, and Hojjat Adeli. 1998. 'Cost optimization of concrete structures', Journal of structural engineering, 124: 570-78.

Schmitt, Lothar M. 2001. 'Theory of genetic algorithms', Theoretical Computer Science, 259: 161.

Shim, Hyung Seop, and Seung Hyun Lee. 2017. 'Balanced allocation of bridge deck maintenance budget through multi-objective optimization', KSCE Journal of Civil Engineering, 21: 1039-46.

Silver, Edward A, R Victor, V Vidal, and Dominique de Werra. 1980. 'A tutorial on heuristic methods', European Journal of Operational Research, 5: 153-62.

Thomas, Omar, and John Sobanjo. 2016. 'Semi-Markov models for the deterioration of bridge elements', Journal of Infrastructure Systems, 22: 04016010.

Torrent, R, and G Frenzer. 1995. "A method for the rapid determination of the coefficient of permeability of the "covercrete"." In International Symposium Non-Destructive Testing in Civil Engineering (NDT-CE), 985-92.

Torrent, Roberto J. 1992. 'A two-chamber vacuum cell for measuring the coefficient of permeability to air of the concrete cover on site', Materials and structures, 25: 358-65.

Wu, Zheng, Gerardo W Flintsch, and Tanveer Chowdhury. 2008. 'Hybrid multiobjective optimization model for regional pavement-preservation resource allocation', Transportation research record, 2084: 28-37. 
Zhang, Le, Liangliang Fu, Weihua Gu, Yanfeng Ouyang, and Yaohua Hu. 2017. 'A general iterative approach for the system-level joint optimization of pavement maintenance, rehabilitation, and reconstruction planning', Transportation Research Part B: Methodological, 105: 378-400.

Zhang, Weili, and Naiyu Wang. 2017. 'Bridge network maintenance prioritization under budget constraint', Structural safety, 67: 96-104.

Zhang, Yan, Luc E Chouinard, and David Conciatori. 2018. 'Markov chain-based stochastic modeling of chloride ion transport in concrete bridges', Frontiers in Built Environment, 4: 12.

Zhang, Yan, Luc E. Chouinard, Gabriel J. Power, Charli D. Tandja M, and Josée Bastien. 2020. 'Flexible decision analysis procedures for optimizing the sustainability of ageing infrastructure under climate change', Sustainable and Resilient Infrastructure, 5: 90-101. 


\section{Chapter 7. Original Research Contributions and Recommendations}

\section{for Future Research}

\subsection{Original Research Contributions}

- In this study, numerical models of the diffusion process and chemical reactions of chloride ions in concrete are used to estimate the time to initiation of corrosion and for the progression of corrosion. The analyses are performed for a range of typical concrete properties, exposure and climatic conditions. The results from these simulations are successfully used to develop parametric surrogate Markov chain models of increasing states of deterioration. The surrogate models are more efficient than physical models for the portfolio analysis of a large number of structures. The procedure provides an alternative to Markov models derived from condition ratings when historical inspection data is limited.

- This research introduces a new framework that incorporates risks in economic benefits and costs by modelling the interactions and uncertainties associated with physical and financial variables in the context of infrastructure management. This framework includes in the model a variable capturing traffic density and the loss of usefulness to the driver (congestion implies less time saved). As the metropolitan area grows, the bridge may not yield much economic benefit if there is too much congestion. Moreover, the framework also allows for different climate change scenarios to better capture the true long run uncertainty facing decision-makers in infrastructure. By making the infrastructure last longer and by postponing the need for building new infrastructure, the proposed approach 
in this work is environmentally more sustainable and is applicable to any infrastructure project.

- This study also successfully develops an efficient updating procedure to reduce the uncertainty on diffusion parameters of concrete, using observations from core sample data. A reduction in this uncertainty allows for improved estimates of the residual life of structures, which is the most important input in planning and allocating funds for maintenance/repair/replacement of bridges. The procedure can be applied for multiple core samples as well as for observations of chloride content at different depths. A surrogate model is also proposed for the conditional mean and variance of the chloride content given that the core sample was obtained at a given time and depth using a point estimation procedure that greatly reduces the requirements for the number of simulations that need to be performed with the full finite element/finite difference model. The model can also account for the spatial correlation between predictions at different depths.

- Considering the numerous sources of uncertainties associated with the performance of structures and economics over their life cycle, a risk-informed decision-making process is proposed in this research to identify the most effective strategies to satisfy performance requirements at minimal cost. The decision problem is formulated as a multi-objective optimization problem for targeted performance levels and total costs and solved using both MOPSO and NSGA-II. The presentation of optimal solutions as a Pareto Front defines a spectrum of solutions that provides flexibility as a function of the priorities of the decisionmaker. The proposed work is also able to determine the optimal sequence of maintenance/repair/replacement activities over the service life of a structure, and 
moreover, have a better understanding of the effectiveness and interaction between minor and major repairs.

- The analysis of the generated trade-offs between objectives shows that the model was able to generate a wide range of optimal trade-off solutions through the consideration of all specified policies and constraints, and therefore the decision-makers could select the maintenance strategy for a specific bridge based on the available budget. A consensus should be reached between the relevant authority with jurisdiction and the owners in terms of the criteria regarding a suitable level of reliability and serviceability.

\subsection{Recommendations for Future Work}

- The original procedures that are developed in this thesis were applied to the concrete deck of a reinforced bridge. The next step is to expand the application of these procedures to the other elements of bridge that have different deterioration rates and impacts on level of service. One interesting aspect will be to examine the performance of models for elements in the splash and mist exposure zones in a bridge, which are produce multiple wet/dry cycle and zones where severe damage is often observed. Results from research that is currently being done on the micro-climate of bridges (temperature and humidity profiles, splash and mist patterns) should be incorporated in future deterioration models.

- Results obtained in this thesis have highlighted how core sample data can be used to update parameters for deterioration models. The method should be used on bridges with more core samples and also on bridges where samples have been obtained form elements with 
different types of exposure (i.e. splash and mist). The results from updating would be useful to make inferences on the performance of the model for the different types of exposures. The model updating procedure should be extended to include the case where embedded chloride ion probes provide continuous information on the chloride content.

- The observations of visual distress at the surface of concrete elements are the primary input for the condition assessment of bridge elements. There is a need to better understand the relation between these visual signs of distress and the true state of deterioration. This can be accomplished through the models and the procedures that have been outlined in the thesis.

- The optimization procedures that were presented in this thesis could be extended to include all possible tasks in the maintenance/repair of bridge elements to minimize the number of disruptions during the lifecycle of a bridge as well as for a network of bridges. In the latter case, impacts on overall transportation networks can be greatly amplified.

- The evaluation of costs associated with users are based on shadow costs associated with the average user of the bridge. In some cases, these costs have been shown to greatly exceed the costs of repairs themselves. There is a need to revaluate shadow prices in order to determine if they truly represent the economic impact to maintenance/repair traffic disruptions since they have potentially a dominant impact on optimal planning decisions. 